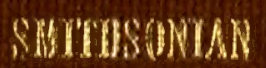

JomRaHes 


Livr. VI.

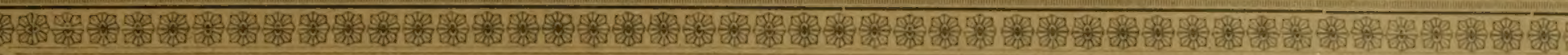
899

\section{Siboga-Expeditie}

RÉSULTATS OES EXPLORATIONS • ZOOLOGIQQUES, BOTANIQQUES, OCÉANOGRAPHIQ̨UES ET GÉOLOGIQQUES ENTREPRISES AUX

INDES NÉERLANDATSES ORTENTAYRS en 1899-1900,

à bord du SIBOGA SOUS R.R COMMANDEMENT DE G. F. TYDEMAN punLtís pare M A X:W W H F $\mathbf{R}$ Chef de l'expédition.

*T. Introduction et deseription de l'expédition, M ax Weber. *II. Se bateau et son équipement seientifique, G. F. Ty deman. III. Résultats hydrographiques, G. F. Tydeman. IV. Foraminifer:.

V. Radiolaria, M. Hartmann.

VI. Porifera, G. C. J. Vosmaer et J. H. Vermhoul. VII. Hydropolypi, Ch. Julin.

VIII. Hydrocorallinae, S. J. H i kson.

IX. Siphonophora, Mlles Lens et van Riemsdijk:

X. Hydromedusae, O. Mass.

XI. Scyphomedusae, $O$ Mas.

XII. Ctenophorn, Milo F. Moser.

* XIII. Gorgonidae, Alcyonidae, J. Versluy s I).

XIV. Pennatulidae, S. J. Hi ckson.

XV. Actioiaria, P. Me Murrich.

XVI. Madreporaria, A. A leock et I. Döderlein.

XVII. Antipatharia, P. N. van Kampen.

XVIII. Turbellaria, L. von Graff et R. R. von Stummer.

XIX. Cestodes, J. W. Spengel.

XX. Nematodes, A. A. W. Hnbrecht.

XXI. Chaetognatha, G. H. Fowler.

XXII. Nemertini, A. A. W. Hubree ht.

XXIII. Myzostomidae, R. R. von Stummer.

XXIVa. Polychacta errantia, R. Horst.

XXIVb. Polychreta sedentaria, M. Caullery et F. Mesnil.

XXV. Gephyrea, C. Ph. Sluiter.

XXVI. Finteropueusta, J. W. Spengel.

XXVII. Brachiopoda, J. F. van Bemmelen.

XXVIII. Bryozoa, S. F. Harmer.

XXIX, Copepoda, A. Seott.

XXX. Ostrneoda, G. W. Müller.

XXXI, Cirrhipedia, P. P. C. Hoek.

XXXIIa. Isopoda, H. J. Haugen.

XXXIIb. Epiearidas, J. Bon u ier.

XXXIII. Amphinoda, J. Bonnier.

XXXIV. Caprellidae, P. Mayer.

XXXV. Stomatopoda, H. J. Ha n sen.

XXXVI. Leptostraca, H. J. Hans en.

XXXVII. Schizopoda, H, J. Hansen.

XXXVIII. Sergestidae, H. J. H an sen.

XXXIX. Decapoda, J. G. de Mau.

XL. Pantopoda, J. C. C. Lom an.

XLI. Halobatidee, J. Th. Oudemans.

XLII. Crinoidea, L. Dödorlein p P.

XLIII. Echinoidea, J. C. H. de Me yere

- XLIV. Holothurioides, C. Ph. Sluiter.

XIV. Ophiuroidea, R. Köhler.

XLVI. Asteroidea, I. Döder le in.

- XLVII. Solenogastres, H. F. Nierstrasz

XLVIII Chitunidae, H. F. Nierstrasz.

XLIX. Prosobranchia, M. M. Sche pman.

L. Opisthobranchia, R. Bergh.

II. Heteropods, J. J. 'T es ch.

III. Pteropoda, J. J. Tesch.

LIII. Lamellibranchista. P. Pel seneer et Ph. Da utzen berg

LIV. Scaphopoda.

IV. Cephalopoda, L. Jo u bin.

LVI. Tunieata, C. Ph. Sluiter.

IVII. Pisces, Max Weber.

LVIII. Cetacea, Mar Weber.

LIX. Liste des algues, Moue A. We ber.

I.X. Halimeda, Mile H. S. Barton.

LXI. Melobesieae, Mwo A. Weber et M. Poslic.

LXII. Dinoflagellata, Coccosphaeridae, J. P. J 0 tsy.

LXIII. Distomseeae, J. P. Lutsy.

LXIV. Deposita marina, O. B, Bög gild.

LXV. Résultats géologiques, A. Wi ch man.

\section{DER GORGONIDEN DER SIBDGA-EXPRDITION}

I. DIE CHRYSOGORGIIDAE

VON

\author{
J. VERSLUYS \\ Privat-Docent" an der Universität Amsterdarn
}

Mit 170 Figuren im Text

Monographie XIII aus:

\section{UITKOMSTEN OP ZOOLOGISCH, BOTANISCH, OCEANOGRAPHISCH EN GEOLOGISCH GEBIED}

verzameld in Nederlandsch Oost-Indië r899-1900

aan boord H. M. Siboga onder commando van

Luitenant ter zee Ie kl. G. F. TYDEMAN

UITGEGEVEN DOOR

Dr. MAX WEBER

Prof. in Amsterdam, Leider der Expeditie

(met medewerking van de Maatschappij ter bevordering van het Natuurkundig onderzoek der' Nederlandsche Koloniēn)

BOEKHANDEL EN DRUKKERIJ

E. J. BRILL

LEIDEN 


\section{Voor de uitgave van de resultaten der Siboga-Expeditie hebben bijdragen beschikbaar gesteld:}

De Maatschappij ter bevordering van het Natuurkundig Onderzoek der Nederlandsche Koloniën.

Het Ministerie van Koloniën.

Het Ministerie van Binnenlandsche Zaken.

Het Koninklijk Zoologisch Genootschap "Natura Artis Magistra" te Amsterdam.

De "Oostersche Handel en Reederij" te Amsterdam.

De Heer B. H. DE WAAL, Consul-Generaal der Nederlanden te Kaapstad, 
SIBOGA-EXPEDITIE. 


\section{Siboga-Expeditie}

\section{UITKOMSTEN}

OP

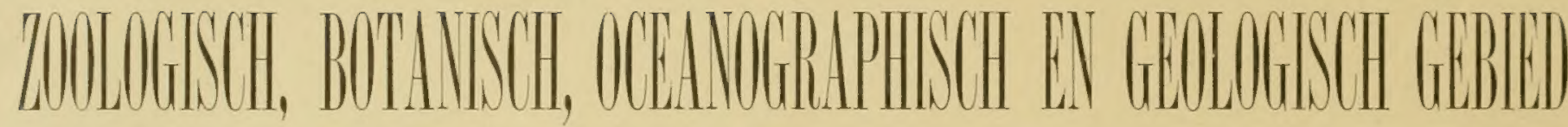

VERZAMELD IN

NEDERLANDSCH OOST-INDIE I 899-I900

AAN BOORD H. M. SIBOGA ONDER COMMANDO VAN

Luitenant ter zee $1^{e}$ kl. G. F. TYDEMAN

UITGEGEVEN DOOR

\section{Dr. MAX WEBER}

Prof. in Amsterdam, Leider der Expeditie

(met medewerking van de Maatschappij ter bevordering van het Natuurkundig

onderzoek der Nederlandsche Koloniën)

BOEKHANDEL EN DRUKKERIJ

E. J. BRILL 


\title{
GORGONIDEN DER SIBOGA-EXPEDITION
}

\author{
I. DIE CHRYSOGORGIIDAE
}

VON

\section{Di. J. VERSLUY'S}

Mit 170 Figuren im Text 



\title{
DIE GORGONIDEN DER SIBOGA-EXPEDITION
}

\section{DIE CHRYSOGORGIIDAE}

\author{
$\operatorname{rox}$ \\ Dr. J. VERSLUYS, \\ Privat-Docent an der Universität Amsterdam \\ Mit 170 Figuren im Text.
}

\begin{abstract}
Vorwort.
Von der Ausbeute der Siboga-Expedition hat Herr Professor MAx IVEBer mir freundlichst die Gorgoniden und Alcyoniden zur Bearbeitung iberlassen. Da diese Sammlung eine selı' umfangreiche ist, erschien es winschenswerth die Bearbeitung derselben in verschiedene Theile zu zerlegen. Als ersten Theil möchte ich vorliegend die Resultate der Untersuchung der Chroysogorgiidae, diese eigenthümliche, gut abgegrenzte Familie der Gorgoniden, bekannt machen.

Ich bin hierbei Herrn Professor Dr. F. JefFrey BeLl zu besonderem Danke verpflichtet für sein freundliches Entgegenkommen bei meiner Untersuchung der Typen der ChallengerSammlung im "British Museum of Natural History", sowie für weitere werthwolle Hiilfe.

Der Liberalität von Herm Professor Dr. H. F. E. JungERsex verdanke ich ein grösseres Fragment von Hcroplita regia Steenstrup. Durch seine Vermittelung hatte Herr Inspector Dr. G. M. R. Levinsen die grosse Freundlichkeit mir Photographiën der grossen Kolonic dieser Art, welche sich im Staatsmuseum zu Kopenhagen befindet, zukommen zu lassen.

Endlich spreche ich den Herrn Professoren Max Weber und C. Ph. Sluiter in Amsterdam, die meine Arbeit vielfach unterstiitzten und förderten meinen verbindlichsten Dank dafür aus.
\end{abstract}




\section{Beschreibender Theil.}

\section{Familie Cimrsogorgndat Verrill.}

Clerysogorgidac Verrill, Bull. Mus. Comp. Zool., vol. I I, ISS3, S. 2 I.

Dasygorgidue Wright \& Studer, Challenger Report, vol. 3I, IS\$9, S. XXXIX und S. I.

Von dieser Familie der Gorgoniden sammelte die Siboga-Expedition 2 I Arten, worunter I5 neue. Eine Art gehört zu einem neuen Genus. Weitere 6 Arten waren bereits von der Challenger-Expedition her bekannt. Diese sammelte im Gebiete des Malayischen Archipels zwei weitere Arten, welche ron der Siboga-Expedition nicht zuruickgefunden wurden. In's gesammt sind also jetzt 23 Arten dieser Familie aus dem Nalayischen Archipel bekannt; ausserdem enthält die Siboga-Sammlung Material von + anderen Arten, das aber zur Aufstellung neuer Arten nicht genïgt. Damit ist der Reichtum aber gewiss noch lange nicht erschöpft; sind ja doch die meisten Arten nur erst einmal aufgefunden worden und ist nur eine einzige Art von mehreren Stationen bekannt. Hicraus darf wohl gefolgert werden, dass noch viele Arten zu erbeuten sind.

Ausser dem Siboga-Material untersuchte ich auch die Typen der Challenger-Sammlung im "British Museum" in London. Und da es sich herausstellte, dass die Beschreibungen von MrignT und STUDER im Challenger-Report für verschiedene Arten nicht genigend sind, in einigen Fällen sogar unrichtige Angaben enthalten, habe ich auch eine neue Beschreibung dieser Arten aufgenommen. Dass mir wirklich die 'Typen von Wrigut und Studer's Arbeit vorlagen, ist nicht zweifelhaft. Herr Professor Dr. F\% JefFrer Belt theilte mir mit, dass die l'laschen der Challenger-Sammlung sich noch in dem Zustande befinden, in welchem sie im Britischen Museum anlangten. Die Flaschen waren seitdem niemals geöffnet und trugen noch die Eiketten, welche sie beim Empfang im Museum trugen, wohin sie von den Bearbeitern geschickt worden waren. Uebrigens stimmten die Arten (mit einer Ausnahme) auch geniigend mit den Beschreibungen im Challenger-Report iberein, sodass dieselben mit Gewissheit als die Typen zu erkennen waren.

Ich untersuchte auch ein Fragment der Type von Horophila regia Steenstrup) (Riisca farbiculata Duch. \& Mich.) aus dem Zoologischen Museum in Kopenhagen.

Von den +1 bekannten Arten habe ich demgemäss 29 Arten untersucht und von den 6 Genera lag nur eines mir nicht vor. 
In der Begrenzung der Familie Chry'sogorgäidac schliesse ich mich vollständig an WRGIT \& Studer an (1. c. S. XXXIX, ramilie Dasygorgidac). Doch muss ich ihre Diagnose ergänzen, sodass dieselbe, meines Erachtens, eine natülichere und schïrfere Begrenzung der Familie giebt, wie nachstehend angegeben.

\section{Diagnose der Familie Chrysogorgmde.}

Gorgoniden mit ungegliederten Achsen. Entweder unverzweigt oder mit Zweigen, die nur auf einem Längsstreifen der Aeste in einer Reihe über einander entstehen. Dieser zweigbildende Streifen bleibt entweder nahezu an derselben Seite je eines Astes oder er beschreibt eine steile Spirale um denselben. Ausserhalb des Streifens werden niemals Seitenzweige gebildet. Polypen meist an einer Seite der Zweige in einer Reihe, mitunter zerstreut, regellos, niemals aber in Wirteln oder einander gegenuber stehend. Primitiv ist wahrscheinlich der Zustand, dass Polypenund Zweige-tragender-Streifen der Rinde zusammenfallen, was gegenwärtig aber meist verwischt ist. Polypenrumpf vorstehend, nicht in das Coenenchym zurückzichbar. Die 'Tentakel legen sich bei Contraction uiber die Mundscheibe zusammen. Bei einigen Arten können die Tentakel sich so stark nach innen umlegen, dass sie theilweise im Polypenrumpf aufgenommen werden und nu ihre Bases sichtbar bleiben. Niemals aber finden sich besondere Ausbildungen der Polypenwand, wodurch ein Zurückziehen der Tentakelkrone in den Rumpf möglich würde. Faltungen und Unlegungen der Rumpfwand bei der Tentakelbasis finden nicht statt.

Am eigenthümlichsten ist für diese Familie zunächst die Lateralität der Stämme und Aeste, welche bemerkbar ist an der Art der Verzweigung, bei vielen, namentlich bei den unverzweigten Lepidogorgiznae, aber daran, dass die l'olypen auf einen Längsstreifen des Coenenchyms beschränkt sind. Eigenthiimlich ist ferner, dass die Polypen nicht retractiel sind.

Aus den weiter unten folgenden ausfihrlicheren Auseinandersetzungen iber die V'rzweigung der verschiedenen Arten wird man sich von der Bedeutung des Verzweigungs-Modus überzeugen können. Um Wiederholungen zu vermeiden, gehe ich hier darauf nicht weiter ein.

Wright und STUder ${ }^{1}$ ) haben die Familie Dasygorgidae benannt nach dem typischen Genus Dasygorgia Verrill. Weiter unten werde ich aber versuchen, die Identität dieses Genus mit dem älteren Genus Chrysogorgia Duch. \& Mich. zu beweisen. Da damit der Name Dasygorgia verfällt, muss auch der Familienname Dasygorgizdae in Chrysogorgizdac umgeändert werden. Dies ist auch richtiger in Hinblick auf die Priorität des letzteren, von Verrill eingefïhrten Namen. Das Genus Riisca Duch. \& Nich. ist zwar noch früher beschrieben, ist aber nicht typisch, sondern ziemlich abweichend. Aus letzterem Grunde möchte ich die Familie nicht nach demselbe benennen.

Verril. \&) hat zuerst die Familie Chrysogorgizdae aufgestellt, darin die Genera Chryso-

1) Challenger-keport, vol, $31,1889,5$ xגix und $\leqslant$. I.

2) 13ull. Mus. Comp. Zool. Ilarvarcl College, vol. II, IS8 $3, S .21$. 
gorgia, Dasygorgia und Iridogorgia vereinigt und später ${ }^{1}$ ) noch das neue Genus Lepidogorgia hinzugefuigt. WRIGHT und STUDER ${ }^{2}$ ) brachten in dieselbe Familie, die sie Dasygorgidae nannten, das von ihnen aufgestellte Genus Strophogorgia (welches aber mit Lepidogorgia synonym ist) und das Genus Riisca Duch. \& Mich. Ich füge endlich noch das neue Genus Plourogorgia hinzu und habe es vorgezogen für Dasygorgia melanotrichos Wr. \& St. das neue Genus Mctallogorgia aufzustellen.

Wright \& StUder ${ }^{3}$ ) vertheilen die Familie in zwei Subfamilien, die Strophogorginae mit ruthenformigen, unverzweigten Kolonien und die Chrysogorginac die alle verzweigten Arten umfasst.

Die Subfamilie Strophogorginac behalte ich unverändert bei, nur muss der Name in Lcpidogorgiincre umgeändert werden. Die verzweigten Arten vertheile ich aber in zwei Subfamilien, indem ich Riisea von den Chrysogorgiinae trenne, und mit Pleurogorgia in der neuen Subfamilie Rïscinac vereinige.

Ich unterscheide also folgende drei Subfamilien:

I. Lepidogorgi ina mit unverzweigten, ruthenförmigen Kolonien; Polypen in einer Reihe uiber einander stehend: Genus Lepidogorgia.

II. Chrysogorgi inae. Kolonien verzweigt, mit deutlichem Stamm, dessen Seitenäste entweder unverzweigt oder mehrfach verzweigt sind. In letzterem Falle gehen die Seitenzweige immer alle nach einer Seite ab und diese zweigtragende Seite ist für die Zweige nachfolgender Ordnung entgegengesetzt, abwechselnd. Rinde dünn, mit verhältnissmässig wenigen Scleriten. Polypen gleichfalls mit relativ wenigen, grossen Scleriten; ihre Tentakel bei Contraction meist nur zusammengelegt, selten so tief nach innen umgebogen, dass ihre Spitzen im Polypenrumpf aufgenommen werden: Genera Chrysogorgia, Mctallogorgia, Iridogorgia.

III. Riiseinae. Kolonien mehrfach verzweigt. Die Seitenzweige werden nur an einer Seite der Aeste angelegt, welche Seite nicht abwechselnd ist bei den Zweigen nachfolgender Ordnung. Rinde nicht diunn, mit sehr zahlreichen kleinen Kalkkörpern. Polypen mit dicker Wand, worin viele kleine Scleriten. Die Tentakel biegren sich bei Contraction stark nach innen um und werden dabei bis über die Hälfte in den Polypenrumpf aufgenommen, unter starker Wölbung der Mundscheibe nach innen: Genera Pleurogorgia und Riisea.

Fir die Erklärung und genauere Beschreibung der unterscheidenden Merkmale sehe man weiter unten.

Iste Subfamilie Lepidogorgiinae.

Subfan. Strophogorginac Th. Studer, Archiv. f. Naturgesch., Jhrg. 53, Bd. I, I887, S. 4 I.

Subfam. Strophogorginae Wright and Studer, Challenger Report, vol. 3I, I889, S. XL und S. 2.

Kolonien mit ruthenförmig-unverzweigtem Stamm. Rinde diinn bis sehr diun, mit wenigen Scleriten. Die Polypen in einer Reihe iiber einander stehend, an ilteren Stammabschnitten auch

I) American Journal of Science and Arts, Ser. 3, vol. $2 \mathrm{~S}, 1 S S_{4}, \mathrm{~S} .220$.

2) Challenger licport, vol. $3 \mathrm{I}, 18 \mathrm{~S} 9, \mathrm{~S} . \mathrm{XI}$, und S, 1 .

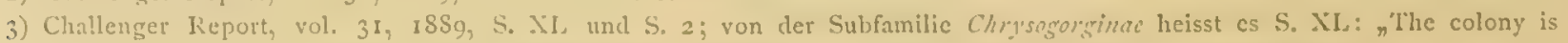
lranched, consisting of a main axis around which the branches arc spirally disposed". Das trifit aber fiir fiiser nicht zu. 
wohl neben einander, aber dann doch immer auf einen schmalen Längsstreifen der Rinde beschränkt. Polypenwand mit wenigen, verhältnissmässig grossen Scleriten. Die Tentakel legen sich bei Contraction der Polypen ziemlich unregelmässig über die Mundscheibe zusammen ${ }^{1}$ ), werden dabei nicht in den Rumpf aufgenommen. Nur ein Genus:

Lepidogorgia Verrill.

Lepidogorgia A. E. Verrill, Amer. Journal of Science and Arts, Ser. 3, vol. 28, I884, S. 220. Lepidogorgia A. E. Verrill, Report. U. S. Comm. of Fish and Fisheries for $18 S_{3}$, part. II, 1885 , S. 512 .

Strophogorgia E. P. Wright, Narrative Challenger-Expedition, vol. I, part. 2, 1885, S. 691. Strophogorgia Th. Studer, Archiv. f. Naturgesch., Jhrg. 53, Bd. I, I887, S. 4I.

Strophogorgice Wright and Studer, Challenger Report, vol. 3I, I889, S. 2.

IVenn man die Beschreibungen der beiden Genera Lepidogorgia Verrill und Strophogorgia Wright vergleicht, sieht man, dass gar kein Unterschied zwischen ihnen besteht. Da Lcpidogorgin eher beschrieben wurde, im Jahre 1884 , Strophogorgia dagegen in 1885 , thatsächlich sogar erst im Jahre I 887 von Studer, da Wrigit im Challenger Narrative weder Diagnose noch Abbildung seines neuen Genus gab, muss der Name Lcpidogorgia Verrill beibehalten werden.

VERRILI's Diagnose (1.c. I884, S. 220) lautet: „Axis simple, iridescent, with calcareous, ramose roots; polypcells large, oblique, covered with fusiform spicula; coenenchyma thin, covered with small oblong scales".

Auch sagt er (1. c. I 885, S. 512$)$; "the polyps are..... secund....", dieselben stehen also in einer Reihe über einander, wie bei Strophogorgia.

Die Diagnose der Subfamilie ist auch die des Genus. Dazu kommen noch folgende Merkmale oder beachtenswerthe Eigenschaften.

Die Kolonie erhebt sich entweder vom Boden, während reichlich verzweigte basale Stolonen sie im Schlammboden festlegen und aufrecht erhalten (Fig. I5), oder die Kolonie ist anscheinend liegend (bei L. fragilis $\mathrm{Wr}$. \& St.) mit sehr zartem Stamm. Die Achsen der basalen Stolonen sind vollständig verkalkt, milchweiss, glatt, die stärkeren an der Unterseite mit einer Furche. Die sich vom Boden erhebenden Achsen sind goldglänzend, bei den von mir untersuchten Arten durch kurze feine Längsrisse uneben, die stärkeren etwas unregelmässig vierseitig mit gerundeten Kanten. Der Goldglanz schimmert meist durch die dinne Rinde hindurch. Dic Grenze zwischen den weissen Stolonen und dem goldglänzenden Stamme ist eine scharfe.

In vereinzelten Fällen erheben sich zwei Stämme aus cinem Basalstolo. Die Rinde ist dünn, membranös, nicht zerbrechlich; demzufolge kann man sie von den stïrkeren Stämmen in grösseren Abschnitten der Länge nach abziehen. Dies hängt zusammen mit der geringen Zahl von Scleriten. Untersuchung der Rinde des Stammes bei Lcpidogorgia potersi IIr. \& St. (Exemplare der Siboga-Sammlung), auch auf Schnittserien, ergab Folgendes. Die Mesogloca besteht aus einer schr diinnen inneren Lamelle un die Achse und aus einer ziemlich dicken unter der Epidermis, welche von einander getrennt sind durch die in einem Ring stehenden,

I) Die Angabe von Wrignt und STuder, Challenger Report, vol. 33, S. 2: , the tentacles are retractile, formiug by theil basal portions quasi-opercular coverings" ist, wenigstens fü dic drei von mir untersuchten Arten, nicht zutreltend. 
längsverlaufenden Ernährungskanäle und verbunden werden durch die nicht zahlreichen Längssepta

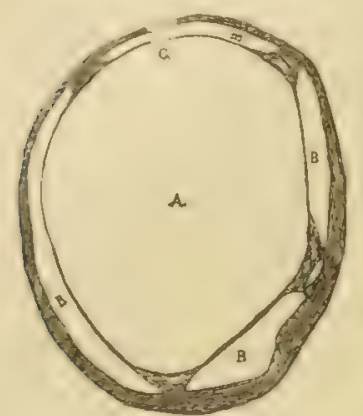

Fig. 3. Querschnitt durch die Rinde von $l$. pitersi, z. Th. schematisch.

A. von der Achse eingenommene Höhle; $B$, die 4 stärkeren Längskanäle; bei C. war die Rinde gespalten; $\times \mathbf{I} 7$. zwischen den letzteren. Die Ernährungskanäle sind von sehr verschiedener Weite, die grösseren, entsprechend der geringen Dicke der Rinde, auf dem Querschnitt stark abgeflacht; daneben giebt es kleinere, mehr runde Kanälen, von denen die engeren wohl zu zweien in der Dicke der Rinde neben einander liegen (Fig. I). Die Zahl der Längskanäle ist nicht sehr gross; auf stärkeren Stammtheilen mag es deren etwa zwölf bis zwanzig geben. Es ist wahrscheinlich, dass es vier grössere Kanäle giebt, entsprechend den vier flachen Seiten der stärkeren Achsen. Einem dieser Kanäle sitzen dann die Polypen auf. Der ihm gegenüberliegende ist der am meisten abgeflachte der vier grösseren Längstämme. An den Rändern derselben verlaufen je 2 bis 5 kleinere Kanäle. Da meine Schnittserie aus einem von der Achse abgelösten Stiick der Rinde hergestellt wurde, das dazu noch an einer Seite gespalten werden musste und von welchem die innere Mesogloea-Lamelle, die ziemlich fest mit

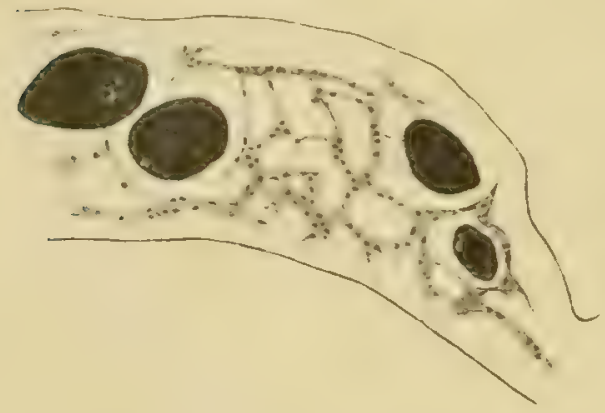

Fig. 2. Ouerschnitt durch die Mesogloen der Pulypenwand ron $L$. pefirsi, nahe der Polypenbasis. Die nahezu querdurchschnittenen Scleriten sind schwarz angegeben; die kleinen schwarzen Flecken sind Zellkerne. $\times 200$.

Protoplasmin-

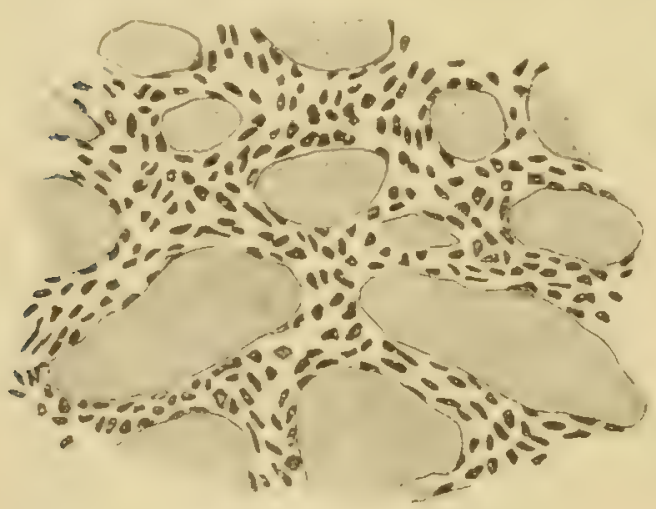

Fig. 3. L. felersi, Zellstränge in eler Rinde der Stolonen; Zellkerze schwarz, I'rotoplasma weiss. $X 200$. der Achse verbunden ist, theilweise fehlte, kann ich die obigen Angaben nur unter Vorbehalt geben.

Es gelingt die äussere und innere Lamelle der ilesogloea von einander zu trennen. Da dies auch bei der Rinde der Stolonen möglich ist, müssen auch dort die beiden Lamellen nur durch wenige Septa verbunden sein.

Die Rindenscleriten liegen nur in der äusseren Lamelle der Mesogloea und in den Septa.

Die dickere äussere Lamelle enthält neben den Scleriten zahlreiche Zellen ${ }^{1}$ ), welche zu netzförmigen Strängen von verschiedener Stärke vereinigt und überdies durch zahlreiche feine Epidermis, mit dem Entoderm der Ernährungskanäle und mit den Sçleriten verbunden sind (Fig. 2).

Namentlich deutlich und engrmaschig fand ich dieses Zellennetz. in der Rinde der Stolonen. Fin Lumen konnte ich auch in den stärkeren Zellsträngen nicht finden (Fig. 3).

Für histologische Untersuchungen genügen meine Präparate nicht.

Zahl, Form und Grösse der Scleriten der Rinde ist sehr verschieden, niemals aber finden sich sehr zahlreiche kleine Scleriten iber einander geschichtet.

Es finden sich besondere kleine, kegelförmige Erhebungen auf dem Coenenchym, mit terminalem Kissen ron Nesselzellen. Die Zoöide von Iridogorgia und Chrysogorgia, fehlen bei Lcpidugorgia.

Die Polypen stehen in einer Reihe in etwas wechselnder Entfernung genau iber einander.

I) Vergleiche die ausfuhrlichere Darstellung bei vox Kocn: Gorgoniden. Fauna und Flora des Golfes ron Neapel, 1857 , S. 25 . 
Bisweilen verspringt plötzlich diese Reihe um ein weniges, sodass die oberen nicht über den unteren Polypen stehen; meist aber bleibt die Reihe genau an derselben Seite des Stammes oder dreht sich nur sehr allmählig um denselben herum.

Zwischen den alten Polypen entstehen immer neue, was aus dem Vorkommen sehr kleiner, bisweilen kaum erkennbarer Polypen auf älteren Stammtheilen erschlossen werden muss. Bei fortwährender Neubildung von Polypen wird die Reihe derselben bisweilen unregelmässig.

Der untere Abschnitt des Stammes trägt keine Polypen.

Die Polypen stehen meist schräg auf dem Stamm, mit der Mundscheibe den nächsthöheren Polypen zugewendet. Bei Contraction können sie sich dem Stamme eng anschmiegen. Damit hängt eine eigenthümliche Verkiirzung der dem Stamme zugewendeten Seite des Rumpfes zusammen, auch ist der entsprechende Tentakel viel kleiner als die anderen Tentakel. Weitcres darüber findet man bei der Art-Beschreibung weiter unten. Lcpidogorgia fragilis, clie ich nicht untersuchen konnte, bildet nach der Figur und Beschreibung im Challenger Report ${ }^{1}$ ) diesbezigglich eine Ausnahme. Ihre Polypen sind radiär-symmetrisch, die \& Tentakel wahrscheinlich gleichgross; die Polypen legen sich bei Contraction anscheinend niemals gegen den sehr dünen Stamm.

Diese eigenthümliche Anpassung der Polypen wurde von Wrigit und Studer nicht bemerkt.

Scleriten der Polypen relativ gross und nicht zahlreich, stabförmig.

I. Lepidogorgia petersi Wright \& Studer.

Strophogorgia petersi IVright and Studer, Challenger Report, vol. 3I, IS89, S. 2.

Stat. 52. $9^{\circ} 3^{\prime} \cdot 4$ S., I $19^{\circ} 56^{\prime} .7$ O. Zwischen Lombok und Paternoster-Inseln. 959 M. GlobigerinenSchlamm; eine Kolonie und einige Fragmente.

Stat. $85.0^{\circ} 36^{\prime} .5$ S., I I $9^{\circ} 29^{\prime} \cdot 5$ O. Makassar-Strasse. 724 M. Feiner, grauer Schlamm; drei basalc Abschnitte ohne Polypen.

Stat. 88. $0^{\circ} 34^{\prime} .6$ N., I $19^{\circ} 5_{5}^{\prime}$ O. MIakassar-Strassc. 1301 II. Feiner, grauer Schlamm; cine Kolonic olune Basis.

Ich untersuchte die Typen der Challenger-Sammlung und auf ihnen beruht nachstehende Beschreibung. Vollständige Kolonien fand ich darunter nicht. WrignT und STUDER geben an, dass die Länge einiger Exemplare mehr als $6 \mathrm{dm}$. betrage; die Kolonien werden aber gewiss wohl bis I,70-1,80 M. lang, wie die Vergleichung mit den I,42 und I,68 M. langen Kolonien der Siboga-Sammlung lehrt, welche letztere noch. einen etwas diunneren Stamm haben als die dicksten Fragmente der Challenger-Sammlung.

Der Durchmesser des Stammes ist unten bis $3 \mathrm{~mm}$., nach der Spitze wird er allmiahlich diinner.

Die Achse ist verkalkt, goldglänzend, unten unregelmässig vierseitig mit grerundeten Kanten; ihre Oberfläche ist durch zahlreiche kurze Längsrisse uneben. Aus der Basis des Stammes gehen bis zu sieben Stolonen ab. Dieselben verzweigen sich bald, geben viele kleine Aeste ab und breiten sich in einer flach-trichterförmigen Libene aus. Die Stolonen sind bis $5 \mathrm{~mm}$. dick, deutlich höher als breit.

1) Vol. 3r, S. 4, Taf, 2, Hig. 2. 
Die Rinde des Stammes ist membranös und dünn, sodass die goldene Ache dcutlich durchschimmert. Sie enthält sparsam Scleriten, die in einer Schicht liegen, vielfach einander

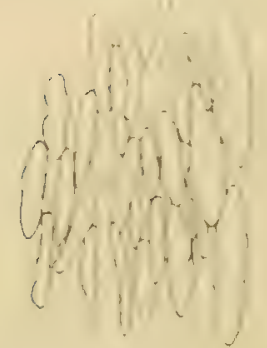

Fig. 4. L. Actersi, Type der Chall.-Sammlung.

Lmrisse der Scleriten der Rinde von der Mitte des Stammes in natiirl. Lage. $\times 35$. mit den Rändern bedeckend, andererseits aber auch kleinere Abschnitte der Mesogloea zwischen sich frei lassend (Fig. 4 und 6). Die Scleriten zeigen in Grösse, Form und Oberflächensculptur eine erhebliche Variabilität; beinah immer sind sie aber in einer Richtung verlängert und mit dieser längsten Achse dem Stamme nahezu parallel gelagert.

Im weitaus grössten, mittleren Abschnitt der Kolonie, welcher sich von den untersten Polypen bis etwa $20 \mathrm{~cm}$. von der Spitze entfernt ausdehnt, sind die Scleriten wie die in Fig. 4 und 5. Sie sind viel dünner als breit, jedoch in der Mitte merklich verdickt, also nicht schuppenartig dünn. Ihre Oberfläche wird von unregelmässigen Längsleistchen bedeckt, welche von kleinen aneinander gereihten Wärzchen gebildet werden. Der Rand ist fein und unregelmässig gezähnelt. Scleriten bis $0,8 \mathrm{~mm}$. lang und $0,13 \mathrm{~mm}$. breit, die meisten aber kürzer als $0,5 \mathrm{~mm}$.

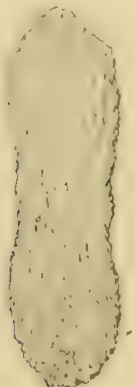

Fig. 5. L. fetersi, Type der Chall.-Sammlung.

ñalkkörper der Rinde ron der Mitte des Stammes. $\times 150$. und nur $0,06 \mathrm{~mm}$. oder weniger breit. Sie sind derartig in der Rinde vertheilt, dass vier Streifen grösserer Kalkkörper mit vier Streifen kleinerer abwechseln (Fig. 4 zeigt die Grenze zweier solcher Streifen).

Im unteren Abschnitt der Kolonie, wo der Stamm keine Polypen trägt, sind die Scleriten erheblich kleiner. So waren in einer Kolonie, I dm. von der Stammbasis entfernt, Kalkkörper von mehr als $0,4 \mathrm{~mm}$. Länge schon sehr selten (z.B. ein $0,4 \mathrm{I} \mathrm{mm}$. langer und $0,054 \mathrm{~mm}$. breiter der grösste in einem Präparate), die meisten zwischen 0,36 und $0,18 \mathrm{~mm}$. lang. Dazu sind die Scleriten auch dünner und haben oft nur wenige Wärzchen, welche nicht zu Längsleistchen vereinigt sind.

Etwa 20 dm. unterhalb der Spitze der Kolonie ändert sich nach oben zu gleichfalls der Typus der Scleriten. Im Vergleich mit den Kälkkörpern des mittleren Abschnittes

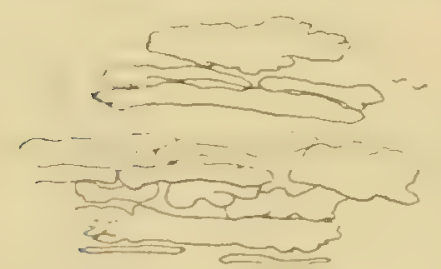

Fig. 6. L. fitirsi, Type der Challenger-Sammlung.

Sicleriten der linde ron den Spitzen-Abschuirt des Stammes, in naturl. lage. $\times 35$. sind sie diinner und durchschnittich grösser, nicht selten eine Län'se von $0,75 \mathrm{~mm}$. und mehr erreichend; so war die Länge und Breite einiger

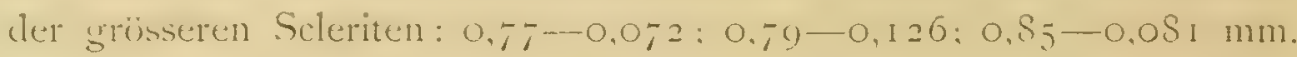
Der Rand ist oft mit grösseren Ausbuchtungen versehen (Fig. 6). Die Wärzchen und Leistchen sind nur selten deutlich; meist sind sie schwach entwickelt oder fehlen vollständig. Ueberall finden sich vermittlende Formen und der Uebergang vom einen Typus von Scleriten zum anderen ist ein allmähliger.

Der Stamm trägt von nahezu $100 \mathrm{~mm}$. von der Basis ab bis zur Spitze an einer Seite die Polypen, welche im Mittel 3 bis $3.5 \mathrm{~mm}$. von einander entfernt stehen. Die Entfernung varïrt stark; das folgt auch aus der erwähnten Neubildung von Polypen (S. 7) zwischen den älteren. Letzteres wird zwar zum Theil ausgeglichen durch ein lange andauerndes Längenwachsthum der Rinde $^{3}$ ), trotzdem stehen auf den ältesten Stammtheilen 
die Polypen so dicht beisammen, dass kein Raum zwischen ilmen übrig bleibt und die neuen Polypen einigermaassen neben den älteren stehen. Die grössten Polypen erreichen eine Lünge von $7 \mathrm{~mm}$., wobei die Tentakel noch nicht vollständig vorgestreckt sind; meist aber sind sie

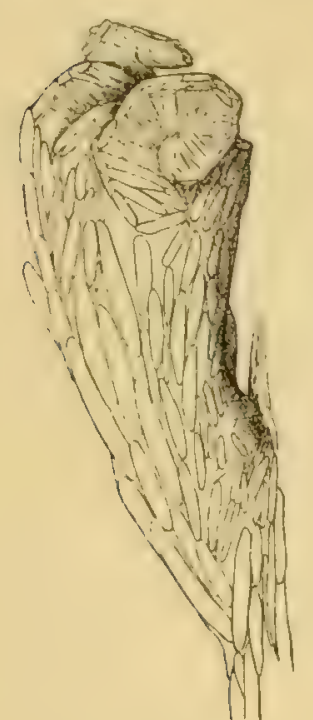

Fig. 7 .

Polyp ron L. petersi, ron der Seite gesehen. $X 15$. erheblich kleiner. Auf Stammfragmenten von $2 \mathrm{~mm}$ ? Durchmesser, also vom mittleren Abschnitt einer Kolonie, sind die Polypen 5 bis $6 \mathrm{~mm}$. lang; bei einem anderen gleichstarken Stammfragmente sind die meisten $4 \mathrm{~mm}$., vereinzelte bis $5 \mathrm{~mm}$. lang. Auch diese kleineren Polypen sind mit Geslechtsprodukten gefullt, also erwachsen. Im Allgemeinen findet man auf den untersten und dicksten Stammabschnitten auch die grössten Polypen, was nur aus einem lange fortgesetzten Wachsthum erklärt werden kann. Die Polypen sitzen dem Stamme schräg auf (Fig. 7), mit ihrer Tentakelkrone dem nächsthöheren Polypen zugekehrt (siehe Challenger Rep., Tab. 2, Fig. I) und mit ihrer einen Seite oft dem Stamme und dem nächst höheren Polypen (wenn letzterer ihm genähert ist) eng angeschmiegt. Diese Innenseite der Polypen ist concav. Der iber ihrer Mitte stehende Tentakel ist rudimentär (Fig. 8), die beiden ihm benachbarten

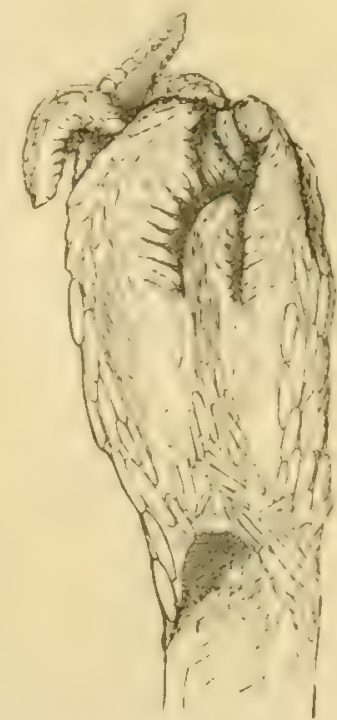

$13 i s$

l'olyp von $L$. petersi, von der Innenseite gesehen: in der Mitte der rudimentäre Tentakel. $\times 15$.

kleiner als die 5 anderen, welche der freien Seite der Polypen, welche man als Aussenseite bezeichnen kann, angehören. Der Uebergang von der Innen- zur Aussenseite ist deutlich und die Rumpfwand springt dort etwas als Kante vor. In der Mitte der Rumpfwand der Innenseite liegt ein Streifen von nur wenigen Scleriten, der sich ïber den Rücken des kleinen Tentakels fortsetzt. Auch ist die Wand hier viel diinner als an der freien Aussenseite. Letztere wird nahezu vollständig von einer Schicht von Scleriten bedeckt, welche in der Mitte der Aussenseite am grössten sind (Fig. 7); ich fand hier Kalkkörper von beinahe $4 \mathrm{~mm}$. Länge $\left.{ }^{1}\right)$. An der Polypen-Basis sind die Seiten nur unvollständig von Kalkkörpern bedeckt.

Die Kalkkörper (Fig. 9) sind stabförmig, gerade oder schwach gebogen, im Querschnitt rund oder oval, mit gerundeten Enden. Ihre Oberfläche ist mit feinen Wärzchen bedeckt, welche grösstentheils zu Längsleistchen verschmelzen. Scleriten von derselben Form, aber kleiner, nur bis $0,9 \mathrm{~mm}$. lang, finden sich in der Aussenseite, d. i. die von der Mundscheibe abgekehrte Seite der Tentakel; hier liegen bis zu vier Kalkkörper neben einander. In den Seitenflächen der Tentakel fand ich Gruppen von einzelnen bis zu zehn Scleriten, jedesmal eine Gruppe bei der Basis der Pinnulae und zum Theil in letzteren liegend.

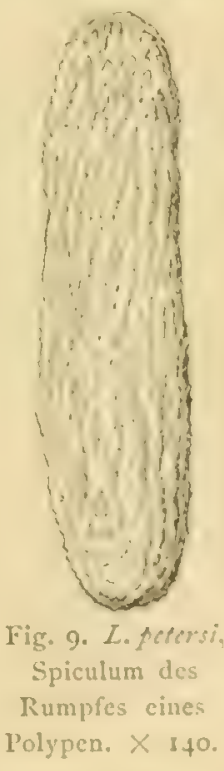

Bei Contraction der Polypen legen sich die Tentakel zusammen, wobei die fünf grösseren Tentakel der Aussenseite nach dem Stamm überbiegen (Fig. 7). Niemals fand ich die Tentakel

1) Das ist erheblich grösser als im Challenger Report, 1. c. S. 3, angegeben wird.

SIHOGA-EXPEDIT: XIII 
so regelmässig zusammengelegt, dass sie ein Operculum über den AIund bildeten, wie das von IVRIGIT und STUder ${ }^{1}$ ) angegeben wird. Selbstverständlich schützen die Kalkkörper der Tentakel clabei die Mundscheibe, aber das ist doch nicht genügend um von einem Operculum reden zu dürfen.

$\mathrm{Zu}$ dieser Art glaube ich einige von der Siboga-Expedition erbeutete Krolonien rechnen zu müssen. Dieselben stimmen in vieler Hinsicht sehr gut mit den Typen der Lepidogorgia petersi ïberein.

Die Dicke der Stämme, demnach auch w̧ohl die Grösse der Kolonien, ist die gleiche; namentlich aber auch der Bau der Polypen und die Vertheilung und Form der Scleriten. Auch sind die aus verschmolzenen Wärzchen gebildeten Leistchen der Scleriten vorhanden; der Kalk-
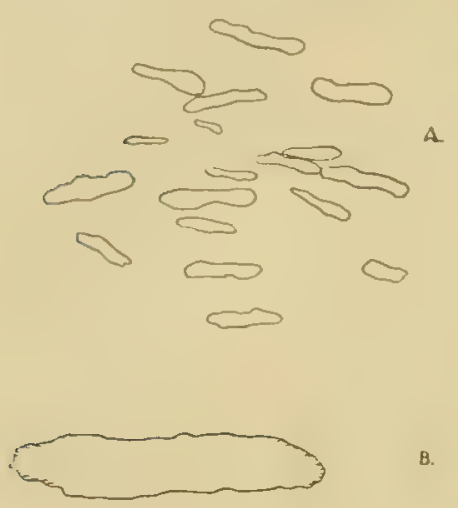

Fig. 10. L. petersi,

Siboga-Exp. St. 52 .

Scleriten der Rinde etwas oherlialb der Stammbasis; $A$ in nat. Lage. $\times 47 ; 13 . \times 200$. körper der Figur 9 ist ja von einem der Siboga-Exemplare, so auch die Figuren 7 und 8 eines Polypen. Daneben fand ich aber einige Unterschiede.

Die maximale Länge der Polypen ist bei zusammiengelegten Tentakeln nur 4,5 mm., bei halbvorgestreckten Tentakeln $5 \mathrm{~mm}$., gegen $7 \mathrm{~mm}$, bei den Typen. Die Polypen-Scleriten sind gleichfalls stets kürzer, höchstens $2 \mathrm{~mm}$. lang bei der einen Kolonie von Stat. 88, Siboga-Exp., nur 1,3 mm. bei der von Stat. 52, Siboga-Exp. Doch sind die Polypen der meisten Fragmente der Challenger-Sammlung gleichfalls nicht $7 \mathrm{~mm}$. lang; so haben die Polypen von verschiedenen Stammabschnitten, die doch anscheinend dem unteren Theile einer gut ausgewachsenen Kolonie angehörten, auch nur 4 bis 4,5 mm. Länge. Die Grösse der Polypen und ihrer Scleriten ist bei dieser Art eben sehr veränderlich und liefert keinen specifischen Unterschied.

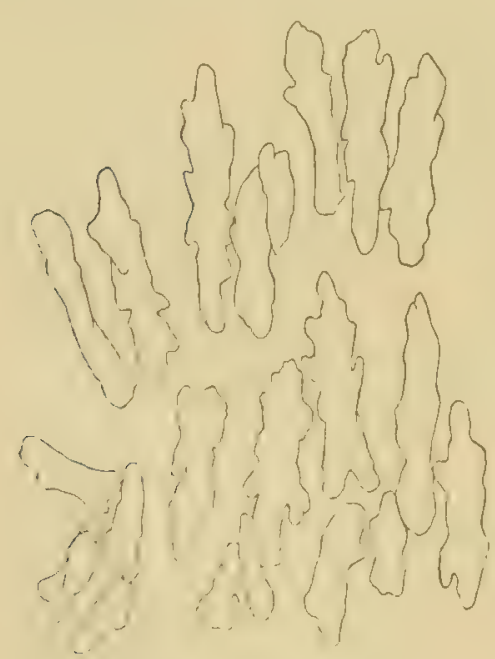

1:ig. I1. L. petersi

Sibogra-Exp. St. 52.

Scleriten der Rinde von der Mitte des stammes, in nat. Lagre. $\times 47$.

Der Polypen-Abstand ist bei dem einen der Siboga-Exemplare (Stat. 52) im Mittel nur wenig grösser als bei den ChallengerExemplaren, unten 4,5 bis $5 \mathrm{~mm}$., in der Mitte $4 \mathrm{~mm}$., nahe der Spitze noch etwas weniger. Bei dem anderen Exemplar (Stat. 88) ist diese Entfernung erheblich mehr: unten $7,5 \mathrm{~mm}$., in der Nitte 4,6 , bei der Spitze $4,8 \mathrm{~mm}$. Weit mehr als bei den Typen variiren auch die Entfernungen in beiden Kolonien.

Die Scleriten der Rinde sind bei ihnen sowohl unter einander als von denen der Typen verschieden; dagegen zeigt ein Basal-Abschnitt einer Kolonie von Stat. 52 ganz dieselben Rinden-Scleriten wie die typischen Exemplare der Challenger-Sammlung. Die vollständige Kolonie von genannter Station hat im Basal-Abschnitt (Fig. 10; A und B) weniger und kleinere Scleriten (Länge $0,2 \mathrm{~mm}$, selten wenig mehr, bei den Typen 0,36 und sogar bis $0,4 \mathrm{~mm}$.), welche ganz glatt sind, während. bei den Typen von $L$. petersi die meisten kleine $W$ ärzchen tragen. Von den untersten Polypen ab bis etwa 2 dm. unterhalb der Spitze sind die Scleriten wie die in Fig. I I

1) Challenger keport, vol. 3 I, S. 3: "when the tentacles are retracted they form an operculat covering over the oral cavity" 
uncl Figr. I2, A und li alurebildeten: sie unterscheiden sich von denen der Typen durch die

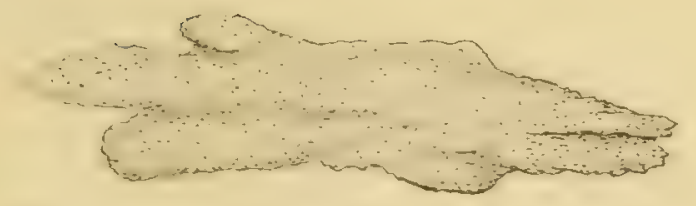

Fig. I2 A. L. fecersi, Siboga-Exp. St. 52. Kalkkörper der Rinde von der Stamm-Mitte. X I 50.

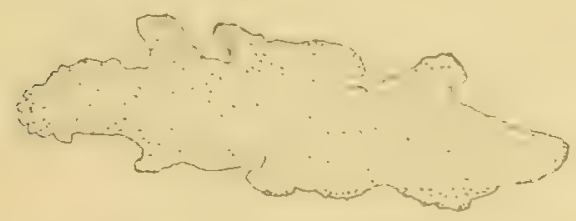

Fig. 12 B. L. pecersi, Siloga-Exp. St. 52.

Kalkkörper der Rinde aus der Nähe der unteren Polypen. $X \mathbf{1 5 0 .}$
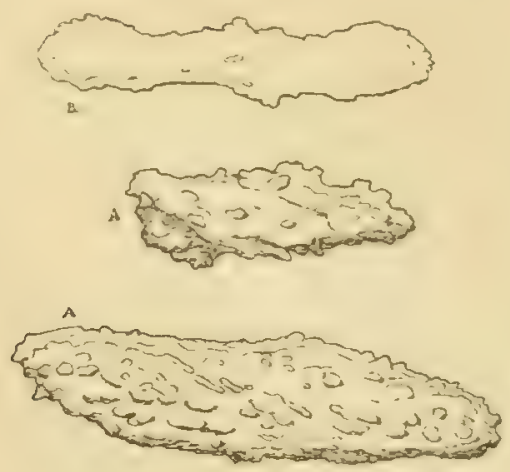

Fig. 13. Rinden-Scleriten ron L. petersi, Siboga-Exp. St. SS. A von der Mitte; $\mathbf{B}$ von der Basis des Stammes. $\times 150$.

kleineren, nicht zu Leistchen verschmolzenen Wärzchen, den mehr buchtigen Rand, auch sind sie etwas dünner und im Mittel etwas grösser. Im obersten Theil der Kolonie treten diese Scleriten zurück gegenüber kleineren, dünneren und flachen, während die mit dem buchtigen Rand der Typen (Fig. 6) ganz fehlen. Weit mehr sind die Rinden-Scleriten der Kolonie von Stat. 88, Siboga-Exp., von denen der typischen Exemplare verschieden. Sie sind aus der Nähe der Basis des Stammes bis etwa $20 \mathrm{~mm}$. unterhalb dessen Spitze ausgezeichnet durch grosse Höcker (Fig. I 3; A). Auch sind die meisten dick, nur einige merkbar abgeplattet; sie sind etwas kleiner als bei den Typen und liegen dichter beisammen, namentlich im unteren Theil des Stammes. Meist sind sie 0,2 bis $0,3 \mathrm{~mm}$., mitunter bis $0,46 \mathrm{~mm}$. lang, 0,06 bis 0,09 $\mathrm{mm}$. breit, bis $0,04 \mathrm{~mm}$. dick. In dem Spitzen-Abschnitt der Kolonie sind die Scleriten meist kleiner und

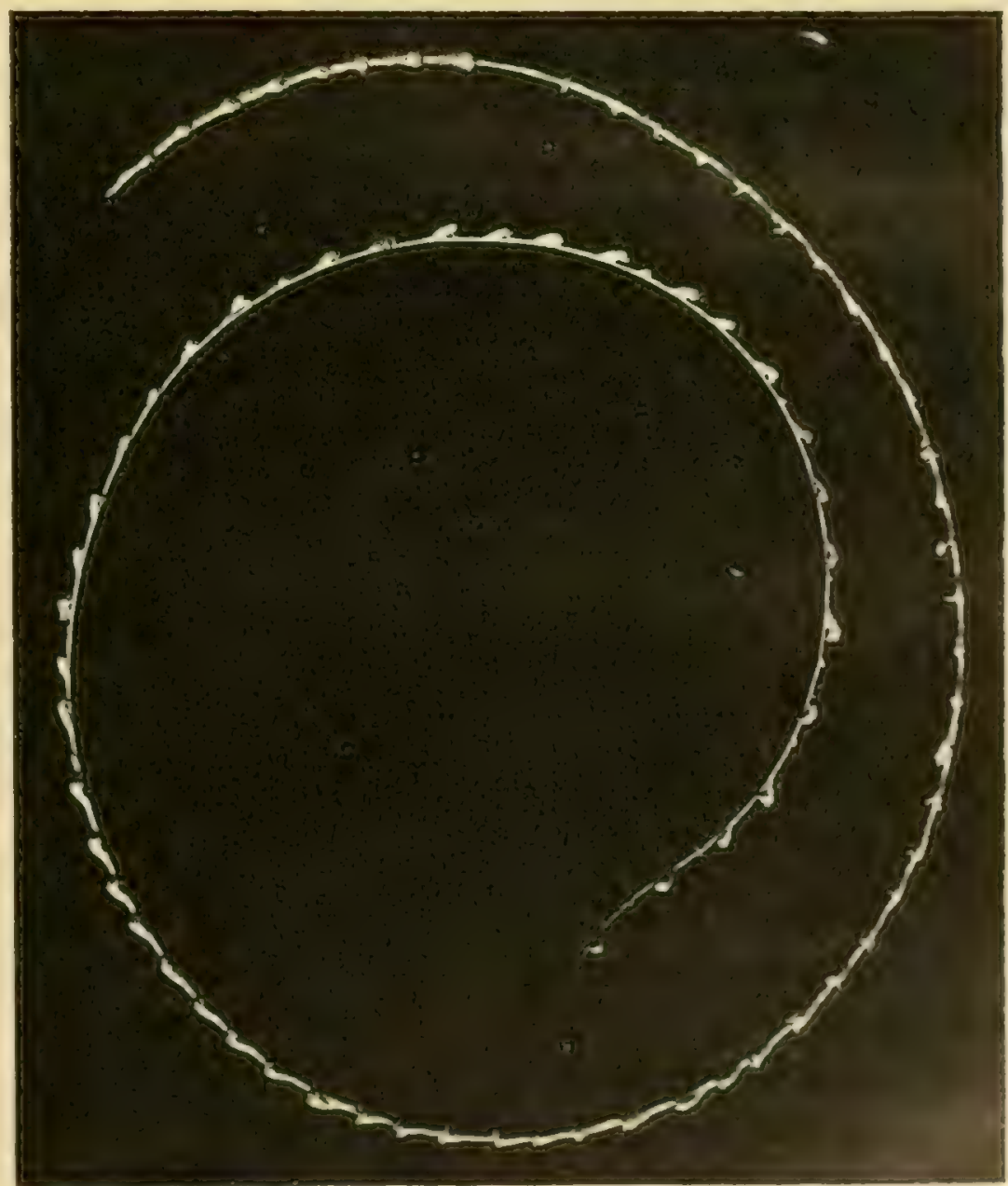

lig. 14. L. petersi, Siboga-Lxp. St. SS. Spitzen-Abschnitt einer Kolonie. nat. Gr.

dünner, aber höckerig wie die in Fig. $I_{3}$ bei $\mathrm{A}$ abgebildeten. Ganz unten sind die Scleriten meist glatt, wie in Fig. I 3 bei $B$. 
Ueberall firiden sich vermittelnde Formen:

In der Nähe der Basis der Polypen aller Kolonien werden die Scleriten dicker und länger, wodurch sie sich denen der Polypen nähern; auf dünneren Abschnitten des Stammes sind diese Zwischenformen bisweilen die herrschenden.

Bei den Challenger-Exemplaren fand ich keine erhebliche Variabilität der Rindenscleriten, habe aber wegen Zeitmangels nur einige Präparate hergestellt und verglichen. Darin zeigten die Rinden-Scleriten immer die typischen Längsleistchen.

Für die Kolonie der Siboga-Sammlung von Station 52 sind typisch die kleinen zerstreuten Wärzchen der Rinden-Scleriten, die etwas grössere Entfernung der kleineren Polypen und die kleineren Polypen-Scleriten.

Die nahezu vollständige Kolonie der Station 88 hat kleinere, dickere, grosshöckerige Rinden-Scleriten, und erheblich grössere Entfernung der gleichfalls kleineren Polypen. Auch fällt bei Vergleichung auf, dass bei den Typen die Spitzen der Kolonien schon ziemlich grosse und gedrängt stehende Polypen tragen, die Siboga-Kolonien dagegen einen viel längeren Spitzen-Abschnitt zeigen (Fig. I4), ausgezeichnet durch die erheblich kleineren Polypen, welche nach unten zu nur sehr allmählich grösser werden und die Grösse der normalen. Polypen erst in einiger Entfernung von der Spitze des Stammes erreichen. Dieser Unterschied kann sehr gut eine Folge sein von schnellerem Spitzen-WVachsthum bei den Siboga-Kolonien und ich wage es nicht ihm den Werth eines Artmerkmals zu zu erkennen.

Meines Erachtens sind beim vorliegenden Material die Unterschiede nicht genügend zur Aufstellung verschiedener Arten; es ist sehr gut möglich, dass hier nur individuelle Variationen einer und derselben Art vorliegen.

Geographische Verbreitung: bei Japan, Insel Yedo (Challenger-Exp.) und im Ost-Indischen Archipel (Sibog-Exp.) in Tiefen von 62 I bis I $301 \mathrm{~m}$; auf Schlammboden.

\section{Lepidogorgia verrilli IVright \& Studer.}

Strophogorgia verrilli Wright, Challenger Report, Narrative of the Cruise, vol. I, part. 2, 1885, S. 69I; ohne Beschreibung oder Figuren.

Strophogorgia verrilli Wright and Studer, Challenger Report, vol. 3 I, IS89, S. 3.

Stat. $85.0^{\circ} 36^{\prime} .5$ S., $119^{\circ} 29^{\prime} .5$ O. Makassar-Strasse. 724 M. Feiner, grauer Schlamm; eine vollständige Kolonie.

Die von der Siboga-Expedition erbeutete Kolonie stimmt vollständig mit dem Fragmente der Challenger-Sammlung, das ich im „British Museum” gesehen habe, überein. Die nachfolgende Beschreibung stiitzt sich denn auch auf beide, namentlich_aber auf das Exemplar der SibogaExpedition, welches Fig. I 5 in natürlicher Grösse vorführt.

Der Basalstolo der (in der Figur) links vom Stamme abgeht, zeigt dort, wo er sich verzweigt den Ansatz eines zweiten, abgebrochenen Stammes. Der vorhandene Stamm erreicht eine Länge von $26 \mathrm{~cm}$, ist unten nur $0,4 \mathrm{~mm}$. dick, an der Spitze sehr dünn, rund und glatt, sehr biegsam, gelblich weiss, durchscheinend, mit nur schwachem Goldglanz.

Die Scleriten der sehr dïnnen Rinde sind lange, schmale, flache Kalkkörper (Fïg. I6) 
mit nur sehr fein gerunzelter Oberfläche, an den Enden gerundet oder zugespitzt. Scleriten mit Ausbuchtungen der Ränder sind selten; einige nähern sich den auf Fig. I $2 \mathrm{~A}$ abgebildeten Scleriten von $L$. petersi. Sie sind etwa $0,5 \mathrm{~mm}$. lang oder kürzer, meist etwa $0,03 \mathrm{~mm}$., mitunter bis $0,09 \mathrm{~mm}$. breit. In der Nähe der Polypen sind die Scleriten grösser, bis $0,9 \mathrm{~mm}$. lang, nadelförmig, an den Enden meist zugespitzt, auf dem Querschnitt rund oder wenig abgeplattet, mit nahezu glatter Oberfläche. Auf dünneren Stamm-Abschnitten und in der Nähe der Polypen enthält die Rinde der Kolonie von L. pctcrsi von Station 88 (Siboga-Exp.) ähnliche Scleriten. Auf dem unteren Theile des Stammes, wo keine Polypen stehen, sind die Kalkkörperchen dünn, parallel dem Stamme verlängert, mit gerundeten Enden, oft in der Nitte verschmälert und mit sparsamen Wärzchen (Fig. I 7); sie sind bis $0,3 \mathrm{~mm}$. lang, bis $0,04 \mathrm{~mm}$. breit und beinahe stets weniger als 0,0 I $\mathrm{mm}$. dick.

In einer Entfernung von $65 \mathrm{~mm}$. von der Stammbasis steht der unterste Polyp; von da ab bis zur Spitze der Kolonie stehen die Polypen in

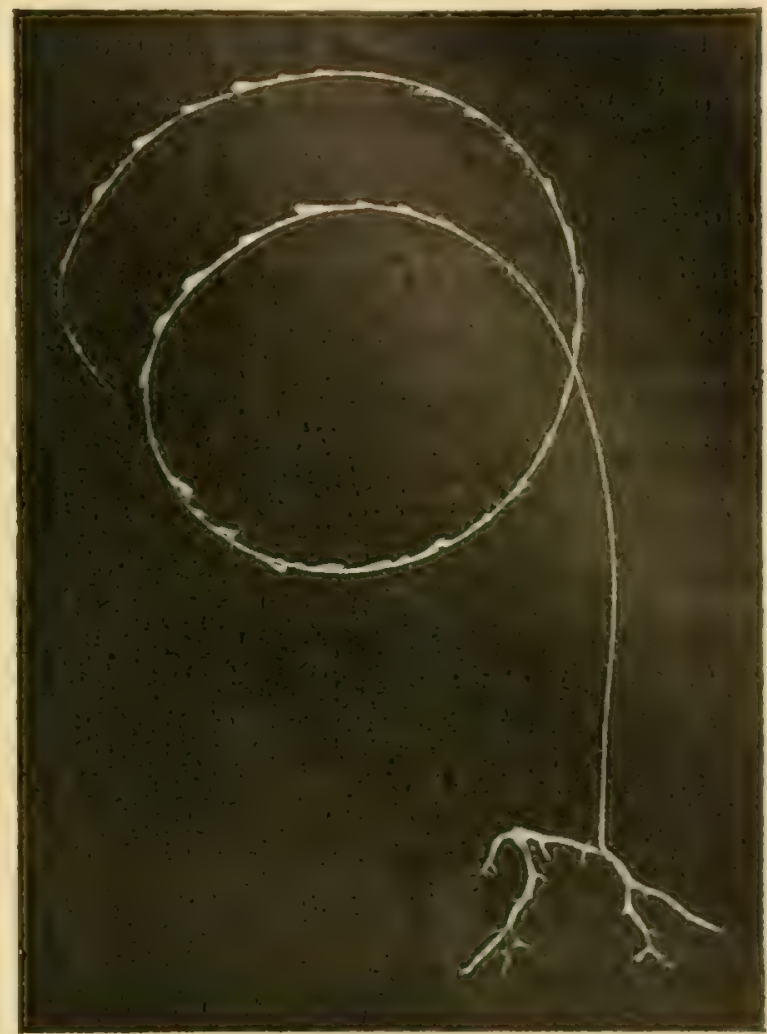

Fig. I 5. L. verrilli, Kolonie in nat. Grösse. einer Reihe über einander; die mittlere Entfernung beträgt reichlich $4 \mathrm{~mm}$. bei der SibogaKolonie, 4,7 mm. beim Fragment der Challenger-Sammlung. Im Challenger Report (S. 3) wird eine Entfernung von $6 \mathrm{~mm}$. angegeben; dieser Unterschied mag davon herrühren, dass eine andere Kolonie der Challenger-Sammlung, welche ich nicht sah, von WRIgirt und Studer gemessen wurde, aber auch wohl davon, dass die genannten Untersucher die zahlreichen sehr kleinen Anlagen von neuen Polypen nicht mitgerechnet haben, was ich stets thue. Mruils und STuner erwähnen derselben gar nicht. Im ('ebrigsen variirt bei jeder Kolonie diese Entfernung erheblich, beim Siboga-Exemplar von 2 bis $6 \mathrm{~mm}$. Hierüber vergleiche man den Abschnitt iiber das Längenwachsthum am Ende dieser Arbeit.

Die grössten Polypen waren beim Challenger-Exemplar $31 / 2$, beim Siboga-Exemplar gut $3 \mathrm{~mm}$. lang, beide mit zusammenscelesten Tentakeln. Viele P'olypen sind viel kleiner, einige nur eben als kleine Erhebungen der Rinde sichtbar.

Die Polypen haben, ganz wie bei L. petersi, eine dem

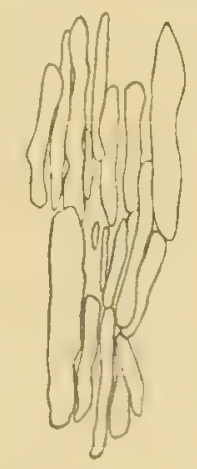

Fig. 16. L. a'crilli, Type iler othollenserSumulums slevi: $\mathrm{nt}+1$ Rinde in natiirl. Iage. $\kappa+7$.

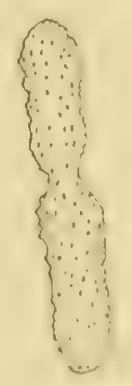

Fig. 17. L.:

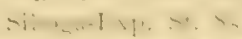
K.11.1, t? 1 ! . Lis. . $1 \quad \therefore \because>\therefore$. ol $\cdots, 2.2$. Stamme zugekehrte concave Innenseite mit sehr kleinen Tentakeln, die sich eng an den Stamm anlegen kann. Die Scleriten dieser Seite sind aber nicht so reducirt wie bei L. petersi.

WRight und Studer geben für die Polypen-Scleriten eine Länge bis zu $2 \mathrm{~mm}$. an, was 
ich auch beim Siboga-Exemplar fand; bei zwei Polypen des Challenger-Fragmentes, das ich untersuchte, waren dieselben nur bis I, $3 \mathrm{~mm}$. lang. Form und Oberfläche dieser Kalkkörper ist wie bei L. petersi (siehe Fig. 9); namentlich fand ich auch die eigenthümlichen, aus verschmolzenen Wärzchen gebildeten Leistchen.

Diese Art steht der L. petersi sehr nahe. Thatsächlich ist der Spitzen-Abschnitt der Kolonie, welche die Siboga-Expedition auf Station 52 erbeutete und welche ich zu L. petersi gestellt habe, durch Grösse und Entfernung der Polypen mit L. verrilli ganz gleich. Die Unterschiede zwischen den Coenenchym-Scleriten sind gering und bei der grossen Variabilität derselben nicht verwerthbar. Zwischen L. verrilli und einer jungen Kolonie von L. petcrsi kann ich keine Unterschiede angeben. Vielleicht sind die Arten identisch; wenn man aber die Typen der L. petersi mit $L$. verrilli vergleicht, scheint dies wieder fraglich. Möglich ist auch, dass die von mir zu L. petcrsi gebrachten Kolonien der Siboga-Sammlung nicht zu dieser Art gehören, sondern ältere Kolonien von $L$. verrilli sind. Nur Vergleichung jüngerer Kolonien, die gewiss zu L. petersi gehören, mit L. verrilli könnte hierin Klarheit bringen; mein Material reicht dazu nicht aus. Die Unterschiede zwischen den vorliegenden Exemplaren in Grösse und Entfernung der Polypen und Länge der Kolonien können ebensogut Alters- wie Species-Unterschiede sein, und auch die Grenzen der individuellen Variabilität sind unbekannt.

Geographische Verbreitung: Von der Challenger-Expedition auf den Stationen 235 und 237 bei Japan in Tiefen von 1017 und 3375 M. erbeutet. Nur von ersterer Station sah ich ein Fragment von I $51 \mathrm{~mm}$. Länge im „British Museum”; von Station 237 sah ich kein Material. Von der Siboga-Expedition in der Makassar-Strasse, also in weiterer Entfernung von ersteren Fundorten in nur 724 M. Tiefe erbeutet. Wächst auf Schlammboden.

\section{Lepidogorgia challengeri Wright \& Studer ${ }^{1}$ ).}

Strophogorgia challengeri Wright, Challenger Report, Narrative of the Cruise, vol. I, part. 2, I 885, S. 691; ohne Beschreibung oder Figuren.

Strophogorgia challengeri Wright and Studer, Challenger Report, vol. 3I, I889, S. 3.

Diese Art wurde von der Siboga-Expedition nicht erbeutet.

Die Untersuchung der Typen im „British Museum” giebt zu folgenden, Wrighit und STUDER's Beschreibung theilweise ergänzenden Bemerkungen Anlass. Die Achse zeigt unten dieselben kurzen Längsrisse wie bei $L$. petersi; im dünneren oberen Theile ist sie nahezu glatt. Sie zeigt keine Verdickung bei den Polypen, wenn WRight und Studer (1. c. S. 4) sagen: „the axis is slightly swollen at the places where the polyps are attached", so ist mit „axis" wohl der Stamm gemeint, welcher durch die dickere Rinde wirklich bei jedem Polypen eine Anschwellung zeigt, doch das findet man auch auf den dïnneren Stamm-Abschnitten der anderen Arten dieses Genus.

Die Rinde ist zart, mit nur sehr wenigen Scleriten; letztere sind meist mässig dünne Scheiben mit unregelmässigem Rand und mit vereinzelten ziemlich grossen Wärzchen (Fig. I8; die untere der beiden mit $\mathrm{A}$ bezeichneten Figuren); daneben findet man auch sehr dünne, in einer Richtung verlängerte, in der Mitte etwas verschmälerte Schuppen (Fig. I8; die obere der

1) Ein vor der Zahl einer Art bedeutet, dass dieselbe nicht in der Siboga-Sammlung vorkommt. 
beiden mit A bezeichneten Figuren). In der Nathe der Stammbasis sind die Scleriten dicker und zeigen mehrere Wirzchen (Fig. $18 \mathrm{~B}$ ). Sie sind bis $0,12 \mathrm{~mm}$. lang und bis $0,07 \mathrm{~mm}$. breit. In der Nihe der Polypen sind die Scleriten meist zahlreicher.

Die Entfernung der Polypen wechselt meist von 4 bis $5 \mathrm{~mm}$; auf einer Stammspitze standen die ( 13 ) Polypen im Nittel beinahe $7 \mathrm{~mm}$. aus einander

Die Länge der Polypen ist, wenn die Tentakel vorgestreckt sind, 2,5 bis höchstens $3 \mathrm{~mm}$; die Rumpflänge (von der Achse des tragenden Astes bis zur Mundscheibe) höchstens I mm., meist 0,9 oder $0,8 \mathrm{~mm}$. und weniger.

Wichtig ist, dass auch bei dieser Art die Polypen sich bei Contraction gegen den Stamm schmiegen und dementsprechend bilateral-symmetrisch sind. Der Tentakel, welcher dabei dem Stamme angepresst wird, ist rudimentär.

Die Kalkkörper des Polypen-Rumpfes sind wenig zahlreich, sie liegen

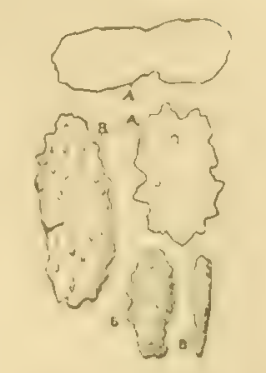

Fig. IS. L challensert, Kinden-ticleriten: $\triangle$ aus der Mitte, li aus der Basis des Stammes: das unterste Exemplarrechts von der kiante gesehen $\times 200$. in acht Längsreihen, wovon aber oft nur die fünf Reihen der freien Seite sich auf der Polypenbasis bis zum Stamme fortsetzen.

In jeder Reihe liegen meist zwei Scleriten neben einander. Die Reihen liegen genau in der Verlängerung der Tentakel, also zwischen den Septa, wie es auch der Fall ist mit der ScleritenReihe, die bei L. verrilli und L. petersi in der concaven Innenseite des Polypen-Rumpfes liegt.

Auf den Tentakel-Rücken setzen die Kalkkörper sich in einer $z$ bis 3 Scleriten breiten Reihe fort. Die Kalkkörper der Polypen sind lang, schmal, dünn oder nahezu rund auf dem Querschnitt, mit kleinen Wärzchen (Fig. 19, A, B); sie erreichen $0,4 \mathrm{~mm}$. Länge und $0,04 \mathrm{~mm}$. Breite.

Vom Tentakel-Rücken bis weit in die Pinnulae hinein liegen Scleriten wie auf Fig. 19 bei ( almedidelet, in den Pinnulae meist mit zurespitztem Ende. Dieselbe liegen in regelmässiger Entfernung von einander, warscheinlich einer in jeder Pinnula. Letztere waren aber nicht genügend gut erhalten um dies mit Bestimmtheit auszumachen. Diese Scleriten sind bisweilen ziemlich gross; ich fand einen von $0,25 \mathrm{~mm}$. Länge; die meisten sind aber 0,10 bis O, I $2 \mathrm{~mm}$. lang.

Ich fand keine Polypen bei denen die Tentakel regelmässig sich zusammenlegten und ein Operculum bildeten, wie auf Fig. I $a$, Tafel I des Challenger Report ${ }^{1}$ ) von den beiden obersten abgebildeten Polypen angegeben

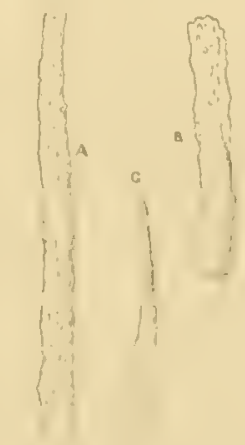

Fig. 19. L.challingeri, Pulypen-Sicleriten: $A$, li aus dem kumpf, $C$ aus einer Hinnula. $\times$ I.50. ist, ebensowenig solche mit acht gleich gut entwickelten Tentakeln, wie auf derselben Figur von dem unteren Polypen gezeichnet ist. Die grosse Mehrzahl der Polypen ist gewiss bilateralsymmetrisch mit concaver Innenseite und dariber einen rudimentären Tentakel.

Die Figur I, Tafel $r$ des Challenger Report von einer Kolonie dieser Art in natirlicher Grösse giebt den Habitus derselben sehr gut wieder.

Geographische Verbreitung: nur von der Challenger-Expedition im Atlantischen Ocean bei Cadiz in 1080 M. Tiefe gefunden auf Schlammboden, in zahlreichen Exemplaren. 
4. Lcpidogorgia sracilis Verrill.

Lepidogorgia gracilis Verrill, American Journ. of Science and Arts, Ser. 3, vol. 28, I884, S. 220.

Lepidogorgia gracilis Verrill, Report U. S. Comm. of Fish and Fisheries for $188_{3}$, part. II, I 885 , S. 512 .

Diese Art wurde von der Siboga-Expedition nicht erbeutet und ich habe dieselbe nicht gesehen.

VERRILL's Beschreibung ( $\mathrm{I} 88_{4}$ ) lautet: „Axis tall, slender, terete, tapering to a flexible tip; roots large, thick, irregularly but finely arborescently branched, the branchlets white, round, tapering and coral-like. Polyp calicles large, prominent, distant, obliquely seated, often thicker than the stalk, covered with large spicula, longitudinally placed. Spicula of the Coenenchyma small, flat, oblong, or constricted in the middle, with rounded ends. Color, when fresh, orange or salmon. Height often $900 \mathrm{~mm}$. or more; diameter of axis, at base I- I,5 mm.; of polyps, I mm.; distance between polyps, 5 to $10 \mathrm{~mm}$."

Im Report U. S. Comm. of Fish and Fisheries, etc. giebt VERrill an, dass die Polypen in einer Reihe stehen ( secund") und dass die Rinden-Schuppen eine dünne Schicht auf dem Stamme bilden. Dazu giebt er eine Figur der Basalstolonen in natürlicher Grösse und die eines Stamm-Abschnittes mit 2 Polypen in vierfacher Vergrösserung. In letzterer Figur ist der grösste Polyp etwa $4 \mathrm{~mm}$. lang, I mm. dick, mit $3 \mathrm{~mm}$. Rumpflänge (d. i. die wahre Grösse; in der Figur sind diese Maasse vier Mal grösser wegen der Vergrösserung). Die Tentakel sind kurz und alle acht nahezu gleich gross abgebildet.

Unsere Kenntniss von dieser Årt ist also leider ziemlich dürftig. Sie scheint etwas zarter und kleiner als L. petcrsi, ist aber erheblich grösser als die anderen Lepidogorgia-Arten. Wie gross die Polypen werden können ist unbekannt; ihre Entfernung variirt erheblich, wie bei den anderen Arten. Die Polypen sehen auf VerRiLl's Abbildung anders aus als bei $L$. pctersi und verrilli.

Geographische Verbreitung: im Atlantischen Ocean in einiger Entfernung von der Westküste der Vereinigten Staten von Nord-Amerika zwischen $38^{\circ} 50^{\prime}$ und $41^{\circ} 53^{\prime} \mathrm{N}$. Br. an drei Orten in 1544 bis $3120 \mathrm{M}$. Tiefe auf Schlammboden gefunden (Albatross-Exp. I $\$ 8_{3}$ ).

\section{*5. Lcpidogorgia fragilis Wright \& Studer.}

Strophogorgia fragilis Wright and Studer, Challenger Report, vol. 31, ISS9, S. 4.

Diese abweichende, von der Siboga-Expedition nicht erbeutete Art fand ich leider nicht in der Sammlung des "British Museum”. Zwar fand ich zwei kleine Fragmente unter diesem Namen in jener Sammlung, der Etiquette nach auf Station yo der Challenger-Expedition erbeutet, aber dieselben gehören ohne Zweifel zu einer anderen Art, wahrscheinlich zu L. worilli.

Die Polypen waren durch die Rinde verbunden, darin befand sich aber keine Achse; die Fragmente waren offenbar ron einer Achse abgestreift und die Höhlung im Coenenchym deutet auf eine viel stärkere Achse als sie L. fragilis zukommt (Challenger Report, P1. 2, Fig. 2). Die Polypen stehen alle schräg auf dem Coenenchym und sitzen demselben mit breiter Basis auf. Die der Rinde zugekehrte Seite der Polypen ist concav, wahrscheinlich auch mit 
rudimentärem Tentakel. Hieraus ist ersichtlich, dass Wrignt und StunER's Beschreibung nicht auf diese Fragmente gegrindet ist und mir die Art der genannten Autoren nicht vorlag. Daraus folgt aber, dass die Type derselben sich nicht im „British Museum" befindet.

Nach Wright und Studer unterscheidet diese Art sich von den vorhergehenden Arten dieses Genus namentlich durch die sehr dünne, vermuthlich dem Boden aufliegende Achse, welcher die Polypen mit selır stark verengter Basis aufsitzen. Die Polypen sind 4 bis $4,5 \mathrm{~mm}$. lang. Geographische Verbreitung: nur einmal vom Challenger im Atlantischen Ocean, westlich ron den Açoren, in 3015 M. Tiefe erbeutet; auf Schlammboden.

$2^{\text {te }}$ Subfamilie Chrysogorgiinae.

Subfam. Chnysogorginae p.p. Th. Studer, Archiv. f. Naturgesch., Jhrg. 53, Bd. I, I88\%, S. 4 I. Subfam. Chry'sogorginae p.p. Wright and Studer, Challenger Report, vol. 31, 1889, S. XL und S. 2 .

Kolonien verzweigt, mit einem Stamme, der entweder unverzweigte Aeste abgiebt (bei Iridogorgia) oder diese Aeste sind wiederholt verzweigt (bei Chry'sogorgia und Metallogorgia). Im letzteren Fall ist die Fähigkeit Seitenzweige zu bilden auf einen schmalen Längsstreifen der Rinde der Aeste beschränkt, welcher zweigbildende Streifen entweder streng auf einer Seite der Aeste verbleibt oder in einer mehr oder weniger steilen Spirale um die Aeste verläuft. Im ersteren Fall hat die Ausbreitung jedes Astes mit allen seinen Verzweigungen in einer Ebene statt, im letzteren Falle stehen die Zweige in einer Spirale und ist die Ausbreitung der Aeste in einer Ebene mehr oder weniger verwischt. Dabei ist die Seite nach welcher Seitenzweige abgegeben werden, für alle Aeste einer Generation dieselbe, ist aber entgegengesetzt fur Aeste nachfolgender Generationen. Auch das kann durch die Spiraldrehung des zweigbildenden Streifens mehr oder weniger undeutlich sein, namentlich in den 'Weigspitzen ${ }^{1}$ ).

Die Rinde ist dünn, niemals mit mehreren Schichten von Scleriten.

Die Polypen haben gleichfalls wenig zahlreiche, oft nur wenige, verhältnissmässig grosse Kalkkörper. Tentakel bei Contraction meist nur zusammengelegt, selten mir ihren Spitzen so weit nach innen gebogen, dass dieselben im Polypenrumpf aufgenommen werden.

Hierher die drei Genera Chry'sogorgia, Iridogorgia und Mctallogorgia.

\section{Chrysogorgia Duchassaing \& Michelotti.}

Chry'sogorgia Duchassaing et Michclotti, Supplément au Mémoire sur les coralliaires des Antilles; Memoric d. R. Accad. di Torino, Seric 2, Tom. 23, 1866, S. 107 und S. II5.

Chry'sogorgia Duchassaing de Fontbressin, Revue des Zooplyytes et des Spongiaires des Antilles, Paris 1870, S. 17 .

Chrysostorgia J. L: Gray, Catalogue of Lithophytes or stony Corals in the collection of the British Muscum, London i37\%, S. 45.

I) Vergleiche hieriber das weiter unten beim Genus Chrysogor,riz Gesagte. Wenn Jritogorgia einen sympodialen Stamm hat, ist sic verzweigt wie l'lauregorgin, welche zu den f'iiscina gehürt. 
Chrysogorgia A. E. Verrill, Bull. MIus. Comp. Zool., vol. II, ISS 3, S. 2 I.

Dasygergia A. E. Verrill, ibid.

Chrysogorgia Th. Studer, Versuch eines Systemes der Alcyonaria, Archiv. f. Naturgesch. Ihris. 33. Bal. I, I\$\$T, S. +1 .

Dasygorgia Th. Studer, ibid.

Cliry'sogorgia Wright and Studer, Challenger Report, vol. 3I, ISS9, S. XLI und S. 23.

Dasygorgia p.p. IVright and Studer, 1. c., S. XLI und S. 6.

In diesem Genus vereinige ich alle bis jetzt beschriebenen Arten der Genera Chrysogorgia und Dasygorgia mit Ausnahme der Dasygorgia melanotrichos Wright \& Studer, für welche Art ich wegen des ganz anderen Baues des Stammes der Kolonien das neue Genus 1Mctallogorgia aufstelle. Die Vereinigung der übrigen Arten zu einem Genus begründe ich durch Folgendes:

Die Unterschiede zwischen den Genera Chrysogorgia Verrill und Dasygorgia Verrill genügen, nach den Angaben von Verrill und von Wright und Studer selbst, nicht zu deren Trennung. Es würde zu viel Raum erfordern, wenn ich Verrill's und Wright und Studer's Beschreibungen hier wiederholen wollte. Aus ihren Mittheilungen und aus der Untersuchung einer neuen Art der Siboga-Sammlung (Chr. oricntalis), welche unbedingt mit Chrosogorgia fewkesi nahe verwandt ist, geht aber Folgendes hervor.

Die Verzweigung der Kolonien ist bei beiden Genera identisch.

Die Polypen sind ähnlich; eine erweiterte Polypenbasis, die Verrill als Genusmerkmal für Dasygorgia angiebt, ist nur ein Folge von der Anwesenheit einer beträchtlichen Menge von Geschlechtsprodukten, fehlt bei einigen Dasygorgia-Arten (D. expansa u. a.) und kommt dagegen bei Chry'sogorgia orientalis vor. Rindenscleriten mit Wärzchen, welche von VERriLI als unterscheidendes Merkmal für Chry'sogorgia angegeben und abgebildet werden (1.c. Pl. II, Fig. $6 a, 6 b$ ), finden sich auch bei Dasygorgia flcxilis, während diese Kalkkörper bei Chr. oricutalis ohne Wärzchen sind. Die Form der Polypenscleriten ist bei Dasygorgia sehr verschieden; es giebt aber Arten mit denselben warzigen, nadelförmigen Kalkkörpern wie bei Chrysogorgia, darunter auch oft gebogene Scleriten.

Der einzige Unterschied, der einigen Werth hat, ist die quere Lage der Kalkkörper in der Polypenbasis (vergleiche Fig. 8 I von Chr. oricntalis). Dasselbe findet sich aber auch bei den meisten Polypen der Dasygorgia squarrosa und zwar meist nur an einer Seite der Polypen (vergl. Fig. 85). Diese Art nimmt dadurch eine vermittelnde Stellung zwischen Verrill's Genera Dasygorgia und Chry'sogorgia ein. Ich kann daher in diesem nicht immer constanten und dann doch auch wenig wichtigen Merkmal kein Gattungs-Merkmal anerkennen ${ }^{2}$ ).

Ich vereinige deshalb beide Genera, was auch insofern glücklich ist, als wir sonst einen Umtausch der Namen durchfihren müssten der leicht Anlass zu Verwirrung geben würde. V'errill's Genus Chrosogorgia ist mämlich nicht identisch mit Duchassaing und Michelotmis älterem Genus Chry'sogorgia, während mehrere Arten des Genus Dasygorgia von VERruL und Wrigirt und Studer (nämlich die "Squamosae" von WRIGIT und STuder) zu Chrysogorgia Duchassaing und Michelotti gehören. Zu dem was Wrignt und Studer (1.c. S. I und 23) uiber diesen Punkt schreiben, habe ich Folgendes zu bemerken.

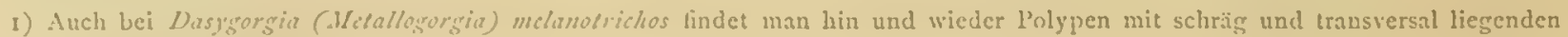
Scleriten in ihren Bases (vergl. Fig. 152). 
Duchassaing und Michelotti haben ihr neues Genus Chrysogorgia zweimal in derselben Arbeit beschrieben (1. c. S. 107 und II 5), wobei die Beschreibungen zwar erheblich verschieden sind, was auch WRIGHT und STUDER hervorheben, aber nichts enthalten was nicht auf dasselbe Genus zu beziehen wäre; auch stimmt ihre Fig 5, Tafel I genügend mit Fig. 6, Tafel + überein. Später hat Ducinssaixg (1. c. I870, S. I7) noch ausdrücklich hervorgehoben, dass die beiden Beschreibungen sich auf dieselbe Art beziehen. Ich kann deshalb Wrignit und Studer nicht beistimmen, wenn sie behaupten, dass Duchassaivg und Michelotri unter den Namen Chry'sogorgia zwei gänzlich verschiedene Genera beschrieben hätten; diese Behauptung ist unrichtig.

Duchassaing und Mrcuelottr's Genus Chrysogorgia ist durch die Abbildungen und Beschreibungen genügend erkennbar, mindestens so gut wie die Mehrzahl der älteren Genera der Gorgoniden. Ob die Art, Chr. desbonni, auch erkennbar ist, hängt wohl in erster Linie davon $\mathrm{ab}$, ob in der Gegend woher dieselbe stammt, noch andere ähnliche Arten vorkommen. Chry'sogorgia Duch. \& Mich. hat aber beschuppte Polypen, und da Chrysogorgia Verrill nadel. förmige, warzige Scleriten hat, sind diese Genera nicht identisch. Die Verzweigung der Chryssogrorgia desbonni Verrill's ist auch, soweit aus der Beschreibung ersichtlich, anders als die der Chry'sogorgia desbonni Duch. \& Mich. Da letztere in den Polypen schuppenförmige Scleriten hat, kann von einer ringförmigen Zone querer Nadeln um die Polypenbasis: Hauptmerkmal des Genus Chrysogorgia Verrill's, auch keine Rede sein. Die Abbildungen der Polypen sind denn auch gänzlich verschieden. Wollte man das Verrill'sche Genus aufrecht erhalten, so miisste man dasselbe neu benennen.

Dagegen enthält das Genus Dasygorgia beschuppte Arten (D. squamata Verrill, D. geniculata Wr. \& St., D. axillaris Wr. \& St. u. a. m.), welche in keiner Hinsicht von Chrysogorgia Duch. \& Mich. verschieden sind und gewiss, wie auch alle andere Arten des Genus Dasygorgia ${ }^{1}$ ), zu Chrysogorgia Duch. \& Mich. gebracht werden müssen. Ich behaupte also:

I. Dasygorgia Verrill ist synonym mit dem älteren Genus Chrysogorgia Duch. \& Mich.

2. Chry'sogorgia Verrill ist nach Verrill's Diagnose nicht synonym mit Chrysogorgia Duch. \& Mich., und müsste einen anderen Namen erhalten, wenn nicht

3. der Unterschied zwischen beiden ungenügend wäre, sodass die Trennung der zwei Genera Dasygorgia Verrill (synonym mit Chry'sogorgia Duch. \& Mich.) und Chrysogorgia Verrill unberechtigt ist.

4. Alle von Verrill und Wright und Studer beschriebenen Arten der Grenera Chryogorgiat und Dasygorgia, mit Ausnahme von Dasygorgia molanotrichos, gehören in ein Genus, das dann den Namen Chrysogorgia Duchassaing \& Michelotti führen muss, da die älteste bekannte Art unter diesem Genusnamen von letatgenannten Autoren beschrieben wurde.

5. Der Familiennamen muss dann auch Chrysogorgridac (nach VErRILL), nicht Dasygurgizidac (nach WRight und STUDER) heissen.

Die Diagnose des Genus Chrysogorgia ron Duchassnixg und Mrcmelorrer ist aber jetzt nicht mehr genügend. Der neuen Diagnose muss aber erst eine kurze Uebersicht iiber den Bau der zugehörigen Arten vorausgehen.

1) Mit ausnahme der D. melanotrichos Wr. \& St. 
Die Kolonien zeigen stets einen deutlichen, starken Stamm, der mehrfach verzweigte Aeste trägt.

Die Achsen sind vollständig verkalkt, rund, glatt, bernsteinfarbig oder gelblich oder braun, mit mehr oder weniger ausgeprägtem Goldglanz oder Metallschimmer. Sie bestehen aus regelmässigen, concentrischen Schichten, welche um eine diunne centrale Kalksäule abgresetzt sind. Kölliker hat diese centrale Säule in seinen Icones histiologicae ${ }^{1}$ ) „Centralstrang" genannt; von Kocr") gab ihr den Namen "Axenkanal". Besser ist wohl Achsencylinder, da es ein Cylinder ist, der bei einem Theil der Gorgoniden hohl bleibt, mit Flüssigkeit erfüllt ist und also kein "Strang" ist; bei vielen anderen Gorgoniden (so bei den Chrysogorgiidae) aber später durch Kalkablagerung ganz solide wird, also kein „Kanal” ist.

Der Achsencylinder ist die primäre Achse, wie dieselbe in den Zweigspitzen direct durch Spitzenwachsthum entsteht; die concentrischen Lamellen sind die später vom Achsenepithel gebildeten Verdickungsschichten. Ausführlicheres hierüber findet man bei von Kocr (1. c. S. 20 u. f.). Dünnere Zweige bestehen nahezu nur aus dem Achsencylinder. Die Seitenzweige entstehen seitlich in einiger Entfernung von der Zweigspitze und haben einen eigenen Achsencylinder, der

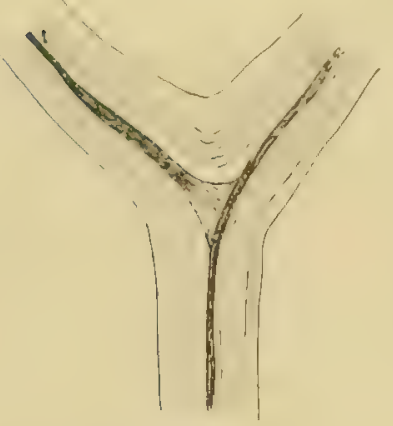

Fig. 20. Querschliff durch den Ansatz eines. Astes an einem anderen; man sieht dic konische Basis der Achsencylinder des Seitenastes.

Astes von dem er ausgeht und scheint jener der Seitenast zu sein. Dadurch ist es bei Clurysogorgia bei rein äusserlichẹ Betrachtung ohne Untersuchung des Verlaufes der Achsen. cylinder, nicht immer möglich mit Sicherheit zu entscheiden, was Haupt- und was Nebenast ist. Nur bei jüngeren Zweigen hat Knickung des Hauptastes noch nicht statt gefunden und sind die Seitenzweige meist schon äusserlich als solche $z u$ erkennen. Bei den stärkeren Zweigen müssen zur Untersuchung des Verlaufs des Achsencylinders Schliffpräparate angefertigt werden. In diesen ist der Achsencylinder bei der Mehrzahl der Arten durch dunklere Farbe leicht kenntlich, bei einigen Arten gleicht sie aber der Farbe der späteren Verdickungsschichten und ist dann auf Längsschliffen oft schwer zu erkennen, z.B. bei Chr. squarrosa und anastomosans.

Die Untersuchung der Verzweigung der Arten des Genus Chrysogorgia hat sehr eigenthimliche Verhälnisse aufgedeckt. Wie schon VERRILL mitheilt, zeigen alle Arten, soweit nicht nur kleine Bruchstucke vorlagren, einen deutlichen Stamm, der spiralig angeordnete und meist

1) Abth. II, 1:tes Heft, Leipzig $1865, \mathrm{~S} .14 \mathrm{~S}$

2) Gorgoniden, launa und Flora des Golfes von Neapel; Berlin 1887, S. 22. 
in regelmässigen Abständen stehende Aeste trägt (vergleiche Fig. 32 und Fig. 46). Der Stamm bildet bei jedem Astursprung eine Biegung, die aber in älteren Stammabschnitten oft nicht sehr stark ist. Die Richtung der Aeste ist häufig nahezu senkrecht zum Stamme. Schliffpräparate lehren, dass der Achsencylinder jedes Stamminternodiums sich beim Astursprung immer in den Ast fortsetzt, während das nächsthöhere Stamminternodium mit einem neuen Achsencylinder anfängt, also thatsächlich als Seitenast entsteht und nichts anderes ist als der erste, proximalste Seitenast des nächst unteren Astes des Stammes (Figr. 2I). Der Stamm der Chrysogorgia-Kolonicn ist also cin Sympodizun.

Ich untersuchte dies an Schliff räiparaten durch ältere Stammtheile von Chr. flexilis, rigida, pondula und orientalis. Es muss auch unbedingt zutreffen fur die anderen Arten dieses Genus, welche die gleiche Verzweigung haben. Nur Chr. japonica, von der kein Stamm bekannt ist, weicht vielleicht $a b$. In diesem Falle muss dann wohl ein neues Genus für sie errichtet werden. Ich fertigte auch zwei Schliffpräparate durch Astursprünge von Chr. squarrosa an, welche sich durch grosse und unregelmässige Entfernung der Aeste auszeichnet. Die Art erwies sich aber als nicht günstig und der Verlauf der Achsencylinder konnte nicht festgestellt werden. Doch deuteten die Präiparate auf einen Bau wie bei den andereu Arten; die Art ist anscheinend verwandt mit Chr. oricntalis, welche gleichfalls einen etwas unregelmässigen Aststand aufweist. Auch Chr. desbonni Verrill (nec. Duch. \&

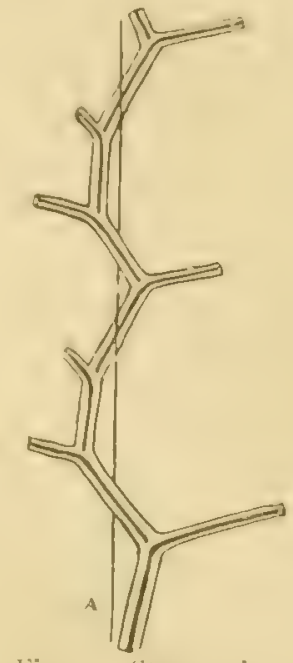

Fig. 21. Stamm einer Chrysogorgia mit Aststand $1 / 3$, links gewunden: der Verlauf der Achsencylinder beweist, dass der Stanm sympodial gelsaut ist; 1 Vertikale un welche der Stamm sich in ciner Spirale dreht. Schema. Mich.) scheint abweichend verzweigt zu sein; doch geht aus Verrill's Beschreibung hervor, dass sie einen deutlichen Stamm hat, und da die Polypen auf eine nähere Verwandtschaft mit Chr. oricntalis hinweisen, ist ihr Stamm auch wohl sympodial gebaut.

In den Spitzen der Kolonien ist oft der Stamm bis ans Ende erkennbar; meist ist dann auch deutlich, dass sein oberstes Internodium nur ein Seitenast ist und dass erst später, durch starkes Dickenwachsthum und Veränderung der Stellung das unterste Astinternodium ein neues Stamminternodium bilden wird (Fig. 22).

Die vom Stamme abgehenden Aeste nenne ich Stammästc; dieselben bestehen aus einen Hauptust, welcher die directe Verlängerung der Achsencylinder des zugehörigen Stamminternodiums enthält und dessen Seitenäste. Die Stammäste stehen fast immer in einer ziemlich regelmässigen Spirale in gleichen Abständen von einander. Durch den Stamm und die basalen Internodien der Stammäste kann man Ebenen legen, welche selbstverständlich der- Vertical-Achse der Kolonie parallel sind. Der Winkel, welchen zwei solche durch nachfolgende Stammäste gelegten Ebenen einschliessen, ist der Divergenz-

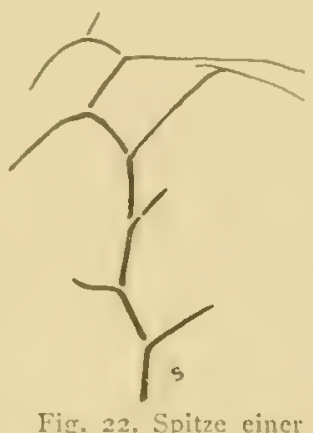

$$
\text { Fig. 22. Spitze einer }
$$
jungen Kolonic von Chr. flexilis; Seiteuiste jedesmal durch einen kleinen Zwischenraum ron den tragenden Aesten getrennt dargestellt: $S=$ Stamm; schematixch, $\times 2$. Winkel jener zwei Stammäste. Derselbe variirt bei den verschiedenen Arten, ist aber für jede Art meist ziemlich constant. Bei mehreren Arten beträgt er nahezu $90^{\circ}$, sodass jeder fuinfte Stammast iiber dem ersten steht und die Stammaiste in vier Reihen (Ortostichen) iiber einander stehen. Bei anderen Arten misst der Divergenz-Winkel im Mittel $120^{\circ}$; alsdann steht jeder 
vierte Stammast ïber dem ersten und die Stammäste stehen in drei Längsreihen. Endlich giebt es mehrere Arten, bei denen der Winkel im Nittel $144^{\circ}$ beträgt; es steht also jeder sechste Stammast über dem ersten und die Spirale, worin dieselbe stehen, geht vom ersten zum sechsten Stammast zweimal um den Stamm; die Stammäste stehen dann in fünf Längsreihen.

Bei den Pflanzen werden die analogen Anordnungen der Blätter durch die Brüche $1 / 4$, $1 / 3$, resp. $\%$ angedeutet, deren ich mich weiterhin auch bedienen werde.

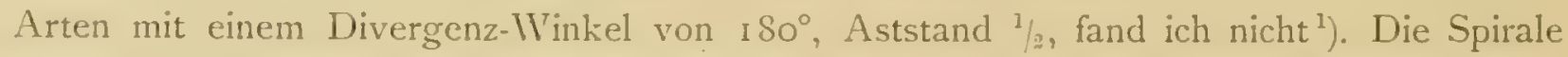
der Stammäste ist entweder eine links- oder eine rechtsgewundene, je nachdem dieselbe, wenn man die Kolonie mit der Basis nach unten vor sich hat, nach rechts oder links vom Beobachter aufsteigt, also beim Aufsteigen dem Zeiger einer Uhr entgegengesetzt oder wie dieser sich dreht.

Die Drehung ist nicht nur bei derselben Art stets die gleiche, sondern auch bei Arten, die auch in anderer Hinsicht näher verwandt sind. Daraus geht eine geringe Veränderlichkeit des Aststandes hervor, sodass derselbe zur Unterscheidung kleinerer Gruppen von Arten wichtig erscheint.

Bei einigen Arten ist der Aststand ziemlich unregelmässig, sodass der Divergenz-Winkel so sehr variirt, dass der Aststand in einem Abschnitt einer Kolonie ${ }^{1} / 3$, in einem anderen ${ }^{2} / 3$ ist z.B. bei Chr. oricntalis. Bei Chr. squarrosa endlich ist die Spirale in derselben Kiolonie theilweise links, theilweise rechts gewunden.

Die Stammäste sind meist kurz; die Zahl der Internodien eines Hauptastes ist dann

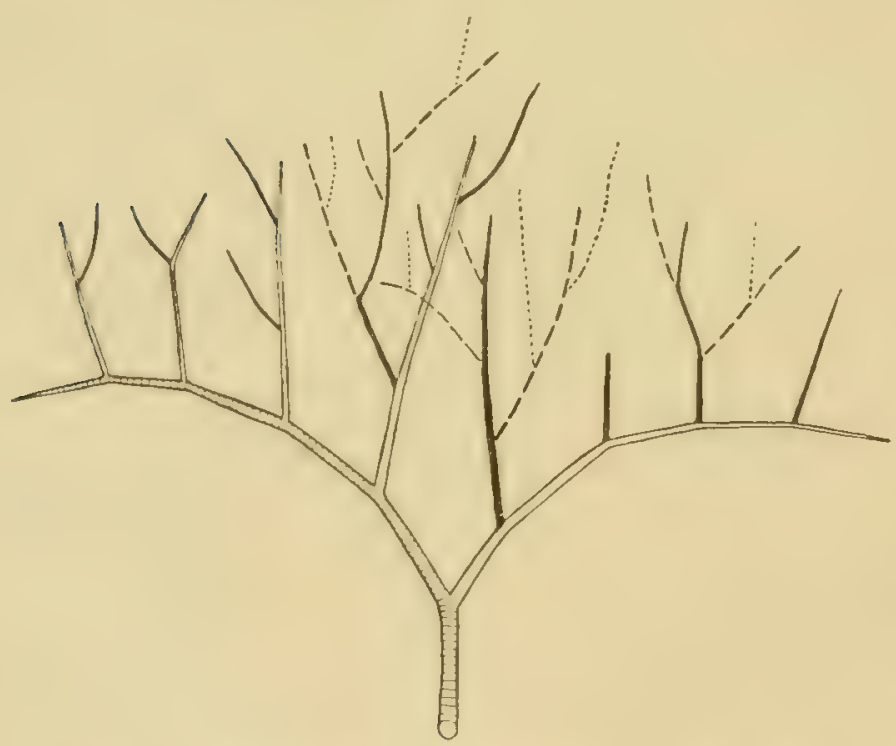

Fig. 23. Terzweigung cines Stammastes von Chr. laht. Scitenzweige verschiedener Ordnung sind verschieden angegeben; die proximalen Internodien lagen alfe in der Fibene der Zciclinung; iergrösscrt. wir, dass der Hauptast desselben nur nach einer Seite Zweige abgiebt: die Scitenzweige erster Ordnung (Fig. 23). Ich fand dies bei Chr. rigida, gcniculata, flexilis, latu und oricntalis. Diese einseitige Verzweigung ist in einigen Fällen schon äusserlich sichtbar, z.B. bei Chr. geniculata

I) Wohl mit Linrecht wird von WRIGIrT und Stuner (1.c. S. 7) angegeben: ,In the simplest case the branches arise from the stem in alternating series from the two opposite sides". Sie geben hierfur auch kein Beispiel. 
und rigida, indem der Hauptast sich durch grössere Stärke auszeichnet; sie wurde denn auch bereits von Wright und STUder ${ }^{1}$ ) entdeckt. Eine Ausnahme macht immer das Stamminternodium, das nach oben, auf den Stammast folgt, und das, wie oben dargelegt, nur der unterste Seitenast des Hauptastes ist. Dasselbe liegt nämlich meist nicht in derselben Ebene, wie die anderen Seitenäste erster Ordnung; diese Ausnahme muss wohl als secundär, als Folge der Bildung des Stammes betrachtet werden (siehe unten im Abschnitt über den Aststand).

Bei verschiedenen Arten liegen auch alle Seitenzweige der Seitenäste $I^{\text {ster }}$ Ordnung, also die Seitenäste $2^{\text {ter }}$ Ordnung, nahezu in derselben Ebene wie der Hauptast und die Seitenäste I ster Ordnung. In diesen Fällen gelsen alle Seitenïste t twe ()rhung nur nach einer Seite solche $2^{\text {ter }}$ Ordnung $a b$, und zwar nach der Seite, welche der Spitze des Hauptastes zugewendet, von dessen Basis abgewendet ist (vergl. Fig. 23). $\mathrm{Wl}^{T}$ o ein Seitenast $\mathrm{I}^{\text {ster }}$ Ordnung mehrere Zweige $2^{\text {ter }}$ Ordnung abgiebt ist bei den distalsten diese Beziehung zum Hauptast meist undeutlich, da letztere in einer anderen Ebene liegen

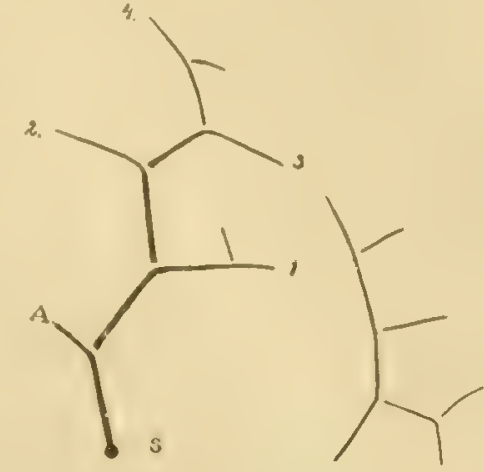

Fig. 24. \%wei Aeste von Chr. squtr\%. rosı; die Seitenäste sind jedesmal durch einen kleinen Zwischenraum von den tragenden Aesten getrennt dargestellt $\mathrm{S}=$ Stamm; $\mathrm{A}=$ Hauptast $;-4$ Seitenäste 1 ster bis $4^{\text {ier Otdung. }}$ und bei Projection in der Ebene der Zeichnung mitunter an der der Spitze des Hauptastes abgewendeten Seite des Zweiges I ster Ordnung zu liegen kommen (so ein Ast $2^{\text {ter }}$ Ordnung auf Fig. 23). Besonders verfolgt wurde dies bei Zweigen von Chr. lata, goniculata, rigida, flexilis und squarrosa; nur bei letzterer

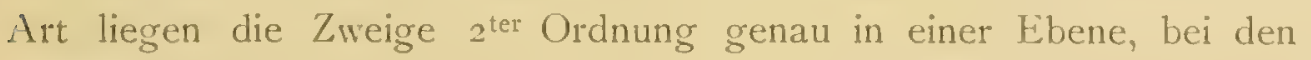
anderen Arten findet man immer bei den distalen Zweigen $2^{\text {ter }}$ Ordnung kleinere oder grössere Abweichungen von der Ebene der Verzweigung. Die Seitenäste $3^{\text {ter }}$ und höherer Ordnung fand ich beinahe immer so gestellt, dass sie nicht in die Ebene der mehr proximalen Astinternodien fallen. Bei Chr. squarrosa fand ich aber alle Seitenäste, worunter solche bis zur $4^{\text {ten }}$ Ordnung, noch in einer Ebene liegren. Wie aus Fig. 24

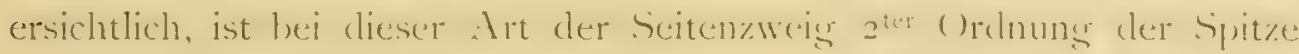

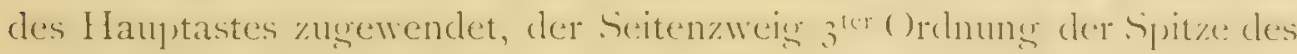
Seitenzweiges $I^{\text {ster }}$ Ordnung und der $4^{\text {ter }}$ Ordnung wieder der Spitze des Zweiges $2^{\text {ter }}$ Ordnung. Giebt ein Ast nur nach rechts (vom Beobachter, dem die Basis zugekehrt ist) Seitenzweige ab, dann tragen letztere alle nur Seitenzweige, die nach links abgehen. Ein schönes Beispiel hierfur war ein Fragment einer neuen Species, welche weiter unten bei der Artbeschreibung direct nach Chr. lata unter 2 aufgefuihrt wird. Dasselbe ist in Fig. 25 schematisch dargestellt. Es hat Seitenäste wenigstens bis zur $6^{\text {ten }}$ und $7^{\text {ten }}$ Ordnung, die alle obiger Regrel folgen.

Die Acste vieler Chrysogorgia-Arten geben also nur nach einer

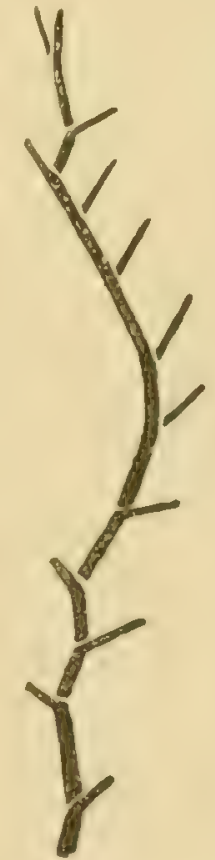

Fig. 25. Chersosoryia spic. 2 ; Ver. zweigung eines Framentes; Scitenzweige jedesmal durch einen kleinen Zwischenraum vom tragenden Aste getrennt dargestellt. Ihic Verkwei. gung an der sipitze des fragmentes steht schräg zur Elone der /eichnumg; etwas vergrussert.

Seite Seitenzweige $a b$ und diese Seiten wechseln bei den Aesten nachfolgender Ordnung ab.

1) Challenger Report, vol. $3 \mathrm{I}, \mathrm{I} 8 \mathrm{S9}, \mathrm{S} .7$ : "every branch gives off twigh from one side only"; in Textfigur I, S. S ist ths von ihnen abgebildet. 
Geben die Aeste $n^{\text {ter }}$ Ordnung nur Seitenzweige nach links ab, dann geben letztere, also die Zweige $n+I^{\text {ter }}$ Ordnung, nur Zweige nach rechts ab und umgekehrt.

Ist es nun möglich zu entscheiden, ob diese Verzweigung in einer Ebene und nach bestimmten Seiten, der ursprüngliche Zustand ist, vom dem sich der unregelmässige Aststand anderer Chrysogorgia-Arten herleitete oder umgekehrt? Nimmt man die unregelmässige Verzweigung, wie sie die distalen Ast-Abschnitte der meisten Arten zeigen, als die primitivere an, dann kann man sich sehr gut vorstellen, dass solche Aeste mehr und mehr eine Verzweigung nahezu in einer Ebene annahmen. Man denke nur an verschiedene fächerförmige Gorgoniden, bei denen ein solcher Vorgang stattgefunden haben muss. Alsdann ist aber weder für die Beschränkung der Seitenäste auf nur eine Seite jeden Astes, noch für die Abwechselung dieser Seite bei nachfolgenden Zweiggenerationen eine Ursache ersichtlich. Abgabe der Seitenzweige von den beiden entgegengesetzten Seiten der Aeste müsste Folge dieses Vorganges sein, und das findet man auch bei den fächerförmigen Gorgoniden ${ }^{1}$ ).

Ich bin denn auch der Meinung, dass die regelmässige einseitige Anordnung der Seitenäste als ursprünglicher Zustand $\mathrm{zu}$ betrachten ist und dass die unregelmässige Verzweigung hieraus hervorging.

Der Grund für diese Anordnung kann nur im Bau der Rinde liegen. Man muss annehmen, dass dieselbe so differenziert ist, dass nur ein schmaler Längsstreifen derselben die Fähigkeit der Zweigbildung besitzt. Bei einen Ast, der nur nach einer Seite Seitenzweige abgiebt, verläuft der Streifen auf jener Seite der Achse. Bei den Aesten, deren Seitenzweige nicht in einer Ebene liegen, stehen letztere doch nicht ganz regellos, sondern in einer Spirale, woraus bei einem solchen Ast auch auf einen Verlauf des zweigbildenden Streifens in einer Spirale um die Achse geschlossen werden darf. Falls man nicht annimmt, dass die Stelle des Auftretens der Seitenzweige in dieser Weise eingeschränkt ist, bleibt die Stellung derselben in einer Spirale räthselhaft. Meine Hypothese giebt wenigstens eine Ursache an, wesshalb die Seitenzweige aus der Ausbreitung nach einer Seite nicht zur regellosen Stellung, sondern zur Anordnung in einer Spirale um den tragenden Ast herum übergehen.

Ist die Spirale sehr steil, dann gehen die Seitenzweige noch annäherend nach einer Seite ab und liegen zusammen in einer schwach gebogenen Ebene. Ist die Spirale weniger steil, dann wird der Stand der Seitenzweige höherer Ordnung zum Theil ganz regellos und ist die einseitige Verzweigung verschwunden. Dies ist schon in geringem Masse der Fall bei Chr. goniculata, sibogac, u. a. m.; deutlicher ist es bei Chr. flexilis. Noch stärkere Drehung der Spirale, sodass dieselbe nicht gut mehr erkennbar ist und der Aststand regellos erscheint, zeigen Chr: lata, cupressa u. e. a..

STUDER nimmt bereits eine solche Drehung an zur Ableitung der dichten Verzweigung bei Chr. fruticosa ron einer mehr regelmïssigen; es heisst bei ihm ${ }^{2}$ ): "Cette ramification se fait d'après le système ordinaire dans ce genre, la Cyma helicoidea unipara, mais par une

1) Ich kenne nur cine Ausnahme, Ctenocilla fectinata, cine fächerformige zu den Goryonellidae gehürige Art; bei derselben weben die starken basalen, nahezu horizontalen Stämme nur an ciner Seite, der Oberseite, verticale Seitenäste ab. Der Verlauf der Stämme parallel dem Boden bedingt wohl diese cinscitige Verzweigung und ich betrachte dieselbe als secundär; fur die Chrysogorgiidae erscheint eine solche Beziehung zum Boden ausgeschlossen.

2) 13ull. Mus. Comp. Zool., vol. 25, I594, S. 6 I. 
torsion spirale que subissent les branches, sous des plans différents, et comme les internodes sont très courts, la colonie entière présente un aspect très touffu". Hier sei bemerlit, dass die "Cyma helicoidea unipara" nicht in einer Ebene verzweigt ist; es erscheint mir daher fraglich, ob Studer hier die dichte Verzweigung aus einer Ausbreitung jeden Stammastes in einer Ebene hervorgehen lassen will, wie meine Auffassung ist.

Dass die urspringlich von dem zweigbildenden Streifen eingenommene Seite der Aeste bei den nachfolgenden Zweiggenerationen jedesmal abwechselt, trifft auch bei den Aesten mit starker Drehung des zweigbildenden Streifens zu; das wurde an Chr. geniculata und Chr. Lata festgestellt.

Wie oben beschrieben wurde, entsteht jedes Stamminternodium als erster Seitenast des nächst unteren Hauptastes. Man muss daher annehmen, dass dasselbe auf dem zweigbildenden Streifen mit den anderen Seitenästen des Hauptastes entsteht. Da nun bei vielen Arten (z.B. Chr. rigida, geniculata, oricntalis, sibogae) der proximalste Seitenast des Hauptastes (den Stamm selber nicht mitgerechnet) in einer Ebene liegt, die nahezu senkrecht zum Stamme verläuft, muss bei diesen Arten eine Drehung des zweigbildenden Streifens um $90^{\circ}$ zwischen Stamm und jenem Seitenast angenommen werden. Derartire I)rehung, aber von weit geringerer Excursion, lernten wir oben bereits für die mehr distalen Seitenzweige kennen. Wir können jetzt hinzufügen, dass sie entweder in gleichem Sinne statt findet, wie die Drehung zwischen Stamm und proximalstem Seitenast des Hauptastes, oder aber in entgegengesetztem Sinne (z.B. Chr. rigida, geniculata und flexilis). Bei den verticalen Stammast-Reihen scheint

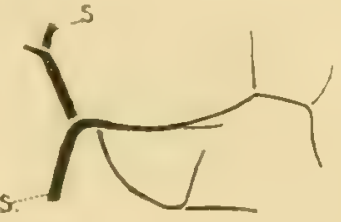
Fig. 26. Chr. pentulu, Verzweigung eines Stanmastes; $\mathrm{S}=\mathrm{Stamm} . \times \mathbf{I}^{1 / 2}$ mir die Art der Drehung bei den genannten Arten immer gleich für alle Hauptäste, doch ist dies nur durch Untersuchung vieler Hauptäste fest zu stellen.

Bei Chr. pendula ist, wie aus Fig. 26 und Fig. I I 4 ersichtlich, der erste Seitenast jedes Hauptastes der Basis der Kolonie zugewendet; es muss hier eine Drehung des zweigbildenden Streifens um $180^{\circ}$ zwischen diesem Seitenast und dem Stamm angenommen werden: bei der sehr kurzen Entfernung eine sehr starke Drehung. Hierin kann ich aber keinen genügenden Grund sehen, meine Hypothese eines zweigbildenden Streifens als unrichtig zu betrachten.

Mit der Annahme es bestehe ein solcher ist auch im Einklang, dass niemals zwei Seitenzweige von derselben Stelle abgehen ${ }^{1}$ ). Zusammenfassend ist meine Ansicht also wie folgt:

I. Die Verzweigung der Stammäste fand ursprünglich bei Chry'sogorgia in einer Ebene statt (Fig. 27).

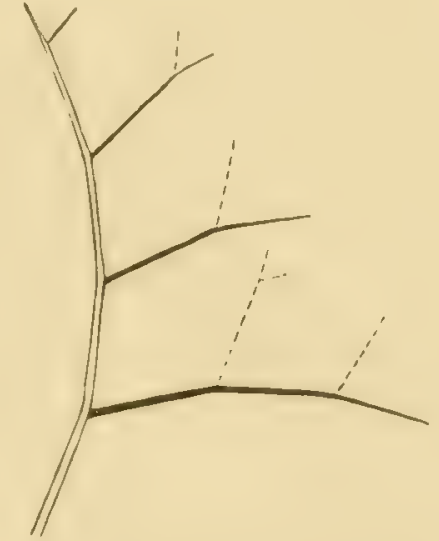

Fig. 27. Schematische Darstellung der Verzweigung beiChrysegersia; Zweige nachfolgender Ordnung sind verschicden angegeben.

2. Jeder Ast trägt nur an einer Seite, auf einem zweigbildende Streifen der Rinde, Seitenäste; diese Seite ist bei den nachfolgenden Zweiggenerationen abwechselnd, stets aber der Spitze des Astes der nächstvorhergehenden Generation zugewendet.

3. Abweichende Aststände sind Folge von Drehung des zweigbildenden Streifens um die Aeste herum.

1) In Folge von Verletzung könnte dies doch als Abnormalität stattfinden. Isei Chr. findula geht der erste seitenast des IJaptastes bisweilen nahezu in gleicher Iöhe mit dem nächsten Stamminternodium ab; dic Achsencylinder der beiden sitzen aber dem des Hauptastes doch immer in einer linternung yon wenigstens I mm. von einander auf. 
Leider gelang es mir nicht den Bau der Rinde genügend zu untersuchen, um feststellen zu können, ob in ihr eine bilaterale Symmetrie auftritt, ob ein zweigbildender Streifen, wie wohl erwartet werden durfte, auch zu erkennen sei.

Zur eingehenden Untersuchung von Chr. pendula fehlte es mir an Material. Auch Chr. japonica, welche in der Siboga:Sammlung fehlt, habe ich nicht untersucht; äusserliche Betrachtung derselben macht es aber sehr wahrscheinlich, dass die Verzweigungsregel auch fiir diese Art Geltung hat.

IV'Right und Studer ${ }^{1}$ ) sagen von der Verzweigung von Chrysogorgia folgendes: „The "ramification of the branches is again highly characteristic, and may best be compared with "the form of the uniparous helicoid cyme common in plants.

„Every branch gives off twigs from one side only, and every twig may, in the same „way, bear lateral twigs, which may further anastomose. At the point where a twig or a lateral "twig is given off, the main twig is bent at an angle in the opposite direction. Hence the "appearance of bifurcation frequently arises, the twig that comes off forming a right or an acute "angle with the next node ${ }^{\circ}$ ), a condition which has induced VErrill, in his diagnosis, to make "use of the expression: furcately branched".

Daneben geben sie eine schematische Figur zur Darstellung des Verzweigungsmodus, die

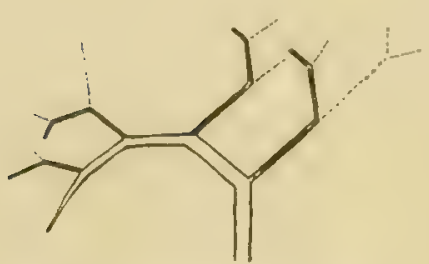

Fig. 2S. Verzweigung eines Astes nach WRIGIT und STUDER; Copie ihrer Fig. 1. ich hier wiedergebe (Fig. 28). Wrigrit und STUder haben also die einseitige Astabgabe gesehen und ihre Bedeutung auch gewürdigt. Nur haben sie sich darin geirrt, dass sie die nachfolgenden Zweiggenerationen immer nur nach derselben Seite wieder Seitenzweige abgeben lassen (vergl. ihre Textfigur I, copirt in Fig. 28), während diese Seiten abwechseln (Fig. 27). Sie haben offenbar die Verzweigung nicht durch Verfolgen der Achsencylinder festgestellt; dadurch ist ihnen auch der sympodiale Aufbau des Stammes entgangen.

Nicht glücklich finde ich den Vergleich der Verzweigung der Hauptäste mit der Cyma helicoidea unipara. Wright und Studer geben nicht näher an, wie sie sich diesen Vergleich denken, z.B. ob sie die Polypen mit Blüthen vergleichen oder nicht. Das Typische einer Cyma ist, dass die Achsen an ihrem Ende stets eine Bluthe tragen, also ein begrenztes Längenwachsthum haben und eine bestimmte Zahl von Seitenachsen tragen. Etwas Aehnliches vermisse ich aber bei Chrysogorgia. Die Achse der Cyma helicoidea ist ein Sympodium, der Hauptast bei den typischen Chrysogorgia-Arten, wie Chr. flexilis $\mathrm{W}_{1}$. \& St., spiculosa Wr. \& St., cupressa Wr. \& St., ein Monopodium.

Die von L. und A. BRAvais ${ }^{3}$ ) gegebenen Definitionen sind folgende:

I. Cime: groupe floral centrifuge dont les pédoncules naissent les uns des autres.

2. Cime unipare, bipare...., multipare, si les pédoncules produisent un, deux ou plusieurs pédoncules, selon le nombre des gemmes latéraux stériles ou fertiles.

3. Cime hélicoide: cime où les fleurs successives sont rangées en spirale autour du pseudothalle.

1) Challenger lieport, vol. $3 \mathrm{y}, \mathrm{S} .7$ und 8.

2) Hier wird wohl , internode" gemeint scin.

3) Disposition des inflerescences; Annales des Sciences Na!urelles, Botanique, zième Ser. Tome 7, IS 37, S. I96 und 220, T. 9, Irig. 15. 
Mit "pseudothalle" ist die sympodiale Achse der Cyma gemeint; unter "pédoncule" verstehen die Herrn Bravas eine vollständige in einer Blüthe endigende Achse, welche auch die Zahl der Achsensprossen sei, welche der Blüthe vorangehen, also welche auch die Zahl der Internodien sei.

Ich bin der Meinung, dass weder die schematische Darstellung der Verzweigung eines Stammastes, welche Wright und Studer geben (meine Fig. 28), noch die von mir gefundene etwas abweichende Verzweigung, mit der Verzweigung einer Cyma helicoidea unipara uibereinstimmt; ich habe daher diesen Vergleich aus der Diagnose des Genus Chry'sogorgia (Dasygorgia Wr. \& St.) gestrichen.

Die Achsen werden ron einer stets zarten und dünnen Rinde oder Coenenchym iberzogen. Dieselbe zeigt, ganz wie bei Lcpidogorgia, eine innere diunnere und cine äussere dickere Lamelle von Mesogloea, die durch duinne Septa verbunden sind und zwischen denen in einem Kreise die grossen Entodermkanäle liegen. Nach aussen wird die Mesogloea von dem Epithel der Epidermis, nach innen rom Achsenepithel überzogen (letzteres habe ich nicht mit Gewissheit auffinden können). Bei Chr. lata bilden die Entodermkanäle einen nahezu vollständigen Kreis um die Achse, bei Chr. flcxilis schienen mir diese Kanäle getrennt zu sein durch grössere Abschnitte der Mesogloea, welche zu breit waren um sie noch Septa nennen zu können. Für eine befriedigende Untersuchung der sehr zarten Rinde fehlte es mir an Zeit und Material. Namentlich kann ich, wie schon hervorgehoben, nichts über einen, mit dem Vorkommen eines zweigbildenden Streifens in Einklang stehenden Baues angeben.

Die Rinde enthält bei beinahe allen Arten Scleriten; die Zahl derselben wechselt aber sehr und bei einigen Arten sind grössere Strecken der Rinde gänzlich frei von ihnen. Bei anderen Arten bilden sie eine nahezu vollständige, lïckenlose Schicht, welche einen oder wenige Scleriten dick ist. Die Kalkkörper sind immer dünn, flach, aber von sehr verschiedener Form und Oberflächensculptur; grössere Warzen sind selten und mir nur von Chr. flcxilis, focukesi und occidentalis bekannt.

Im Challenger Report finde ich über diese Kalkkörper folgendes (1. c. S. 6): „The spicules „always form several layers upon the stem and polyps.... They form an outer layer of scales „or spindle-shaped calcareous bodies, which overlap one another on opposite sides and exhibit na very fine sculpture, which, however, can only be made out with a somewhat high magnifying „power; and an inner layer of small plates, at times branched, which are united with one „another by toothed edges and often exhibit a double or fourfold structure".

Thatsächlich aber fand ich bei vielen Arten nur eine Schicht von Scleriten, welche dazu oftmals noch sehr unvollständig war. Bei anderen Arten lagen zwar die Kalkkörper iber einander, streckenweise sogar in einer, mehrere Kalkkörper dicken Schicht (so in der Kinde der Stammbasis bei Clr. flexilis), aber zur Ausbildung einer besonderen tiefen Schicht kommt es niemals. Ebensowenig fand ich Scleriten, welche mittelst der gezahnten Rändern verbunden wären.

Die Polypen sind im Verhältniss zum Durchmesser der Aeste stets gross und sitzen der Rinde frei auf, oft mit etwas verengter Basis (Chr. sibogac, axillaris, etc.). Sie sitzen immer in einiger Entfernung von einander, meist nur wenige oder sogar nur ein cinziger, bei einigen Arten bis zu IO-I3 auf einem Internodium. Die proximalsten Internodien der Stammiste sind 
bistweilen ohne Polypen; bei Chr. octagonos tragen nur die distalsten Internodien (die EndInternodien) Polypen, meist nur einen, bisweilen zwei.

Der Stamm ist bei einigen Arten ganz ohne Polypen (Chr. rigida, flexilis), bei anderen tragen nur die jüngsten Internodien einen oder zwei Polypen (Chr. lata und cupressa); bei verschiedenen Arten findet man auf allen Stamminternodien einen bis zwei Polypen. (Clir. geniculata, sibograc, pontasticha). Da der Stamm nur eine Differenzirung der basalen Internodien der Hauptäste ist, liess sich dies auch erwarten.

Meist ist ein Polyp dem Ende der Zweige sehr genähert, sitzt letzterem auch wohl seitlich auf (Chr. octagonos); terminale Polypen, deren Achse in der Verlängerung der Zweigachse fiele, findet man aber niemals.

Die Polypen sind durchaus nicht stets nur auf eine Seite der Zweige beschränkt. Auf einem Internodium mit mehreren Polypen haben dieselbe bisweilen einen sehr verschiedenen Stand (Chr. sibogac), doch ist die Mehrzahl der Polypen wohl immer der Spitze der Kolonie zugewendet. In Fig: I, T. 3 des Challenger Report, vol. 3 I, sind alle Polypen einer Kolonie von Chr. cupressa mit der Mundöffnung nach unten gezeichnet; dies war bei den typischen Exemplaren dieser Art, die ich im "British Nuseum" untersuchen konnte, nicht der Fall; es scheint mir wahrscheinlich, dass wir es hier mit ein Versehen des Zeichners zu thun haben. Es wäre auch die denkbar ungünstigste Stellung für den Fang von Nahrung. Es giebt Arten bei denen die Unterseite der Zweige keine oder nur sehr vereinzelte Polypen trägt (Chr. anastomosans, curvata, pentasticha).

Die Grösse der Polypen einer Kolonie varïrt oft sehr erheblich; auf demselben Internodium findet man oft neben ausgewachsenen Polypen mit Geschlechtsprodukten, kleine bis sehr

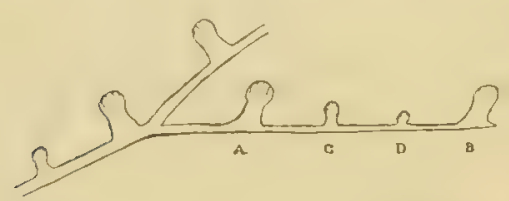

Fig. 29. Zweig ron Chrysogorgia; man sieht 3 junge Polypen, welche wischen erwachsenen Polypen entstanden sind: A, B, C, D ist muthmasslich die Reihenfolge in welcher die Polypen des Endzweiges cntstanden. kleine. Dabei sind diese kleinen Polypen meist nicht diejenigen, welche den Zweigspitzen am meisten genähert sind, sondern sie finden sich auch auf älteren, stärkeren Astinternodien zwischen den erwachsenen Polypen vertheilt (Fig. 29, C, D). Das haben auch Wrigit und Studer schon bemerkt, denn es heisst bei ihnen, 1. c. S. 9: nSo far as can be made out from the material at disposal, the „budding of new polyps takes place on the terminal twigs, between "the endpolyp and the base of the twig". Ich kann mich dieser IIeinung nur anschliessen, bemerke aber, dass die kleinen Polypen sich bei einigen Arten auch auf den älteren Astinternodien finden (so bei Chr. pentasticha und mixta). Auch sind die distalen, den Zweigspitzen am meisten genäherten Polypen, oftmals kleine, junge. Näheres hieruber findet man im Abschnitt, in welchem das Längenwachsthum der Chrysogorgiidae besprochen wird.

Die Polypen können nicht in die Rinde zurückgezogen werden und niemals findet man einen basalen Polypen-Abschnitt als Kelch differenziert, in welchen der distale Theil des Rumpfes und die Tentakelkrone zurückgezogen werden könnte. Die Tentakel können sich über die Mundscheibe zusammenlegen und zwar, wenigstens bei einigen Arten, regelmässig (so bei $C h r$. Hexilis, Fig. 55); dabei fand ich die Tentakel aber niemals so weit nach innen gebogen, dass sie theilweise im Polypen-Rumpf aufgenommen würden. Bei anderen Arten traf ich die Tentakel nur ziemlich unregelmässig ïber einander gelagert (Chr. tctrasticha, Fig: 4I), oder mehr oder 
weniger vorgestreckt (Chr. lata, Fig. 34). Solange man aber die Polypen nicht in normalen Umständen beobachtet hat, ist es nicht möglich die Grenzen der Contractilität der Tentakel fest zu stellen; möglich ist es, dass alle Arten ihre Tentakel regelmässig zusammenlegen künnen. Die acht Tentakel fand ich immer gleich gross.

Die Polypen können sich nicht an die Aeste anschmiegen und zeigen denn auch keine dementsprechend umgeänderten Wandstrecken, wie wir sie bei Lepidogorgia antrafen. Die Polypen stehen meist senkrecht auf den Aesten; bei vielen Arten aber sind mehrere der älteren Polypen, vor allem die, welche nahe der Spitze eines Zweiges stehen, schräg gestellt und haben eine proximalwärts längs dem Aste ausgezogene Basis (Chr. mixta, Fig. 89; Chr. octagonos, Fig. Ior). Verrill erwähnt dies von den distalen Polypen der Chir. spiculosa und bildet es auch ab ${ }^{1}$ ).

Die Scleriten der Polypen sind immer verhältnissmässig gross und niemals sehr zahlreich, bei verschiedene Arten (z.B. Chr. lata, Fig. 34) selbst nur in geringer Zahl vorhanden.

Nach ihrer Form kann man in den Polypen zwei Haupttypen von Kalkkörpern unterscheiden: die Schuppen und die Spicula. Die typischen Schuppen sind sehr dünn, meist glatt, mitunter mit sehr feinen Wärzchen; sie sind häufig annäherend kreisförmig, meist aber oval bis lang oval und dann oft in der Mitte merklich verschmälert (z.B. Chr. japonica, Fig. I I und Chr. pondula, Fig. I 16).

Die typischen Spicula sind kurz stabförmig, auf dem Querschnitt rund bis kurz oval an den Enden meist stumpf gerundet (Clur. tetrasticha, Fig. 42), bei einigen Arten zum Theil zugespitzt (Chr. orientalis, Fig. 82, A); dazu sind sie immer mehr oder weniger dicht mit Wärzchen bedeckt. Daneben giebt es noch andere Typen von Scleriten, z.B. dicke höckerige, an den Enden wie abgestutzte Kalkkörper in den Tentakeln von Chr. expansa, octagonos (Fig. IO3) und curvata (Fig. I08). Bei Chr. squarrosa sind die Polypenscleriten viel länger als breit, meist duinn bis sehr dünn, mitunter aber bis halb so dick wie breit, mit kleinen Wärzchen. Während also ein Theil derselben lange Schuppen sind (Fig. 86, A), sind andere so dick, dass sie als abgeplattete Spicula betrachtet werden müssen (Fig. 86, B); einige der duinneren zeigen vorstehende Kanten auf ihren flachen Seiten (Fig. 86, C).

Der Polypen-Rumpf der Chrysogorgia-Arten, mit Ausnahme der Chr. squarrosa, enthält entweder nur typische Schuppen, oder nur Spicula, oder nach innen von einer mehr oder weniger unvollständigen Schicht von Spicula noch eine, meist auf die Polypenbasis beschränkte und meist unvollständige Schicht von Schuppen (deutlich in Fig. 89 von Chr. mixta $)^{2}$ ).

Alle Arten mit Spicula im Rumpf haben auch Spicula in den Tentakeln (z.B. Fig. 4 I); die Arten ausschliesslich mit Schuppen im Rumpf haben meist auch nur Schuppen in den Tentakeln. Daneben aber giebt es Arten, die in den Tentakeln typische Spicula (Chr. intermedia, Fig. 95) oder abweichende, dicke, höckerige Scleriten (Chr. curata, Fig. 10\%, 108) zeigen.

Bei Chr. orientalis treten die Spicula im Rumpfe gegen diinne, schuppenartige aber lange Kalkkörper zurïck, während bei der nahe verwanten Chr. fewkesi erstere noch der vorherrschende Typus sind.

I) Bull. Mus. Comp. Zool., vol. 11, ISS 3, T. 2, Yig. 5 .

2) Bei diesen Arten findet man also zwei verschicdene Schichten von Scleriten im Polypenrumpf, wic WRIOMT und STUDER im Challenger Report, S. 8-9, angeben; aber bei den meisten Chrysogorgia-drten fehlt cine besondere tiefe Schicht; niemals fand ich Scleriten, die mittelst gezahnten Kändern mit einander verbunden waren. 
Wright und Studer haben eine Trennung aller Arten ihres Genus Dasygorgia in Spiculosac mit Spicula im Polypen-Rumpf und Squamosae nur mit Schuppen, durchgeführt.

Diese Vertheilung scheint mir eine natüliche und brauchbare zu sein. Die beiden Typen von Scleriten sind gut unterscheidbar und sie verleihen den Polypen auch einen gänzlich verschiedenen Habitus, wenn man sie unter dem Nicroscop betrachtet (vergl. z.B. Fig. 4I, von Chr. tctrasticha mit Fig. 98, von Chr. cxpansa).

Schwierig ist Chr. intermedia einzureihen, da sie im Rumpf nur Schuppen hat wie die Squamosae, in den Tentakeln aber Spicula (Fig. 95). Ich stelle dieselbe mit drei anderen Arten, Chr. expansa, octagonos und curvata, deren Rumpf auch nur Schuppen, deren Tentakel aber dicke, unregelmässige Scleriten enthält (Fig. I07), in eine dritte Gruppe, die Squamosac abcrantes, welche Gruppe aber nur als eine provisorische, wahrscheinlich nicht natüliche, betrachtet werden darf. Ich errichte dieselbe denn auch nur, weil ich nicht entscheiden kann, ob Clir. intcrmedia zu den Spicalosae oder zu den Squamosae gestellt werden muss und auch die drei anderen in ihren Tentakeln von den echten Squamosac sehr verschieden sind und Chr. curvata in denselben neben anderen Formen von Scleriten auch Spicula aufweist.

Die Arten, welche im Rumpfe und in den Aussenseiten der Tentakeln nur typische Schuppen aufweisen, bilden dan die Squamosac typicac.

Zu den Spiculosae gehören alle Arten, deren Polypen in Rumpf und Tentakeln typische Spicula, daneben, meist mehr untergeordnet, auch wohl Schuppen aufweisen. Hierzu gehören auch die Arten des VerRill'schen Genus Chrysogorgia; und da Chr. squarrosa diesen letzteren Arten in ihren Polypen ähnlich ist, habe ich sie auch zu den Spiculosae gerechnet, wiewohl ihre Scleriten meist zu einem zwischen Schuppen und Spicula vermittelndem Typus gehören.

$W_{\text {Right }}$ und Studer geben an ${ }^{1}$ ), die Pinnulae der Tentakel seien immer ohne Scleriten.

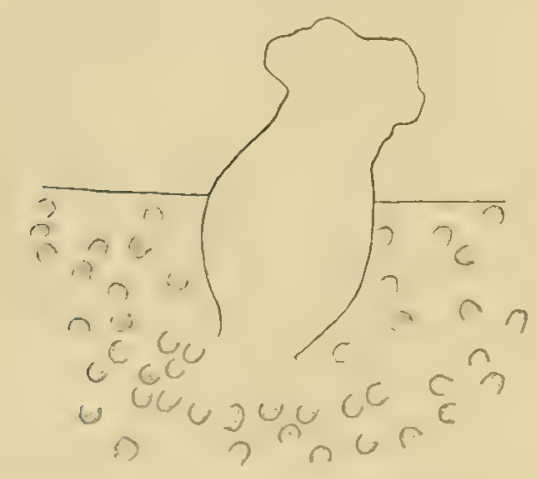

Fig. 30. Chr. sibegae; Oberflïche des Stammes anit cinem Polypen und zahl. reichen Tuberkeln (Zoüide Verrill) $\times 23$.

Thatsächlich aber findet man in den einander zugekehrten Seitenflächen der Tentakel beinahe immer Scleriten, welche von denen der Aussenseite oder Ruickenseite der Tentakel in der Form verschieden sind und mehr oder weniger senkrecht zu letzteren gerichtet sind. Dieselbe liegen (meist?) nur dort, wo eine Pinnula abgeht, sich vielfach bis in letztere hinein erstreckend, wodurch sie oft deutlich den Pinnulae angehören (Fig. 34 von Chr. lata). Dies ist namentlich auffallend bei einigen Squamosac, wo in jeder Pinnula ein einziger, aber sehr langer Kalkkörper liegt (Fig. I 35 , Chr. geniculata).

Bei mehreren Arten findet man auf der Rinde zahlreiche kleine, cylindrische bis conische Tuberkel (Fig. 30): die Zoöidc von Verrili ${ }^{2}$ ) und $\mathbb{W}_{\text {righit }}$ und Studer (1. c. S. 5-8). Am grössten sind dieselbe bei Chr. japonica, wo sie nach WRIGIIT und STUder bis $1 / 2 \mathrm{~mm}$. Länge erreichen können. Bei Iridogorgia pourtalesii kommen sie nach VERrill auch auf den Polypen vor; das fand ich bei Chrysogorgia nicht. Oft sind die Zoöide auf den Stamm und die stärkeren Zweige beschränkt.

1) Challenger Report, vol. 31, ISS9, S. 8 .

2) Bull. Mins. Comp. Zool., vol. $11,1 \mathrm{SS}_{3}, \mathrm{~S} .26$ und 27. 
Bei allen Arten fand ich das Epithel der Epidermis auf der Spitze der Zoöide deutlich abweichend von der übrigen Epidermis ${ }^{3}$ ); mehr als die Hälfte der Kerne fürbten sich clort mit Hämalaun viel dunkler als die der normalen Epidermis-Zellen (Fig. 3I), auch sah ich bisweilen an ungefärbten Zellen ein stark-lichtbrechendes Bläschen. Ich halte diese Zellen mit den genannten Forschern für Nessel-Zellen.

Nach Wrigth und Studer sollen diese Zoöide bei Chr. acanthella, cxpansa und japonica: die drei Arten bei denen sie überhaupt Zoöide gefunden haben, eine seitliche, ihrer Basis genäherte Mundöffnung aufweisen. Die der Chr. japonica fand ich zur genaueren Untersuchung zu schlecht erhalten; von den Zoöiden der beiden anderen Arten aber kann ich bestimmt versichern, dass sie keine Mundöffnung haben. Die Epidermis fand ich an gefärbten Präparaten lückenlos. Wohl sah ich bei vielen Zoöiden an der Basis eine runde oder ovale,

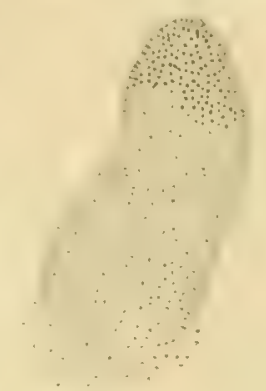
oft nur an einer Seite deutlich umrandete Oeffnung, aber genauere Untersuchung Fis. 31. Nematozoöid von Chr. siliogac; die schwarzen l'unkie sind die Kerne der ergab, dass sie nur die Communication darstellt zwischen Entoderm-Kanälen der Rinde und der geräumigen Höhle in den Zoöiden, aber nicht nach aussen führt. Auch auf Schnitten durch die Rinde der Chr. lata zeigten die Zoöide keine Mundöffnung. Eine solche fehlt gewiss den Zoöiden aller Arten des Genus Chrysogorgia, bei denen Zoöide bis jetzt gefunden sind, mit Ausnahme vielleicht von Chr. japonica.

Bei letzterer Art enthalten die Zoöide oft Scleriten.

Es ist sehr gut möglich, dass diese Zoöide umgebildete Polypen sind ${ }^{2}$ ), welche die F unktion von Nesselorganen haben. Ihr Vorkommen bei verschiedenen, nicht näher verwandten Arten, weist auf ein höheres Alter hin, namentlich auch das Auftreten derselben bei Iridogorgia pourtalcsii. Wegen der Funktion schlage ich den Namen Ncmatosoüide vor. Da sie, wenigstens die Mehrzahl, keine Nundöffnung haben, ist der Namen Siphonozoöide ${ }^{3}$ ) nicht haltbar; in Bau und Funktion sind sie von den so benannten Polypen der Pennatuliden und Alcyoniden verschieden. Sie kurzweg Zoöide zu nennen, wie Wright und STUder meist thun, is auch nicht empfehlenswerth, da auch die normalen Polypen oft so genannt werden, so in letzterer Zeit noch von L. Rovle ${ }^{\text {t) }}$ und Bourne $\left.{ }^{6}\right)$.

Wie hervorgehoben, deutet das Vorkommen der Nematozoöide bei sehr verschiedenen, gar nicht näher verwandten Arten auf ein hohes Alter derselben hin. Es kommt auch vor, dass von zwei sehr nahe verwandten Arten nur die eine Nematozoöide besitzt, z.B. Chr. lata mit Nematozoöiden, cupressa ohne diese. Die grosse Aehnlichkeit dieser beiden Arten deutet darauf hin, dass ihre Trennung eine recente ist. Die Ausbildung der Nematozoöide muss doch wohl eine relativ erhebliche Zeit in Anspruch genommen haben; dagegen kann Rückbildung schnell stattfinden und scheint mir dieselbe bei Chr. cupressa unbedingt angenommen werden zu müssen. Die Möglichkeit, die Nematozoöide entwickelten sich bei verschiedenen Chrysogorgia-Arten

I) Die Zoöide der Chr. japonica, die ich gesehen, waren zu schlecht erhalten dies fest zu stellen; nach WrignT und Sruber sind bei dieser Art die Nessel-Zellen nur in geringer Zahl anwesend.

2) Eine analoge C'mbildung findet man bekanntlich bei verschicdene IYydrozor, wie Podocorynt und den Iy'drocorallinac.

3) Challenger Report, vol. 31 , S. XXXIX.

4) Coclentérés, Campagne du Caudan, Ann. Lniv. Lyon, $1 S q 6,5.305$.

5) Anthozox, in: Ray Lankester, Treatise of Zoology, l'art. 2, 1900, S. 5. 
unabhängig von einander, scheint mir auch desshalb sehr unwahrscheinlich, weil dieselben bei den verschiedenen Arten so voliständig ähnlich sind; nur die der Chr. japonzica weichen vielleicht etwas ab. Die Annahme, dass die Stammformen des Genus Chrysogorgia bereits Nematozoöide gehabt haben und dass, wo sie fehlen, dies nur durch Rückbildung geschah, giebt eine gute Erklärung für die regellose Verbreitung dieser Organe. Sie scheint mir auch dann die allein haltbare, wenn man in den Nematozoöiden keine rückgebildeten Polypen-sieht, sondern secundär entstandene Nesselorgane der Rinde. Wenn wirklich eine Mundöffnung auch bei den Nematozoöiden von Chr. japonica fehlt, so ist aus dem Baue derselben nichts bekannt, was sich nur durch Herkunft von Polypen erklären liesse.

Nematozoöiden kommen vor bei folgenden Arten:

$$
\begin{gathered}
\text { Spiculosae: }\left\{\begin{array}{l}
\text { Chr. lata nov. spec. } \\
\text { Chr. tetrasticha nov. spec. } \\
\text { Chr. pusilla nov. sp. }
\end{array}\right. \\
\text { Squamosac aberrantes: Chr. expansa (Wr. \& St.). } \\
\text { Squamosae typicac: }\left\{\begin{array}{l}
\text { Chr. japonica (Wr. \& St.). } \\
\text { Chr. sibogae nov. spec. } \\
\text { Chr. axillaris (Wr. \& St.). } \\
\text { Chr. acanthella (Wr. \& St.). }
\end{array}\right.
\end{gathered}
$$

Die Annahme, dass ihr Fehlen Folge sei von Rückbildung, lässt erwarten, dass Rückbildung auch jetzt noch bei einigen Arten stattfinde; man darf erwarten ein Stadium zu finden, in welchem die Nessel-Zellen nicht mehr in einer Erhabenheit, dem Nematozoöid, liegen, aber noch in kleinen Gruppen zusammenliegen. Diesen Zustand fand ich bei Clur anastomosans. Die Gruppen fielen schon an der ungefärbten Epidermis (in Glycerin) auf, indem die NesselZellen deutliche helle Bläschen zeigten; mit Hämalaun färbten ihre Kerne sich, ganz wie bei den Nematozoöiden, viel dunkler als die der normalen Epidermis-Zellen, wodurch die Anordnung in Gruppen sehr deutlich wurde. Daneben sah ich nur sehr wenige, vereinzelt liegende NesselZellen. Bei Chr. acanthella waren viele Nematozoöide sehr klein, einige nur noch eine Gruppe von Nessel-Zellen, und da dies in der relativ alten Epidermis des Stammes statt hatte, so können die sehr vielen unvollständigen Nematozoöiden kaum als eben angelegte, sondern wahrscheinlich nur als in der Entwicklung gehemmte gedeutet werden.

Die Rückbildung der Nematozoöide bei so verschiedenen Arten macht, dass man ihre Anoder Abwesenheit selbst für die Unterscheidung kleinerer Artengruppen nicht verwenden kann.

Die Chrysogorgia-Arten sind in Alcohol weiss, bisweilen etwas gelblich gefärbt.

Vorstehende Morphologie des Genus Chrysogorgia führt mich zur Aufstellung folgender Diagnose :

Achsen rund, mit glatter Oberfläche, die stärkeren mit Gold- oder Metallglanz. Kolonien mit deutlichem, sympodial gebautem Stamm. Aeste wiederholt verzweigt, beinahe immer wenigstens annäherend in einer Ebene ausgebreitet. Die Seitenzweige immer nur auf einem schmalen Längsstreifen der Rinde gebildet. Dieser zweigbildende Streifen verlïuft auf den Seitenzweigen nachfolgender Ordnung abwechselnd rechts und links, also auf den einander gegeniberstehenden 
Seiten. Dies ist oft durch Drehung theilweise undeutlich. Rinde dünn, mit wenig zahlreichen Scleriten, welche niemals eine Sonderung in oberflächliche und tiefere Schichten von verschiedener Form unterscheiden lassen. Polypen nicht auf eine Seite der Zweige beschränkt, bei vielen Arten ziemlich regellos, aber immer in einiger Entfernung von einander angeordnet. Die Tentakel können sich über die Mundscheibe zusammenlegen, werden aber niemals im Polypen-Rumpf aufgenommen. Polypen-Scleriten immer relativ gross und nicht sehr zahlreich, auch in einem Streifen längs der Rückenseite (Aussenseite) der Tentakel liegend. Meist ein oder einige Scleriten in einer Pinnula, niemals aber zahlreiche, selten gar keine.

\section{Gruppe A: Spiculosac.}

Polypen im Rumpf und in den Tentakeln mit Spicula: das sind kürzere oder längere stab- oder nadelförmige Kalkkörper, mit gerundeten oder zugespitzten Enden, deren Oberfläche immer mit Wärzchen bedeckt ist. Daneben auch wohl Schuppen. Ausnahmsweise sind die Rumpfscleriten alle ziemlich dünn, aber dann doch mehrere Male länger als breit, theilweise mit sehr kleinen Wärzchen und im distalen Theil des Rumpfes alle längsliegend.

\section{Unter-Gruppe A r.}

Aststand $1 / 4$, links gedreht; Polypen nahezu ausschliesslich mit Spicula ${ }^{1}$ ), welche wenig zahlreich sind und im Rumpf meist in acht Längsreihen liegen, die mit den Ansatzlinien der Septa an der Rumpfwand correspondiren. Rückenseite der Tentakel bis zur Spitze mit Spicula, ohne Schuppen.

\section{Chry'sogorgia lata nov. spec.}

Stat. I I9. $1^{\circ} 33^{\prime} .5$ N., $124^{\circ} 41^{\prime} \mathrm{O}$. bei Menado. Igor M. Boden steinig. I Ex.

Es liegt mir nur eine Kolonie vor (Fig.32), von der ein, wahrscheinlich kurzer, unterer Abschnitt des Stammes fehlt, hoch I $5 \mathrm{~mm}$., breit bis $69 \mathrm{~mm}$., im Umriss

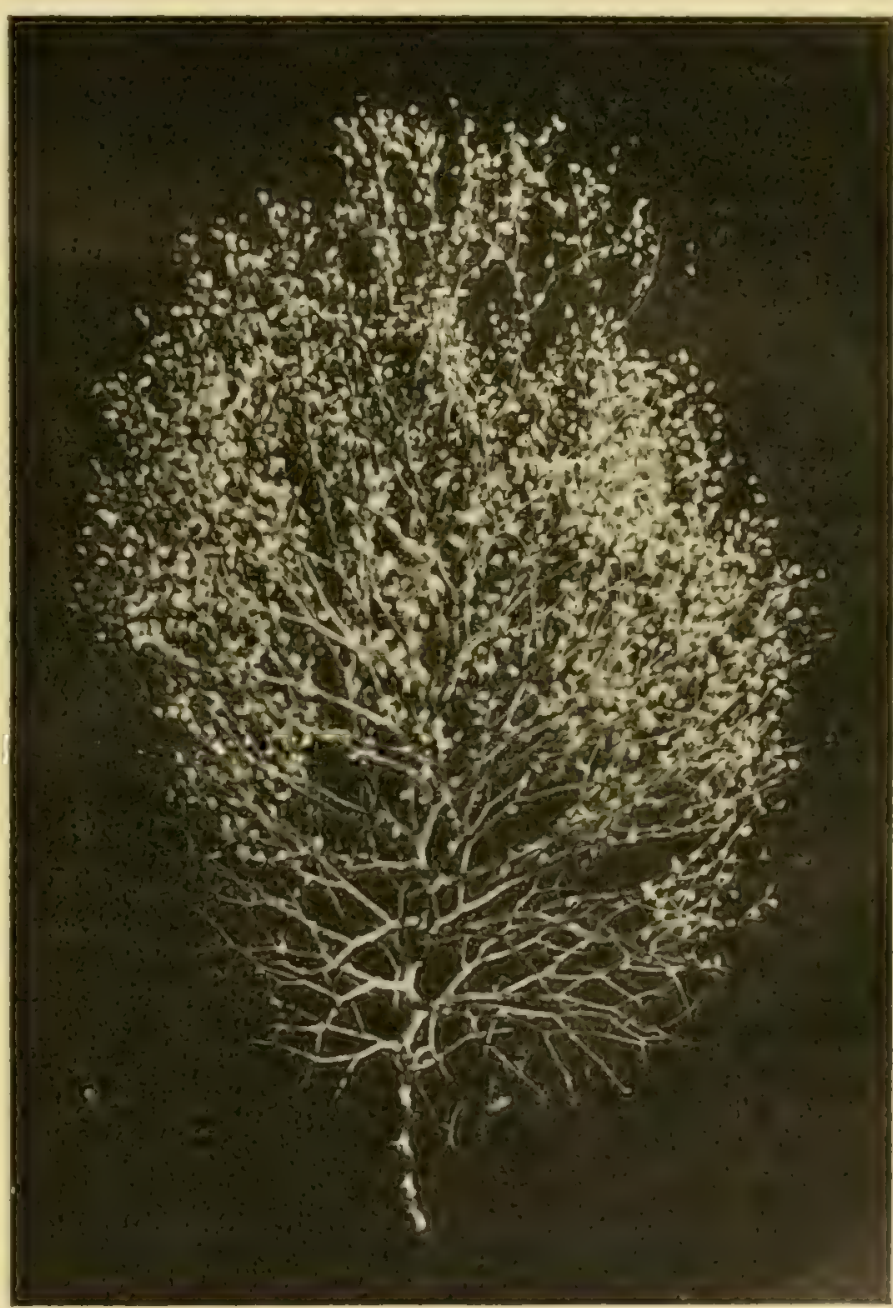

Fig. 32. Chr. hak. Kolonie in nat, Gróss. eiförmig. Die Achse des Stammes ist unten grün metallisch schimmernd, oben braun mit Gold-

1) Hin und wieder fand ich bei den Polypen der Arten dieser Gruppe vereinzelte kleine Schuppen in ler liasis der l'olypen, so bei Clir. lata. 
glanz, der dünnste Theil, ebenso wie die Achsen der Zweige, mehr gelb mit schwächerem Goldschimmer. Der Stamm zeigt bei jedem Astabgang eine deutliche Biegung.

Aststand $1 / 4$, links gewunden; die Divergenz zweier nachfolgender Stammäste der Spirale variirt aber nicht unerheblich um den Nittelwerth von $90^{\circ}$. Trotzdem sind die vier Verticalreihen der Stammäste deutlich: Die Entfernung zweier Stammäste derselben Verticalreihe ist bis $9 \mathrm{~mm}$, die Länge eines Stamminternodium 2 bis $2^{1} / 4 \mathrm{~mm}$. Nur die untersten Stammäste stehen nahezu senkrecht zum Stamme, die höheren sind aufgerichtet, bis die obersten Stammäste einen Winkel von 50 bis $60^{\circ}$ mit der Verticalachse der Kolonie bilden.

Die Stammäste sind wiederholt verzweigt, anscheinend dichotomisch (Fig. 33), sodass

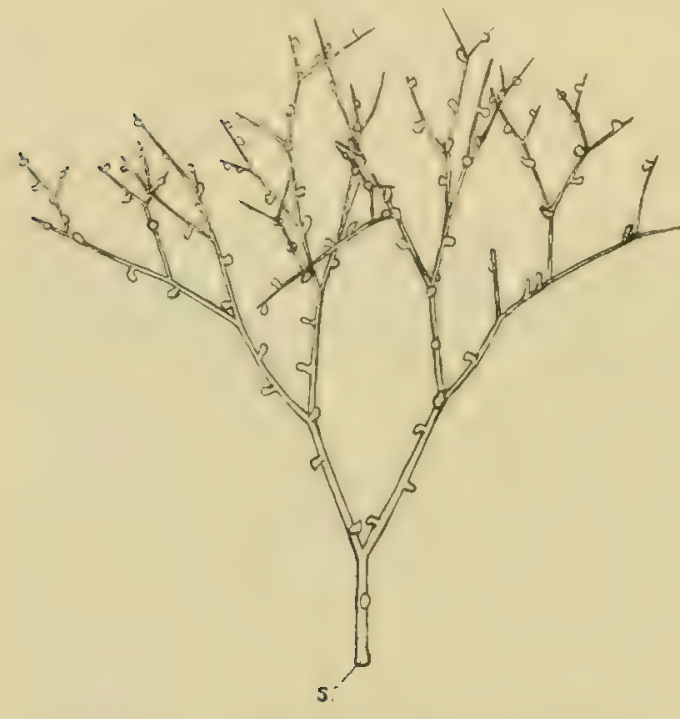

Fig. 33. Stammast ron Chr. lalk, nat. Grösse; $S=$ Stamm im Querschnitt. rechte und linke Hälfte eines Stammastes ziemlich ähnlich verzweigt sind. Der Hauptast ist dadurch äusserlich nicht von seinem untersten Seitenast unterscheidbar. Die proximalen Verzweigungen finden meist genau in einer Ebene statt, welche bei den unteren Stammästen senkrecht zum Stamme gerichtet ist, bei den oberen, welche aufgerichtet sind, aber meist senkrecht zu der durch den Stamm und das unterste Internodium des Stammastes bestimmten Ebene (dies ist die Ebene welche den ganzen Stammast in rechte und linke Hälfte theilt). Die distalen Zweige der Stammäste liegen unregelmässiger und meist nicht mit den proximalen in gleicher Ebene.

Das proximale Hauptast-Internodium (wenn man das Internodium, das am Aufbau des Stammes betheiligt ist, nicht mitrechnet) ist 4 bis $6 \mathrm{~mm}$, , bei den untersten

Aesten nur $3 \mathrm{~mm}$. lang. Das zweite Internodium beträgt 6 bis I I mm., selten weniger, wie z.B. eines von nur $2 \frac{1}{2} \mathrm{~mm}$. Länge: Die weiteren Internodien sind 5 bis $8 \mathrm{~mm}$. lang, bisweilen noch etwas mehr. Es giebt bis zu 7 successive Internodien und jeder Stammast hat Seitenäste bis zu solchen vierter Ordnung (vergl. Fig. 23, S. 2z).

Rinde nur mit ganz vereinzelten Scleriten, welche denen des Polypen-Rumpfes vollständig gleich sind. Die Oberfläche ist auf dem Stamm und den stärkeren Astinternodien mit zahlreichen Nematozoöiden bedeckt, welche derselben ein rauhes Ansehen verleihen. Die dünneren Zweige und die obersten, dünnen Stamminternodien mit nur wenigen oder ohne Nematozoöiden. Letztere den in Fig. 3I, S. 3I, abgebildeten sehr ähnlich, aber kürzer; sie sind zweifellos ohne Mundöffnung.

Auf den jüngsten Stamminternodien und auf allen Internodien der Aeste stehen ein bis vier, im Mittel zwei, Polypen auf jedem Internodium. Sie sind regellos nach allen Seiten gerichtet. Sie sind klein, variiren aber erheblich in Länge, sowohl in Folge ihrer verschieden starken Contraction als auch dadurch, dass viele unerwachsen sind. Sie erreichen mit zusammengelegten Tentakeln \pm I mm. Länge, mit stark vorgestreckten Tentakeln bis $\mathrm{I}^{3} / 4 \mathrm{~mm}$.. Der Querdurchmesser ihres Rumpfes ist 0,5 bis $0,65 \mathrm{~mm}$., die Rumpflänge (vom Ast bis zur Nundscheibe) meist 0,55 bis $0,6 \mathrm{~mm}$; viele Polypen sind aber viel kleiner. 
Scleriten in den Polypen wenig zahlreich (Fig. 34), oft sogar im Rumpfe nur sehr wenige (weniger als in der Figur), vor allem bei kleinen, jungen Polypen. Sie liegen im Rumpfe in acht septalen Reihen, welche oben jederseits mit den Scleritenreihen der Rückenseite der beiden benachbarten Tentakel zusammenhängen. Die Scleriten sind typische Spicula, mit rundem Querschnitt, immer mit stumpfen gerundeten Enden (Fig. 35); die grösseren sind 0,2 bis $0,24 \mathrm{~mm}$. lang, bis $0,057 \mathrm{~mm}$. breit und dick; auf der PolypenBasis sind sie kürzer, bis $0,14-0,16 \mathrm{~mm}$. lang; dort fand ich bisweilen auch einige Schuppen. Dieselben Spicula liegen auch längs der Aussenseite der Tentakel, meist zwei neben einander, etwa 15 in jedem Tentakel (das variirt aber sehr); nach der Tentakelspitze zu werden dieselbe immer kleiner,

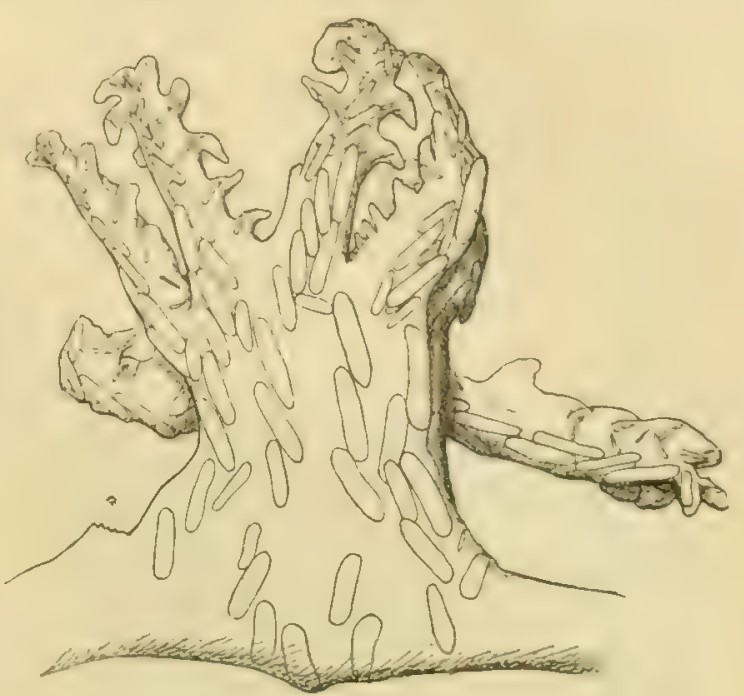

Fig. 34. Polyp von Chr. lata; bei th ein Zweig abgebrochen; der Ste Tentakel ist nicht sichtbar. $\times 47$. der Typus ändert sich aber nicht; z.B. war eine der kleineren lang $0, \mathrm{I} \mathrm{mm}$., breit und dick $0,023 \mathrm{~mm}$.

In den Bases der Pinnulae fand ich kleine, schmale, sehr dünne Scleriten mit glatter Oberfläche, nur bisweilen mit einigen wenigen kleinen Wärzchen (Fig. 36); Länge und Breite, welche

Fig. 35 . Polypenspiculum von Chr. lata. $\times 140$. sehr verschieden sind, waren bei drei derselben 0,075 resp. 0,0 7 ; 0,085 resp. 0,02 und 0,9I resp. 0,016 mm.. Es liegen ähnliche kleine Kalkkörperchen auch in der Mundscheibe.

Verbreitung: Celebes-See (Siboga-Exp.).

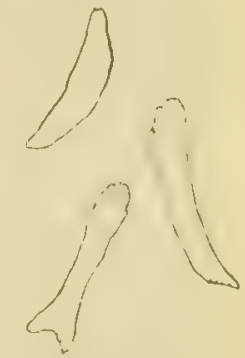

Fig.36. Chr. lata; Scleriten aus den Pinnulae. $\times 217$.

\section{Chry'sogorgia spec.}

Stat. 266. $5^{\circ} 56^{\prime} .5$ S. $132^{\circ} 47^{\prime} \cdot 7$ O. Kei-Inseln. 595 M. Grauer Schlamm mit Korallstücken und Steinen. Einige Fragmente.

Es liegen mir nur einige Abschnitte von Aesten vor; der Aststand ist also unbekannt. Die Fragmente (Fig. 37) sind sehr stark verzweigt; das grösste ist 7 I mm. lang und hat mehr als zwanzig Internodien von 9 bis nur $4 \mathrm{~mm}$. Länge und weniger. Die eine Seite der Fragmente stellt sich dadurch als Unterseite dar, dass ihr Seitenzweige fehlen und dass sie nur sehr wenige Polypen trägt. Verwachsung der Zweige, wo sie sich kreuzen, kommt vor.

Rinde ohne Scleriten und mit zahlreichen Nematozoöiden. Die Polypen sind denen der vorhergehenden Art so ähnlich, dass die Figur 34 auch für sie zutreffend ist.

Diese Art unterscheidet sich von Chr. lata nur

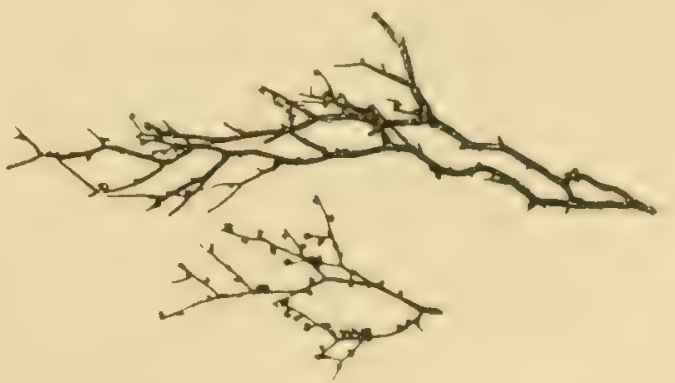

Fig. 37. Chr. 2; Astragmente; etwas kleiner als nat. Grüsse.

durch die stärkere und unregelmässigere Verzweigung der lïngeren Aeste; sie ist unbedingt mit derselben nahe verwandt, wesshalb der Aststand auch wohl $\%$, linksgewunden, ist. In der 
Verzweigung sind die Fragmente der Chr. anastomosans ähnlich, durch die Tentakelscleriten aber von dieser Art und den anderen Arten der Subgruppe A 2 verschieden.

Ich ziehe es vor, diese Art, da nur so wenig Material vorliegt, nicht zu benennen.

3. Chrysogorgia tetrasticha nov. spec.

Stat. $251.5^{\circ} 28^{\prime} .4$ S. $132^{\circ} 0^{\prime} .2$ (). Kei-Inseln. 204 II. Harter Korallensand. I Ex.

Von dieser neuen Art wurde eine Kolonie erbeutet, von welcher nur ein kleiner unterer

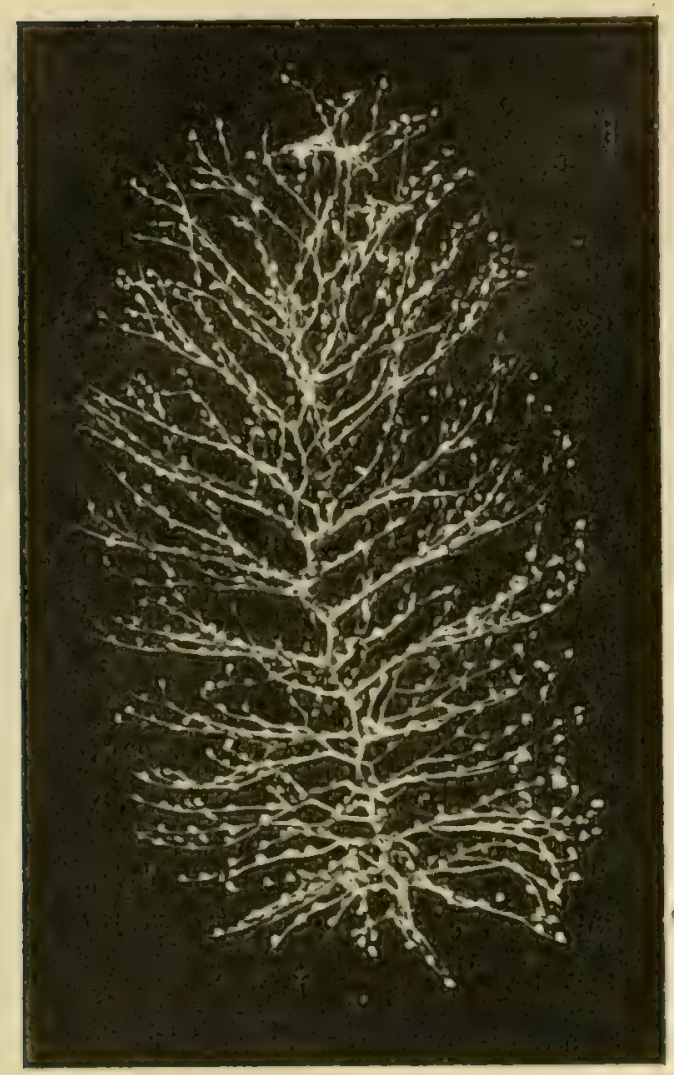

Fig. 38 . Chr. tetrasticha. Kolonie in nat. Grösse. Abschnitt fehlt (Fig. 38); dieselbe ist $85 \mathrm{~mm}$. hoch, bis $48 \mathrm{~mm}$. breit, lang-eiförmig.

Die Achse des Stammes ist unten I mm., in halber Höhe $2 / 3$ mm. dick, gelb, goldglänzend. Aststand ${ }^{1} / t$, linksgewunden, die Divergenz deutlich variirend, im Mittel etwas mehr als $90^{\circ}$, sodass die vier Längsreihen von Stammästen sich ein wenig um den Stamm drehen. Die Entfernung zweier Aeste derselben Verticalreihe beträgt bis reichlich $8 \mathrm{~mm}$., ist unten nur 5 , ganz unten nur $3 \mathrm{~mm}$.; die Länge der Stamminternodien ist bis $2 \mathrm{~mm}$..

Die untersten Stammäste stehen nahezu senkrecht auf dem Stamm, mit ihren Endzweigen sogar nach dem Boden geneigt, die oberen sind aufgerichtet bis ihre basalen Internodien einen Winkel von nur $45^{\circ}$ mit der Vertical-Achse der Kolonie bilden (Fig. 38).

Stammäste regelmässig, anscheinend dichotom verzweigt, alle ihre Zweige ziemlich genau in einer Ebene liegend (Fig. 39); ein Stammast hat bis 5 nachfolgende Internodien und Seitenzweige bis zur dritten Ordnung sind vorhanden. Das proximale Stammast-Internodium ist $\pm 4 \mathrm{~mm}$. lang, das $2^{\text {te }}$ meist $\pm 6 \mathrm{~mm}$., zwischen 2 und $7 / 2 \mathrm{~mm}$. variirend; die weiteren Inter-

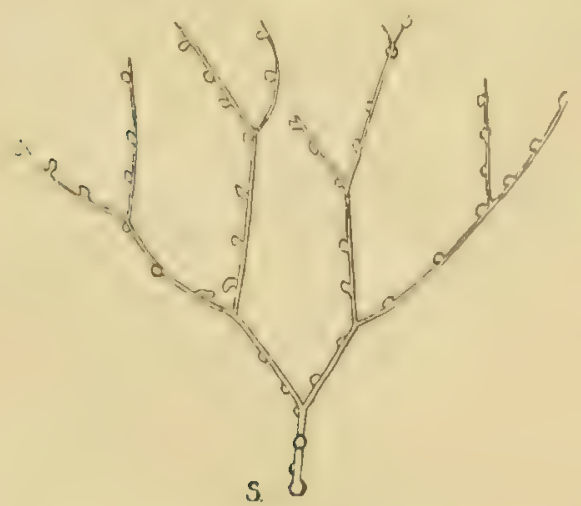

Fig. 39. Stammast ron Chr. ectrasticha. $\mathrm{S}=$ Stamm. $\times 2$. nodien sind $5 \%$ bis $10 \mathrm{~mm}$, zwei Endinternodien sogar 16 und $\mathrm{II}^{1} / 2 \mathrm{~mm}$. lang, letztere im Mittel aber nur 6 bis $7 \mathrm{~mm}$..

Rinde mit wenigen, langen, glatten Scleriten (Fig. 40), welche höchstens halb so dick wie breit sind. Länge resp. Breite einiger derselben: 0,19-0,03 mm.; O, I67--0,035 mm.; $0,105-0,015 \mathrm{~mm}$. und weniger. Mit zahlreichen Nematozoöiden, welche in Grösse und Bau denen der Chr. lata ähnlich sind. Sie sind

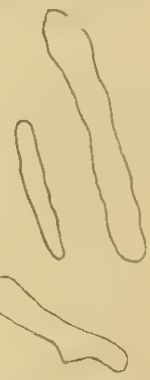

Fig. 40. RindenScleriten ron Chr. tetrasticha (von der Achsc). $\times 145$. 0,03 bis $0,06 \mathrm{~mm}$. hoch, an der Basis 0,048 bis $0,06 \mathrm{~mm}$. breit. Auf den jüngsten Internodien des Stammes und der Aeste fand ich keine. 
Polypen auf dem ganzen Stamm, einer bis zwei auf jedem Internodium, gleichfalls auf allen Internodien der Aeste. Dabei ist ihre Mundöffnung meist nach oben oder nach der Peripherie, sehr selten nach unten gekehrt. Auf dem proximalen Stammast-Internodium stehen 1 bis 3 , meist 2 Polypen; auf dem $2^{\text {ten }}$ I bis 5 , meist 2 oder 3 Polypen, auf den weiteren Internodien I bis 6 , meist 3 oder 4 Polypen.

Totallänge der Polypen bei zusammengelegten Tentakeln $\pm \mathrm{I}, 2 \mathrm{~mm}$; bei vorgestreckten Tentakeln bis -1,6 mm.; Rumpflänge 0,5-0,6 mm., Breite bis 0,6 und $0,7 \mathrm{~mm}$.

Die Polypen sind ziemlich reich an Scleriten (Fig. 4I), wodurch meist nur wenig von einer Anord-

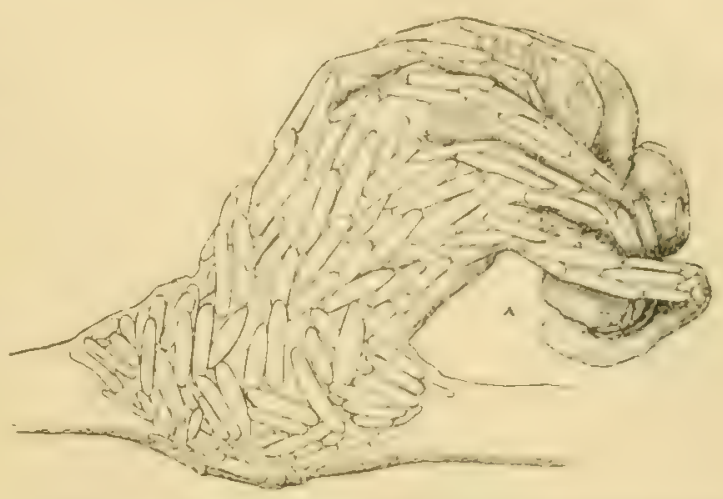

Fig. 4I. Polyp von Chr. tetrasticha; bei A sind dic Scleriten nicht eingezeichnet, weil sie dort offenbar verschoben waren. $\times 47$. nung derselben in 8 septalen Längsreihen bemerkbar ist ${ }^{1}$ ) und nur kleine Strecken der Rumpfwand frei von Scleriten bleiben. Auch die Polypen-Basis enthält beinahe immer eine vollständige Schicht von Scleriten. Letztere sind am Ende gerundete, auf dem Querschnitt runde Spicula, mit vielen kleinen Wärzchen (Fig. 42), welche letztere zahlreicher und etwas kleiner sind als bei Chr. lata; Länge bis $0,24 \mathrm{~mm}$., Breite bis $0,07 \mathrm{~mm}$., meist aber weniger als $0,18 \mathrm{~mm}$. lang und 0,05 mm. breit. In der Polypen-Basis liegen einige Schuppen.

Die gleichen Spicula liegen in den Tentakel-Rücken, 2-3, bisweilen 4 neben einander (das variirt selbstverständlich mit dem Contractionszustand), in jedem Tentakel 20 oder mehr. Nach der Tentakelspitze zu werden die-

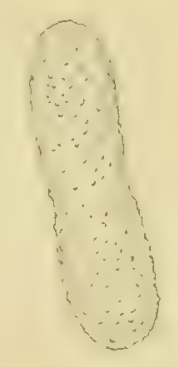

Fig. 42. Chr. tetrasticha; Spicula der Polypen. $\times 187$. selben viel kleiner, bleiben aber doch Spicula. Scleriten in und bei den Pinnulae ziemlich zahlreich, klein, dünn, mit deutlichen Wärzchen, lang bis $0,06 \mathrm{~mm}$. oder etwas mehr, breit $\pm 0,016 \mathrm{~mm}$. (Fig. 43).

Diese Art steht der Chr. lata sehr nahe. Sie unterscheidet sich von derselben durch die schmalere Form der Kolonie ${ }^{2}$ ), die weniger starke Verzweigung der Stammäste, welche sich auch mehr in einer Ebene ausbreiten und nicht so stark aufgerichtet sind; durch die etwas grössere Zahl von Polypen auf jedem Internodium, namentlich aber durch das Auftreten von besonderen Scleriten in der Rinde; durch die viel grössere Zahl der Kalkkörper in den Polypen,

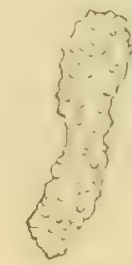

Fig. 43. Chr. tetraslicha; Kalkkörper aus einer Pinuula. $\times 447$. und die zahlreicheren, warzigen Scleriten der Pinnulae.

4. Chry'sogorgia spec. (tetrasticha?).

Stat. $297.10^{\circ} 39^{\prime} \mathrm{S}$., $123^{\circ} 40^{\prime}$ O. Oestlich von Rotti. 520 M. Weicher graucr Schlamm. Zwei Astfragmente.

Die beiden Fragmente sind Astabschnitte ohne Stamm; der Aststand ist also unbekannt. Die Ausbreitung der Zweige findet nicht in einer Ebene statt, die Verzweigungsebenen haben

1) Bisweilen ist das doch erheblich deutlicher als bei den Polypen der Fig. 41 .

2) Soweit aus nur ciner Kolonic jeder Art auf ihre typische form geschlossen werden kann. 
sehr wechselnden Stand. Ich fand keine Nematozoöide; dieselben fehlen aber auch bei Chr. tetrasticha in den distalen Abschnitten der Kolonie. Polypen und Scleriten wie bei dieser Art, nur variirt die Zahl der Polypenscleriten etwas mehr.

Von Chr. pusilla unterscheiden sich die Fragmente durch die längeren Astinternodien, welche meist 2 bis 3, mitunter bis 6 Polypen tragen, während bei ersterer Art die Zahl derselben I bis 2, seltener 3, aber niemals mehr beträgt. Auch sind die Polypen von Chr pusilla kleiner.

Das Material genügt nicht, die. Frage zu entscheiden, ob die Fragmente zu Chr. tctrasticha, zu pusilla oder zu einer dritten neuen Art gehören.

\section{Chroysogorgia pusilla nov. spec.}

Stat. $297.10^{\circ} 39^{\prime}$ S., $123^{\circ} 40^{\prime}$ O. Oestlich von Rotti. 520 M. Weicher grauer Schlamm. I Ex.

Eine Kolonie, deren Basis fehlt (Fig. 44), hoch $68 \mathrm{~mm}$., breit bis $36 \mathrm{~mm}$, etwas

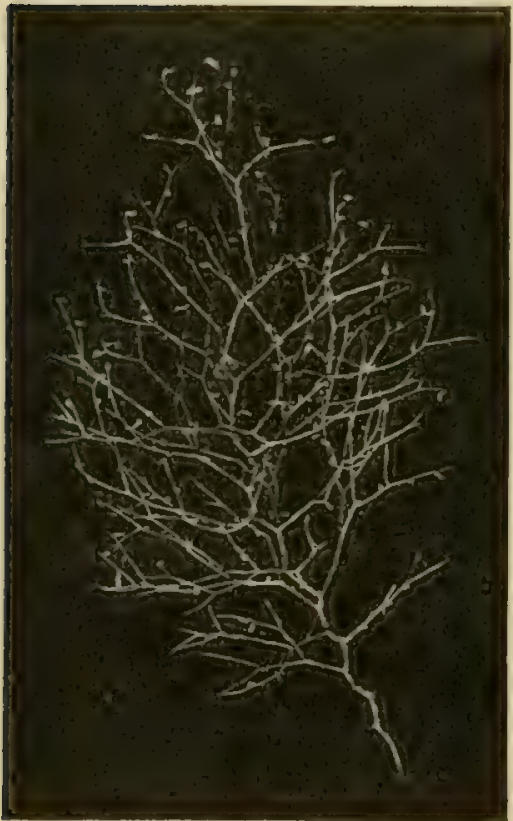

Fig. 44. Folonie von Chr. pusilla. Sehr wenig vergrössert. unregelmässig eiförmig. Achse des Stammes dünn, unten noch nicht ganz $1 / 2 \mathrm{~mm}$. dick, gelb, etwas grünlich goldglänzend, bei jedem Astabgang sehr stark gebogen. Aststand $1 / 4$, linksgewunden: die Divergenz der Zweige variirt aber noch mehr als bei Chr. tetrasticha und der Aststand ist denn auch weniger deutlich als bei dieser Art und bei Chr. lata. Die Entfernung der Stammäste einer Verticalreihe ist unten $7 \mathrm{~mm}$., oben bis 9 und $\mathrm{IO} \mathrm{mm}$.; Länge der Stamminternodien $\mathrm{I}^{3} / \mathrm{s}$ bis $21 / 2 \mathrm{~mm}$. Stammäste aufgerichtet, die unteren nur wenig, die oberen so stark, dass sie einen Winkel von $65^{\circ}$ mit der Verticalachse der Kolonie bilden.

Nur die proximalen Internodien der Stammäste liegen in einer Ebene, welche dann senkrecht steht zu einer durch Stamm und basales Astinternodium gelegten Ebene; die mehr distalen Internodien der Aeste sind aber regellos gestellt. Jeder Ast hat 3 bis 4 , einige 5 successive Internodien. Die Länge derselben ist für das proximale 4 bis $6 \mathrm{~mm}$. (bei einem Stammaste 7), für die weiteren 4 bis $5 \frac{1}{2} \mathrm{~mm}$., wenn sie Endinternodien sind bis $7 \mathrm{~mm}$. Die Verzweigung ist auch dadurch unregelmässig, dass oft die beiden Aeste einer Dichotomie, auch der proximalsten, sehr verschieden stark sind; dies ist aber regellos und der Hauptast liess sich, soweit ersichtlich, nicht durch regelmässig grössere Stärke verfolgen.

Rinde mit nur vereinzelten Scleriten, welche formal denen der Chr. tctrasticha gleich sind, aber kleiner bleiben. Nematozoöide wenig zahlreich, vereinzelt oder zu kleineren Gruppen vereinigt, oft auf ganzen Strecken der Rinde fehlend ${ }^{1}$ ). Sie sind wie bei Chr. lata gebaut, aber kleiner, nur bis $0,04 \mathrm{~mm}$. hoch und an der Basis $0,045 \mathrm{~mm}$. breit. Stamm der Kolonie unten ohne Polypen, von der Mitte ab ein Polyp auf jedem Internodium. Unterstes Stammast-Inter-

1) Die vielen Verunreinigungen, welche die Epidermis bedecken, machen es schwierig, dies bestimmt festzustellen, vielleicht ind die Nematozoüide an vielen Stellen verloren gegangen, abgerieben, und habe ich die Zahl derselben unterschätzt. 
nodium mit I bis 3, meist 2 Polypen, die weiteren mit I oder 2 Polypen, die Endinternodien mit I bis 3 , meist 2 Polypen.

Polypen mit zusammengelegten Tentakeln bis $0,85 \mathrm{~mm}$., mit vorgestreckten Tentakeln bis 1,55 mm. lang. Rumpflänge bis 0,6 mm., meist aber erheblich kleiner. Die Polypen sind schmal, vor allem die längeren, meist weniger als $0,4 \mathrm{~mm}$. breit. Das Volumen eines Polypen ist jedenfalls merklich kleiner als bei Chr. lata und tetrasticha, mehr noch als aus obigen Zahlen ersichtlich ist (vergleiche die Figuren 32, 38 und 44). Polypen immer mit zahlreichen Scleriten, sodass eine Anordnung in 8 septale Reilsen nur bei wenigen erkennbar ist und nur kleine oder gar keine Strecken der Rumpfwand frei von Scleriten bleiben. Die Scleriten sind Spicula, wie die der Chr. tetrasticha, nur etwas schmäler und mit weniger zahlreichen Wärzchen; sie sind lang bis 0,23 und breit bis $0,04 \mathrm{~mm}$. (z.B. Länge und Breite von zwei normalen Kalkkörpern: $0,2-0,02$ und $0,14-0,175 \mathrm{~mm}$.). Auf den Tentakel-Rücken liegen höchstens zwei Scleriten neben einander; die Zahl derselben ist etwas geringer als bei Chr. tetrasticha.

Es liegen nur sehr wenige Scleriten in den Seiten der Tentakel bei den Bases der Pinnulae; dieselbe sind schmäler und kleiner als bei Chr. tetrasticha, mit ganz glatter Oberfläche.

Die Untersuchung dieser Art wurde sehr erschwert durch die vielen fremden Partikelchen, welche die einzige Kolonie überall bedecken. Dies machte es mir unmöglich eine getreue Abbildung eines Polypen mittelst Zeichenprismas herzustellen, weshalb ich keine Abbildung einesPolypen gebe.

Die Art unterscheidet sich von Chr. lata, ausser durch die viel geringere Grösse der Kolonie, die möglicherweise Folge von geringerem Alter ist, durch folgende Merkmale:

Astinternodien mit Ausnahme des proximalsten, erheblich kürzer; Verzweigung viel unregelmässiger, Zahl der successiven Internodien eines Hauptastes 5 gegenüber 7 ; jedes Astinternodium mit $\mathrm{I}-2$ Polypen, bei Chr. lata mit 2-3 bis 4 Polypen; Zahl der Polypenscleriten viel grösser; letztere sind schmäler; mit besonderen Scleriten in der Rinde; die Polypen sind kleiner; Nematozoöide wahrscheinlich viel weniger zahlreich.

Von Chr. tetrasticha trennen sie folgende Unterschicde:

Aeste stärker aufgerichtet, auch die untersten; Astinternodien, mit Ausnahme des proximalsten, kürzer, jedes mit I - 2 Polypen, gegen meist $3-4$ bei Chr. tctrasticha; Verzweigung der Stammäste viel unregelmässiger und nicht in einer Ebene; Polypen kleiner, namentlich schmäler; Scleriten der Pinnulae ohne Wärzchen und weniger zahlreich; Nematozoöide wahrscheinlich nicht zahlreich.

Diese Unterschiede sind allerdings nicht erheblich und einige derselben sind vielleicht Folge von verschiedenem Alter oder verschieden günstigen Wachsthums-Bedingungen. Es bedürfte eines reicheren Materiales um zu entscheiden, ob diese Art zu Chr. tctrasticha gehört; dann wäre letztere Art allerdings sehr variabel. Soweit unser Kenntniss jetzt geht, scheint Abtrennung in zwei Arten mir geboten.

Verbreitung: Timor-See (Siboga-Exp.).

6. Chry'sogorgia spec.

Stat. I $56.0^{\circ} 29^{\prime} \cdot 2$ S., $130^{\circ} 5^{\prime} \cdot 3$ O. Halmaheira-See bei Waigeu. 469 M. Grober Sand. Fragmente.

Das grösste Fragment ist ein $7^{S} \mathrm{~mm}$. langer Zweig-Abschnitt, demnach noch etwas 
länger als bei Chr. cupressa. Dasselbe zählt bis 20 Internodien; es ist vorherrschend in einer Ebene ausgebreitet, mit einer Unterseite ohne Seitenzweige und Polypen. Die Verzweigung ist unregelmässig, wie bei dem in Fig. 37, S. 35 abgebildeten Astfragment; einige Verwachsungen sich kreuzender Zweige kommen vor. Die Länge der Internodien ist meist etwa $4 \mathrm{~mm}$.

Die Rinde ist sehr schlecht erhalten; ich fand keine Scleriten und keine Nematozoöide. Meist stehen 2, selten I Polyp auf jedem Astinternodium; 3 fand ich niemals; dieselben sind etwa so gross wie bei Chr. pusilla. Sie enthalten ziemlich viele Scleriten, sodass die Rumpfwand keine scleritenfreien Strecken aufweist. Die Kalkkörper sind stumpfe Spicula mit nur kleinen Wärzchen. Ohne Schuppen im Rumpf und in den Tentakelspitzen.

Die Art ist durch das Fehlen von Rindenscleriten und Nematozoöiden mit Clur. cupressa, durch die Polypen mit Chr. pusilla verwandt, in der starken Verzweigung von beiden verschieden. Zur Aufstellung einer neuen Art finde ich die Fragmente ungenügend.

\section{Chroysogorgia cupressa (Wright \& Studer).}

Dasy'gorgia cupressa Wright and Studer, Challenger Report, vol. 3I, I889, S. II.

In der Challenger Sammlung des „British Museum” fand ich von dieser Art vier Kolonien (nicht drei, wie im Challenger Report angegeben). Die grösste derselben stand in der Schausammlung und habe ich nicht genauer untersucht; die nachfolgende Beschreibung ist vor allem auf die anderen drei Kolonien gegründet.

Die Art befestigt sich mit kalkiger, scheibenförmiger Basalausbreitung auf Kurallentrümmern ${ }^{1}$ ). Die grösste Kolonie (die der Schausammlung) erreicht eine Höhe von $\pm 160 \mathrm{~mm}$.; die zweitgrosse von $120 \mathrm{~mm}$. bei einer Breite von $100 \mathrm{~mm}$. Im Umriss sind die Kolonien kurzeiförmig. Der Stamm ist bei der zweitgrossen Kolonie unten $3 \mathrm{~mm}$, in halber Höhe noch $\mathrm{I}^{3} / 4 \mathrm{~mm}$. dick. Sie ist bei allen Exemplaren, relativ und absolut, viel stärker als bei den vorhergehenden Arten. Von dem Habitus dieser Art giebt die Figur I, Tafel 3 im Challenger Report vol. 3 I ein gutes Bild. Der Stamm ist nur schwach geknickt. Die stärkeren Abschnitte der Achsen von Stamm und Aesten sind grünlich metallisch, die dünneren gelblich goldglänzend.

Die Stammäste entspringen schon in einer sehr geringen Entfernung, etwa $5 \mathrm{~mm}$, von der Basis des Stammes, die unteren sind aber meist abgebrochen.

Aststand $1 / 4$, linksgewunden; die 4 verticalen Astreihen sind ziemlich regelmässig: Die Entfernung von zwei Stammästen einer selben Verticalreihe ist nahezu $6 \mathrm{~mm}$., nur bei den unteren Aesten ist sie kleiner, bis wenigstens $3^{1 / 1} \mathrm{~mm}$. Die untersten Stammäste horizontal abgehend oder sogar etwas nach dem Boden gesenkt; die oberen Stammäste stets mehr aufgerichtet, sodass die mittleren einen Winkel von $50^{\circ}$ bis $60^{\circ}$, die oberen von nur $40^{\circ}$ bis $30^{\circ}$ mit der Längsachse der Kolonie bilden.

Länge eines Stammastes bei der zweitgrossen Kolonie bis $6_{3} \mathrm{~mm}$, bei der grössten

1) Eine ähnliche lefestigung auf festem Boden kommt wahrscheinlich auch den vorhergehenden Arten zu; die Kiolonien sinc ja alle iber der Basis abgebrochen, was bei $\Lambda$ rten die mit verzweigten Stolonen nur lose im Schlamm wurzeln, befremdend wäre; bei den Arten wo letzteres der Fall ist, erhielt ich auch beinalo immer die Basis der Kolonien, so bei Chr. Mexilis (zahlreiche Ex.), Chr. peneasticha und bei den Arten des Genus Lepidogorgia. 
Kolonie noch mehr; sie sind stark verzweigt. Die Hauptäste zählen bis 9 Internodien. Auffallend ist die sehr geringe Länge, nur 2 bis $3 \mathrm{~mm}$, des proximalsten Internodiums der Stammäste: die anderen Internodien sind 4 bis $15 \mathrm{~mm}$. lang, die Endinternodien sogar bis $1 \mathrm{~S}$ mm.. Die Verzweigung ist oft anscheinend dichotomisch, der Winkel welchen beicle Zweige einer Dichotomic bilden bisweilen nur $30^{\circ}$ und noch weniger, im Mittel schärfer als bei Chr. pusilla und lata, erheblich kleiner als bei Chr. tetrasticha. Der Hauptast könnte äusserlich nicht mit Gewissheit bis zum Ende erkannt werden. Den Verlauf der Achsencylinder habe ich nicht verfolgt; aus der Untersuchurig anderer Chrysogorgia-Arten geht aber hervor, dass die Verzweigung ein wenig anders ist als sie von Wrigrt und Studer in ihrer Textfigur 3 (1. c. S. I I) dargestellt ist. Siehe hierüber oben S. 26 .

Die proximalen Verzweigungen finden meist alle in einer Ebene statt, welche senkrecht steht auf der Ebene, welche man durch den Stamm und das untere Stammast-Internodium legen kann. Die distalen Aeste gehen regellos nach allen Seiten ab. Die proximalen Astinternodien sind sehr dick, die Endzweige sehr zart.

Rinde ohne Scleriten und ohne Nematozoöide.

Der Stamm und die proximalsten 2-3 Internodien der Stammäste tragen keine Polypen, die weiteren Ast-Internodien 2-3, mitunter 4 oder 5 Polypen. Die Grösse der Polypen wechselt ziemlich erheblich; die meisten sind sehr klein; bei den drei kleineren Kolonien der ChallengerSammlung ist wohl kein Polyp mit zusammengelegten Tentakeln länger als I mm., die meisten sind nur $3 / \mathrm{mm}$. lang. Die grösste Kolonie hat aber durchschnittlich grössere Polypen, worunter solche, die bis zu $2 \mathrm{~mm}$. Länge erreichen. Die Polypen sind regellos gestellt, durchaus nicht alle nach unten gekehrt, wie es im Challenger Report Tafel 3 Fig. I abgebildet ist.

Die Polypen sind in Zahl und Vertheilung der Scleriten denen der Chr. lata sehr ähnlich, Abbildung daher überflissig. Bei den im Challenger Report, Tafel 3, Fig. I a abgebildeten Polypen sind die Kalkkörper viel zahlreicher angegeben als ich sie jemals gefunden; auch sind dieselben in der Rinde eingezeichnet, wo sie ja fehlen. Die septalen Scleritenreihen im Polypen-Rumpf zählen je 5 bis \& Kalkkörper; die Reihen gehen meist bis zur Polypenbasis; bei einigen Polypen liegen auch einige Scleriten in der Rinde an der dem Polypen entgegengesetzten Seite des Zweiges, der sie trägt. Die Pinnulae-Scleriten sind bei Chr. cupressa etwas zahlreicher als bei Chr. lata, die Zahl der Pinnulae selber schätze ich auf 8 bis 12 an jeder Seite eines Tentakels; sie waren meist schlecht erhalten.

Die Spicula von Rumpf und Tentakel sind lang, auf dem Querschnitt nahezu rund, mit abgerundeten Enden, mit kleinen, nicht sehr zahlreichen Wärzchen (Fig. 45). Länge und Breite beträgt meist etwa o, I resp. 0,035 mm., doch giebt es auch grössere Spicula, bis zu 0,243 $\mathrm{mm}$. Länge und $0,038 \mathrm{~mm}$. Breite, auch viele kleinere. Nizch der Tentakelspitze zu werden die Scleriten kleiner (z.B. Länge und Breite: $0,1-0,027 \mathrm{~mm}$. und $0,065-0,013 \mathrm{~mm}$.) und sind oft etwas dünner als breit. Bei jeder Pinnula, mit Ausnahme der untersten, liegen 3 bis 4 kleine Scleriten (Länge und Breite z.B. o,o6j und 0,0 I $\mathrm{mm}$.):

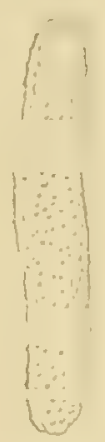

lig. 45 . Chr. cupressa, Type: Spiculum des PolypenKumpes. $X \mathrm{IS}^{\mathrm{s}}$. dünn, mit runden oder zugespitzten Enden, glatt oder mit einigen kleinen Tiärzchen.

Wright und Studer (1. c. S. I3) geben an, es komme in den Polypen noch eine tiefere SIBOGA-EXPFIITIE, XIIt. 
Schicht von Scleriten vor: "the lower layer consists of oval, biscuit-shaped, lancet-shaped, flat" "scales, mostly with finely toothed edges, which are united together by interlocking of the teeth". Ich habe bei den Polypen des zweitgrössten Challenger-Exemplares besonders danach gesucht; sie fehlten dort aber stets. Auch wo ich sonst von Wright und Studer abweiche, habe ich immer meine Angaben genau controllirt. Dass ich die grösste der Kolonien nicht untersuchte, ist vielleicht der Grund einiger Unterschiede in unseren Befunden.

Verbreitung: Kei-Inseln im Ost-Indischen Archipel; Tiefe 252 M.; blauer Schlammboden.

Zu dieser Art glaube ich eine Kolonie bringen zu müssen, welche von der SibogaExpedition erbeutet wurde:

Stat. 260. $5^{\circ} 36^{\prime} .5$ S., $132^{\circ} 55^{\prime} .2$ O. bei Nuhu Jaan, Kei-Inseln. 90 M. Sand-Boden mit Muscheln und Korallen. I Ex.

Eine Kolonie ohne Basis, 86 mm. hoch, die Mehrzahl der Aeste ist abgebrochen (Fig. 46).

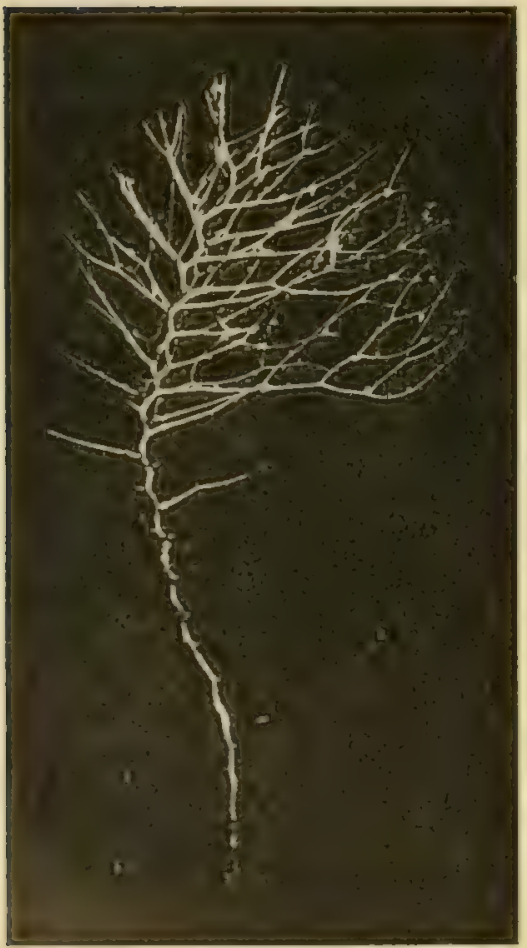

Fig. 46. Chr. cupressa. Sibogn-Sammlung. Niıt. Grösse. Ihr Querdurchmesser mag etwa $55 \mathrm{~mm}$. betragen haben. Die Entfernung zweier Stammäste derselben Verticalreihe ist nur $4^{1 / 2} \mathrm{~mm}$., Stamm und Aeste sind relativ erheblich duinner als bei den Typen der Chr. cupressa. Verzweigung und Länge der Internodien der Stammäste sind ähnlich, nur sind die Winkel, unter welchen die Seitenzweige abgehen meist weniger spitz (Fig. 47). Das erste StammastInternodium ist ohne, das zweite aber oft schon mit Polypen.

Länge der Polypen mit zusammengelegten Tentakeln meist nur $0,7 \mathrm{~mm}$. oder weniger, also noch etwas kleiner als bei den Challenger-Exemplaren. Einige Polypen sind grösser, vereinzelte sogar $3 \mathrm{~mm}$. lang; die grössten derselben enthielten aber einen parasitischen Copepoden, welcher wohl Ursache des starken Wachsthums der Polypen war. Da wohl alle merklich grösseren Polypen von Copepoden bewohnt waren, darf man nur die kleineren als normal betrachten. Die Polypen zeigen meist deutlich weniger

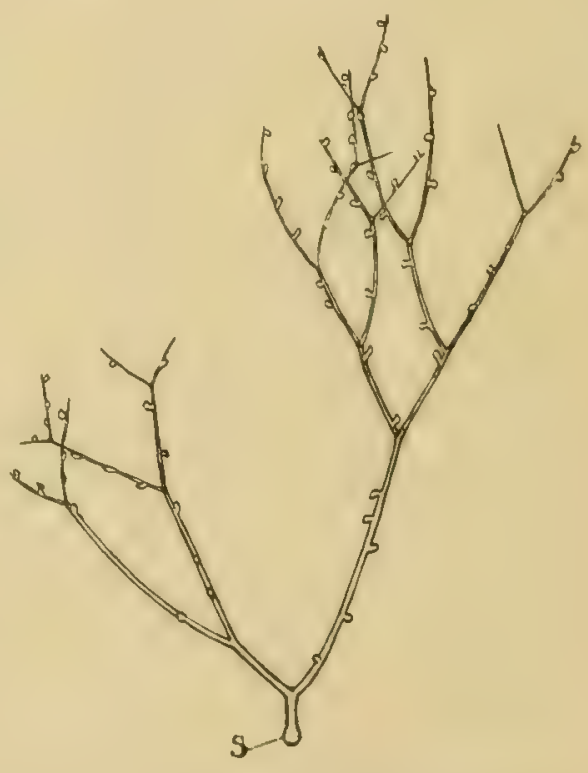

Fig. 47. Chr. cupressa, Siboga-Sammlung. Stammast; die sehr verschieden gerichteten Verzweigungsebenen sind in einer Ebene projiciert; $\mathrm{S}=$ Stamm im Querschnitt. $\times 2$.

Scleriten als bei den Challenger-Exemplaren. Auch sind die Scleriten im Mittel kleiner; die längsten erreichen nur etwa $0,17 \mathrm{~mm}$. Ein wichtiger Unterschied ist, dass diese Spicula meist nur etwa halb so dick als breit sind; auch sind die Wärzchen weniger gross (Fig. 48). Bei der kleineren Zahl der Rumpfscleriten ist keine Anordnung derselben in 8 septalen Reihen erkennbar, 
aber bei einem abnormen, von Copepoden bewohnten, $3 \mathrm{~mm}$. langen Polypen, waren die Reihen deutlich, die Spicula zahlreicher und bis $0,33 \mathrm{~mm}$. lang, also viel grösser als bei den normalen Polypen und sogar grösser als bei den ChallengerExemplaren der Chr. cupressa.

Das Exemplar der Siboga-Sammlung steht der Chr. cupressa (Wr. \& St.) unbedingt sehr nahe. Der Habitus ist etwas verschieden in Folge der geringeren Dicke von Stamm und Aesten und wegen der weniger spitzen Winkel, worunter die Zweige abgehen; die Polypen sind kleiner und haben weniger zahlreiche und dazu abgeplattete Spicula. Gegenüber den vielen Aehnlichkeiten möchte ich aber auf diese Merkmale, solange ihre Constanz nicht aus einem grösseren Material hervorgeht, keine neue Art gründen; ich stelle die Kolonie daher, wenn auch unter Vorbehalt, zu Chr. cupressa (Wr. \& St.).

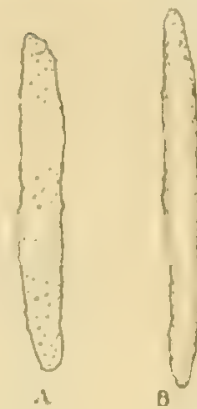

Fig. 4S. Chr. cup, ․ Siboga-Sammlung; Spicula des Polypen-Rumpfes; $\Lambda$ v d. breiten, B v. d. schmalen Seite gesehen. $\times$ is7.

\section{Unter-Gruppe $A 2$.}

Aststand $\%$, rechts gewunden; in der PolypenBasis neben den Spicula meist mit tieferliegenden Schuppen. Spicula im Rumpfe in 8 septalen Längsreihen. Rückenseite der Tentakel an der Basis mit Spicula, welche nach der Spitze des Tentakels zu in kleine Schuppen übergehen.

\section{Chry'sogorgia flexilis (Wright \& Studer).}

Dasygorgia flexilis Wright and Studer, Challenger Report, vol. 3I, I889, p. IO.

Stat. $85.0^{\circ} 36^{\prime} .5$ S., $119^{\circ} 29^{\prime} .5$ O. Makassar-Strasse. 724 M. Feiner, grauer Schlamm. I Ex.

Stat. $\$ 7.0^{\circ} 32^{\prime}$ S., $119^{\circ} 39^{\prime} .8$ O. Makassar-Strasse. 655 M. Feiner, grauer Schlamm. 4 Ex.

Stat. 170. $3^{\circ} 37^{\prime} .7$ S., $131^{\circ} 26^{\prime} .4$ O. Oestliche CeramSee. 924 M. Feiner, grauer Schlamm. 2 Ex.

Stat. I78. $2^{\circ} 40^{\prime}$ S., I $28^{\circ} 37^{\prime} .5$ O. Ceram-See. 835 M. Blauer Schlamm. I Fragment.

Stat. 284 und 286. Südlich von Timor. 828 und 883 M. Schlamm. Mehrere Ex.

Stat. $300.10^{\circ} 48^{\prime} .6 \mathrm{~S}$, $123^{\circ} 23^{\prime} \cdot 1$ O. Oestlich von Rotti. 918 M. Feiner, grauer Schlamm. 4 Ex.

Meine Beschreibung ist auf die Exemplare der Stat. 284 und 286 gegründet, mit denen aber die ubrigen Kolonien der Siboga-Sammlung sehr gut übereinstimmen. Auch habe ich die Typen der ChallengerSammlung untersuchen und die Zugehörigkeit meiner Exemplare zu dieser Art feststellen können.

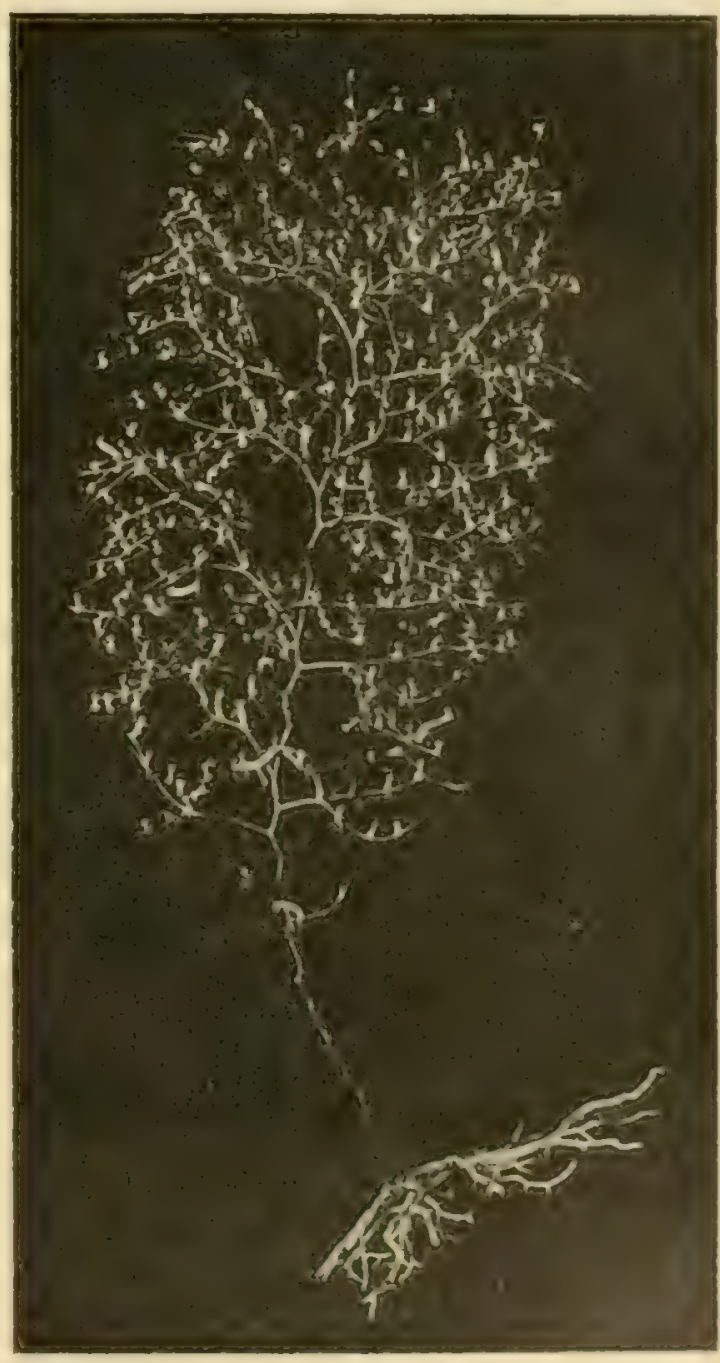

Fig. 49. Chr. flexilis. Kolonie in nat. Grüsse. Dic selur grossen Polypen sind abnormal und enthalien alle einen parasitischen Anncliden.

Kolonien (Fig. 49) bis $140 \mathrm{~mm}$. hoch; Querdurchmesser derselben bis $60 \mathrm{~mm}$. Sie wurzeln 
im Schlammboden mit einem Kreis von milchweissen, gänzlich verkalkten Stolonen. Achsen gelblich goldglänzend, der untere stärkere Theil des Stammes mehr bräunlich. Stamm unten

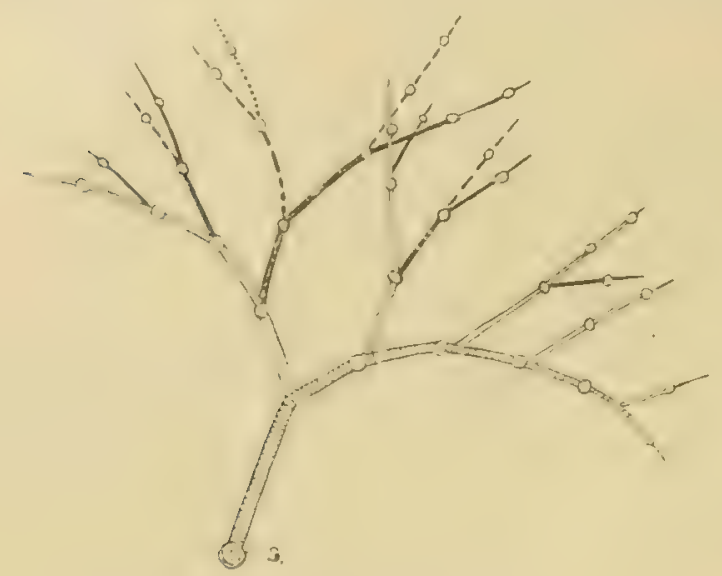

Fig. 50. Stammast von Chr. flexilis.

Seitenzweige verschiedener Ordnung sind rerschieden

angegeben; schematisch. $\times 2.5=S t a m m$. bis I mm., in halber Höhe $0,75 \mathrm{~mm}$. dick. Aststand $\%$, rechts gewunden; die 5 verticalen Stammastreihen sind ziemlich regelmässig und immer deutlich, auch bei den 2 typischen Exemplare der Challenger-Sammlung; die Angabe von Wright und Studer (1. c. S. io), dass die Aeste in drei verticalen Reihen ständen, ist unrichtig. Der unterste Stammast geht in $\pm 10 \mathrm{~mm}$. Entfernung von der Stamm-Basis ab; doch sind die untersten Stammäste immer abgebrochen und nur ihre Ursprïnge sind noch erkennbar (Fig. 49). Die Entfernung zweier übereinanderstehender Stammäste der Verticalreihen ist meist 15 bis $15,5 \mathrm{~mm}$., unten weniger, bis nur $7,5 \mathrm{~mm}$.; die Länge der Stamm-Internodien beträgt bis zu $3 \mathrm{~mm}$.

oder noch etwas mehr. Die basalen Stammast-Internodien stehen nahezu senkrecht zum Stamme, meist nur wenig, die oberen aber etwas deutlicher aufgerichtet. Der erste Seitenast der Hauptäste

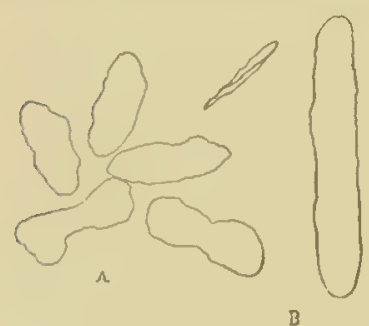

B

Fig. 51. Chr. Mexilis. Scleriten der Kinde, \& $\%$ d. Stammbasis, $B$ aus d. Nähe der untersten Stammäste. $\times 140$. geht meist ziemlich genau in der horizontalen Ebene (d. i. die Ebene senkrecht zum Stamme) ab; die übrigen Seitenäste weichen aber nach der Spitze des Hauptastes zu immer mehr hiervon ab (siehe S. 24). Die Verzweigung ist beinahe immer anscheinend dichotomisch, sodass der Hauptast nicht erkennbar ist. Jeder Hauptast hat 5 bis 6 Internodien; es giebt Seitenäste bis zur vierten Ordnung (Fig. 50). Die Länge des basalen Ast-Internodium ist meist 6 bis $7 \mathrm{~mm}$., bei den untersten Stammästen nur $5 \mathrm{~mm}$.. Die folgenden Internodien sind 4 bis $5,5 \mathrm{~mm}$., die terminalen aber bis 10 , und sogar $13 \mathrm{~mm}$. lang.

Rinde dünn, weiss. Auf den Stolonen enthält sie eine dichte Schicht kleiner, meist ovaler bis lang-ovaler Kalkschuppen, häufig mit sehr unregelmässig gebogenem Rand. Eine dichte,

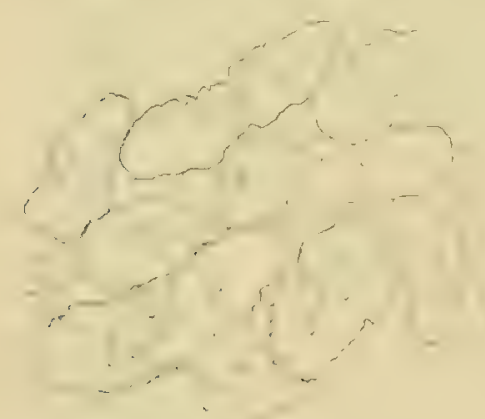

Fig. 52, Chr. flexilis, Rindenscleriten ron der Stammmitte, in situ. $X 140$. mehrere Schuppen dicke Schicht bedeckt auch die Stammbasis; diese Kalkkörper haben aber meist einen mehr regelmässigen, fein gezähnten Rand (Fig. 5I, A); ihre Länge variirt von 0, I I bis $0,6 \mathrm{~mm}$., die Breite von 0,025 bis $0,035 \mathrm{~mm}$; die Dicke ist höchstens 0, or mm.. Sie sind glatt, ohne Wärzchen. Etwas weiter von der Stammbasis entfernt, in der Nähe der untersten Stammäste, fand ich beinah alle Scleriten viel länger, wie auf Fig $5^{\text {I }}$ bei $B$ angegeben, bis 0,19 und sogar $0,22 \mathrm{~mm}$. lang, einige aber nur O, I I und O, I $3 \mathrm{~mm}$.. Dieselbe waren entweder ganz glatt oder mit vereinzelten Wärzchen.

Von den untersten Stammästen nach oben zu liegen die Scleriten in der Rinde des Stammes nur in einer einzigen Schicht, haben einen unregelmässig gebuchteten Rand und bis 10-I2 sehr auffallende, verhäiltnissmässig grosse Höcker (Fig. 52). Aehnliche Scleriten fand ich in der 
Rinde der dickeren Aeste; weitaus die Mehrzahl derselben war weniger als $0,2 \mathrm{~mm}$. lang und

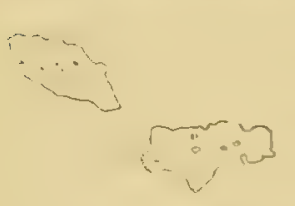

Fig. 53. Cltr. flexilis Scleriten der Rinde eines Astes. $X 1$ fo. $0,06 \mathrm{~mm}$. breit, ein auffallend grosser Kalkkörper aber war $0,33 \mathrm{~mm}$. lang und $0,08 \mathrm{~mm}$. breit (Fig. 53 und 54 ). Auf den Zweigen mittlerer Stärke sind meist einige etwas unregelmässige Längsstreifen der Rinde frei von Scleriten. Auf den dünnsten Zweigen sind die Scleriten oft länger, sehr dünn, mit sehr unregelmässig gebuch-

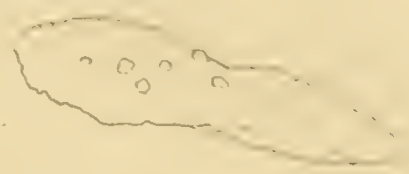

Fig. 54. Chr. flexilis. Kalkkörper der Rinde eines Astes; X 1 q0.

teten Rändern und mit mehreren bis nur vereinzelten Höckern; ihre Länge beträgt bis 0,335 mm., ihre Breite bis etwa $0,055 \mathrm{~mm}$.. Die Schicht der Kalkkörper ist auf den dünnen Zweigen nahezu vollständig, jedoch nur einen Kalkkörper dick.

Nematozoöiden fehlen.

Stamm ohne Polypen; das proximalste Stammast-Internodium meist ohne Polypen, mitunter mit einem, zuweilen sogar mit zwei Polypen. Die anderen Ast-Internodien immer mit einem, die End-Internodien mit einem, zwei, auch wohl àrei Polypen. Die Stellung der Polypen ist auf Fig. 50 angegeben.

Die Länge der Polypen mit zusammengelegten Tentakeln beträgt bis $2 \mathrm{~mm}$.. Die Polypen-Basis wird bei der Bildung der Geschlechtsprodukte stark ausgedehnt und umgreift dabei jederseits den tragenden Ast mit einer sackförmigen Ausstülpung. Polypenrumpf mit 8 deutlichen

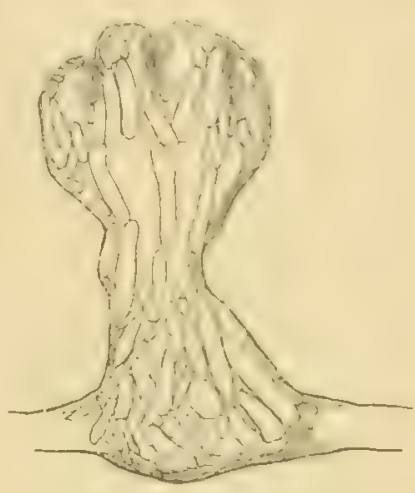

Fig. 55. Chr. fexilis. Polyp mit zusammengelegten Tentakeln. $\times 23$. septalen Scleritenreihen (Fig. 55); bei sehr starker Contraction ist diese Anordnung der Kalk-

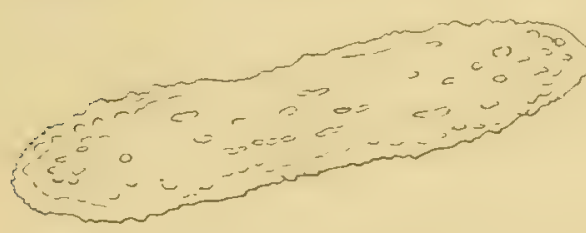

Fig. 56. Chr. fexilis. Kalkkörper aus der Mitte des lumpfes eines Polypen. $\times$ IS7. körper allerdings meist verwischt ${ }^{1}$ ). Die Scleriten sind stabförmige Spicula, mit gerundeten Enden, auf dem Querschnitt merkbar abgeplattet. Die Oberfläche mit ziemlich grossen rundlichen Höckerchen (Fig. 56 und 57 ). Meist O, I 2 bis $0,26 \mathrm{~mm}$. lang und $0,06 \mathrm{~mm}$. oder weniger breit; die Länge steigt aber bis $0,33 \mathrm{~mm}$., die Breite bis $0,07 \mathrm{~mm}$.

Auf der Polypen-Basis liegen Schuppen (Fig. 58), welche eine nahezu vollständig gesclilossene

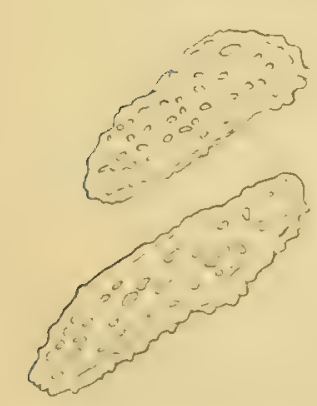

lig 57. Chr. flexilis. Kialkkörper aus der Mitte des Rumples eires Polypen. $\times 187$. Schicht bilden; sie sind namentlich zalileich bei den Polypen, deren Basis durch Geschlechtsprodukte ausgedehnt ist. Die Schuppen liegen mit den Rändern über einander, sind also nicht mittelst feiner Zälnchen an ihren Ränder verbunden (vergleiche WRIGIT und Studer, 1. c. S. I I). Die meisten Schuppen sind in einer Richtung stark verlängert, z.B. O, $15 \mathrm{~mm}$. lang und nur etwa $0,05 \mathrm{~mm}$. breit; die grösste fand ich 0, I $8 \mathrm{~mm}$. lang und $0,055 \mathrm{~mm}$. breit. Zwischen den

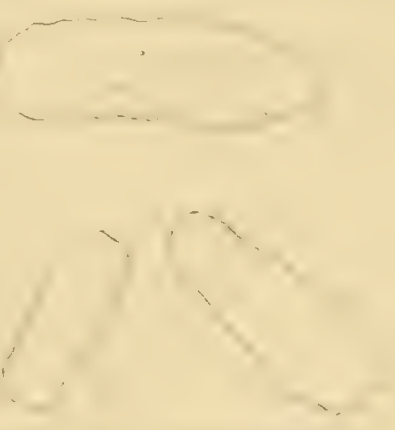

Fig. 58. Chr. mitilis. Kialkkörper der Polypen-Basis. X IS7. glatten Schuppen der Polypen-Basis, den Rindenscleriten und den Spicula der alle denkbaren vermittelnden Iiormen.

1) Das war der Fall bei cinigen Polypen der Challenger-Exemplare; bei anderen Polypen dieser 'lypen alser war die .Inozdnung noch erkennbar. 
In der Aussenseite der basalen Hälfte der Tentakel liegen 2 bis 4 Spicula neben einander
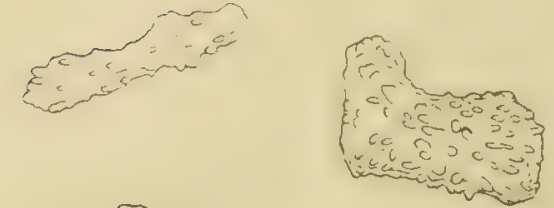

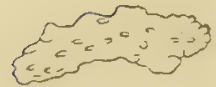

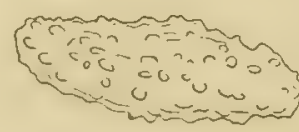

Fig. 59. Chr. flexilis

Spicula der Tentakel-Basis. $\times 187$. mit ihren Längsachsen der Tentakelachse parallel. Sie sind denen des Rumpfes ähnlich, nur meist kleiner (Fig. 55 und 59). Auf der distalen Hälfte des Tentakel-Rückens liegt eine Bekleidung von kleinen Schuppen (Fig. 60 und 6I). Letzteres ist für die Arten der Unter-Gruppe A 2 typisch und kennzeichnet, zusammen mit dem Aststand, dieselben gegenüber der Unter-Gruppe A I (Chr. lata, etc.). Meist sind diese Schuppen glatt (Fig. 6I), bisweilen mit einigen bis mehreren Wärzchen.

Quer zu dieser Bedeckung des Tentakel-Rücken liegen in den Seiten der Tentakel, bis in die Pinnulae reichend, kleine Scleriten (Fig. 6o und 62)

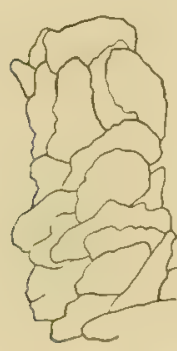

Fig. 61. Chr. fexilis. Schuppenkleid der Tentakel-Spitze. $\times$ IS7 in Gruppen beisammen. Dieselbe sind meist flach, in den Pinnulae zugespitzt, am anderen Ende oft schuppenförmig verbreitert; sie sind bis $0,15 \mathrm{~mm}$. lang, also verhältnissmässig gross.

Die Exemplare der Siboga-Sammlung stimmen sehr

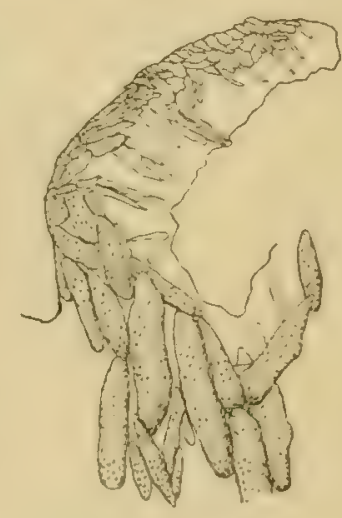

Fig. 6o. Chr. fexilis. Tentakel. $\times 60$. gut mit den Typen im „British Museum" überein; letztere sind aber relativ kleine Kolonien. Die Beschreibung im Challenger-Report ist ziemlich genau, aber zu kurz. Unrichtig ist die Angabe über den Aststand (derselbe sei wie bei Chr. spiculosa, wo der Aststand $1 / 3$ sei; derselbe ist aber bei beiden Arten ${ }^{2} / 6$ ) und über den Zusammenhang der Schuppen im Polypen-Rumpf

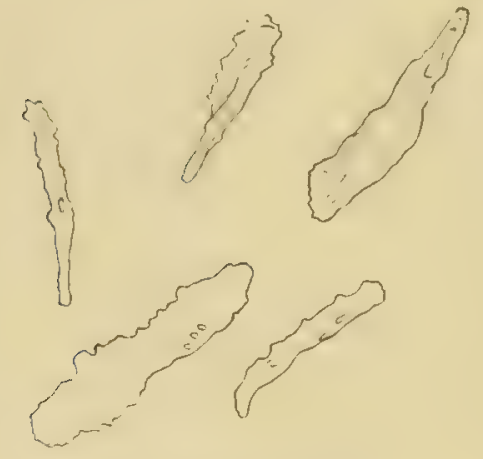

Fig. 62. Chr. Hlexilis. Scleriten aus den Pinnulae. $X \mathbf{1 9 3}$ mittelst der feinen Zähnchen ihrer Ränder. Die Figur 2, $a$ und $b$, auf Tafel 4 des Challenger Report giebt den Habitus der Polypen mit ihrer bei der Entwicklung der Geschlechtsprodukte erweiterten Basis, gut wieder; die Anordnung der Spicula in acht Reihen ist auf denselben aber nicht angegeben.

Einige Kolonien der Stationen 284 und 286 der Siboga-Expedition zeigen einige sehr grosse Polypen (Fig. 49, der unterste Polyp und verschiedene andere). Diese enthielten einen Anneliden, welcher deutlich der verborgenen, parasitischen Lebensweise angepasst war $\left.^{2}\right)$. Die Umbildung dieser Polypen wird wohl durch den Parasiten bedingt; die Zahl der Scleriten ist bei ihnen sehr gross, sodass ein sehr dichtes Kleid von Kalkkörpern, namentlich von einem Anneliden bewohnter lolyp. $\times 23$. Schuppen, gebildet wird. Die Länge dieser Polypen kann nahezu 5 mm. sein. Auf Fig. 63 habe

1) Versturs, Parasieten in de polypen van diepzee Gorgoniden, in: Tijdschrift Nederl. Dierk. Vereeniging, Ser. 2 , rol. 7 , Igo1, p. III; M. WLber, Résultats des Explor. du Siboga, Introduction, I902, Leiden, p. 4 S. 
ich einen solchen Polypen abgebildet; die Anordnung der Spicula in acht septale Reihen ist bei diesen Polypen etwas verwischt, aber doch deutlicher als auf der Fig. 63. In ihr ist die Dicke und die warzige Oberfläche der Spicula nicht angegeben; letztere unterscheiden sich daher nicht so deutlich von den Schuppen, als in Wirklichkeit der Fall ist. Geschlechtsprodukte fand ich in diesen Polypen nicht; doch habe ich wegen der beschränkten Zahl nur einige derselben geöffnet und hierauf untersucht.

Eine der Kolonien von Station 87 der Siboga-Expedition zeigte ähnliche, abnorm verlängerte Polypen; diese enthielten aber keinen Anneliden, sondern immer einige Exemplare eines parasitischen Copepoden, der mit Lamippe Bruz. ${ }^{1}$ ) verivandt ist.

Geographische Verbreitung: Ost-Indischer Archipel (Siboga-Exp.) und Küste von Chili (Challenger-Exp.), in Tiefen von 216 bis 924 M.; auf Schlammboden.

9. Chry'sogorgia affinis n. n.

Dasygorgia spiculosa Wright and Studer, Challenger Report, vol. 3I, I889, p. 9.

Diese Art wurde von der Siboga-Expedition nicht erbeutet.

Ich untersuchte vier, jedoch sämmtlich unvollständige, Kolonien der Challenger-Sammlung, welche Wright und Studer zu Dasygorgia spiculosa Verrill gestellt haben.

Diese Art ist, wie schon Wright und StUder hervorheben, der Chr. flexilis sehr ähnlich.

Eine Kolonie ist $60 \mathrm{~mm}$. lang, eine zweite noch kleiner; von den anderen Kolonien liegen nur Bruchstücke vor, aus denen ihre Länge nicht geschlossen werden kann²). Diese Exemplare sind also erheblich kleiner als die grösseren Kolonien von Chr. Alexilis; dies kann aber, da nur zwei nahezu vollständige Kolonien vorliegen, Folge verschiedenen Alters sein. Der Aststand ist $\%$, nicht $1 / 3$ wie $W_{\text {RIGHT }}$ und STuder angeben. Die Entfernung der Ursprünge zweier auf einander folgender Stammäste einer Verticalreihe ist 7 bis $7^{1 / 2} \mathrm{~mm}$. Die Stammäste sind ein wenig aufgerichtet und werden 2 oder 3 Internodien lang (Fig. 64); solche mit 4 successiven Internodien, wie Wright und STUder in Textfigur 2 abgebildet haben, sah ich nicht. Deren Zahl ist bei Chr. flexitis 5 bis 6 . Die basalen Internodien der Stammäste sind $6-7 \mathrm{~mm}$., die zweiten Internodien 5 bis $6 \mathrm{~mm}$., die End-Internodien bis I I, ja sogar $13^{1} / 2 \mathrm{~mm}$. lang. Die Winkel der Fig. 64. Chr afinis.. anscheinend dichotomischen Verzweigungen (Fig. 64) sind meist $60^{\circ}$ bis $75^{\circ}$, Stammast, nat. Gr. fast stets deutlich weniger als $90^{\circ}$ gross. Die Länge der Stammäste (von der Basis bis zu der am weitesten entfernten Spitze) ist höchstens $2 \mathrm{I} \mathrm{mm}$, nach WRTGHT und STUDer $25 \mathrm{~mm}$.

Rinden-Scleriten wie bei Chr. flexilis. So fand ich auch in der Stamm-Basis die abweichenden kleinen Schuppen (vergl. Fig. 5I, A). Auf den diinneren Zweigen schienen mir die Scleriten zahlreichere und schärfere Wärzchen zu tragen.

1) Bruzelius, R., Oefvers. Vetensk. Akad. Förhandl., vol. 15, p. iSI, 185S, und: Wrecimavs's Archiv. f. Naturgesch., vol. 25, I, S. 286, 1859; Claparede, Ẽd, Ann. Sciences Natur, 5, sér. Zool. vol. S, p. 23, 1867; Scotr, T. and A., Annals and Magazine of Nat. Ilist., 6 ser., vol. 16, 1895, p. 357, beschrciben ein neues Genus Alojonicola, welches anscheinend mit Lamifpe Bruz. identisch ist.

2) Im Challenger Report wird von einem in mehrere Stiicke gebrochenem Fragment gesprochen, dessen Gesammulinge $100 \mathrm{~mm}$. sei; ich habe cin solches in der Challenger-Sammlung nicht gefunden. 
Polypen wie bei Chr. flexilis, aber häufig grösser, mit zusammengelegten Tentakeln bis $3 \mathrm{~mm}$. lang. Ihre Spicula (Fig. 65) zeigen viel grössere und spitzere Höckerchen und sind an den Enden vielfach etwas zugespitzt, nicht immer so stumpt gerundet wie bei Chr. Alexilis. Auch sind diese Kalkkörper etwas grösser als bei Chr. Alcxitis, bis 0,36 mm., einer sogar bis 0,54 mm. lang. Auf der PolypenBasis bilden diese Spicula eine nahezu vollständige Schicht; Schuppen fand ich dort nicht, aber ich habe keine Polypen untersucht, deren Basis von Geschlechtsprodukten erfuillt und dadurch ausgedehnt war und bei Chr. flexilis war ja eben bei solchen Polypen das Schuppenkleid am besten entwickelt.

Es scheint mir nicht fraglich, dass man nicht berechtigt ist, diese Kolonien zu Dasygorgia spiculosa Verrill zu bringen. Abgesehen davon, dass die Beschreibung, welche VERRILl von seiner Art gegeben hat ${ }^{1}$ ), so kurz ist, dass eine Kolonie, die ganz mit V'ERRILL's Diagnose übereinstimmt, darum noch nicht mit Dasygorgia spiculosa Verrill identisch zu sein braucht, besteht auch noch ein Unterschied zwischen Verrill's Art und den Challenger-Kolonien. Bei letzteren fehlen

die besonderen, sehr grossen Scleriten der Polypen-Basis, welche VerriLI von

Fig. 65. Ch\% afinis. Spiculum des Polypen-Rumpfes. $\times$ I 87. den endständigen Polypen seiner Art beschreibt und in Fig. 5 Taf. 2 abbildet. Auf dieser Figur sind einige Spicula nahezu I mm. lang, das grösste sogar I,3 mm., während ich bei den Challenger-Exemplaren kein Spiculum von mehr als $0,54 \mathrm{~mm}$. Länge finden konnte und solche von $0,36 \mathrm{~mm}$. Länge auch bei den terminalen Polypen schon zu den grösseren Kalkkörpern gehören. Deshalb bringe ich die Challenger-Exemplare nicht zu VerriLl's Dasygorgia spiculosa, sondern betrachte sie als zu einer neuen Art, Chr. affinis, gehörig, welche durch die viel geringere Grösse der Spicula der Polypen-Basis, möglicherweise auch noch durch verschiedene andere Merkmale, von Das. spiculosa Verrill verschieden ist, ja derselben vielleicht gar nicht besonders nahe steht.

Geographische Verbreitung: nur an einer Stelle im Atlantik, bei Pernambuco, von der Challenger-Expedition in 630 M. Tiefe auf Schlammboden erbeutet.

10. Chry'sogorgia pentasticha nov. spec.

Stat. $297.10^{\circ} 39^{\prime}$ S., $123^{\circ} 40^{\prime}$ O. Oestlich von Rotti. 520 M. Weicher Schlamm. 2 Kolonien.

Das grösste, nahezu vollständige Exemplar diente mir besonders bei der Beschreibung dieser Art; dasselbe (Fig. 66) ist I $85 \mathrm{~mm}$. hoch, im Querdurchmesser etwa $70 \mathrm{~mm}$., und wurzelt mittelst verzweigter, vollständig verkalkter Stolonen im Schlammboden.

Stamm gelblich-braun, stark goldglänzend, unten I,5 mm. dick. Aststand $\%$, rechts gewunden; die fünf Verticalreihen der Stammäste aber ziemlich unregelmässig, da der DivergenzWinkel von I I $0^{\circ}$ bis $180^{\circ}$ variirt, anstatt immer entsprechend dem Aststand ${ }^{2} \%$, nahezu I $44^{\circ}$, zu sein.

Die untersten Stammiste sind alle abgebrochen, ihre Ansätze aber bis auf $8,5 \mathrm{~mm}$. von der Stammbasis bemerkbar. Die Länge der Stamminternodien ist im Mittel $3,5 \mathrm{~mm}$., variirt

I) 13ull. Mus. Comp. Zool, vol. II, $1 S_{3}$, p. 23. 
ron I mm. (nur ganz unten) bis etwa \& mm.; die Entfernung zweier uibereinander stehender

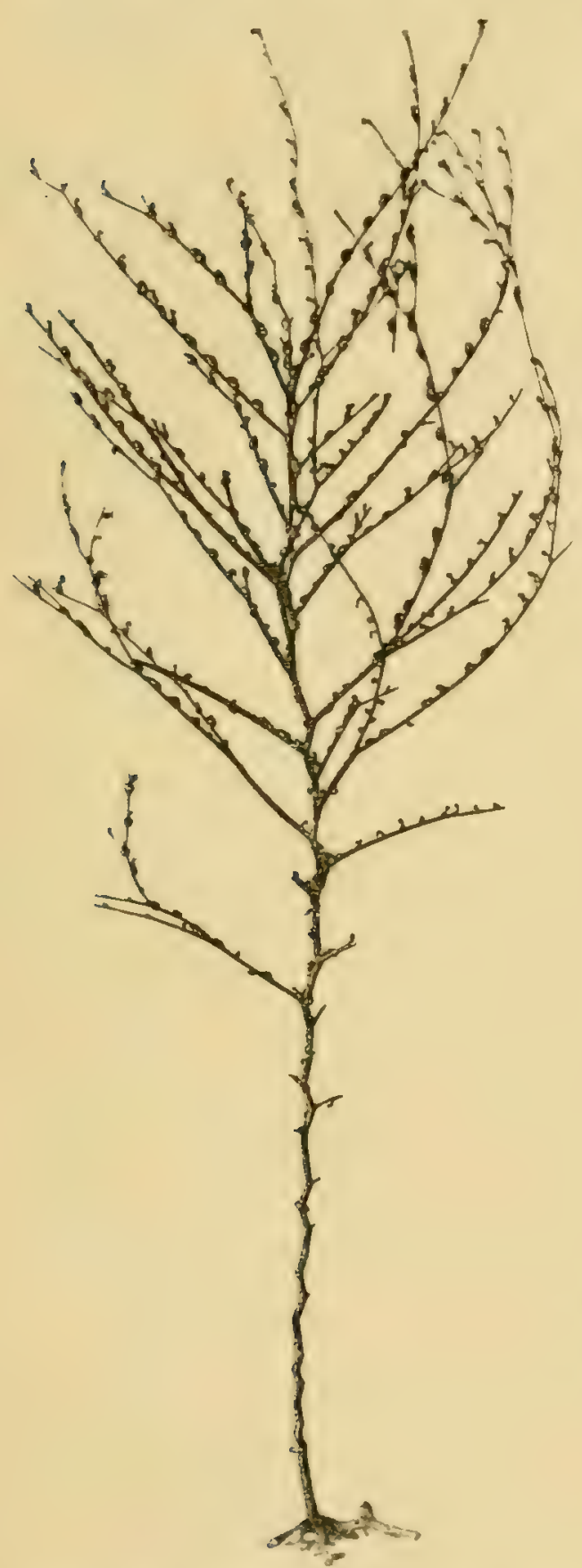

Fig. 66. Chr, fentastichr. Kolonie in nat. Grösse. Stammäste derselben Verticalreihe ist dementsprechend etwa I $8 \mathrm{~mm}$., ganz unten weniger.

Die Stammäste sind stark aufgerichtet; ihre basalen Internodien bilden mit dem Stamme einen $1 \mathrm{~W}$ inkel von $70^{\circ}$ bis nur $40^{\circ}$, der kleiner wird mit der Annäherung des Stammastes an die Spitze der Kolonie (Fig. 66). Die Endzweige verlaufen theilweise parallel dem Stamme.

Jeder Stammast verzweigt sich meist nahezu in einer schwach gebogenen Ebene und zwar ziemlich regelmässig, anscheinend

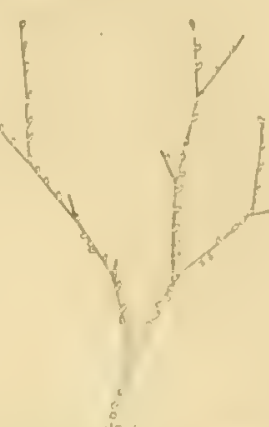

Fig. 67. Chr. pintasticha: Stammast. mehrere Zweige sind abgebrochen. $\times 1 / 2$. dichotomisch, sodass der Hauptast nicht erkennbar ist (Fig. 67) Der Winkel, welchen die Aeste bei der Gabelung bilden, ist stets klein, wohl selten mehr als $45^{\circ}$. Die Zahl der successiven Internodien eines Hauptastes ist 4 bis 5 ; die Länge der Internodien ist II bis $27 \mathrm{~mm}$., die der Endinternodien bis $30 \mathrm{~mm}$., ja eins ist sogar 4 I mm. lang. Die A chsen sind gelblich mit schwachem Goldglanz.

Rinde des Stammes unten, bei dem Ursprung des untersten Stammastes, mit einer nahezu geschlos-

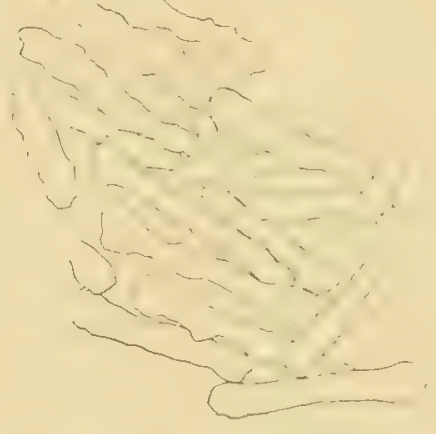

Fig. 6S. Chr. pentasticha. Rindenscleriten rom untersten Theile des Stammes, in nat. Lage. $X 145$. senen Schicht von Kalkkörpern; letztere sind in einer Richtung erheblich verlängerte Schuppen mit meist nur schwach gebuchteten Rändern (Fig. 68) und erreichen eine Länge von 0, I $8 \mathrm{~mm}$. und eine Breite von o,03 mm.. Nach der Mitte des Stammes zu werden die Rinden.

Scleriten grösser, weniger zahlreich, mit weit unregelmässiger gebogenen Rändern (Fig. 69); die meisten sind weniger als 0,35 mm. lang und $0,06 \mathrm{~mm}$. breit, vereinzelte aber viel grösser, so eins $0,67 \mathrm{~mm}$. lang und etwa $0,08 \mathrm{~mm}$. breit. Die Scleriten der stärkeren Zweige sind denen der Fig. 69 gleich; auf den dünneren Zweigen

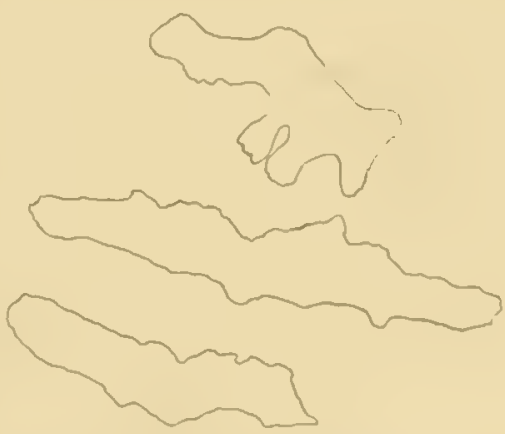

IFig. 69. Chr. penlasficha. Scleriten von der kinde der Stamm-.1litte. $X 145$. sind die Kalkkörper vielfach länger und relativ schmäler (z.B. $0,4+4 \mathrm{~mm}$. lang und $0,05 \mathrm{~mm}$. breit). Nur wenige Scleriten zeigen Wärzchen und dann immer nur vereinzelte; das beinalıe vollstiindige Fehlen derselben ist ein deutlicher Unterschied gegenuber Chr. flcxilis und Chr. affinis. sIROGA-FXPEDTTE: XII. 
II'ie bei diesen Arten sind auf den Aesten, bei Clr. pontasticha ausserdem auch auf dem

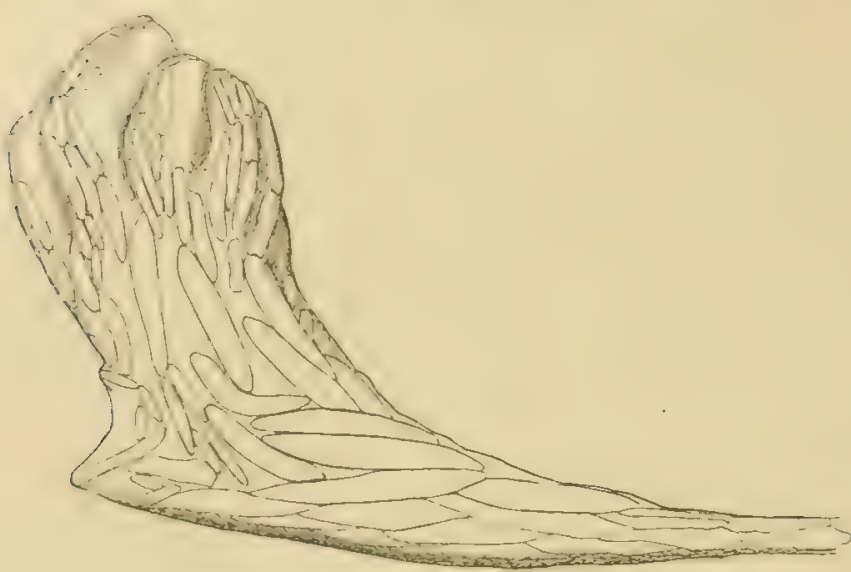

Fig. 70. Chr. pontasticha. Terminaler Polyp. $\times 40$.

Stamm, bedeutende Längsstreifen der Rinde ohne Scleriten.

Nematozoöide fehlen.

Die oberen $\% / 3$ des Stammes mit i oder 2 Polypen auf jedem Internodium, der untere Theil ohne Polypen. Aeste mit 4 bis I 3, meist 6 bis 7 Polypen auf jedem Internodium. Ihre Entfernung wechselt von $\mathrm{I}^{1} / 2$ bis $6 \mathrm{~mm}$. (Fig. 67).

Die Polypen sind mit zusammengelegten Tentakeln meist weniger als 1,6 mm. lang, mit vorgestreckten Tentakeln 2 bis $2,5 \mathrm{~mm}$. und wenn sie mit Geschlechtsprodukten gefüllt sind,

oft noch etwas länger; im letzteren Falle ist die Polypen-Basis stark erweitert. Die Rumpflänge der ausgewachsenen Polypen ist $0,8 \mathrm{~mm}$. Einige, namentlich die terminalen Polypen, welche der Zweigspitze genähert sind, zeigen eine längs dem Zweige proximalwärts ausgezogene Basis (Fig. 7O).

Polypen-Rumpf mit acht deutlichen septalen Reihen von Spicula. Diese Kalkkörper sind auf dem Querschnitt nahezu rund, haben gerundete stumpfe Enden und zeigen mässig zahlreiche Wärzchen auf der Oberfliche (Fig. $7 \mathrm{I}, \mathrm{A}$ ); sie sind bis $0,42 \mathrm{~mm}$. lang, bis $0,083 \mathrm{~mm}$. breit. In der Polypen-Basis sind die Spicula meist grösser und bilden eine nahezu vollständige Schicht, falls nicht die Polypen-Basis durch Geschlechtsprodukte besonders ausgedehnt ist. Letztere Spicula sind aber meist

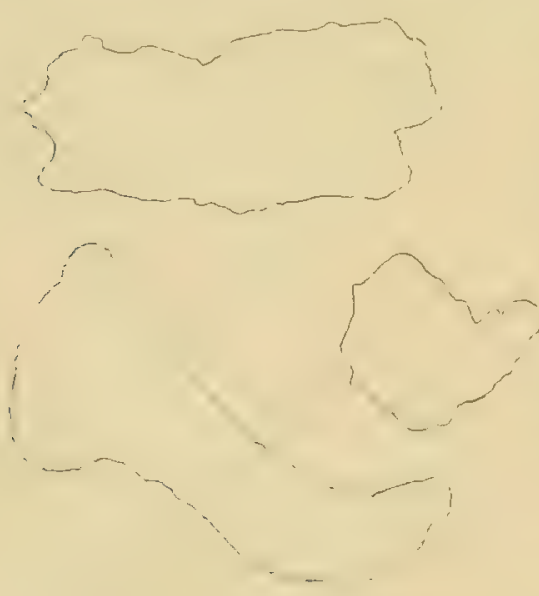

Fig. 72. Chr. fontasticha. Schuppen der Polypen-Basis. $\times 193$. weniger dick, mitunter nur halb so dick als breit; an den Enden oft zugespitzt und nur mit wenigen $W$ ärzchen bedeckt (Fig. $7 \mathrm{I}, \mathrm{B}$ ): bis $0,62 \mathrm{~mm}$. lang und 0, I I mm. breit; meist aber beträgt die Länge 0,4 bis $0,5 \mathrm{~mm}$, die Breite 0,05 bis $0,075 \mathrm{~mm}$.. Nach innen von diesen Scleriten liegt auf der Polypen-Basis eine Schicht glatter, diuner Schuppen (Fig. 72), welche mit den Rändern oft über einander liegen ${ }^{3}$ ); ihr grösster Durchmesser ist bis $0,25 \mathrm{~mm}$.. Es giebt vermittelnde Formen zwischen Schuppen und Spicula.

Auf der Aussenseite der Tentakel liegen, von der Basis bis zur Mitte, $2-4$ Spicula, wie die des Rumpfes, nur kleiner, in einem Streifen neben einander. Von der Mitte der Tentakel bis zur Spitze liegen kleine Schuppen wie bei den anderen Arten dieser Unter-Gruppe. Die Scleriten 
der Tentakel-Seiten und Pinnulae sind klein, dinn und wenig zahlreich (auf Fig. ;o sind dieselben nicht angegeben, weil sie zu undeutlich waren).

Die zweite Kolonie der Siboga-Sammlung ist nur $90 \mathrm{~mm}$. hoch; sie unterscheidet sich von der grossen Kolonie durch den noch unregelmässigeren Stand der Stammäste, sodass stellenweise die Anordnung derselben in fünf Verticalreihen gänzlich rerschwunden ist. Die Ast-Internodien sind kürzer, meist $\pm 10 \mathrm{~mm}$. lang, mit 2 bis 8 Polypen. Der Stamm trägt gar keine Polypen. Auch die Länge der Stamm-Internodien ist kleiner, nur 2,5 mm. gegen $3,5 \mathrm{~mm}$. bei der grösseren Kolonie. Da die Exemplare aber sonst sehr genau stimmen, ist es sehr wahrscheinlich, dass sie zu einer Art gehören. Die meisten Unterschiede sind gradueller Art und können sehr gut Folge verschiedener Wachsthums-Bedingungen sein. Auch das Fehlen der Polypen auf dem Stamme is nicht so wichtig, dass ich darauf eine Trennung in zwei Arten zu begründen wage. Der Habitus ist, soweit der Grössenunterschied ihn nicht beeinflusst, derselbe.

$\checkmark$ on den beiden vorhergehenden Arten unterscheidet sich Chr. pontasticha namentlich durch die längeren, stark aufwärts gerichteten Stammảste mit langen, mehrere Polypen tragenden Internodien und durch die beinahe immer ganz glatten Coenenchym-Scleriten.

Geographische Verbreitung: nur an einer Stelle in der 'Timor-See erbeutet.

II. Clirysogorgia anastomosans nov. spec.

Stat. I45. $\quad 0^{\circ} 54^{\prime}$ S., I $28^{\circ} 39^{\prime} .9$ O. Bei den Vidi-Inseln. 827 MI. Harter Boden. Einige Fragmente. Stat. 297. $10^{\circ} 39^{\prime}$ S., $123^{\circ} 40^{\prime}$ O. Oestlich von Rotti. 520. M. Weicher Schlamm. Ein Fragment.

Die vorliegenden Fragmente genügen nicht ein vollständiges Bild der Art zu geben; ich habe dieselbe trotzdem beschrieben, wegen der eigenthümlichen, vielfachen Verzweigung der Aeste und der zahlreichen Anastomosen derselben. Dass trotz der anscheinend ganz regellosen Verzweigung dennoch die oben S. 23 erörterte Regel der einseitigen Zweigabgabe Geltung hat, geht mit genügender Wahrscheinlichkeit daraus hervor, dass dieselbe für ein ganz ähnlich verzweigtes Fragment einer anderen Art, welche oben unter $\mathrm{N}^{0}=$ aufgefuhrt wurde zutrifft.

Die Beschreibung beruht auf den Fragmenten von der Stat. I 45 ; das Fragment von der Stat. 297 wurde lediglich damit verglichen und die Identität festgestellt. Von einem Stamm liegt nichts vor; die Fragmente sind nur Theile von Aesten. Das grösste Fragment ist in Fig. 73 abgebildet; sie giebt ein besseres Bild von der Verzweigung als eine lange Beschreibung. Bei den Anastomosen legen zwei Aeste sich gegen einander und werden durch gemeinsame neue Schichten der Achsensubstanz verbunden; die Aeste lassen sich aber jenseits der Verwachsungs-Stelle weiter verfolgen.

Die Ausbreitung eines Astes findet vorherrschend in einer Ebene

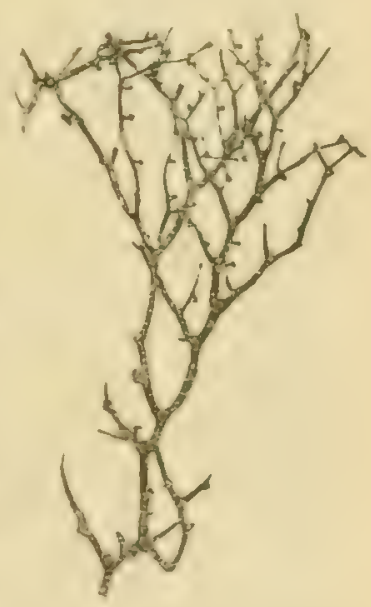

Fig. 73. Chr. anasionterns. Frament, etwas verkleinert. statt; aber die diinneren Zweige sind alle mehr oder weniger nach derselben Seite dicser Ebene gekehrt, wodurch namentlich alle stärkeren Aeste deutlich eine Unterscite ohne Zweigre und eine Oberseite mit Seitenzweigen unterscheiden lassen; der Unterseite fehlen auch Polyjen.

Der stïrkste Ast hat im Anfang einen Durchmesser von $3,5 \mathrm{~mm}$., das ist viel mehr 
als bei den vorhergehenden Arten. Die Länge der Ast-Internodien ist meist 4 bis $5 \mathrm{~mm}$., niemals erheblich mehr; oft sind die Internodien sanft gebogen. Die Achse ist bräunlich-grelb mit starkem Goldglanz: Rinde mässig dick, den Goldglanz der Achsen etwas verdeckend. Die

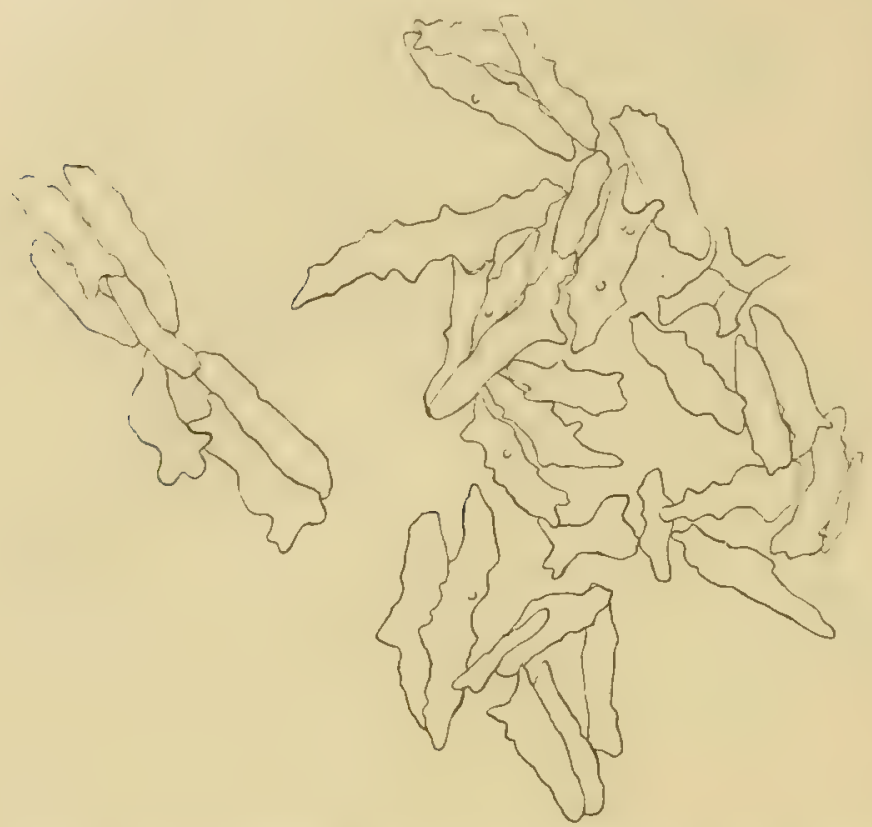

Fig. 74. Chr. anastomosans. Scleriten der Rinde in nat. Lage. $\times 104$ Rinden-Scleriten liegen in regellosen Gruppen, auf den dünneren Zweigen mehr in Streifen parallel den Achsen; sie sind alle dünn und bilden oftmals Schuppen mit unregelmässig gebuchteten Rändern, wie aus Fig. 74 ersichtlich ist. Einige zeigen I bis 4 kleine Wärzchen, die Mehrzahl ist aber ganz glatt; die meisten $0,2 \mathrm{~mm}$. oder weniger lang, einer war $0,25 \mathrm{~mm}$. lang.

Ich fand keine Nematozoöide, wohl aber eine Anordnung besonderer Zellen, wahrscheinlich Nesselzellen, in kleinen Gruppen (vergl. S. 32).

Polypen fehlen auf der Unterseite der stärkeren Aeste; sonst überall regellos verbreitet; meist I oder 2, mitunter auch 3 oder 4 Polypen auf einem Internodium. Die Polypen sind nicht gross, haben alle ihre Tentakel zusammengelegt und sind dann höchstens I,6 mm., meist nur $\mathrm{I}, 3$ bis I,4 mm. lang; die Rumpflänge ist etwa $0,6 \mathrm{~mm}$., der Querdurchmesser des Rumpfes 0,5 bis $0,6 \mathrm{~mm}$.

Die Polypen (Fig. 75) sind in der Form und Vertheilung der Scleriten denen von Chr.

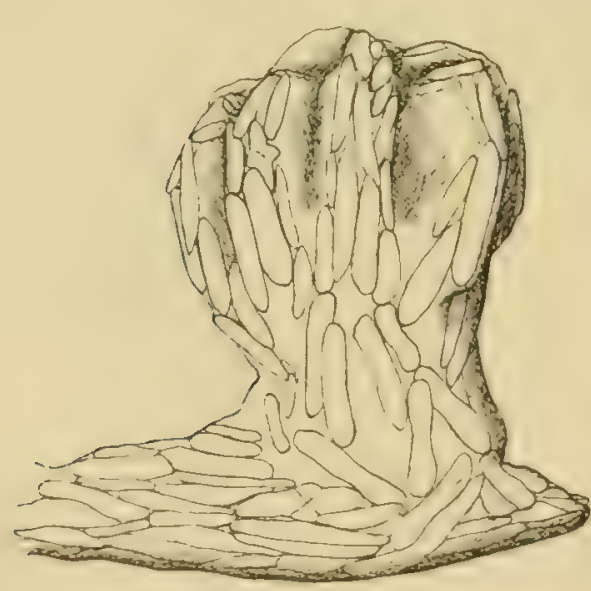

Fig. 75. Chr. anastomosans. Polyp. $\times 42$. flexilis sehr ähnlich, namentlich liegen in dem distalen Theil der Tentakel keine Spicula, sondern dieselben kleinen Schuppen, wie bei den vorhergehenden Arten dieser Unter-Gruppe. Die Spicula der \& septalen Längsreihen sind auf dem Querschnitt rund oder breit-oval; die Enden derselben stumpf gerundet; einige in der Mitte schmäler als an den Enden. Die Höckerchen ihrer Oberfläche sind relativ nicht zahlreich und nur niedrig (Fig. 76). Die Länge dieser Scleriten ist bis $0,31 \mathrm{~mm}$, ihre Breite bis $0,08 \mathrm{~mm}$; in der Tentakel-Basis werden die Spicula noch etwas grösser, so fand

ich eins von $0,36 \mathrm{~mm}$. Länge.

In der Polypen-Basis liegen ziemlich viele Kalkkörper welche eine nahezu geschlossene Schicht bilden; namentlich zahlreich sind dieselben bei den Polypen deren Basis durch Geschlechtsprodukte ausgedehnt ist. Die

Fig. 76 .

Clir. anasioniosans. Spiculum aus der Mitte des l'olypen-Kumpfes. $\times 145$. Scleriten werden hier bis $0,4 \mathrm{I} \mathrm{mm}$. lang; die Mehrzahl ist stark abgeplattet und trägt keine Wärzchen (Fig. 77); dadurch nähern diese Scleriten sich denen der Rinde, sind aber meist 
erheblich dicker. Ihre Dicke beträgt meist ein Viertel bis die Hälfte der Breite. Viele haben spitze Enden. Diese glatten abgeplatteten Kalkkörper entsprechen offenbar den Schuppen der Polypen-Basis bei Chr. flexilis; doch sind nur wenige derselben so dünn wie Schuppen.

Die Scleriten bei den Bases der Pinnulae sind wenig zahlreich, ziemlich lang, aber sehr dün und dadurch undeutlich.

Die Aehnlichkeit, welche die Polypen der Chr. anastomosans mit denen der vorhergehenden drei Arten zeigen, macht es warscheinlich, dass sie diesen sehr nahe verwandt ist. Demgemäss lässt sich vermuthen, dass ihre Kolonien gleichfalls einen Stamm haben, der nach fünf Seiten Stammäste abgiebt, conform der Formel $\%$. Anastomosen der Zweige fand ich vereinzelt auch bei Chr. flexilis. Ich habe denn auch gemeint Chr. anastomosans in die zweite Unter-Gruppe stellen zu können.

Geographische Verbreitung: nur die beiden oben erwähnten Fundorte im Ost-Indischen Archipel.

$\mathrm{Zu}$ diese Unter-Gruppe $A 2$ gehört vielleicht auch Chr. spiculosa Verrill; dieselbe ist aber ungenügend bekannt.

\section{Unter-Gruppe $A 3$.}

Aststand regellos, bei einer Art sind die Kolonien fächerförmig ausgebreitet. Scleriten der Polypen-Basis quer, einen Ring bildend; die der oberen Hälfte des Rumpfes deutlich längsliegend und sich nach der Basis zu unter die queren Scleriten schiebend.

Diese Unter-Gruppe enthält die Arten, die zu VERrill's Genus Chry'sogorgia gehören.

\section{Chrosogorgia orientalis nov. spec.}

Stat. I70. $3^{\circ} 37^{\prime} .7$ S., I $31^{\circ} 26^{\prime} .4$ O. Oestliche Ceram-See. 924 M. Feiner, grauer Schlamm. 2 Ex.

Stat. 300. $10^{\circ} 4 S^{\prime} \cdot 6$ S., $123^{\circ} 23^{\prime} \cdot 1$ O. Ostküste von Rotti, Timor-Sec. 9 IS M. Feiner, grauer Schlamm. I Ex.

Von den drei Kolonien trägt nur die in Fig. 78 abgebildete von Stat. I 70 noch mehrere vollständige Stamm. äste und eine grössere Zahl von Polypen. Auf sie stïtzt sich vornehmlich die nachfolgende Beschreibung. Ihr fellt zwar die Basis. dieselbe ist aber bei den zwei anderen Kolonien erhalten und zeigt, dass diese Art mit verzweigten, verkalkten, ganz weissen Stolonen im Schlammboden verankert ist.

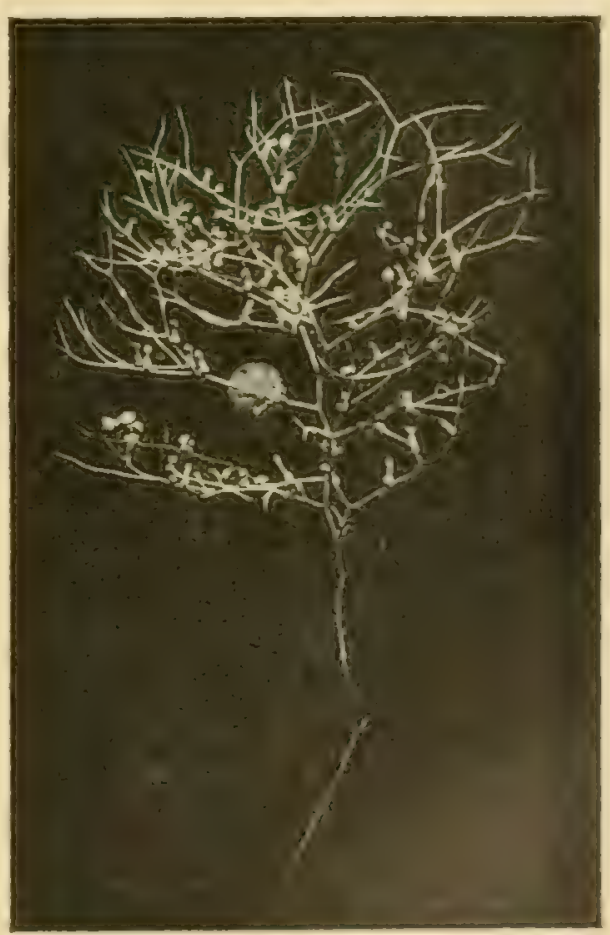

Hig. 78. Chr. oricntalis. Liolonic in nat. Cirosse.

Die Höhe der beiden letzten Kolonien ist I It und $105 \mathrm{~mm}$, beide sind aber oben 
abgebrochen; die abgebildete Kiolonie hat einen erheblich stärkeren Stamm und war vermuthlich eher länger als kiurzer als die beiden anderen.

Die Stammäste entspringen in einer linksgewundenen Spirale vom Stamme. Der Divergenz-

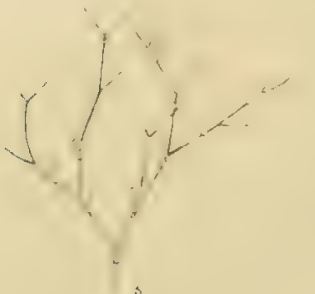

Fig. 79. Stammast von Chr. orientalis. $\mathrm{S}=$ Lisprung vom Stamm; nat. Gr.

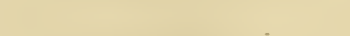
Winkel zwischen zwei folgenden Stammästen der Spirale ist bisweilen nahezu I $20^{\circ}$, also entsprechend dem Aststand ${ }^{1} / 3$, bisweilen nahezu $144^{\circ}$, entsprechend dem Aststand $\%$. Die Länge der Stamm-Internodien ist 4 bis $5 \mathrm{~mm}$; der unterste Astursprung ist etwa $30 \mathrm{~mm}$. von der Stamm-Basis entfernt. Die unteren Stammäste sind bei allen drei Kolonien über eine erhebliche Länge des Stammes abgebrochen.

Die Stammäste sind wenig, nur die nahe der Spitze der Kolonie etwas stärker aufgerichtet; sie sind bis $30 \mathrm{~mm}$. lang und haben bis $z$ 6 Internodien (Fig. 79). Die Verzweigung findet in sehr verschiedenen Ebenen statt, jedoch so, dass die Stammäste sich vorherrschend quer zum Stamme ausbreiten. Der Winkel der

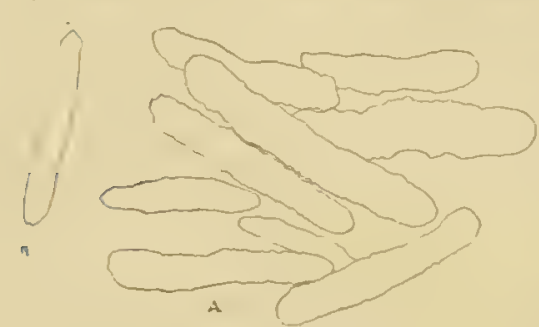

Fig. So. Chr. orientalis. Kinden Scleriten,

A a. d. Stamm-Basis in nat. I.age,

I3 a. d. Stamm-Mitte. $X \geq 16$. Gabelung beträgt meist zwischen $90^{\circ}$ und $65^{\circ}$, selten ist er grösser oder kleiner. Die Internodien der Aeste sind 5 bis $9 \mathrm{~mm}$. lang, die End-Internodien sogar bis $14 \mathrm{~mm}$.

Rinde des Stammes unten, wo keine Stammäste abgehen, mit einer Schicht langer dünner Scleriten, mit unregelmässig gezähntem Rand, mit nur vereinzelten, sehr kleinen Wärzchen oder ohne diese; an den stumpfen Enden oft feiner und mehr regelmässig gezähnt (Fig. So, A). Länge derselben bis 0,26 mm., meist aber weniger als $0,2 \mathrm{~mm}$., Breite meist zwischen 0,035 und $0,04 \mathrm{~mm}$. Höher oben auf dem Stamme sind die Kalkkörper viel weniger zahlreich und fehlen in ganzen Strecken der

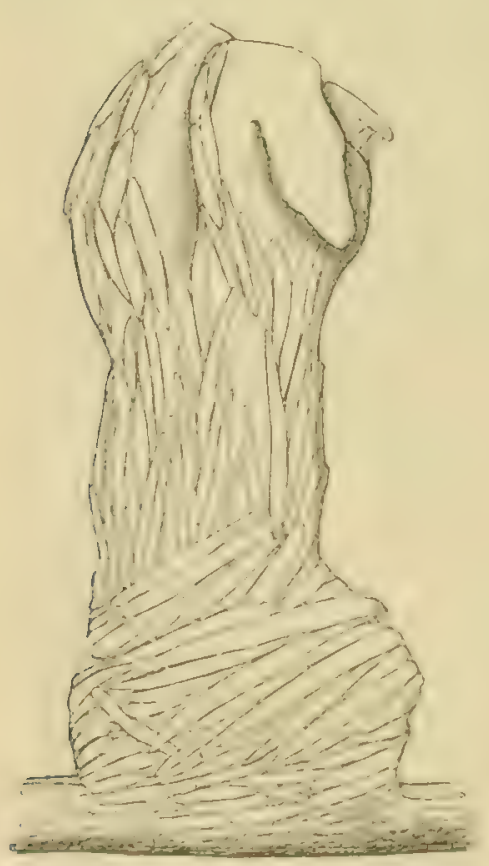

Fig. Sr. Chr. oricutalis. 1'olyp. $\times 34$. Rinde; auch sind sie dort schmäler, kaum mehr als $0,03 \mathrm{~mm}$. breit und nahezu ganzrandig (Fig. So, B). Auf den Aesten sind die Scleriten wieder zahlreicher, meist, namentlich auf den dünneren Zweigen, eine Schicht ohne grössere Lücken bildend; ihre Form ist wie die der Kalkkörper der Stamm-Basis, nur bisweilen mit unregelmässiger gebuchteten Seitenrändern.

Nematozooide fehler.

Stamm ohne Polypen; Aeste mit einem, ausnahmsweise mit 2 Polypen auf jedem Internodium.

Die Polypen sind mit zusammengelegten Tentakeln bis $2,75 \mathrm{~mm}$. lang; Rumpflänge 1,2, sogar bis 1,6 mm.; Querdurchmesser des Rumpfes 0,65 bis $0,8 \mathrm{~mm}$., an der Basis oft bis I mm. und wenn der Polyp Geschlechtsprodukte enthält, noch mehr. Seine Basis ist in diesem Falle stark verbreitert; andernfalls haben die Polypen cinen lang-cylindrischen Rumpf. Rumpf-Scleriten der oberen Hälfte längsliegend, in der Polypen-Basis aber quer (Iiig. 8I), was die typische Anordnung bei dieser Unter-Gruppe ist. Die Scleriten sind von zweierlei Art: erstens lange, spitze, dicht mit kleinen Wärzchen bedeckte Spicula, beinahe bis 
$1 \mathrm{~mm}$. lang, auf dem Querschnitt rund oder nur wenig abgeplattet (Fig. S2, A), zweitens kleinere, sehr dünne Scleriten, ohne Wärzchen, meist auch viel länger als breit (Fig. S2, B, C, D). Uebergangs-Formen sind zahlreich.

In der oberen Hailfte des Polypen-Rumpfes und in den Tentakel-Rücken fand ich beinahe nur typische Spicula. In einigen Polypen (Fig. 8 I ) zeigten dieselben im Rumpfe eine Anordnung in 8 Streifen (ob septal konnte ich nicht feststellen), bei anderen lagen sie in einer geschlossenen Schicht. Nach der Tentakel-Spitze zu werden die Spicula sehr klein, ändern aber ihren Typus nicht.

Die längsliegenden Scleriten setzen sich bis auf die basale Hälfte des Rumpfes fort, werden dabei aber meist dünner, während die

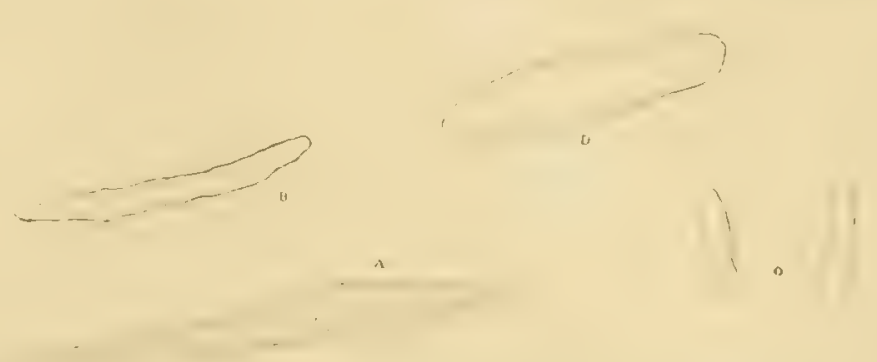

Fig. S2. Chr. orientalis. A Spiculum a. d. Kumpf-IItte cines Polypen; 13 Schuppen a. d. Polypen-Basis; C und D a.d. inneren Schicht der Polypen-Basis. A, B und $\mathrm{C} \times$ So, $\mathrm{D} \times 193$.

Wärzchen schwinden (Fig. S2, B); sie werden aber dort von den querliegenden Kalkkörpern uiberlagert (Fig. 8I). Letztere sind zum Theil typische Spicula, wenn auch meist deutlich abgeplattet, die Mehrzahl ist sogar ziemlich dünn und mit wenigen oder ohne Wärzchen. Die längeren sind immer parallel der Oberfläche der Polypen gebogen. Nach innen von dieser Schicht liegen unregelmässig gelagerte Schuppen, wie sie in der Fig. 82 bei C und D abgebildet sind. Dieselben bilden hier eine dichte Schicht, sie sind den Scleriten der Rinde ähnlich und sind die Fortsetzung der Schicht dieser Scleriten in der Polypen-Basis.

In den S'eiten der Tentakel, bei den Pinnulae, liegen zerstreut sehr diinne, ziemlich lange, an den Enden stumpfe Kalkkörper (dieselben waren nicht deutlich genug, um sie in Fig. $\delta 1$ einzuzeichnen; die Tentakel waren stets undeutlich und ich konnte dieselben in dieser Figur nur etwas schematisch angeben).

Die Polypen der einen, auf Stat. 300 erbeuteten Kolonie weichen nicht unerheblich darin ab, dass die Scleriten ihrer Basis alle sehr dünn sind, ohne Höcker und dass sie theilweise schräg, anstatt nahezu quer liegen. Da nur wenige Polypen dieser Kolonic vorhanden sind, konnte ich nur drei derselben untersuchen, die alle die nämliche Abweichung zeigten. Aber auch bei der typischen Kolonie ist die quere Anordnung der Scleriten auf der Polypen-Basis oft weniger deutlich als beim abgebildeten Polypen. Dieser Unterschied genugt aber nicht um darauf die Kolonie der Station 300 als besondere Art aufzustellen.

Geographische Verbreitung: im Ost-Indischen Archipel, in Tiefen ron 918 und 92+ MI., auf Schlammboden.

I3. Chrysogorgia fewkesi Verrill.

Chry'sogorgia desbonni Pourtales, Bull. Mus. Comp. Zool., vol. I, i868, p. I31 (nach Verrate's Angabel.

Chrysogorgia ferukesi Verrill, Bull. Mus. Comp. Zool., vol. II, I883, p. 26.

Diese, durch die Blake-Expedition erbeutete Art habe ich nicht gesehen; ich verweise daher auf die, anscheinend genügende, Beschreibung, welche VERrilt gegeben hat. Nach derselben 
unterscheidet sich diese Art von Chr. oricntalis durch die warzigen Rinden-Scleriten und die stärker verzweigten Aeste (T'ERrill S. 26: „final branchlets numerous"). Auch ist es eine viel stärkere, namentlich breitere Art; so ist eine Kolonie von Chr. ferukesi. I $10 \mathrm{~mm}$. breit und I jo mm. hoch, gegenüber Chr. orientalis von nur $40 \mathrm{~mm}$. Breite und einer Höhe von wahrscheinlich mehr als $100 \mathrm{~mm}$..

Geographische Verbreitung: Bei St. Vincent an verschiedenen Stellen und bei Cuba.

"I4. Chrysogorgia occidcntalis n. n.

Chrysogorgia desbonni Verrill (nec. Duchassaing \& Michelotti), Bull. MLus. Comp. Zool., vol. I I, 1883 , p. 25.

Die von VERrill als Chr. desbonni beschriebene Art unterscheidet sich in einigen wichtigen Eigenschaften von Chr. desbonni Duch. \& Mich. Erstens ist VerriLl's Art fächerförmig verzweigt, die Type von Duchassang und Mrchelotti aber nicht, wie aus der Figur 5, Tafel 4 der Abhandlung ${ }^{1}$ ) von Duchassaing und Michelotti hervor geht. Ferner sind bei letztere Art die Kalkkörper der Polypen nicht Spicula sondern Schuppen, auch fehlt eine Bedeckung der PolypenBasis mit queren Spicula vollständig. Die Form der Polypen ist auch gänzlich verschieden, wie aus den Figuren von Verrill und Duchassaixg und Michelotti ersichtlich ist. Die typische Chr. desbonni Duch. \& Mich. gehört zu den Squamosae.

Die Exemplare, die VERRILl vorlagen gehören also zu einer,anderen und zwar zu einer neuen Art, die ich Chr. occidentalis nennen will. Für die Diagnose muss ich auf VerriLL's Arbeit verweisen:). Durch ihre fächerförmige Verzweigung ist die Art von den anderen Arten dieser Unter-Gruppe und von allen Chrysogorgia-Arten uberhaupt verschieden.

Geographische Verbreitung: an zahlreichen Stellen im Caraibischen Meere, bei den Antillen und bei Cuba, in Tiefen von 158 bis 5 rg M.

"I5. Chrysogorgia squarrosa (Wright \& Studer).

Dasygorgia squarrosa Wright and Studer, Challenger Report, vol. 3I, 1889, p. I4.

Das gebrochene Fragment der Challenger-Sammlung hat einen $105 \mathrm{~mm}$. langen Stamm,

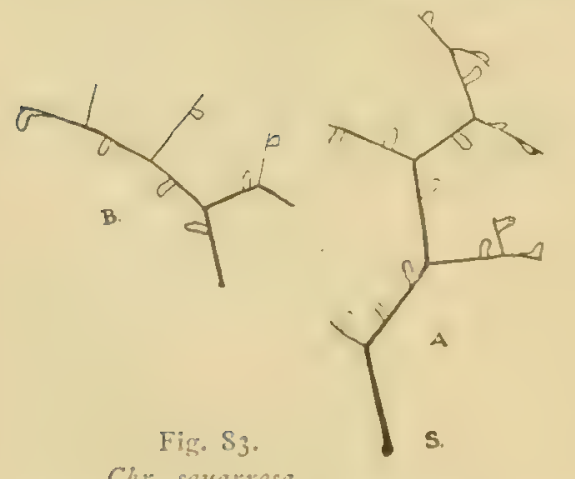

Chr. squarrosu.

Zwei Stammäste. Nat. Grüsse. $\mathrm{S}=$ Stamm. der an beiden Enden abgebrochen ist. Derselbe ist unten I $\mathrm{mm}$., oben kaum $1 / 2 \mathrm{~mm}$. dick; seine Achse is braungoldglänzend. Wo er einen Stammast abgiebt ist er meist nur schwach geknickt. Die Stamm-Internodien sind 10 bis $12 \mathrm{~mm}$. lang. Der Aststand ist regellos, verticale Stammast-Reihen kann man nicht unterscheiden. Die Stammïste sind an ihrer Basis nur wenig düner als der Stamm; sie erreichen eine Länge von etwa $40 \mathrm{~mm}$., vielleicht noch erheblich mehr. Zwei Aeste sind in Fig. $\$_{3}$ abgebildet; der eine (B) zeigt deutlich die einseitige Astabgabe; der andere (A) ist sympodial gebaut (vergl. S. 23). An der Spitze des letzteren Astes erblickt man den jüngsten Seitenast, der

1) Memorie della K. Accad. d. Sc. di Torino, Ser. 2, Tom. 23, IS65; wenn dic Art fächerfürmig rerzweigt wäre, hätten diese Untersucher dies auch wohl milgetheilt.

2) Vergleiche auch weiter unten bei Chr. dishmni Duch. \& Mich.. 
später wahrscheinlich die Fortsetzung des sympodialen Astes bilden wird. Die Textfigur 5, S. It, des Challenger Report giebt auch ein typisches Bild eines Astes. Die Ausbreitung jedes Stammastes findet meist nahezu in einer Ëbene statt; diese Ebene ist aber in Beziehung zum Stamme bei den nachfolgenden Stammisten sehr verschieden gerichtet, meist mehr dem Stamme parallel als senkrecht zu ihm. Die Ast-Internodien sind bis I I mm. lang; die Winkel unter denen die V'erzweigungen stattfinden sind alle stumpfe, oder betragen doch mindestens $90^{\circ}$. Die Rinde von Stamm und Zweigen mit einer nahezu vollständigen, d. h. von grösseren Lücken freien Schicht von flachen Scleriten deren Form und Anhäufung aus Fig. $S_{4}$ ersichtlich ist. Die grosse Mehrzahl dieser Kalkkörper ist sehr dünn, mit etwas unregelmässig gebuchteten Rändern, oft mit kleinen aufgerichteten Leistchen auf ihrer flachen Seite und ohne oder mit nur sehr wenigen Wärzchen: sie sind bis $0,35 \mathrm{~mm}$. lang. Zwischen ihnen liegen, wenigstens in der Rinde des Stammes, mehr zerstreut längere, etwas dickere Scleriten, von denen zwei in Fig. $\delta_{+}$bei A abgebildet sind. Dieselben zeigen hin und

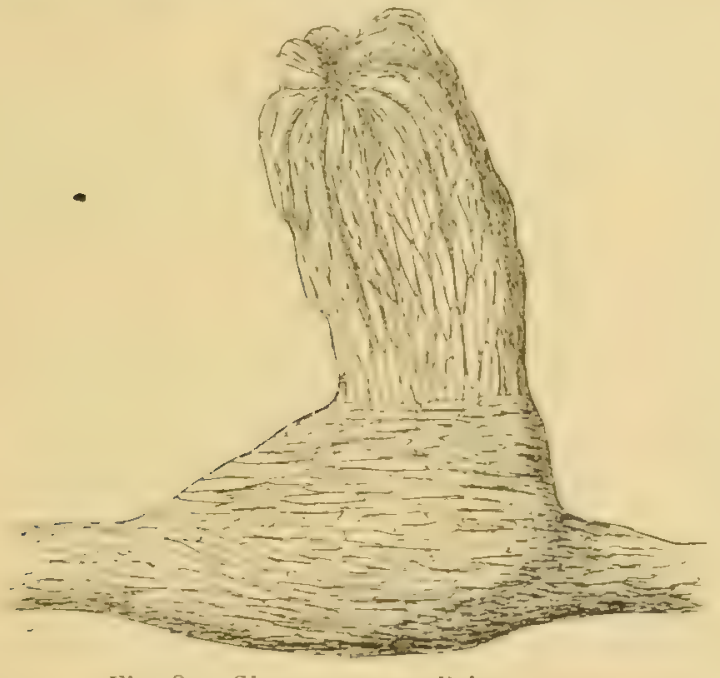

Fig. $\mathrm{S}_{5}$. Clur. siquarosa. l'olyp. $\times 20$ wieder mehrere kleine Wảrzchen, und sind bis etwa $0,6 \mathrm{~mm}$. lang.

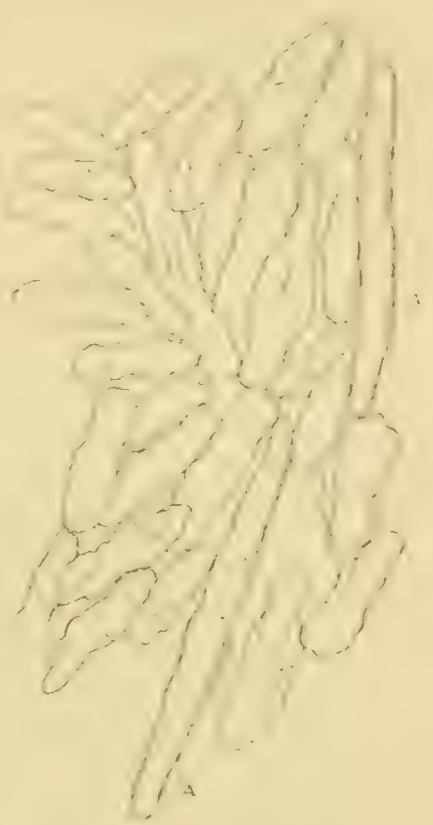

Fig. Sq. Clir. simurrost. Rinden-Scleriten aus der Vitte Auf den diunneren Zweigen fand des Stammes, in nat. Lage. $\times$ So.
ich die letzteren abweichenden Scleriten nicht, doch laben hier die Kalkkörper oft etwas mehr Wärzchen.

Nematozooide fehlen.

Jedes Internodium des Stammes und der Aeste mit einem oder zwei Polypen, die mit zusammengelegten Tentakeln gut $3 \mathrm{~mm}$. Länge erreichen. Sie stehen entweder senkrecht auf den Zweigen, oder sind nach deren Spitze zu geneigt. Meist sind sie cylindrisch, wenn sie aber reifende Geschlechtsprodukte enthalten ist ihre Basis stark ausgedehnt (so in dem in Fig. 85 abgebildeten Polyp).

Die Rumpfwand der Polypen enthält eine nahezu lückenlose Schicht von längsliegenden Scleriten; zu ihr gesellt sich in der Basis eine äussere Schicht von querliegenden Kalkkörpern, welche cinen Ring um die Polypen-Basis bilden, wie das schon bei Chr. oricntalis beschrieben wurde (Fig. 85). Dieser quere Ring ist aber nur bei wenigen Polypen vollständig; meist fehlt er in einem Theil der Polypen-Basis, indem die Scleriten dort zwar zu $2-3$ übereinander liegen, aber schräg und nicht genau quer. Der Ring ist niedrig.

Die Polypen-Scleriten sind von wechselnder Form; die meisten sind sehr dün (Fig. S6, A), ein Theil aber dicker, bis mehr als halb so dick wie breit und diese haben oft eine unebene Oberfäche (Fig. 86, 13).
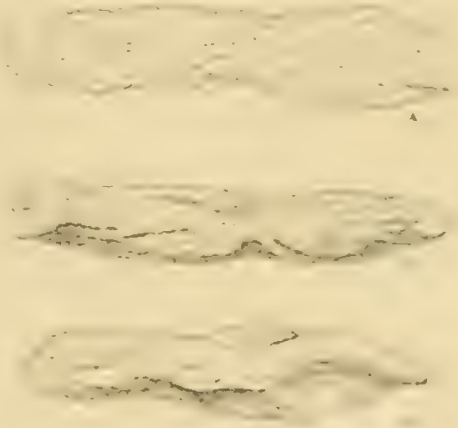

Fig. S6. Chr. sizarmest. kiallkörper der bulypen; .1. li, C: siehe im Text. $\times 1.45$.

Auch kommt es vor, dass die Scleriten, namentlich die dünneren, hohe dünne Leisten auf der SILOCA-F.XPEIITIE XII. 
flachen Seite tragen (Fig. 86, C). Die Oberfläche der Kalkkörper ist rauh, oft höckerig. In der Polypen-Basis sind die Scleriten meist alle dünn, in den Tentakeln dagegen meist dick, die kleineren im Spitzen-Abschnitt der Tentakel auf dem Querschnitt sogar rund und dazu regelmässig mit kleinen Wärzchen bedeckt; es sind also typische Spicula. Letztere fehlen sonst in den Polypen.

Die Polypen-Scleriten sind meist 0,3 bis $0,4 \mathrm{~mm}$. lang, die grössten bis $0,5 \mathrm{~mm}$. In den Seiten der Tentakel an der Basis der Pinnulae liegen nur vereinzelte, sehr düne stabförmige Scleriten, welche nicht in die Pinnulae vorragen.

Diese Art ist, wie die Polypen zeigen und damit stimmt auch der regellose Aststand, warscheinlich mit Chr. oricntalis verwandt. Ich habe sie daher mit letzterer in dieselbe UnterGruppe und zu den Spiculosae gestellt, obwohl Spicula sich nur in den Tentakelspitzen finden. Der Stamm ist warscheinlich sympodial gebaut; ich konnte das aber leider nicht sicher feststellen, namentlich weil der Achsencylinder schwer erkennbar war.

Geographische Verbreitung: nur einmal in der Celebes-See, suidlich von den Philippinen auf Schlammboden in 900 M. Tiefe von der Challenger-Expedition erbeutet.

Die von Fräulein ISA Hiles beschriebene Chrysogorgia constricta ${ }^{1}$ ) gehört nicht hierher, iiberhaupt nicht in die Familie der Chry'sogorgiidae. Sie gehört zwar zu der Familie Dasygorgidae wie Wright und Studer dieselbe gekennzeichnet haben; sie unterscheidet sich aber durch die alternierende Anordnung der Polypen auf zwei Seiten der Achsen und durch die Verzweigung von den typischen Chrysogorgiidae und fällt ausserhalb der Familie Chrysogorgiidae, wie ich dieselbe definiert habe. Ich könnte kein Genus angeben, wozu diese Art dann wohl gehört. Dieselbe nimmt unter den bekannten Arten wohl eine isolirte Stellung ein.

$\mathrm{Zu}$ den Spiculosae gehört auch noch folgende neue Art, welche nicht zu einer der drei obenstehenden Unter-Gruppen gestellt werden kann, für welche ich aber, da es sich leider nur um eine unvollständige Kolonie handelt, auch keine vierte Unter Gruppe aufstellen möchte:

16. Chrysogorgia mixta nov. spec..

Stat. I 22. I $5^{\circ} 8^{\prime} .5$ N., I $25^{\circ} 0^{\prime} .5$ O. Celebes-See, bei Menado. 1264-I165 M. Steiniger Boden. Einige Fragmente, ohne Stamm.

Der laingste, in Fig. 87 abgebildete Ast, erreicht eine Länge von I $5 \mathrm{~mm}$. Ob derselbe ein vollständiger Stammast ist, oder ob ihm noch ein proximaler Abschnitt fehlt, lässt sich nicht entscheiden. Die Verzweigung entspricht der von den anderen Chrysogorgia-Arten bekannten und desshalb kann wohl nicht daran gezweifelt werden, dass auch bei Chr. mixta die Stammäste in eine1 Spirale vom Stamme entspringen. Leider fehlt der Stamm, sudass der Aststand unbekannt ist.

Der längste Ast zählt 6 successive Internodien, die anderen drei Aeste nur 4; die Länge der Internodien wechselt von 15 bis $30 \mathrm{~mm}$., steigt sogar auf $46 \mathrm{~mm}$. für die EndInternodien. Die Achse des grössten Astes ist ganz unten noch weniger als I mm. dick; die

I) The Gorgonacea collected by I)r. WILLEY; WInLEv's Zoological Results, Part. 2, ISS9, S. 195. 
Enden der Zweige sind sehr dünn und biegsam. Die Ausbreitung jedes Astes findet annäherend in einer Ebene statt.

Rinde dünn, mit einer nahezu geschlossenen Schicht von Scleriten; oft liegen diese zu 2 oder 3 über einander. Sie sind lang, dünn wie Schuppen, wie in Fig. 88 abgebildet, mit glatter Oberfläche und sehr fein gezähnten, etwas buchtigen Rändern; bis $0,5 \mathrm{~mm}$. lang und 0, I mm. breit, die Nelırzahl aber zwischen 0,2 und $0,4 \mathrm{~mm}$. lang.

Nematozoöide fehlen.

Polypen ziemlich zahlreich, weitaus die meisten auf einer Seite der Aeste stehend, einige aber hiervon abweichend. Sie sind meist 5 bis $6 \mathrm{~mm}$. von einander entfernt; 2 bis 5 Polypen stehen auf jeden Internodium, auf den End-Internodien auch wohl 6.

Die Polypen sind gross, mit zusammengelegten Tentakeln bis $4 \mathrm{~mm}$. lang und sitzen beinahe alle den Zweigen sehr schräg auf (Fig.

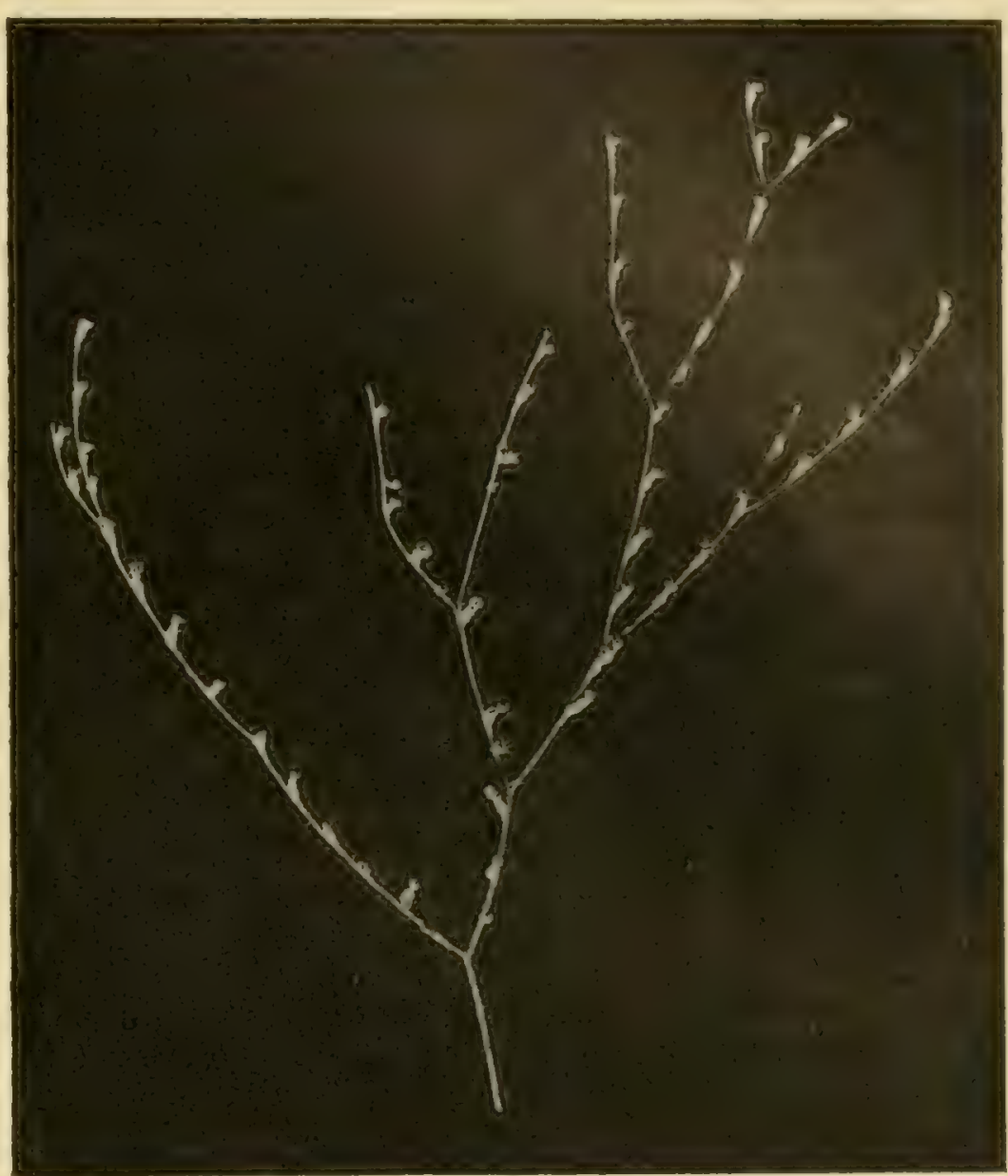

Fig. 87. Fragment von Chr. mixto, nat. Giösse. 87 ), sodass ihre Längsachse einen Winkel von etwa $45^{\circ}$ mit dem Zweige bildet. Dabei ist die Basis der Polypen längs dem Zweige proximalwärts verlängert, wie ausgezogen (Fig. 89).

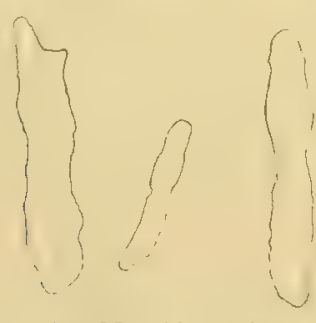

Fig. 8S. Chr, mixtu. Rinden-Scleriten, $\times 60$.

Tentakel-Ruicken bis an die Spitze mit warzigen, stumpfen, auf dem Querschnitt runden Spicula und ohne Schuppen. Auf dem Rumpfe ziehen acht septale Längsreihen von grossen Spicula zur Polypen-Basis (Fig. S9). Die grössten Scleriten liegen in der ausgezogenen P'olypen-13asis, wo 
sie sogar bis $2,5 \mathrm{~mm}$. lang und $0,25 \mathrm{~mm}$. dick werden können. Aber auch die Spicula der anderen Lïngsreihen sind gross, bis $1,5--1,7.5 \mathrm{~mm}$. lang. Neist sind dieselbe an clen Enden zugespitzt, oft gebogen; ihre Oberfläche trägt zahlreiche Wärzchen (Fig. 90). In der Polypen-Basis liegt eine geschlossene Schicht von dünnen Scleriten, mit spitzen oder stumpfen Enden und mit wenigen oder ohne Höckern (Fig. Fig. 90. Clir, mixpa.

Spiculum aus der Basis eines Tentakels. X I 75. 9I, A). Viele derselben, namentlich die mehr nach innen liegenden, sind echte Schuppen mit unregelmässig-buchtigem Rande (Fig. 9I, B). Diese Schicht geht allmählich in das Schuppenkleid der Zweigrinde über. In der Basis der Pinnulae der Tentakel liegen dünne, ziemlich lange, an den Enden

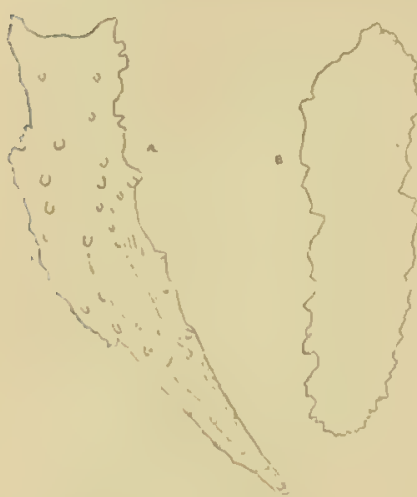

Fig. 91. Chr. mixta. Scleriten aus der Basis eines Polypen; $\Lambda$ obernächlich, 13 tief grelagerte. $\times 145$. stumpf-gerundete, oft etwas verbreiterte; Scleriten, deren Oberfläche mit feinen Wärzchen bedeckt ist. Sie erreichen eine Länge von 0,25, eine Breite von $0,06 \mathrm{~mm}$..

Die Art steht in ihren Polypen den Arten der Unter-Gruppe A 2 am nächsten, ist von ihnen aber durch das Fehlen von Schuppen auf den Tentakel-Rücken verschieden. Sie ist an den ziemlich langen, nicht stark verzweigten Aesten und an den grossen Polypen mit sehr grossen Spicula leicht kennbar.

Von Chr. spiculosa Verrill ${ }^{1}$ ) wird eine ähnliche Ausdehnung der Polypen proximalwärts längs den Zweigen angegeben, aber nur von den endständigen Polypen; diese enthalten auch bei dieser Art besonders grosse Spicula, doch sind dieselben nach VERrilL's Abbildung (1. c. Taf. 2, Fig. 5) nur bis I mm. lang. Daneben unterscheidet Verrill's Art sich auch noch von Chr. mixta durch die unregelmässigere Verzweigung der Aeste und durch die nur etwa halb so grossen Polypen (nach Verrill's Figur zu schliessen; er giebt keine Maasse). Wiewohl eine nähere Verwandtschaft der beiden Arten möglich scheint, ist Verrill's Beschreibung doch zu kurz, dies zu entscheiden.

Geographische Verbreitung: nur einmal in der Celebes-See bei Menado gefunden.

Zu den Spiculosae müssen auch noch folgende Arten gestellt werden:

*7. Chrysogorgia agassizii (Verrill).

Dasygorgia agassizii Verrill, Bull. Mus. Comp. Zool., vol. I I, I883, S. 22.

Dasygrorgia agassizii L. Roule, Campagne du Caudan, Annales de l'Université de Lyon, IS96, S. 304 .

Ich habe diese Art nicht gesehen. Die Polypen-Scleriten sind meist abgeplattet; typische Spicula mit warziger Oberfläche liegen nach Verrill's Beschreibung nur in der Nähe der Tentakel und in den Tentakeln selber. Aststand $\%$.

Geographische V'erbreitung: im Nord-Atlantischen Ocean bei George's Bank in 2236 M. (Blake-Exp.) und im Golf von Gascogne in 570 bis 700 und in I710 M. (Camp. du Caudan). 
Is. Chry'sogorgia spiculosa (Verrill).

Dasy'gorgia spiculosa Verrill, Bull. Mus. Comp. Zool., vol. I1, 1883 , S. 23.

Die von Wrigirt und Studer hierher gerechneten Kolonien der Challenger-Ausbeute gehören nicht zu dieser Art (vergleiche oben bei Chr. affinis, S. 47).

Ich habe die Art nicht gesehen; der Aststand ist angeblich

Geographische Verbreitung: in West-Indien an 6 verschiedenen Orten, bei Dominica, Martinique, St. Vincent und Santa Lucia, in 600 bis etwa Iooo M. Tiefe (Blake-Lxp.).

i 9. Chrysogorgia splendens (V'errill). Dasy'gorgia splendens Verrill, Bull. Mius. Comp. Zool., vol. i1, $188_{3}, \mathrm{~S} .25$.

VERrill's Beschreibung genügt nicht, diese Art mit Bestimmtheit einreihen zu können. Nir blieb sie unbekannt.

Geographische Verbreitung: sie wurde nur bei Santa Cruz in IVest-Indien an zwei Stationen von der Blake-Expedition erbeutet in I050 MI. Tiefe.

20. Chysogorgia clegans (Verrill).

Dasy'gorgia elegans Verrill, Bull. Mus. Comp. Zool., vol. II, $188_{3}$, S. 23.

Auch diese Art habe ich nicht gesehen; sie steht nach Verrilu der Chr. agassizii sehr nahe; im Polypen-Rumpf liegen warzige Spicula.

Geographische Verbreitung: bei Grenada und bei Barbados in 427 bis 625 M. Tiefe auf drei Stationen von der Blake-Expedition erbeutet.

\section{Gruppe B. Squamosae aberrantes.}

Polypen im Rumple nur mit sehr dünnen, schuppenförmigen Kalkkörpern, in den Tentakeln aber mit dicken, unregelmässigen Scleriten, welche theilweise echte Spicula sein können: bei einer Art liegen ausschliesslich typische Spicula in den Tentakeln.

\section{Unter-Gruppe BI.}

Tentakel-Rücken nur mit typischen Spicula; Polypen-Rumpf mit einem vollständigen typischen Schuppenkleid; Aststand unbekannt.

21. Chry'sogorgia intermedia nov. spec.

Stat. $297.10^{\circ} 39^{\prime}$ S., $123^{\circ} 40^{\prime}$ O. Oestlich von Rotti. 250 MI. Weicher, grauer Schlamm. Fragmente.

Ein Stamm wurde nicht erbeutet; da aber die Aeste ganz ähnlich wie bei anderen Chrysogorgia-Arten verzweigt sind, werden auch die Kolonien der Chr. intermedic wohl einen Stanm haben, von welchem die Acste in einer mehr oder weniger regelmässigen Spirale abgehen. 
Es liegen zwei Fragmente vor (Fig. 92); ob dieselben vollständige oder doch nahezu

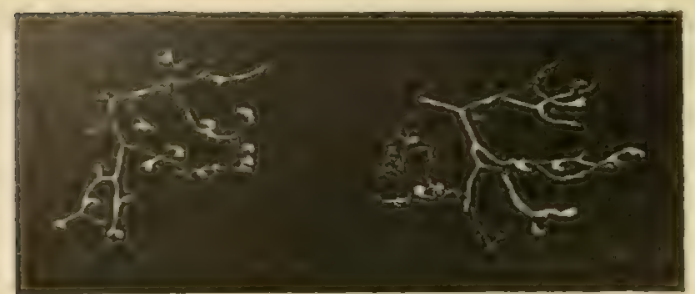

Fig. 92. Chr. inermedia. Fragmente; nat. Grösse. vollständige Stammäste sind, ist nicht mit Gewissheit $\mathrm{zu}$ entscheiden, scheint mir aber wahrscheinlich wegen des Fehlens von Polypen auf den proximalen Internodien; auch spricht die erhebliche Breitenausdehnung der Fragmente dafür.

Die Fragmente zeigen sechs nachfolgende Internodien; sie sind nicht in einer Ebene ausgebreitet. Die beiden Aeste einer Gabelung sind oft ungleich stark, oft aber nahezu gleich dick. Die Internodien sind bisweilen schwach gebogen, geschlängelt und 2 bis $7 \mathrm{~mm}$. lang. Die Achsen sind blass-ockergelb, glänzend, mit nur sehr schwachem Goldglanz.

Rinde dün, mit wenigen, regellos zerstreuten, oft in kleinen

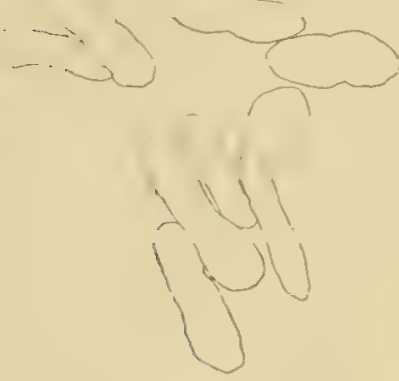

Hig. 93. Chr. intermedia. Scleriten der Rinde eines Astes, in mat. I.a.re. $X I+5$. Gruppen beisammenliegenden Scleriten, die sehr dünne glatte Schuppen sind, deren Form aus Fig. 93 ersichtlich ist. Ihr Rand ist äusserst fein gezähnelt; Länge bis $0,13 \mathrm{~mm}$., Breite bis $0,032 \mathrm{~mm}$; einige Schuppen sind nahezu rund.

A uf den vorliegenden Fragmenten fand ik keine Nematozooiden; daraus kann aber auf ihr Fehlen auf dem Stamme nicht geschlossen werden.

Je ein oder zwei Polypen nur auf den letzten und vorletzten Ast-Internodien. Sie sind nicht auf eine Seite der Zweige beschränkt. Ihre Länge beträgt, mit zusammengelegten Tentakeln, I, 8 bis $2 \mathrm{~mm}$.; Rumpflänge 0,65 bis $0,8 \mathrm{~mm}$., Querdurchmesser des Rumpfes bis $0,75 \mathrm{~mm}$.

Polypen-Rumpf mit einer zwei- bis dreifachen Schicht sehr dünner Schuppen, welche regellos über einander liegen und meist in einer Richtung erheblich verlängert und alsdann häufig quer dazu in

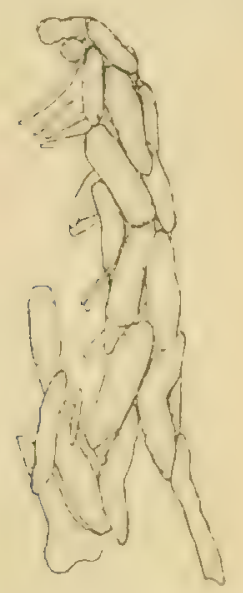

Fig. 95. Chr. intirmedic. Scleriten eines Tentakels, in nat. Lage, etwas von der Seite. $\times 54$. der Mitte etwas verschmälert sind (Fig. 94, A und C). Etwa ein Zehntel der Scleriten
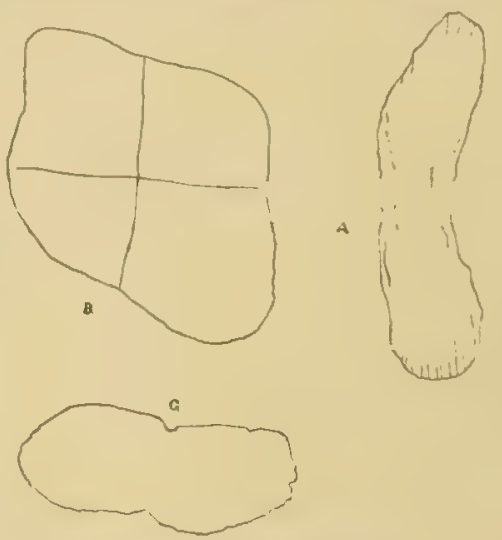

Fig. 94. Chr. intermedia. Scleriten des Polypen-Rumpfes. A, 1 , C siehe im Text. $\times 145$. (was aber nur eine rohe Schätzung ist) sind Vierlinge: bestehen aus vier deutlich begrenzten Stiicken (Fig. 94, B). Die Grösse der Schuppen wechselt sehr; die grössten, die ich finden konnte, hatten 0,41 und $0,43 \mathrm{~mm}$. als Maximal-Durchmesser. In dem Tentakel-Rücken liegen typische

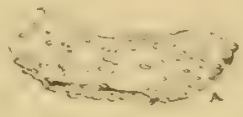
Spicula (Fig. 95 und 96) und zwar zu zwei oder drei neben einander in der Breite des Riickens. Nach der Tentakelspitze zu werden dieselben kleiner, bleiben aber sonst unverändert. Sie haben meist stumpfe Enden, sind etwa halb so dick wie breit, also merklich abgeflacht. Ihre

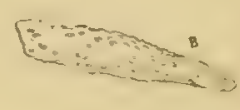

Fig. 96. Chr. intermedia. Spicula aus den Tentakeln, Av d. breiten, 13 v. d. schmalen Seite. $\times 193$.

Oberfläche ist mit kleinen Wärzchen nicht dicht bedeckt. Ich fand in einer Tentakel-Basis ein 
Spiculum, das $0,47 \mathrm{~mm}$. lang war; die anderen waren alle kleiner. Ein mittelgrosses war $0,28 \mathrm{~mm}$. lang, 0,09 mm. breit und nur 0,036 mm. dick. Scleriten, welche zum Theil im Tentakel, zum Theil im Rumpfe liegen, verhalten sich im Tentakel wie ein typisches Spiculum, in der Rumpfwand aber sind sie glatt, dunn und verbreitert wie die Rumpf-Schuppen (Fig. 95).

In den Seiten der Tentakel, bei den Bases der Pinnulae und in letztere hineinreichend, liegen stets mehrere lange, sehr düne, schmale Scleriten, deren den Scleriten der TentakelRücken anliegendes Ende meist verbreitert ist; ihre Oberfäche ist ganz glatt. Der längste Sclerit den ich fand war $0,23 \mathrm{~mm}$. lang, in der Mitte $0,017 \mathrm{~mm}$. breit und beim TentakelRücken bis zu 0,03 mm. verbreitert; ein anderer, 0,195 mm. langer Kalkkörper war beim Tentakel-Rücken $0,045 \mathrm{~mm}$. breit.

Wiewohl für die vollständige Beschreibung dieser Art keine genügenden Stiicke vorliegen, habe ich dieselben dennoch beschrieben, wegen ihrer vcrmittelnden Stellung zwischen Spiculosac und Squamosae.

Geographische Verbreitung: nur in der Timor-See einmal von der Siboga-Expedition erbeutet.

\section{Unter-Oruppe B2.}

Tentakel-Rücken mit dicken, unregelmässigen, längsliegenden Scleriten; das Schuppenkleid des Rumpfes bildet einen vorspringenden Ring um die Tentakel-Bases herum; Astsand ${ }^{3} /$, rechtsgewunden.

22. Chrysogorgia expansa (Wright \& Studer).

Dasygorgia expansa Wright and Studer, Challenger Report, vol. 31, 1389, S. 16.

Ich untersuchte einige grössere Fragmente, welche sich unter diesem Namen in der Challenger-Sammlung des „British Museum” befinden. Dieselben stimmen genügend zu WRIGIT und Studer's Beschreibung, namentlich in den Polypen und in der Verzweigung der Aeste.

Unter den Fragmenten fand ich einen $30 \mathrm{~mm}$. langen, reichlich $1 \mathrm{~mm}$. dicken, braunen Abschnitt des Stammes, mit starkem Metallglanz. Aststand $1 /$, rechts gewunden. Im ChallengerReport (S. I6) wird $1 / 3$ als Aststand angegeben; das trifft zu für eine Kolonie, warscheinlich von Chr. geniculata, welche ich in derselben Flasche fand, möglicherweise hat Verwechselung mit derselben Wrignir und Studer zu ihrer unrichtigen Angabe gefuhrt.

Die Länge eines Stamm-Internodiums ist \pm 2 mm.; die Entfernung zweier Stammäste einer Verticalreihe dementsprechend $8 \mathrm{~mm}$.. Die Stammäste gehen senkrecht zum Stamme ab und verzweigen sich sehr reichlich in verschiedenen Ebenen, aber sie dehnen sich doch vorherrschend in einer dem Stamme parallelen Ebene aus. Ich zählte an einem Stammast bis IS successive Internodien. Die Zweige kreuzen sich oft und ich fand denn auch einige Verwachsungen, auch von stärkeren Aesten (das wird auch von WRIGnT und STUder angegeben). Die Lïnge der Internodien ist 2 bis $10 \mathrm{~mm}$; die terminalen sind meist kurz.

Rinde des Stammes mit zerstreut liegenden diunnen Schuppen, deren Form und Anord- 
nung aus Fig 97 ersichtlich ist; der Rand derselben ist sehr fein, unregelmässig gezähnelt (nur

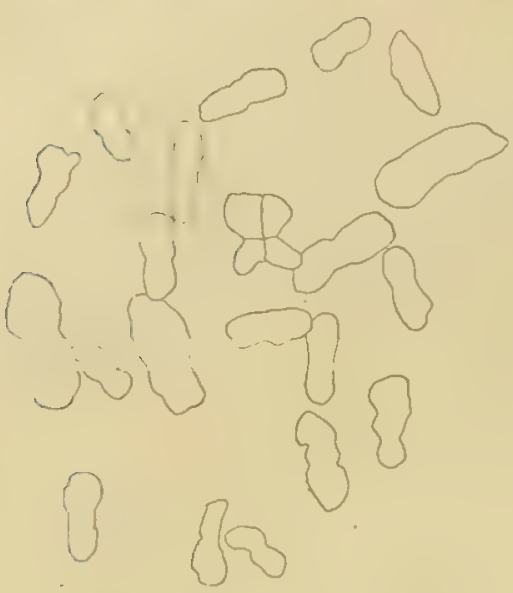

Fig. 97. Chr. crpansa. Scleriten der Stamm-Rinde, in nat. Lage. $X$ So. bei starker Vergrösserung deutlich). Der grösste Durchmesser erreicht $0,2 \mathrm{~mm}$.. Auf den Aesten liegen die Scleriten stellenweise dichter beisammen und werden auch grösser (grösster Durchmesser bis $0,36 \mathrm{~mm}$.$) ; ihre Form ändert sich aber nicht.$

Stamm und Aeste mit Nematozooiden, die von WRIGIrT und STUder nicht erwähnt werden.

Der Stamm und die drei oder vier proximalen Internodicn der Stammäste ohne Polypen, die anderen Internodien je mit einem, die terminalen mitunter mit zwei Polypen.

Die Polypen erreichen mit zusammengelegten Tentakeln eine Länge von $1,75 \mathrm{~mm}$; die Rumpflänge ist etwa I $\mathrm{mm}$., mitunter etwas mehr; der Querdurchmesser des Rumpfes ist bis I,25 mm. und dementsprechend haben die Polypen eine auffallend breite, gedrungene Form.

Die Rumpfwand. enthält ein dichtes Schuppenkleid; die Schuppen liegen ziemlich regellos, meist aber mit der grössten Länge quer zur Längsachse des Polypen (Fig. 98). In der Nähe

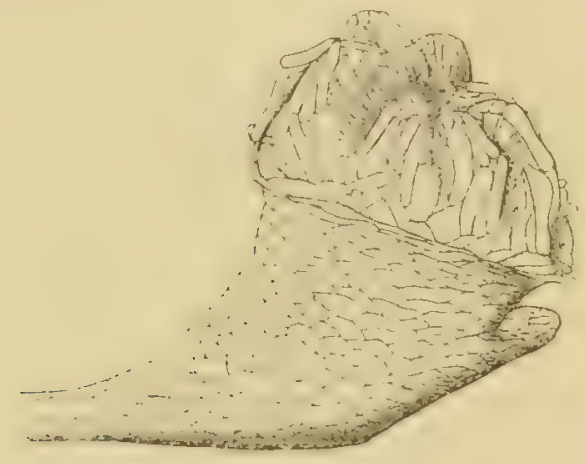

Fig. 98. Chry'sogergia cxpansa. lolyp. $\times 21$. der Tentakel sind die Schuppen in einer Richtung stark verlängert, liegen alle quer und bilden, indem ihr oberer, freier Rand sich immer mehr nach aussen richtet, einen deutlichen scharfen, vorspringenden Ring unter den Tentakel-Bases (Fig. 98). Dies ist auch auf den Figuren im Challenger Report, Taf. 4, Fig. $4 a$ und $4 b$, deutlich angegeben (aus diesen Figuren ist ersichtlich, dass mir wirklich die Type vorlag, obwohl im Aststand solche wichtigen Unterschiede zwischen der Angabe von Wright und Studer und den Exemplaren des „British Museum” bestehen. Möglicherweise haben sie auch die Kolonie von Chr. geniculata bei ihrer Beschreibung berücksichtigt, womit auch ubereinstimmt, dass sie die Nematozooiden nicht auffanden).

Auf den Tentakel-Rücken liegen längsgerichtete, abgeflachte Scleriten; dieselben sind bis $0,5 \mathrm{I} \mathrm{mm}$. lang, meist kaum halb so dick wie breit, mit glatter Oberfläche; es sind also keine typischen Spicula, aber auch keine Schuppen. In der äussersten Spitze der Tentakel werden die Scleriten klein, von unregelmässiger Form, mitunter schuppendünn. In den Bases der Pinnulae liegen lange, schmale, diunne Kalkkörperchen.

Geographische Verbreitung: bei den Kermadec-Inseln im Pacifik, in 936 und roso $\mathrm{MI}$ Tiefe, von der Challenger-Expedition auf den Stationen rjo und I $\mathrm{y}$ erbeutet. Letztere Station wird im Challenger-Report nicht angegeben; ich fand das von der Station 17 I stammende Fragment in der Sammlung des "British Museum" in einer Flasche mit den Typen der Chr. acanthella; es wurde wohl von WrigrT und STUDER ibersehen, oder kam es vielleicht nach der Bearbeitung durch Versehen in diese Flasche? Der Boden ist vulcanischer Schlamm (Stat. I jo) oder hart (Stat. I 7 I). 
23. Chrysogorgia octagonos nov. spec.

Stat. $297.10^{\circ} 39^{\prime}$ S., $123^{\circ} 40^{\prime}$ O. Oestlich von Rotti. 520 M. Weicher grauer Schlamm. Ein Fragment.

Das vorliegende Fragment besteht aus einem kleinen Abschnitt des Stammes, von welchem drei Stammäste abgehen (Fig. 99). Die Länge der Stamm-Internodien ist $3 \mathrm{~mm}$., die Dicke $1 / 2 \mathrm{~mm}$. Der Stamm ist bei den Astursprüngen stark geknickt. Die Stammäste sind etwas aufgerichtet, sodass sie mit dem nächsthöheren Stamm-Internodium einen Winkel von etwa $90^{\circ}$, mit dem nächstunteren einen von I $20^{\circ}$ bilden. Aststand $1 / 4$, rechtsgewunden. Achse des Stammes und der stärkeren Ast-Internodien bräunlich, die der Zweige blassgelb, wenig glänzend.

Stammäste kurz, nicht in einer Ebene ausgebreitet, mit 4 oder 5 successiven Internodien (Fig. 99); Länge derselben $2^{1} \%$, bis $6^{2} \%$, der terminalen bis $9 \mathrm{~mm}$.

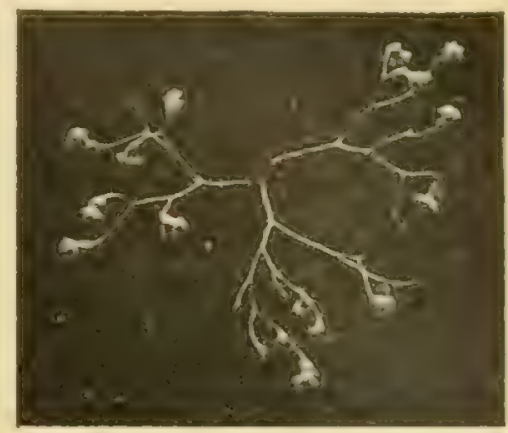

Fig. 99. Chr. oclogonos. Fragmeot; sehr wenig vergrössert

Rinde dünn; die Kalkkörper streckenweise fehlend, an anderen Stellen gehäuft und zu 2 bis 3 über einander liegend (Fig. I00). Es sind dünne Schuppen, die am Rande nur äusserst fein gezähnelt sind und meist 0,15 bis $0,25 \mathrm{~mm}$. messen, einige bis nahezu $0,4 \mathrm{~mm}$.. Ziemlich viele sind Vierlinge.

Ich fand keine Nematozooide; die Rinde ist aber schlecht erhalten und dickere Stammtheile, worauf dieselben bei anderen Arten am zahlreichsten vorkommen, sind nicht vorhanden.

Polypen sitzen nur auf den End-Internodien der Zweige und zwar meist nur ein einziger an der Spitze des Zweiges, auf

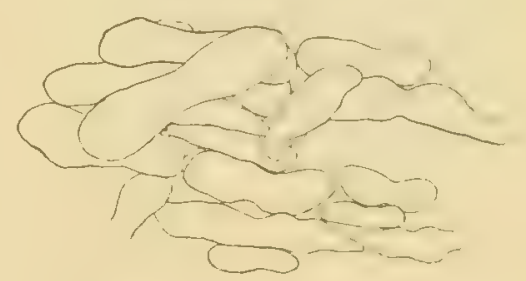

Fig. I00. $\mathrm{Chr}$. octayonos. Scleriten der Zweigrinde, in nat. Lage. $\times$ So. drei terminalen Internodien sass ein zweiter Polyp etwa in der Mitte zwischen proximalem und distalem Ende des Internodium. Mit Ausnahme nur eines der nicht endständigen Polypen sitzen dieselben alle den Zweigen sehr schräg auf (Fig. 99 und IOI).

Die Polypen erreichen mit zusammengelegten Tentakeln eine Länge von $2,5 \mathrm{~mm}$, bei einer Rumpflänge von etwa $1,25 \mathrm{~mm}$.; sie sind daneben sehr breit: in der Mitte des Rumpfes beträgt ihr Querdurchmesser bis $1,75 \mathrm{~mm}$. Doch sind diese Maasse bei dem schrägen Stand der Polypen schwer zu bestimmen.

Der Polypen-Rumpf enthält eine dreifache Schicht von Kalkschuppen; letztere sind meist in einer Richtung erheblich verlängert und liegen dann nahezu quer zur Längsachse des P'olypen (Fig. IOI); dabei bedecken sie einander wie Dachziegel, mit dem freien Rand stets

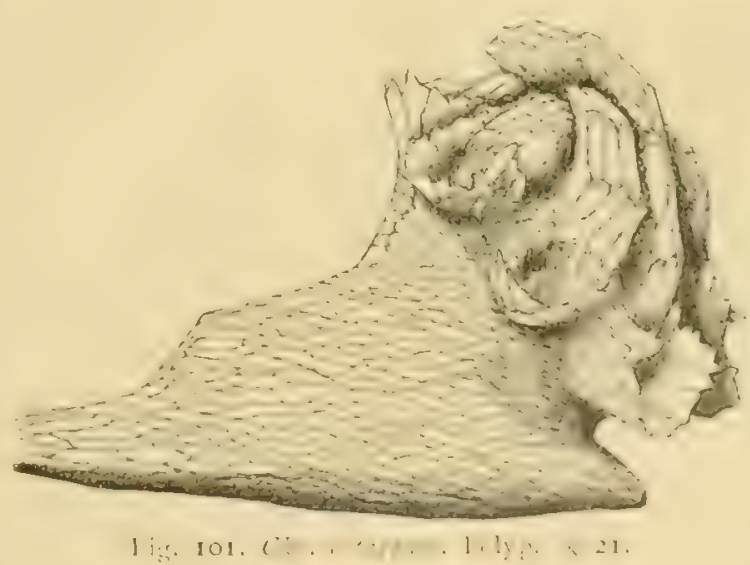
den Tentakeln zugekehrt. Die Form der Schuppen ist aus Fig. 102, A, ersichtlich. Die grösste Schuppe, die ich sah, war $0,6 \mathrm{~mm}$. lang, die Mehrzahl nur 0,21 bis 0,4 mm., ziemlich viele sIBOGA-EXPEDITIE XII. 
noch kleiner. Unter den Tentakeln bilden diese Schuppen einen nach aussen gebogenen, vorstehenden, scharfen Rand, wie ein solcher auch bei Chr. cxpansa entwickelt ist. Doch ist der Rand bei Chr. octagonos viel deutlicher und so ausgebuchtet, dass er unter jedem Tentakel

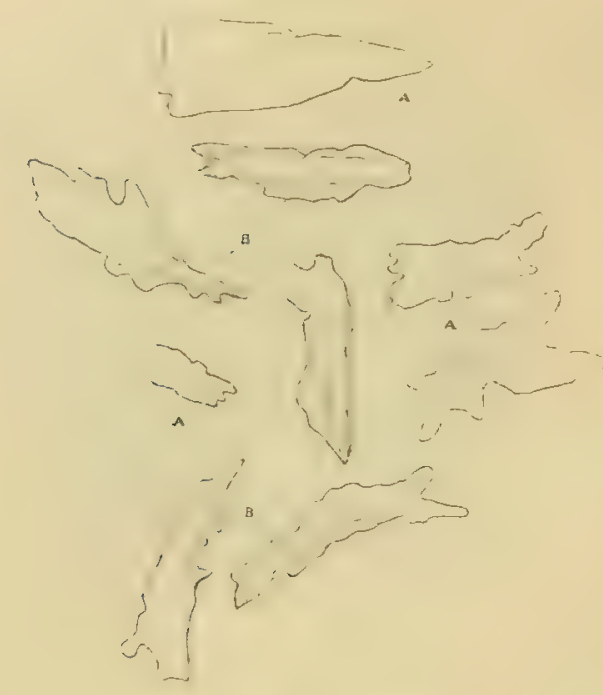

Fig. 102. Chr, octagonos.

Schuppen aus einem Polypen; $A$ aus dem Kumpfe, $B$ von einem Sockel an der Tentakel-Basis. $\times 47$. einen kleinen Sockel bildet, zwischen zwei Tentakeln aber nur schwach angedeutet ist (Fig. IOI). Die Scleriten dieses Randes liegen mit ihrem schuppenförmigen unteren Abschnitt zwischen den Schuppen der Rumpfwand, während ihr oberer, frei vorstehender Abschnitt dicker und mehr oder weniger scharf zugespitzt ist (Fig. 102, B). Der grösste dieser Scleriten erreichte eine Länge von $0,57 \mathrm{~mm}$; andere waren $0,55-$ $0,52-0,49 \mathrm{~mm}$. und weniger lang.

Auf den Tentakel-Rücken liegen andere Scleriten zu 3 oder 4 neben einander. Die auf der proximalen Hälfte des Rückens sind stabförmig, der Achse der Tentakel parallel gelagert; ihre Dicke beträgt $1 / 4$ bis $1 / 3$ ihrer Breite; die Oberfläche ist meist etwas uneben; die Enden sind höckerig, abgestumpft. Wärzchen fand ich nur selten und dann nur vereinzelt (Fig. I03, A). Nach der Tentakel-Spitze zu werden die Scleriten kleiner, dünner, von unregelmässiger Form (Fig. IO3, B). Die Tentakel-Scleriten sind also weder typische Spicula noch Schuppen; sie sind
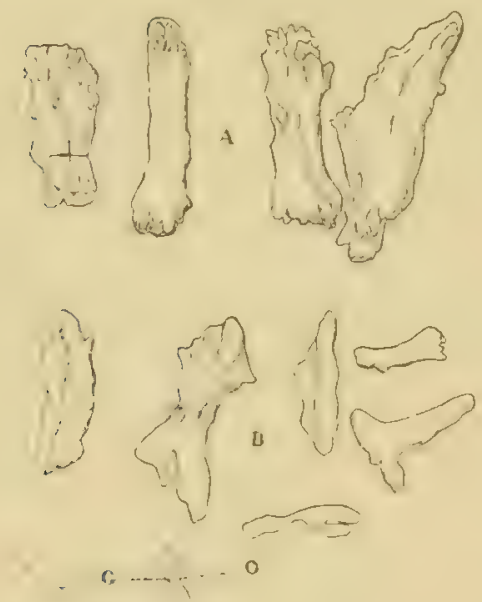

Fig. 103. Chr. octarones. rentakel-Scleriten; $A$ aus der Basis, 13 aus der Mitic und Spitze, $C$ aus len l'innulae. $\times 47$.

einen achteckigen Umfang (Fig. 99), wonach ich die Art genannt habe.

Geographische Verbreitung: nur von der Siboga-Expedition in der Timor-See erbeutet.

Der vorspringende Rand unter den Tentakeln ist bei Chr. cxpansa schon deutlich angelegt; daneben haben beide Arten denselben Aststand, auch sind die Scleriten im Polypen-Rumpt und in den Tentakeln einander ähnlich; sie sind also gewiss nahe verwandt und bilden zusammen eine natiirliche Unter-Gruppe. 
Mit keiner anderen Art näher verwandt, aber wegen ihre dicken Tentakel-Scleriten und wegen des Schuppenkleides des Rumpfes zu den Squamosac aborrantes gehörig, ist folgende Art.

24. Chry'sogorgia currata nov. spec.

Stat. 150. $0^{\circ} 6^{\prime}$ N., $129^{\circ} 7^{\prime} .2$ O. Zwischen Halmahera und Gebe, IOS9 M. Gelbgrauer Schlamm und Sand mit Steinen. Ein Fragment.

Von dieser Art liegt leider nur ein Fragment vor; trotzdem habe ich dieselbe wegen der eigenthümlichen Scleriten der Tentakel beschrieben.

Es ist nicht möglich aus dem nur $44 \mathrm{~mm}$. langen Astfragmente (Fig. ro 4 ) auf Form und Aststand der ganzen Kolonie zu schliessen. Die Verzweigung ist derjenigen der Chr. anastomosans ähnlich. Das Fragment ist vorherrschend in einer Ebene verzweigt, doch gehen von einer Seite, der Oberseite, kürzere Zweige $a b$, nicht aber von der anderen: der Unterseite. Die Internodien sind kurz: 3 bis $4 \mathrm{~mm}$., eines der End-Internodien aber $7 \mathrm{~mm}$. lang. Die Achse ist bis $1,5 \mathrm{~mm}$. dick, bräunlich, mit starkem Goldglanz, welcher durch dass weissliche Coenenchym deutlich durchschimmert. Das Fragment zeigt drei Anastomosen.

Die Rinde ist ziemlich zart und reich an Scleriten, welche eine beinahe vollständige Schicht bilden und mit den Rändern mehr oder weniger weit über einander liegen (Fig. I05). Es sind Schuppen, stets ohne Wärzchen, meist ganzrandig, hin und wieder aber auf kleineren Strecken mit sehr fein gezähnelten Rändern. Die Form der Schuppen ist sehr unregelmässig (Fig. I05); ihr grösster Durchmesser ist 0,0S

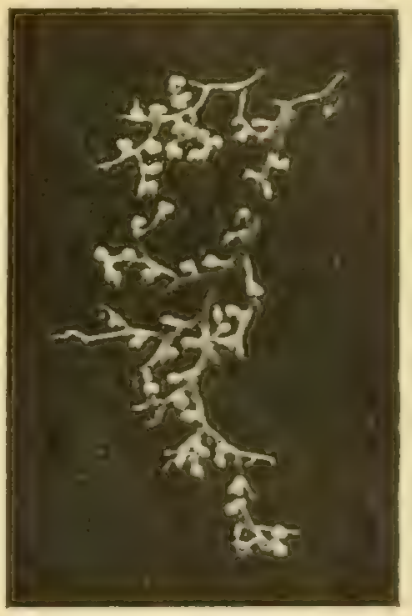

Fig. 104. Chr, cur Eulut Fragment, etwas vergrössert.

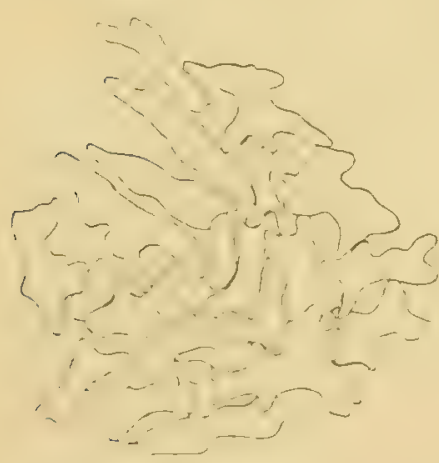

Fig. 105. Chr, curvala. Rinden-Scleriten, in nat. Lage. $\times$ So bis $0,26 \mathrm{~mm}$., selten bis $0,3 \mathrm{~mm}$. oder noch etwas mehr.

Nematozooiden fehlen.

Polypen ziemlich nach allen Seiten gekehrt; sie fehlen nur auf der Unterseite der stärkeren Aeste, während die meisten auf der Oberseite der Aeste stehen. Sie stehen dicht beisammen, oft zwei auf den kurzen Internodien, drei auf dem einen, $7 \mathrm{~mm}$. langen terminalen Internodium. Die Entfernung der Polypen ist denn auch meist nur I, 5 bis $3 \mathrm{~mm}$.

Die Polypen erreichen eine Länge von $2 \mathrm{~mm} .{ }^{1}$ ); dabei sind die' Tentakel nur wenig zusammengebogen und bilden eine kugelige Masse auf dem etwas schmäleren, cylindrischen, nur I mm. hohen Rumpf.
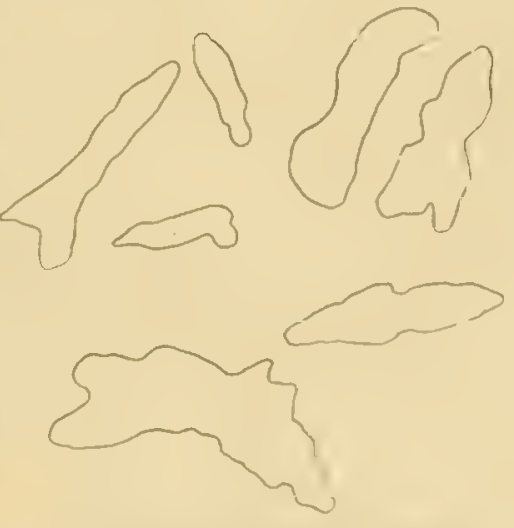

Fig. 106. Chr. curatu. Scleriten aus dem Rumpf eines l'olypen. $\times$ So.

Rumpfwand der Polypen mit einer 2- bis 3-fachen Schicht von Kalkschuppen. Letztere sind glatt, ohne Wärzchen, mit nur sehr fein gezähnelten Rändern. Aus Fig. 106 ist die Form

1) Einige abnormale, von parasitischen Copepoden bewohnte Polypen sind bis 3 mm. lang. 
der Scleriten ersichtlich; die Zähnelung der Ränder ist bei dieser Vergrösserung noch nicht sichtbar und deshalb nicht angegeben; es kommen noch unregelmässigere, stärker eingebuchtete Schuppen vor als die abgebildeten. Am meisten nach innen liegen kleinere, mehr runde Schuppen;

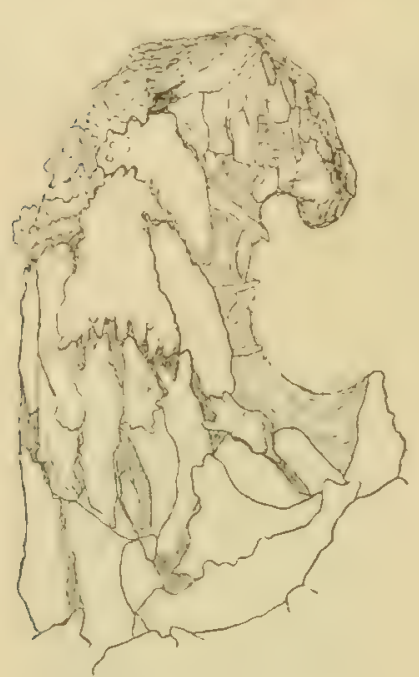

Fig. 107. Chr, curatat Tentakel, von der Rückenseite. $\times$ So. dieselben bilden aber keine besondere innere Schicht, denn sie kommen auch mehr oberflächlich vor. Im oberen Theil des Rumpfes sind die Scleriten deutlich in einer Richtung verlängert und liegen quer zur Längsachse des Polypen. Darin stimmt diese Art mit den beiden vorhergehenden überein, es wird aber bei Chr. curvata kein vorstehender'Rand um die Bases der Tentakel gebildet, sondern die Scleriten-Schicht der Rumpfwand setzt sich direct in die der TentakelRiicken fort.

Wie aus Fig. Io 7 ersichtlich, sind die Scleriten der TentakelRücken von ungewöhnlicher Form. Ganz unten finden sich einige dünne Scleriten, die mit ihrem grössten Durchmesser parallel der Tentakel-Achse liegen und unmittelbar an die querliegenden Schuppen des Rumpfes anschliessen; es liegen deren 5 bis 6 in der Breite des Tentakel-Rückens neben einander. Mehr nach der Mitte der Tentakel zu liegen dickere Scleriten, welche an den Enden zahnartige Höcker tragen, womit sie zwischen ähnliche Höcker der benachbarten Scleriten greifen. Auf Fig. Ios bei $A$ ist ein solcher Kalkkörper abgebildet mit sehr deutlicher, höckeriger Contactfläche am

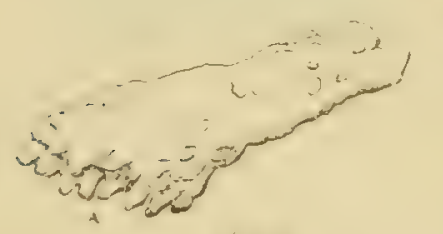
einen Ende. Nach der Tentakel-Spitze zu liegen kleinere, relativ dickere Scleriten mit höckeriger Oberfläche und einigen wenigen kleinen Wärzchen (Fig. Io8, C). Im Spitzen-Abschnitt selbst liegen Scleriten, welche ron den Spicula der Spiculosae im Typus nicht verschieden sind: höckerige, unregelmässige Scleriten wie in Fig. I08 bei B abgebildet.

Die grösste Länge dieser Tentakel-Scleriten ist 0,25 bis sogar $0,3 \mathrm{~mm}$. in der Tentakel-Basis; nach der Spitze zu sind sie aber alle kleiner, z.B. 0,17 mm., 0,088 mm. und sogar nur 0,05 mm. und noch kiirzer.

In den Seiten der Tentakel finden sich noch einige wenige

Fig. xos. Chr. curzata.

Spicula aus dem Tentakclliüken; A u. C Mitte, 13 Spitze des Tentakels. $\times 145$.
Scleriten, welche wahrscheinlich bis in die Pinnulae hineinreichen; es sind duinne, stabförmige, bis o, 175 mm. lange Kalkkörperchen. Nach der Tentakel-Spitze zu treten an ihrer Stelle kleine Schuppen von 0,07-0,05 $\mathrm{mm}$. oder weniger im grössten Durchmesser (Fig. IO7).

Geographische Verbreitung: wie oben angegeben, sonst nirgends aufgefunden.

\section{Gruppe C. Squamosae typicac.}

Polypen nur mit sehr cliunen Kalkkörpern, in Form von Schuppen im Rumpfe und in den 'Tentakel-Riicken. 


\section{Untcr-Gruppe Cr.}

Schuppen im basalen Theile der Tentakel-Rücken ziemlich schmal, längsliegend. Aststand nicht bekannt, rielleicht weicht die einzige hierher gehörige Art in ihrer Verzweigung von der typischen Form mit Stamm und Stammästen ab.

\section{Chrysogorgia japonica (Wright \& Studer).}

Dasygorgia japonica Wright and Studer, Challenger Report, vol. 3I, I889, S. 2 I,

Das von der Challenger-Expedition erbeutete Fragment ist nahezu in einer Ebene ausgebreitet. Es fängt an mit einem $4 \mathrm{~mm}$. dicken Ast, der sich bald in zwei etwas weniger starke Aeste theilt, die wieder zahlreiche dünnere Aeste tragen, von denen der längste mehr als $200 \mathrm{~mm}$. lang ist. Während die stärkeren Aeste meist nur nach einer Seite wieder Seitenäste abgeben, geben die dünneren Aeste oft in der Ebene der Verzweigung nach beiden Seiten neue Seitenzweige $a b$. Die dünnen Zweige aber stimmen in der Verzweigungsweise oft gut uberein mit der bei den anderen Chrysogorgia-Arten ublichen und sind wohl derselben Regel der einseitigen Verzweigung unterworfen. Die anscheinend abweichend verzweigten Aeste sind muthmasslich sympodial gebaut. Da das Fragment im Challenger-Report nicht abgebildet ist, gebe ich hier die Abbildung eines kleinen Abschnittes des-

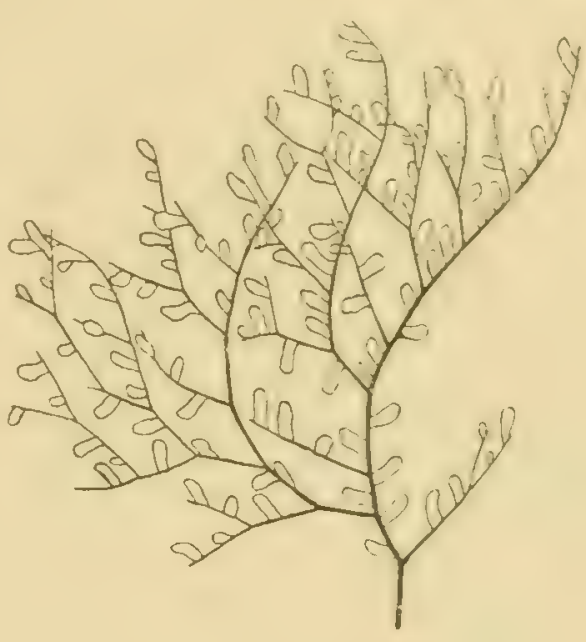

Fig. 109. Chr. jafonica. Kleiner Abschnitt des Fragmentes. Nat. Gr. selben (Fig. 109), welche das Erkennen der Art wohl erleichteren wird.

Ueber die Form einer vollständigen Kolonie kann ich nichts aussagen. Es ist möglich, dass das vorliegende Fragment ein Ast ist einer riesigen, den anderen Chrysogorgia-Arten in der Verzweigung ahnlichen kolonic, wie Wright und STtrek meinen: doch kann das meines Erathens aus dem Fragmente nicht geschlossen werden, da dasselbe doch etwas abweichend verzweigt ist.

Die Zweige sind oft gebogen und wo sie Seitenzweige abgeben sind sie, selbst die stärksten Aeste, geknickt. Die Achsen sind dunkel metallisch glänzend.

Rinde dün; Scleriten ziemlich zahlreich, oft dicht beisammen, auf den dickeren Aesten stellenweise mehr zerstreut liegend, wie auf Fig. I IO abgebildet, aus welcher Figur auch die: Form dieser Lalkkioryer ersichlich ist. Letztere sind statt. dünn wie Schuppen; Vierlinge sind nicht selten. Die Scleriten sind denen der Rinde der C Kr. cxpansa auffallend älunlich, nur

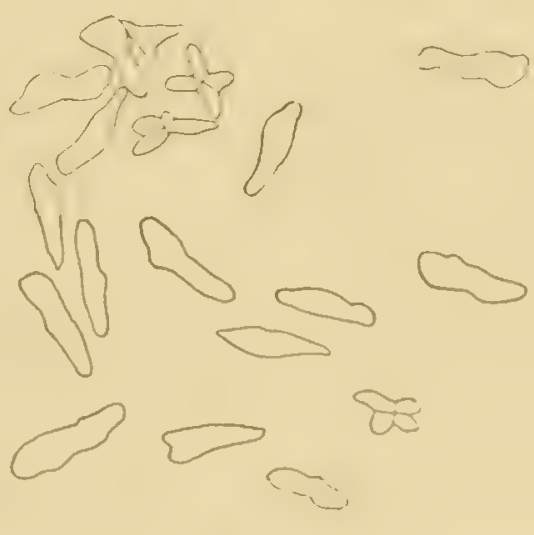
meist relativ schmäler. Die grössten, die ich fand, waren 0,2 bis $0,24 \mathrm{~mm}$. lang; WIRIGHT und STUder fanden Rinden-Scleriten von $0,3 \mathrm{~S}$ bis $0,4 \mathrm{~mm}$. Lïinge. 
Auf der Rinde sitzen grosse, schon mit dem unbewaffneten Auge sichtbare Nematozooide. Ich fand solche bis $0,3 \mathrm{~mm}$. hoch, aber nicht so gross wie Wright und STUder sie antrafen, nämlich $0,5 \mathrm{~mm}$. Meist enthalten sie 2 oder 3 Scleriten, wie die der Rinde; niemals sah ich zahlreichere, in acht Reihen angeordnete Scleriten, wie Wright und STUDER (1. c. S. 23) angeben.

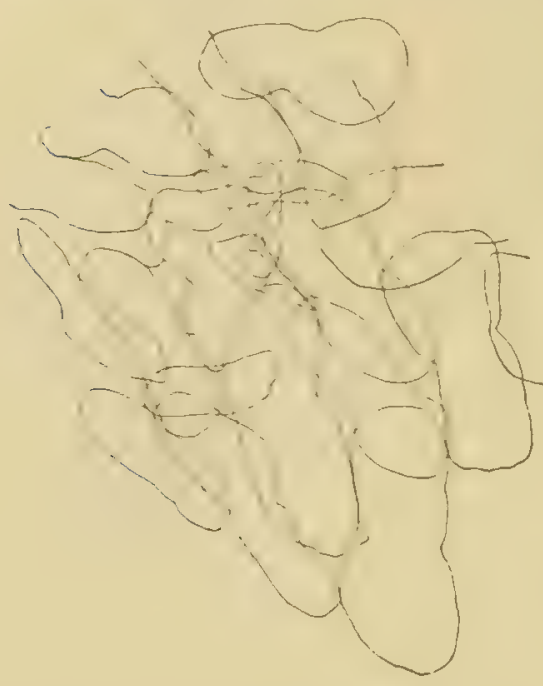

Fig. IIr. Chr. japonica.

Scleriten in der Rumpfwand eines Polypen, bei durchfallendem Lichte gezeichnet; die Basis des Polypen liegt links, die Tentakelkrone rechts. $\times$ So.

als I mm. lang und offenbar sehr jung. Die Polypen sitzen meist, aber nicht immer, den

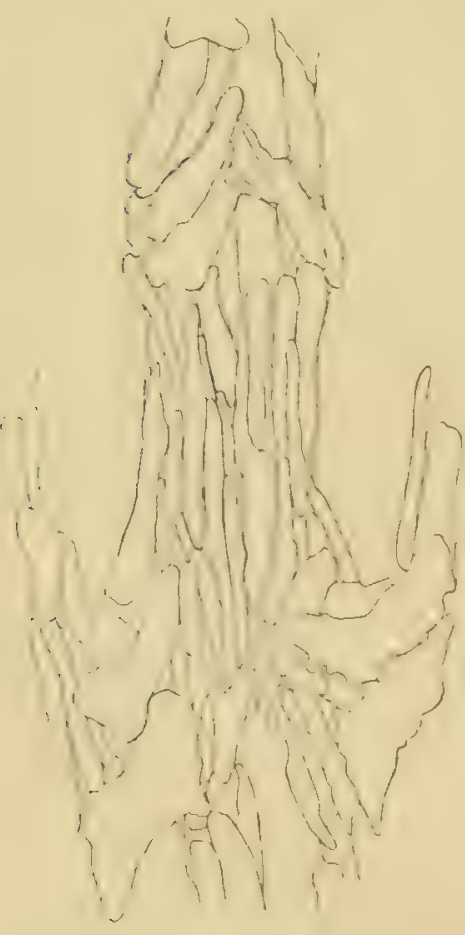

Fig. I12. Chr. jafonica. Scleriten der Tentakel-Basis. $\times$ So. doch habe ich nur etwa zehn Nematozooide unter dem Microscope gesehen und diese waren durch fremde Bestandtheile alle mehr oder weniger undeutlich; auch ihre Epidermis schien mir schlecht erhalten. Deshalb kann ich bezüglich der An- oder Abwesenheit einer Mundöffnung nichts Bestimmtes behaupten. Es kommen neben den Nematozooiden auch junge Polypen vor, worunter sehr kleine; vielleicht haben WRIGHT und STUDER einen solchen mit einem Nematozooiden verwechselt; dies würde ihre Angabe von zahlreichen Scleriten und von der Anwesenheit einer Mundöffnung erklären. An meinem Nateriale kann ich diese Frage nicht erledigen.

Die Polypen sind zahlreich (Fig. Iog), auch auf den stärkeren Aesten, und stehen vorherrschend in der Ebene der Verzweigung. Sie erreichen bei zusammengelegten Tentakeln eine Länge von $4 \mathrm{~mm}$., sind meist aber kürzer, einige sogar weniger Zweigen schräg auf.

IVright und Studer haben dieselben so genau beschrieben, dass ich Nichts hinzuzufügen habe. Man vergleiche auch ihre Fig. S, Taf. 4, die den Habitus der Polypen gut wiedergiebt.

Das Schuppenkleid des Rumpfes ist ein bis drei Scleriten dick; Fig. I I I stellt einen kleinen Abschnitt bei durchfallendem Lichte dar. Die Schuppen liegen mit ihrem grössten Durchmesser schräg, jedoch mehr parallel als quer, zur Längsachse der Polypen. Ihr Rand ist streckenweise fein gezähnelt, meist zu fein um in der Figur anzugeben. Auf der Polypen-Basis ist das Kleid von Schuppen am dichtesten auch liegen dieselben mehr quer. Ihre grösste Länge beträgt höchstens $0,4 \mathrm{~mm}$. Die Fortsetzung des Schuppenkleides in den Tentakel-Rücken zeigt Fig. I1 2. Eigenthümlich sind die schmalen, dünnen Scleriten auf der Tentakel-Basis; so hat der längste in Fig. II 2 eine Länge von $0,375 \mathrm{~mm}$. und eine Breite von nur etwa $0,02 \mathrm{~mm}$; andere sind relativ viel breiter. In der Figur im Challenger-Report (Tafel 4, Fig. S) sind diese Scleriten viel breiter gezeichnet, demzufolge ist ihre Zahl viel niedriger, als ich das stets

Ich fand keine Mundöffnung und keine Eier in den Nematozooiden; fand. Nach der Tentakel-Spitze zu liegen immer kleinere, relativ weit breitere Schuppen, welche in der Spitze deutlich quer zur Längsachse des Tentakels liegen. 
In den Seiten der Tentakel, bei den Pinnulac, finden sich sehr zarte, diunne Schuppen, viel länger als breit, zum Theil in den Pinnulae mit etwas dickerem, zugespitztem Ende; sie sind bis $0,2 \mathrm{~mm}$. und mehr lang, in der Tentakel-Spitze aber sehr klein.

Da die Verzweigung der ganzen Kolonie nicht bekannt ist, ist ihre Verwandtschaft mit den anderen Arten des Genus Chrysogorgia nicht genau fest zu stellen, um so weniger als die Polypen auch im Schuppenkleid der Tentakel-Rücken etwas abweichen. Kommt ihr ein sympodialer Stamm zu, oder lässt ihre Verzweigung, wenn genauer bekannt, sich auf einen solchen Verzweigungs-Modus zurückfuhren, dann findet die Art wohl bei den Squamosac typicae ihren richtigen Platz.

Geographische Verbreitung: nur von einer Stelle bei Japan durch die Challenger-Expedition aus 3375 M. Tiefe, auf Schlammboden bekannt.

\section{Unter-Gruppe C2.}

Schuppen liegen auf den Tentakel-Rücken alle oder doch meist quer, nirgends sind sie deutlich längsgerichtet; Aststand $\%$, linksgewunden.

\section{*26. Chry'sogorgia acanthella (IVright \& Studer). \\ Dasygorgia acanthella Wright and Studer, Challenger Report, vol. 31, I8S9, S. is.}

Die betreffende Flasche im „British Museum” enthielt, neben einer Ast von Chr. cxpansa, 3 Fragmente einer anderen Art, anscheinend die Type der Chr. acanthella. Diese 3 Fragmente gehören zu einer Kolonie, die eine Länge von etwa $150 \mathrm{~mm}$. erreicht haben mag, bei einen Querdurchmesser von nur $35 \mathrm{~mm}$. Der Stamm ist unten $1,5 \mathrm{~mm}$. dick; seine Achse ist griinlich metallisch glänzend; die Achsen der Zweige sind gelb, goldglänzend.

Aststand $\%$, linksgewunden. Länge eines Stamm-Internodium etwa $2 \mathrm{~mm}$; die Entfernung zweier Stammäste einer Verticalreihe ist meist etwa $10 \mathrm{~mm}$, unten nur $8 \mathrm{~mm}$, bei des Spitze des Stammes bis $14 \mathrm{~mm}$.

Stammäste senkrecht vom Stamme abgehend, nur die oberen schräg aufgerichtet. Länge eines Stammastes bis $20 \mathrm{~mm}$., der oberen bis $25 \mathrm{~mm}$; dieselbe haben + oder 5, die oberen 6 nachfolgenden Internodien. Die Stammäste sind vorwiegend senkrecht zum Stamme ausgebreitet. Die Länge ihrer Internodien ist 2,5 bis $5,5 \mathrm{~mm}$; das proximalste ist 3,5 bis $5 \mathrm{~mm}$. lang; die End-Internodien sind meist etwas länger, sogar bis ro und $13 \mathrm{~mm}$.. Die Internodien sind oft schwach gebogen; es kommen einige Verwachsungen von Zweigen vor.

Rinden-Scleriten in Form, Zahl und Vertheilung wie bei Chr. cxpansa (vergleiche I'ig. 97, S. 6.4); nur sind die Ränder der Scleriten meist weniger buchtig als bei letztere Art. Das längste Kalkkörperchen war 0,2 mm. lang.

Die Oberfläche der Rinde ist etwas rauh durch die zahlreichen Nematozooide. Dieselben sind bis etwa $0,1 \mathrm{~mm}$. hoch und an der Basis bis $0,07 \mathrm{~mm}$. breit, ein wenig kleiner als bei Chr. cxpansa. Ich fand keine Mundöffnung und keine Scleriten in den Nematozooiden. 
Jedes Internodium der Aeste mit einem, die End-Internodien bisweilen mit 2 Polypen. Stamm gleichfalls mit Polypen, die aber deutlich kleiner sind, namentlich niedriger, als die Polypen der Aeste (conform Challenger-Report, S. I9). Ich fand keine Geschlechtsprodukte in den Stamm-Polypen.

Polypen mit zusammengelegten Tentakeln bis I,75 mm. lang, mit vorgestreckten Tentakeln bis $2 \mathrm{~mm}$. (im Leben möglicherweise noch länger). Der Habitus der Polypen ist in Fig. 6, Tafel 4 des Challengrer-Report gut wiedergegeben. Sie haben einen annäherend kugeligen Rumpf, welcher an der Polypen-Basis und unterhalb der Tentakel-Krone merklich verengert ist.

Schuppenkleid des Polypen-Rumpfes wie bei Chr. japonica (vergl. Fig. I I I), nur sind die Schuppen bei Chr. acanthella etwas kleiner; es sind viele Vierlinge darunter.

Auf den Tentakel-Rücken fand ich querliegende Scleriten (Fig. I I3). Diese sind dem

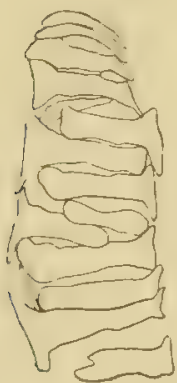

Fig. II3. Chr. acanthella. Scleriten der basalen Hälfte eines Tentakels. $\times 80$. Rücken entsprechend gebogen und an einem, bisweilen an beiden Enden stark verbreitert, indem sie dort nach Basis und Spitze der Tentakel gerichtete, breite Fortsätze abgeben. Diese Fortsätze liegen mehr in den Seitenflächen als im Rücken der Tentakel. Nach der Tentakel-Spitze zu sind die Schuppen kleiner, schmäler und an den Enden nicht verbreitert. Der Rand der Scleriten ist streckenweise fein gezähnelt, die Oberfläche ist schwach chagriniert (letzteres war bei Kalkkörpern die in Glycerin lagen ziemlich deutlich, in Canada-Balsam aber kaum erkennbar).

In den Seiten der Tentakel, bis in die Pinnulae hinein, liegen lange, dünne Scleriten, deren eines, vielfach verbreitertes Ende sich unter die Scleriten des Tentakel-Rückens schiebt. Ihre Grösse wechselt sehr.

Obige Beschreibung weicht von der von WRIGHT und STUDER gegebenen erheblich ab. Die Polypen stimmen ziemlich gut überein, namentlich auch darin, dass Stamm- und Ast-Polypen etwas verschiedene Form haben; nur ist auf der Figur 6, Tafel 4, des Challenger-Report die Bekleidung der Tentakel-Rücken mit Kalkkörpern anders angegeben als ich dieselbe fand. Die Zahl der Polypen stimmt überein; die Nematozooiden fand ich etwas kleiner und immer ohne Scleriten. Der Aststand ist verschieden, ich fand $\%$, Wright und Studer geben $1 /$ an. Die gleichfalls in einige Abschnitte gebrochene Kolonie, welche WrIGHT und StUder beschreiben, erreicht eine Höhe von $200 \mathrm{~mm}$, diejenige die ich sah nur I $50 \mathrm{~mm}$.

Da Wrigit und StUder auch bei anderen Arten den Aststand unrichtig angegeben haben (so bei Clur. cxpansa, cupressa, affinis), möchte ich ihrer, ron meinem Befunde abweichenden Angabe in diesem Falle wenig Werth beimessen. Trotzdem bleibt es immerhin zweifelhaft ob mir dieselbe Art vorlag. Wäre dies nicht der Fall, so fehlte Chr. acanthclla im „British Museum".

Da aber die Beschreibungen, welche WRIGIT und STUDER von den anderen Arten des Genus Chry'sogorgia geben, auch nicht immer sehr genau sind, finde ich die Unterschiede nicht derart, dass die Identität der mir vorliegrenden Kolonie mit Chr. acanthclla verneint werden müsste. Doch ist dies mit Gewissheit nicht zu entscheiden. Da aber, nach der Etikette, die sich auf der Flasche befand, als dieselbe dem „British Museum" von den Bearbeitern zuging, die Flasche Chr. acantholla enthalten muss, da ferner die Exemplare in vielem mit Wrant und 
STUDER's Beschreibung überein stimmen, glaube ich berechtigt zu sein, die vorhandene Kolonie als die Type der Art zu betrachten, bis das Gegentheil bewiesen wird.

Geographische Verbreitung: nur einmal in Pacifik bei den Kermadec-Inseln in roSo $M$. Tiefe von der Challenger-Expedition auf hartem Boden erbeutet.

\section{Chrojsogorgia pondula nov. spec.}

Stat. 266. $5^{\circ} 26^{\prime} .7$ S., $127^{\circ} 36^{\prime} .5$ O. Banda-See bei den Lucipara-Inseln. 1595 MI. Harter Grund mit kleinen'Steinen. I Ex.

Es wurde eine Kolonie erbeutet (Fig. II4), welche an der Basis derart abgrebrochen ist, dass noch ein kleiner Theil der zur Befestigung dienenden basalen Kalkscheibe erhalten ist. Der Stamm, dessen Spitze abgebrochen ist, ist $103 \mathrm{~mm}$. lang, ganz unten $2 \mathrm{~mm}$., in halber Höhe I mm. dick; oben verjünt er sich stark, woraus man schliessen kann, dass nur ein kurzer Abschnitt der Kolonie fehlt, vielleicht nur von $5 \mathrm{~mm}$. Länge.

Die Achse des Stammes ist ganz unten braun, nach oben zu, wie die Zweigachsen, blass-gelb mit starkem Goldglanz.

Die unteren $6 \mathrm{~mm}$. des Stammes sind gerade; von da ab trägt er Aeste und ist bei jedem Astabgang stark geknickt. Aststand $\%$, linksgewunden. Länge eines Stamm-Internodium 3 bis $4^{1 / 2} \mathrm{~mm}$., die Entfernung zweier nachfolgender Stammäste einer Verticalreihe 12 bis $14 \mathrm{~mm}$., ganz unten nur I I $\mathrm{mm}$.

Die Stammäste sind kurz; der längste ist nur I $5 \mathrm{~mm}$. lang; der Querdurchmesser der Kolonie ist denn auch nur $28 \mathrm{~mm}$.. Sehr kennzeichnend für diese Art ist, dass jeder Hauptast schon an seiner Basis oder derselben doch sehr nahe, einen schräg nach unten gerichteten Seitenast abgiebt, der oft mit der Verticalachse der Kolonie einen Winkel von nur $30^{\circ}$ und weniger bildet (Fig. 26, S. 25 und Fig. I I 4); dieser Zweig biegt bald vom Stamme ab, sodass sein End-Abschnitt

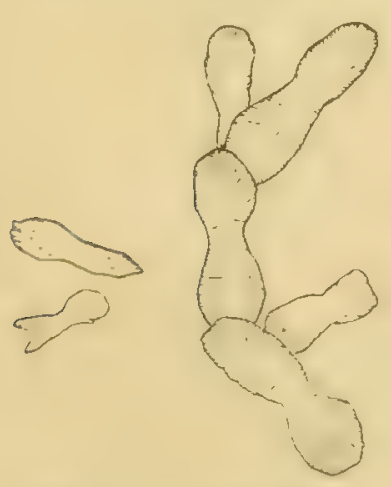

Fig. 115. Chr. pendula Scleriten der Rinde des Stammes, in nat. Lage. $\times 145$. horizontal liegt oder sogar aufgebogen ist. Er giebt einen, mitunter zwei Seitenzweige ab. Der Hauptast selber verläuft nahezu senkrecht zum Stamme, mit mehr oder weniger aufgerichtetem Spitzenabschnitt; er giebt, neben dem schon erwähnten Zweig, noch 2-3 Seitenzweige ab. Die Stammäste sind nahe der Spitze der Kolonie am stärksten, sind dort an der Basis bis ${ }^{1 / 3} \mathrm{~mm}$ dick, werden aber distalwärts bald dünn und biegsam.

Rinde dünn, auf dem Stamme mit nur wenigen Scleriten, welche zerstreut, mitunter in kleinen Gruppen zusammen liegen. Sie sind sehr dünn, mit glatter Oberfläche, meist zwischen 0,1 und $0,15 \mathrm{~mm}$. langr, bisweilen noch etwas grösser; ihre Form und relative Lage ist aus

Fig. II 5 ersichtlich. Die Rinde der Aeste enthält zahlreichere Sleriten, welche auf den dünneren SIEOGA-EXPEDITIE XII. 
Zweigen eine nahezu vollständige Schicht bilden, wobei sie mit den Rändern mehr oder weniger über einander greifen. Form und Grösse ist wie bei denen der Stamm-Rinde; ich fand o, I $73 \mathrm{~mm}$. als grösste Länge.

Nematozooiden traf ich nicht an; die Rinde ist aber stark abgerieben und an anderen

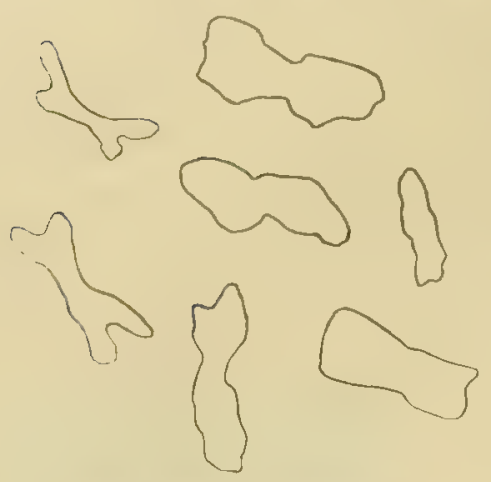

Fig. 116. Chr. pendula.

Scleriten des Rumpfes eines Polypen. $\times$ So.

Stellen mit Fremdkörpern bedeckt, sodass es möglich ist, dass Nematozooiden mir entgangen sind.

Die Polypen sind leider beinahe alle verloren gegangen. Sie fehlen auf dem Stamme; auf den Aesten fand ich einen Polyp auf jedem Internodium. Sie sind ziemlich klein, ihre Länge variirt von $\mathrm{I}, 2$ bis $\mathrm{I}, 4 \mathrm{~mm}$. bei zusammengelegten Tentakeln.

Rumpfwand mit einer dichten Schicht von Schuppen, von denen 2-3 über einander liegen. Auf Fig. I 6 sind einige dieser Kalkkörper abgebildet; sie sind bis $0,3 \mathrm{~mm}$. lang; am Ende sind sie oft gespalten.

Tentakel-Rücken, wie bei Chr. acanthella, bedeckt mit einer Längsreihe von Scleriten, welche mit ihrer grössten Länge quer zur Längsachse des Tentakel

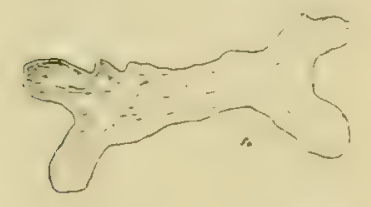

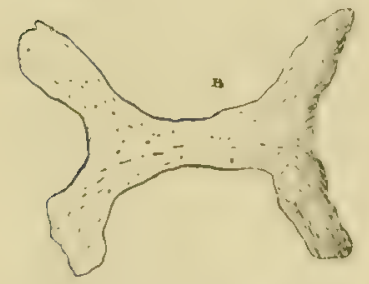

Fig. I17. Chr. pendula. Scleriten des Tentakel-Rücken $A$ von der Innenseite, $B$ von der Aussenseite gesehen. $\times 193$. liegen. Die Form der Scleriten ist aus Fig. I I 7 ersichtlich; sie erreichen einen Durchmesser von $0,22 \mathrm{~mm}$. Sie sind nahezu ganzrandig; ihre Oberfläche ist mit zerstreut stehenden, sehr feinen Wärzchen bedeckt.

In den Seitenflächen der Tentakel liegen relativ sehr grosse, bis $0,24 \mathrm{~mm}$. lange Scleriten, somit von der Länge der Scleriten des TentakelRücken. Mit dem einen, meist verbreiterten Ende (Fig. I I 8) schieben sie sich zwischen die Enden der Scleriten des Tentakel-Rücken; das andere Ende ist meist schmal und ragt, insoweit

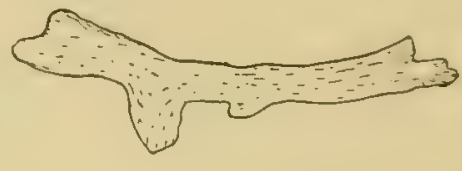

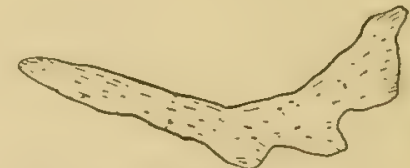

Fig. I1 8 . Chr. pendula.

Scleriten der Pinnulae. $\times 193$.

die schlecht erhaltenen Pinnulae einen Schluss gestatten, weit in letztere hinein, je ein Sclerit in eine Pinnula. Sie sind sehr dünn, mit glatter Oberfläche.

\section{Unter-Gruppe C 3 .}

Scleriten der Tentakel-Rücken alle querliegend; Aststand 1/3, linksgewunden.

28. Chry'sogorgia sibogae nov. spec.

Stat. $251.5^{\circ} 28^{\prime} .4$ S., $132^{\circ} 0^{\prime} .2$ O. Kei-Inseln. 204 M. Harter Korallensand. I Ex.

Von dieser Art liegt nur eine Kolonie vor (Fig. I I9) deren Stamm unten, anscheinend nur wenig oberhalb der Basis, abgebrochen ist. Ihre Höhe beträgt 1 I $5 \mathrm{~mm}$., ihre Breite etwa $65 \mathrm{~mm}$. Die Achse des Stammes ist braun, mit Metallschimmer, die der Aeste weiss, bei den stärkeren etwas bräunlich, mit Goldglanz. Der unten $1 \frac{1}{3} \mathrm{~mm}$. dicke Stamm wird nach ober allmählich diinner, bis er ganz oben nicht mehr von einem Ast zu unterscheiden ist. 
Aststand ${ }^{1} / 3$, linksgewunden; Länge eines Stamm-Internodium unten I mm., weiter oben $2 \mathrm{~mm}$. , in der Spitze der Kolonie $2^{2} / 3$ bis $3 \mathrm{~mm}$. Stammäste am Anfang bis $3 / 4 \mathrm{~mm}$. dick, mit sehr dünnen und biegsamen End-Internodien. Die unteren Stammäste stehen senkrecht zum Stamme, die übrigen sind nach der Spitze des Stammes zu stets mehr aufgerichtet, sodass die oberen Stammäste mit ihrem proximalen Internodium einen Winkel von nur $45^{\circ}$ mit der Längsachse der Kolonie bilden und die End-Internodien vielfach dem Stamme parallel stehen (Fig. I r 9).

Die Verzweigung der Stammäste ist ziemlich regelmässig, anscheinend dichotomisch und hat nahezu in einer Ebene statt, welche senkrecht steht zu der Ebene, die man durch den Stamm und Anfang des Hauptastes legen kann. Da aber die Stammäste meist aufgerichtet sind, liegt jene Ebene nur bei den untersten Stammäste horizontal. Der Hauptast selbst ist äusserlich nicht erkennbar. Die Stammäste erreichen eine Länge von $60 \mathrm{~mm}$; die Hauptäste zählen bis 8 Internodien, die unteren sind kürzer, mit nur 5, 4 und sogar nur 3

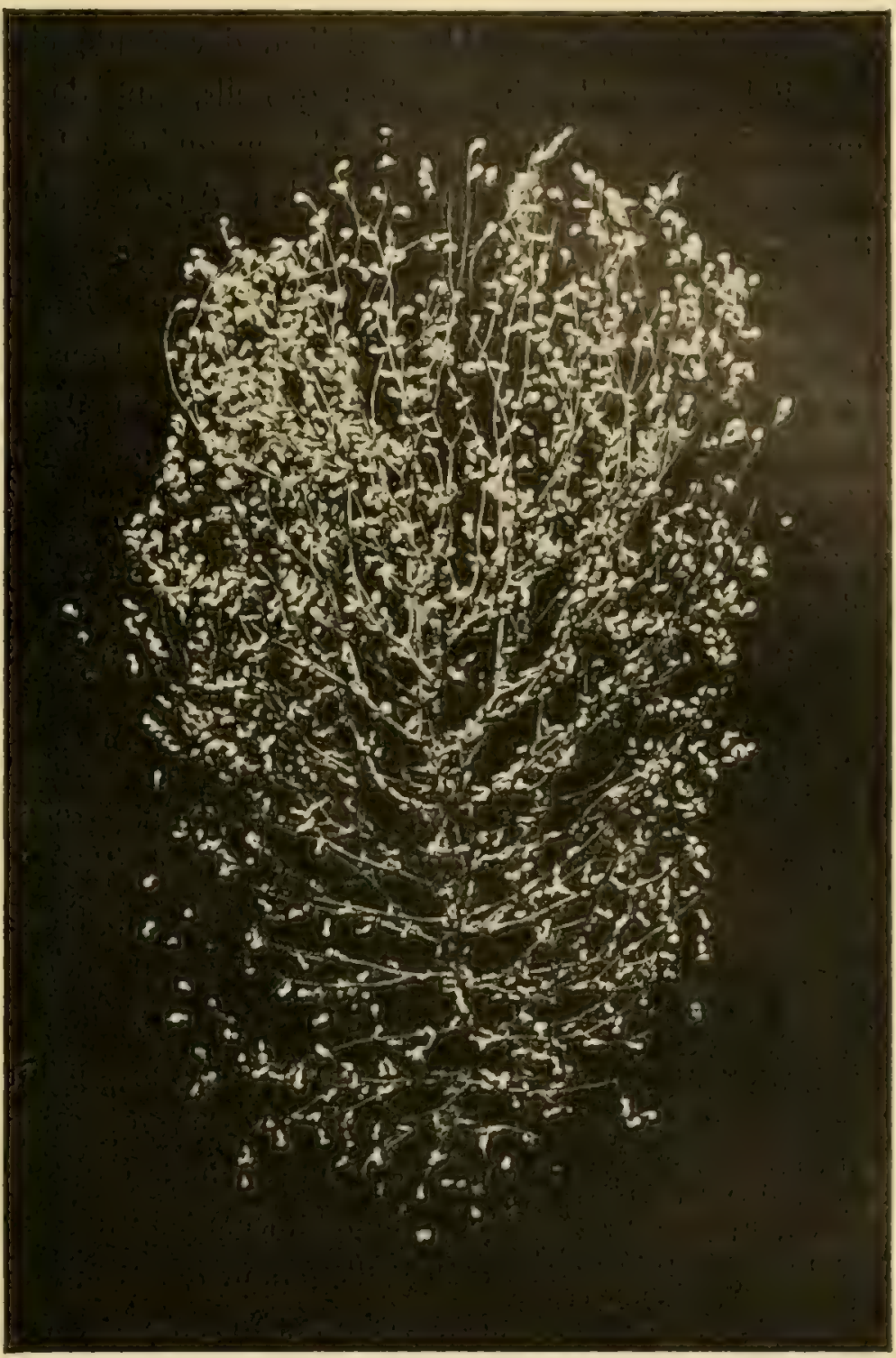

Fig. 119. Chr. sibogae. Kolonie in nat. Grösse. Internodien.

Das basale Internodium der Stammäste ist immer sehr kurz, meist nur 2 bis $3 \mathrm{~mm}$. lang, doch fand ich eins $6 \mathrm{~mm}$., ein anderes sogar $6^{1} / 2 \mathrm{~mm}$. lang. Die anderen Internodien sind 7 bis $22 \mathrm{~mm}$. lang, die terminalen sogar bis $27 \mathrm{~mm}$., meist beträgt die Länge der letzteren aber weniger als io mm..

Rinde mit sehr wenigen, ganz zerstreut liegenden Scleriten. Am zahlreichsten sind sie noch auf dem Stamme (Fig. I 20). Es sind glatte, runde oder ovale Schuppen, mit ganzrandigem aber grob gebuchtetem Rande. Die grössten haben nahezu o, I mm. Durchmesser.

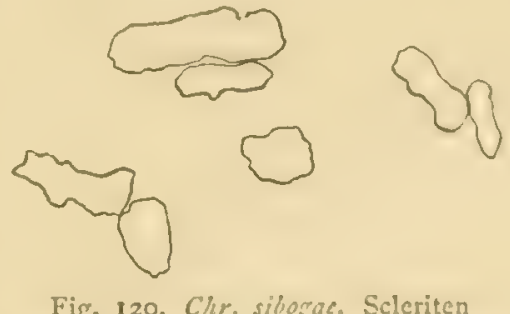

Fig. 120. Chr. sibsac. Scleriten der Stammrinde, in nat. Lage. $\times 190$.

Nematozooide auf dem Stamme und auf den stärkeren Aeste sehr zahlreich (Fig. 30, S. 30), nach den Zweigspitzen zu stets weniger zahlreich, auf dem letzten oder auch auf dem 
vorletzten Internodium fehlend. In Fig. 3 I, S. 3 I habe ich eins abgebildet. Die Länge von zwei der grösseren Nematozooiden war 0,185 und $0,143 \mathrm{~mm}$., der Querdurchmesser 0,07 resp. 0,08 mm.. Die Nematozooide verleihen der Rinde eine sammtartige Oberfläche.

Polypen zahlreich, regellos gestellt, mit der MIundöffnung nach allen Seiten gerichtet. Stamm mit je einem oder zwei Polypen auf den Internodien; dieselben sind von den Polypen der Aeste nicht verschieden. Auf den Ast-Internodien meist 2 oder 3, auf den längeren bis 6 Polypen.

Sie sind sehr verschieden gross; der grösste, den ich sah, war $3,3 \mathrm{~mm}$. lang; mit ganz vorgestreckten Tentakeln können sie wohl eine Länge von nahezu $4 \mathrm{~mm}$. erreichen. Rumpflänge bis $2 \mathrm{~mm}$., Querdurchmesser des Rumpfes bis $1,2 \mathrm{~mm}$.. Junge Polypen stehen überall zwischen den erwachsenen zerstreut. Während die jungen Polypen den Aesten mit relativ breiter Basis aufsitzen, zeigen die älteren, welche Geschlechtsprodukte enthalten, einen dickspindelförmigen Rumpf, welcher mit stark verengter Basis der Rinde aufsitzt (Fig. 30, S. 30). Solche Polypen brechen an ihrer Basis sehr leicht ab.

Polypen-Rumpf mit sehr dünnen Schuppen, welche eine dünne Schicht bilden, die in der

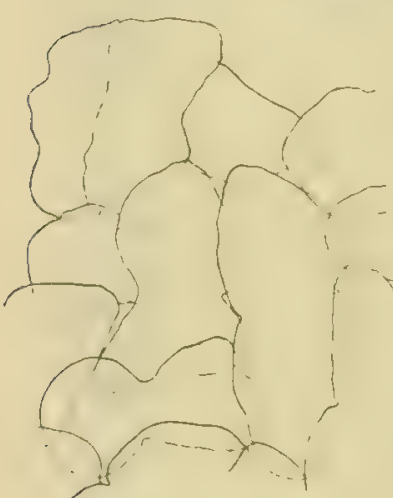

Fig. 12x. Chr. silogac.

Schuppen-Kleid des Polypen-

Rumpfes; die von snderen

Schuppen tiberdeckten Contouren

sind punctirt angegeben, $\times 145$. zu zweien neben einander (Fig. I 23, oben) und sind Mitte und in der Spitze liegen' sie aber deutlich quer. Doch ist die quere Anordnung nicht so regelmässig wie bei den beiden vorhergehenden Arten, was namentlich durch die unregelmässigere Form und das stärkere Uebereinanderschieben der Schuppen bedingt wird. Letztere liegen in der Tentakel-Mitte meist auch noch Basis zwei, in der distalen Hälfte des Rumpfes meist nur eine Schuppe dick ist. Fig. I 2 I giebt einen kleinen Abschnitt des Schuppen-Kleides wieder. Die Schuppen erreichen bis $0,23 \mathrm{~mm}$. Durchmesser. Ihr Rand ist sehr fein gezähnelt (Fig. I 22). Die Schuppen der Tentakel-Rücken sind von sehr unregelmässiger:Form; in der Basis der Tentakel liegen einige derselben schräg oder mehr in der Länge (Fig. 123); in der

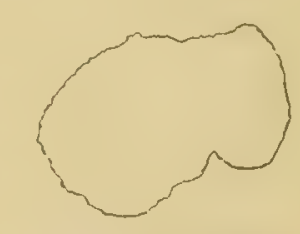

Fig. 122. Chr. sibogac. Schuppe aus dem Polypen-Rumpf. $\times 193$.

dementsprechend stark asymmetrisch, indem nur das auf der Seitenfläche des Tentakels liegende Ende verbreitert ist. In der Nähe der Spitze des Tentakels dehnen die Scleriten sich iiber die ganze Breite des Rückens aus. Einige Scleriten gleichen denen der Fig. I 7 von Chr. pondula. In der Tentakel-Basis erreichen sie $0,27 \mathrm{~mm}$., in dessen Mitte etwa $0,14 \mathrm{~mm}$. als grössten Durchmesser. Die Schuppen bedecken einander wie Dachziegel, wobei der freie Rand der Tentakel-Basis zugekehrt ist.

In den Seitenflächen der Tentakel liegen gleichfalls Schuppen von sehr unregelmässiger Form, welche sich theilweise unter die des Rückens schieben. Daneben liegen Scleriten, die bis weit in die Pinnulae

hineinreichen; es sind lange, glatte, schmale, sehr dünne Kalkkörper,

Fig. 123. Chr. sibogae.

Schuppen-Kleid der TentakelLasis. $\times 74$. an einem oder an beiden Enden etwas verbreitert. In den untersten Pinnulae sind dieselben am grössten, bis $0,134 \mathrm{~mm}$. lang, in den oberen kürzer, z.B. nur 0,06 und 0,047 mn. lang. 
29. Chrysogorgia axillaris (Wright \& Studer).

Dasy'gorgia axillaris Wright and Studer, Challenger Report, vol. 3r, I889, p. 20.

Eine Kolonie dieser Art, welche von der Station 20 I der Challenger-Expedition stammt, habe ich genauer untersucht.

Dieselbe ist bei der Basis abgebrochen, hoch $96 \mathrm{~mm}$., breit $49 \mathrm{~mm}$.. Achse des Stammes unten braun, nahe der Spitze blassgelblich; der Stamm ist unten I $\mathrm{mm}$. dick. Aststand $1 / 3$, linksgewunden. Länge eines Stamm-Internodium etwa $3 \mathrm{~mm}$.. Die Stammäste einer Verticalreihe stehen etwa $9 \mathrm{~mm}$. über einander; sie fangen $8 \mathrm{~mm}$. oberhalb der Stamm-Basis and (im Challenger Report wird $15 \mathrm{~mm}$. angegeben) und stehen nahezu senkrecht zum Stamme, nur wenig aufgerichtet. Die Verzweigung eines Stammastes findet nicht in einer Ebene statt; die Hauptäste zählen bis ro Internodien. Hauptäste, soweit ohne Untersuchung ihrer Centralcylinder geschlossen werden darf, deutlich, indem sie dicker sind als ihre Seitenäste; sie geben nur nach einer Seite, welche vom Stamme abgewendet ist, Seitenäste ab. Ihre Dicke ist höchstens I mm.. Die

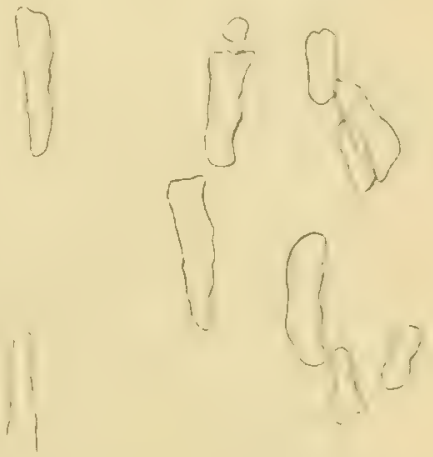

Fig. 124. Chr. axillaris. Scleriten der Kinde, in nat. Lage. $\times$ So. Internodien sind kurz, meist $3-4 \mathrm{~mm}$, mitunter bis $5,5 \mathrm{~mm}$., die meistens kurzen End-Internodien bis $6 \mathrm{~mm}$. lang. Der Winkel unter dem die Aeste sich gabeln, variirt von $50^{\circ}$ bis $90^{\circ}$ und noch mehr, beträgt aber nicht $40^{\circ}-45^{\circ}$ wie Wright und STUder angeben.

Rinde mit zerstreut liegenden, sehr dünnen, meist parallel zu den Achsen stark verlängerten Scleriten (Fig. I 24).

Nematozooide zahlreich, und wie die der vorhergehenden . Irt gebaut, aber etwas grösser. Sie haben keine Mundöffnung.

Der Stamm und das basale Internodium der Stammäste sind

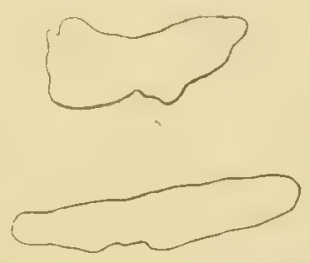

Fig. I25. Chr. axillaris. Scleriten des Polypen-Rumpfes. $\times$ So. ohne Polypen, die anderen Internodien mit einem, die terminalen bisweilen mit zwei Polypen. Die Polypen sind klein, mit vorgestreckten Tentakeln höchstens I,5 mm. lang; die Rumpflänge der grössten Polypen ist kaum $0,7 \mathrm{~mm}$., die Dicke $0,65 \mathrm{~mm}$.. Für ihre Form vergleiche man Fig. 7 auf Taf. 4 des Challenger Report; der Rumpf ist kuglig, an der Basis und unterhalb der Tentakel verengt.

Rumpf mit einer dichten, nahezu uberall doppelten Schicht von Schuppen; dieselbe liegen meist quer und sind namentlich in der Nähe der Tentakel quer zur Längsachse des Rumpfes erheblich verlängert. Die Form ist variabel; in Fig. 125 habe ich einige derselben abgebildet. Sie erreichen nach Wright und Studer $0,48 \mathrm{~mm}$. Durchmesser; unter den wenigen, die ich selbst gemessen, war keine grösser als $0,4 \mathrm{~mm}$.. Ihre Oberfläche ist glatt, der Rand sehr fein gezähnelt.

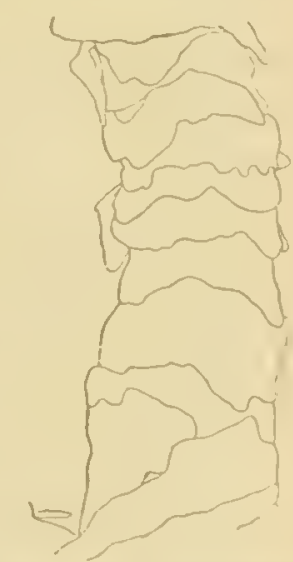

Fig. 126. Chr. axilharis. Schuppenkleid der kiickenseite der basalen IIälfte des Tcatakels. $\times \quad 1+5$.

Auf den Tentakel-Rücken liegen quere Schuppen in einer Reihe (Fig. I 26) wie Dachziegel über einander, mit dem freien Rand der Basis der Tentakel zugekehrt, 
und ohne Lücken zwischen sich zu lassen. Sie sind ziemlich breit und zeigen keine starke Verbreiterung der auf den Tentakel-Seiten liegenden Enden.

In den Seitenflächen der Tentakel liegen dünne, ziemlich breite Scleriten (Fig. 127);

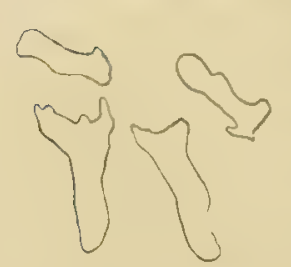

Fig. 127. Chr. axillaris. Scleriten der Pinnulae. $\times 145$ ihr eines Ende liegt in den Pinnulae und ist meist verbreitert und oft unregelmässig grob gezähnelt; das andere, zwischen die Schuppen des TentakelRücken geschobene Ende ist meist einfach gerundet. Sie sind kürzer als die Scleriten des Tentakel-Rücken und ragen sehr wenig in die Pinnulae vor.

Eine andere Kolonie, von der Station I 7 I der Challenger-Expedition stimmte in allem mit der beschriebenen Kolonie überein; Details der Scleriten wurden aber nicht untersucht.

Geographische Verbreitung: bei den Philippinen und bei den Kermadec-Inseln in 148 bis 1048 M. Tiefe von der Challenger-Expedition auf hartem und steinigem Boden erbeutet.

\section{Chry'sogorgia spec.}

Stat. I22. $1^{\circ} 58^{\prime} .5$ N., $125^{\circ} 0^{\prime} .5$ O. Bei Menado. I264-II65 M. Steiniger Grund. I Ex.

Eine nahezu vollständige Kolonie, hoch $55 \mathrm{~mm}$; vom Stamme fehlt ein, wahrscheinlich

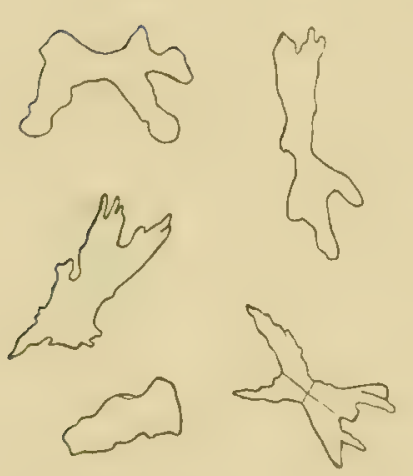

Fig. 128. Chr. spce. 30. Scleriten des Tentakel Rüches. $X 77$ kleiner, basaler Abschnitt. Aststand ${ }^{1} / 3$, linksgewunden. Länge der StammInternodien 3 bis $4 \mathrm{~mm}$., unten weniger. Stammäste nur ein bis zweimal verzweigt; die Verzweigung findet in verschieden-gelegenen Ebenen statt. Liangre der Ast-Internodien 5 bis $6^{1} / 2 \mathrm{~mm}$., der terminalen bis $10 \mathrm{~mm}$.. Rinde zart, mit einer einzigen aber ziemlich vollständigen Schicht von Scleriten. Letztere sind ziemlich lange, ganzrandige, glatte Schuppen, meist etwa $0,2 \mathrm{~mm}$. lang. Ich fand keine Nematozooide; die Epidermis ist aber sehr stark abgerieben.

Die Polypen sind mit zusammengelegten Tentakeln bis $\mathrm{I}^{3} / 4 \mathrm{~mm}$. lang, zum Theil, namentlich die Polypen auf dem Stamme, mit sehr kurzem und breitem Rumpf. Es steht ein Polyp auf jedem Stamm- und Ast-Internodium. Polypen-Rumpf
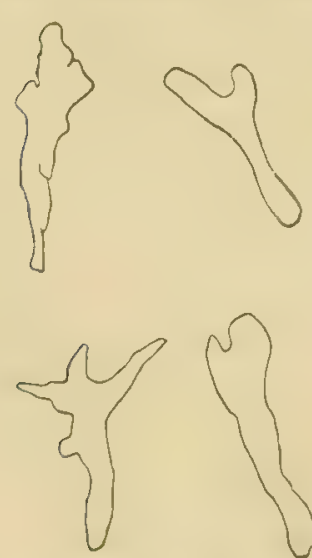

Fig. 129. Chr. spec. 3o. Scleriten der Pinnulae. $\times 77$. mit Schuppen, welche meist in einer Richtung verlängert sind, querliegend, einander wie Dachziegel bedeckend; die Kalkkörper oft 0,2 mm., mitunter bis $0,39 \mathrm{~mm}$. lang.

Tentakel-Rücken mit unregelmässig eingeschnittenen Schuppen (Fig. I2S); die Mehrzahl derselben querliegend und zwar oft zwei in der Breite des Tentakels neben einander. Grösster Durchmesser dieser Kalkkörper meist 0,2 bis $0,3 \mathrm{~mm}$.

In den Pinnulae liegen ziemlich grosse düne Scleriten (Fig. 129), welche sich mit dem einen verbreiterten Ende unter die Scleriten des Tentakel-Rückens schieben, mit dem anderen, schmalen Ende deutlich hervorragen; sie sind bis $0,35 \mathrm{~mm}$. lang.

Durch die Scleriten der Tentakel-Rücken und der Pinnulae unterscheidet diese Art sich von allen anderen Arten dieser Gruppe. Auch in der Verzweigung 
weicht sie ab. Es ist aber wahrscheinlich, dass nur eine junge Kolonie vorliegt, woraus. Verzwei. gung und Habitus der erwachsenen Kolonien nicht abgeleitet und wonach die Art selbst nicht so beschrieben werden kann, dass sie erkennbar wäre. Aus diesem Grunde habe ich dieselbe, wiewohl anscheinend neu, nicht benannt.

31. Chry'sogorgia geniculata (Wright \& Studer).

Dasy'zorgia geniculata Wright and Studer, Challenger Report, vol. 3I, I889, S. I7.

Stat. $262.5^{\circ} 53^{\prime} .8$ S., I $32^{\circ} 48^{\prime} .8$ O. 560 MI. Kei-Inseln. Harter, blaugrauer Schlamm mit oberflächlicher Schicht von weichem braunem Schlamm. 2 Ex..

Der Beschreibung im Challenger-Report kann ich beistimmen. Einige Ergänzungen, namentlich eine Beschreibung der Scleriten der Tentakel, sind aber nothwendig.

Die zwei Kolonien der Siboga-Sammlung sind viel grösser als die der Challenger-Sammlung; die eine erreicht $210 \mathrm{~mm}$., die andere $190 \mathrm{~mm}$. Länge; beide sind unvollständig. In Fig. I 30 ist die kürzere der beiden Kolonien abgebildet; ihr Stamm trägt unten einen kleinen Seitenstamm. Der Querdurchmesser der Kolonien ist im Verhältniss zur Länge gering er beträgt, nur 43 und $47 \mathrm{~mm}$; ihre Form ist die eines langen Cylinders, oben etwas breiter als unten. Die schmale, lange Form ist typisch für diese und die folgende Art. Der Stamm ist relativ dün, kaum $\mathrm{I}^{1} / 2 \mathrm{~mm}$. dick. Die Achse ist bräunlich, mit starkem, vorherrschend blauem, Metallglanz.

Aststand $1 / 3$, linksgewunden; die Entfernung zweier successiver Stammäste einer Verticalreihe beträgt Io bis $\mathrm{I} \mathrm{I}^{2} / 2 \mathrm{~mm}$., die Länge der StammInternodien etwa $3^{1 / 2}$ bis $4 \mathrm{~mm}$. Die Stammäste meist nahezu senkrecht vom Stamme abgehend, die oberen etwas schräg, aufgerichtet, aber doch immer einen Winkel von $90^{\circ}$ oder mehr mit dem nächsthöheren Internodium des Stammes bildend.

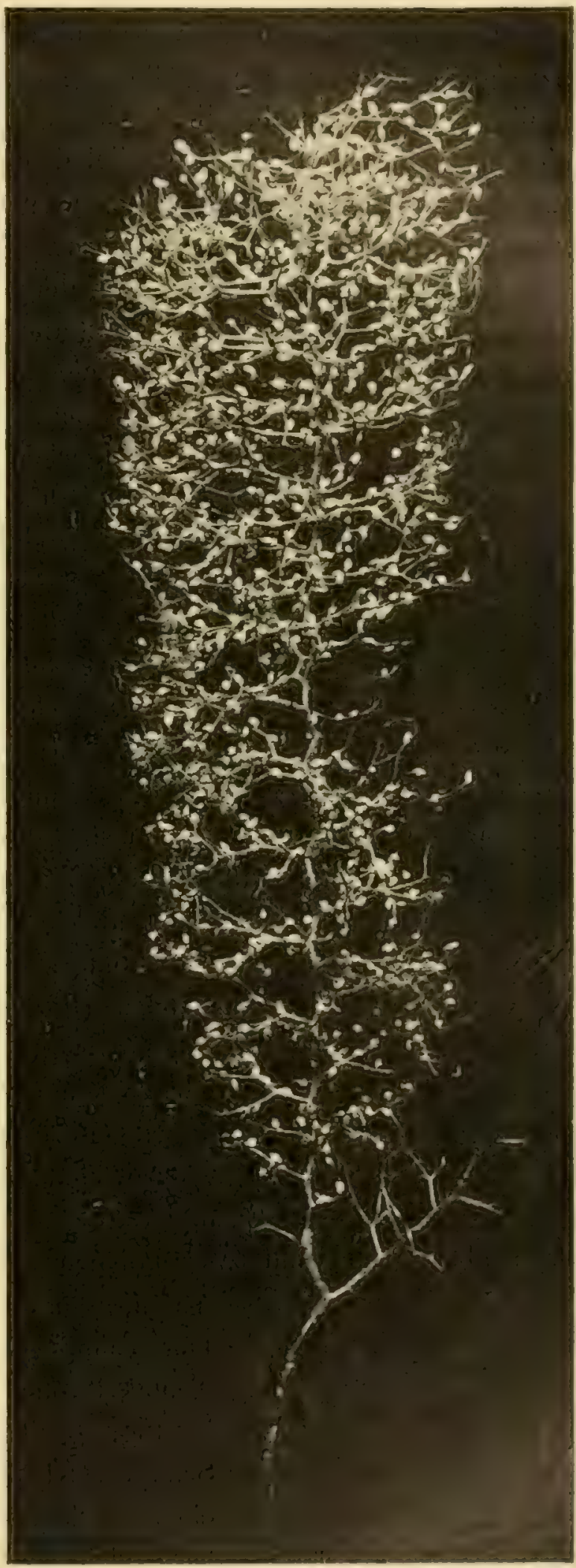

Hig. 130. Chr. geniculat?. Kolonie in nat. Grösse. Ihre Achsen sind blassgelblich, mit Goldglanz. Die unteren Stammäste sind merklich dünner 
als der Stamm, die oberen aber bis I mm. dick, also nicht viel dunner als der Stamme selber dort ist.

Die Stammäste breiten sich nicht in einer Ebene aus; die Ebene der proximalsten Verzweigung liegt meist ungefähr senkrecht zum Stamme, die weiteren Ebenen aber weichen von dieser stets mehr ab. Hierdurch erreichen die Stammäste, obwohl immer noch mehr in der Breite als in der Höhe, d. i. parallel dem Stamme ausgebreitet, dennoch in letzterer Richtung einen ziemlich erheblichen Durchmesser, namentlich in der abgebildeten Kolonie, in welcher die Endzweige der verschiedenen Stammäste einander oft kreuzen und Anastomosen bilden.

Die Hauptäste, die sich häufig durch grössere Stärke und Länge von ihren Seitenzweigen unterscheiden, haben bis 6 oder 7 Internodien und es giebt Seitenzweige bis zur $4^{\text {ten }}$ Ordnung. Die Internodien sind kurz: die basalen 5 bis $8 \mathrm{~mm}$., die anderen meist nur $5 \mathrm{~mm}$. oder nur $4 \mathrm{~mm}$. lang, die terminalen sind oft sehr kurz.

Rinde zart, mit ziemlich zahlreichen Scleriten, welche auf den Aesten oft ziemlich stark

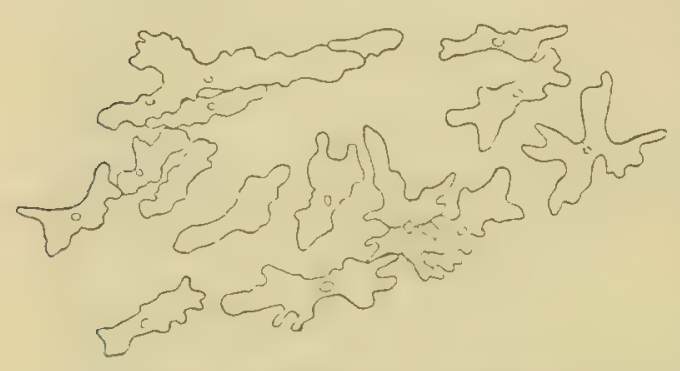

Fig. 13r. Chr. geniculala. Siboga-Ex. Scleriten der Zweigrinde in nat. Lage. $\times$ So. über einander greifen und stellenweise eine nahezu geschlossene Schicht bilden. Sie sind dünn, meist in einer Richtung deutlich verlängert und mit sehr unregelmässig gebuchteten Rändern (Fig. I 3 I). Weitaus die Mehrzahl zeigen nahe ihrer Mitte ein deutliches Höckerchen und eine von demselben ausgehende radiäre Streifung; weiter ist ihre Oberfläche bedeckt mit sehr kleinen punktförmigen, bei 30o-facher Vergrösserung kaum bemerkbaren Wärzchen. Unten auf dem Stamm sind die Scleriten mehr lang-stabförmig, viele ohne centrales

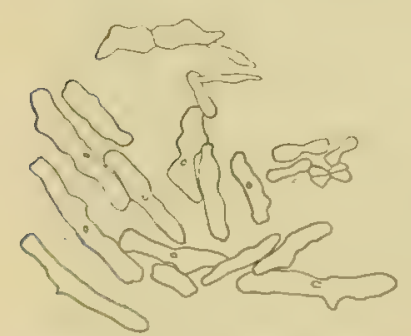

Fig. 132. Chr. geniculata. Challenger-Ex. Scleriten de! Stammrinde. $\times$ So. Höckerchen. Bei einer der Challenger-Kolonien, die ich darauf untersuchte, fand ich auf dem ganzen Stamm nur ziemlich regelmässige, in einer Richtung stark verlïngerte Scleriten, von denen viele ohne centrales Höckerchen (Fig. 132). Es giebt ziemlich viele doppelte Scleriten und Vierlinge. Als grösste Länge der Scleriten fand ich $0,3 \mathrm{~mm}$, meist aber O, I 6 bis $0,2 \mathrm{~mm}$. oder weniger.

Nematozooide fehlen.

Auf jedem Stamm-Internodium (wenigstens bei den SibogaExemplaren) steht ein Polyp; desgleichen meist auch auf den Aesten, welche aber auch wohl zwei Polypen auf einem Internodium tragen. Sie erreichen nahezu

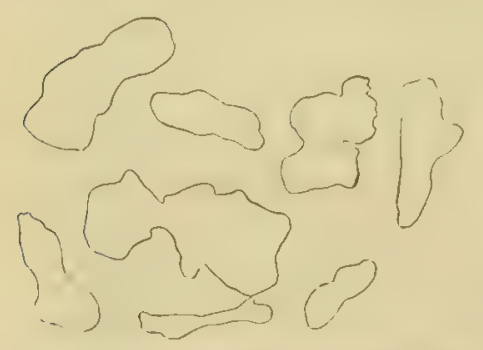

Fig. 133. Chr. geniculata. Siboga-Ex. Schuppen des Polypen-Rumpfes. $\times 60$ $3 \mathrm{~mm}$. Länge, wobei die Tentakel ziemlich weit vorgestreckt sind. Der Rumpf ist klein, nur etwa I $\mathrm{mm}$. lang, etwas unterhalb der Tentakelkrone meist stark verengt; die Form der Polypen ist in Fig. 5, Tafel + des Challenger Report gut wiedergegeben. Schuppen-Kleid ziemlich dicht, meist 2 oder 3 . Schuppen über einander liegend. Die Form der Schuppen ist aus Fig. I 33 ersichtlich; viele sind in einer Richtung bedeutend verlängert und liegen dann quer. Die Oberfläche der Schuppen ist dicht mit punktgrossen, bei 300 facher Vergrösserung eben sichtbaren Wärzchen bedeckt und dadurch wie chagrinirt. 
Auf den 'Tentakel-Rücken liegen quere Schuppen in einer Reihe über einander (Fig. I 34): die Form derselben variirt sehr, alle sind aber entsprechend der Oberfliche des TentakelRückens gebogen, und bei vielen sind die auf den Seiten der Tentakel liegenden Enden verbreitert (Fig. I 34 und I 35). Die Oberfläche ist fein chagrinirt.

Auffallend grosse Kalkkörper gehen von beiden Seiten der Tentakel ab (Fig. I 35), jeder-

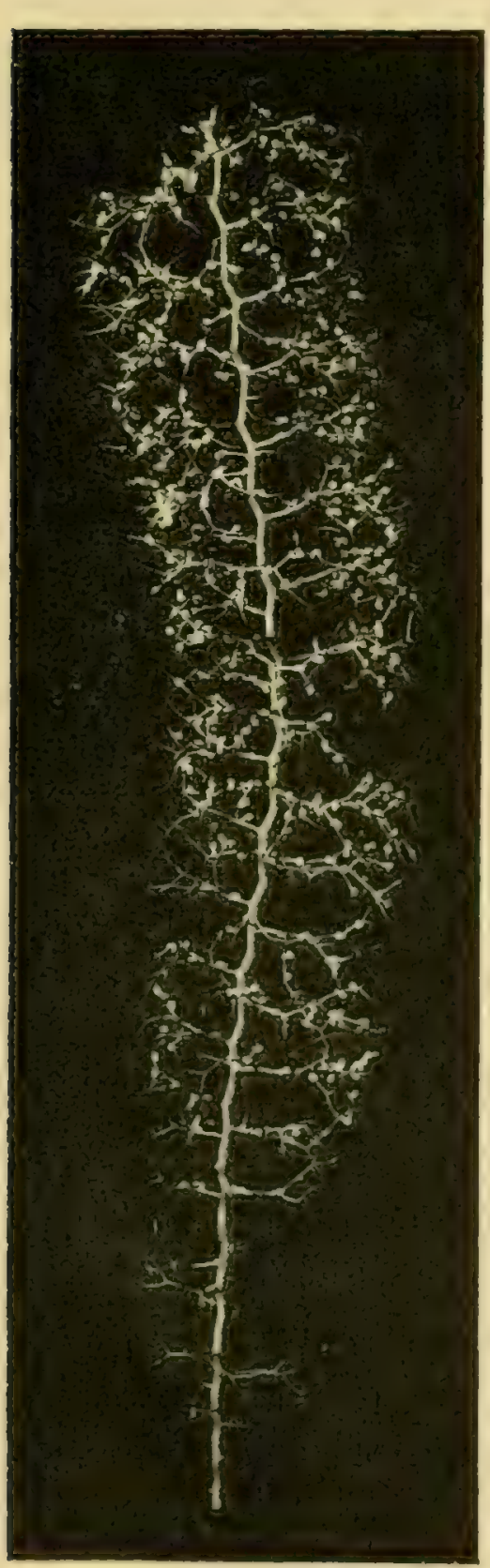

Fig. I36. Chr. rigida. Kolonie in nat. Grösse. seits 7 bis 10 in einer Reihe. Sie liegen in den Pinnulae, schieben sich aber mit ihren

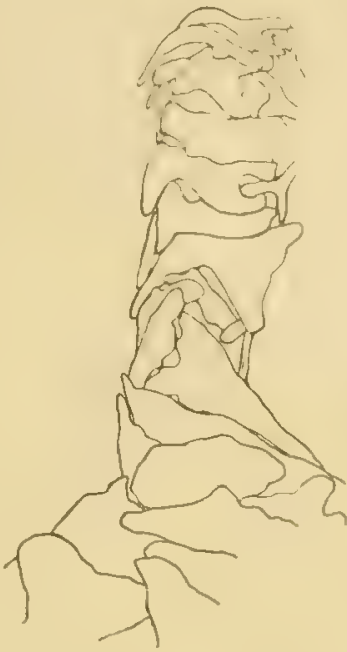

Fig. 134. Chr. artuiculata. Challenger-Ex. SchuppenKleid des Tentakel-Riickens, basale Hälfte. $\times 96$.

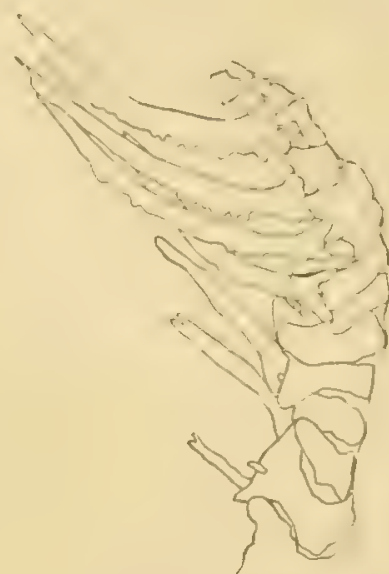

Fig. I 35. Chr. genicu.its. Challenger-Ex. Tentakel-Rücken und Pinnulae-Scleriten. in nat. Lage von der Seite gesehen. $\times 96$

\section{verbreiterten}

Bases zwischen die Seitentheile der Rückenschuppen; sie sind dünn, ziemlich breit, nach der Tentakelspitze und nach rückwärts gebogen, auch sind die Seitenränder aufgebogen zur Bildung eines Halbkanals. Diese Pinnulae-Stacheln sind bis $0,4 \mathrm{~mm}$. lang und geben den Tentakeln ein sehr stachliches Aussehen, wie es von allen Chrysogorgia-Arten nur noch die beiden folgenden Arten zeigen.

Geographische Verbreitung: bei den Philippinen und bei Japan von der Challenger-Expedition, bei den Kei-Inseln von der Siboga-Expedition erbeutet. Steiniger Boden oder Schlamm; in .148 bis 621 M. Tiefe.

\section{Chrysogorgia rigida nov. spec.}

Stat. 95. $5^{\circ} 43^{\prime} .5$ N., I I $9^{\circ} 40^{\prime}$ O. Sulu-Inseln. 522 M. Steiniger Boden; 2 grössere Kolonien und eine sehr junge.

Diese Art steht der vorhergehenden äusserst nahe, sodass es nicht ganz unmöglich ist, dass beide identisch sind.

Die grösste der vorliegenden Kolonien ist I $70 \mathrm{~mm}$. lang (Fig. I 30), die zweitgrösste Iog $\mathrm{mm}$; beicle sind aber oben und unten abgebrochen; die kleinste, vollständige Kolonie ist etwa $47 \mathrm{~mm}$. lang.

Die Unterschiede gegenüber der vor-

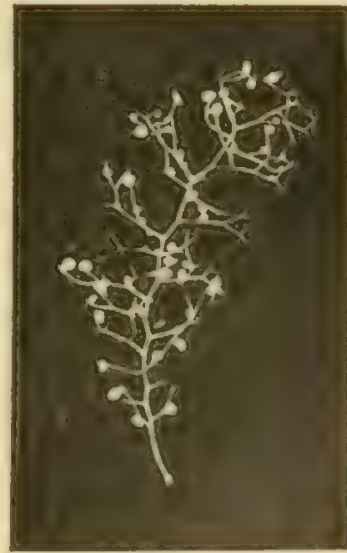

li:1:\%, $1:$. liolonie in nat. (irisse.

hergehenden Art sind folgende: Achse des Stammes viel heller, blassbriunlich mit hellblauem SILOGA-EXIEITTH: XIIT. 
Metallschimmer; sie ist bei der grössten Kolonie von unten bis nahe zur Mitte $2 \mathrm{~mm}$. dick, also viel dicker, namentlich auch im Verhältniss zu den kleineren, dünneren Stammästen. Die Entfernung zweier Stammäste einer Verticalreihe beträgt $\delta-9 \mathrm{~mm}$, bei Chr. geniculata $10-\mathbf{I}^{1} \frac{1}{2} \mathrm{~mm}$.

Die Stammäste sind vorwiegend senkrecht zum Stamme ausgebreitet; demgemäss kreuzen

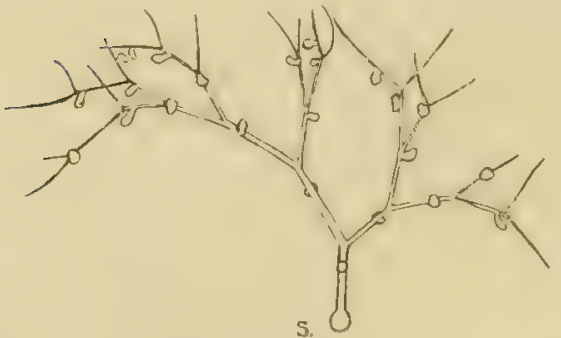

Fig. $138, C l r$, risidu.

Stammast $S=$ Stamm in Querschnitt $\times 2$ sich die Endzweige der verschiedenen Stammäste nur sehr selten und ist die Verzweigung regelmässiger als bei Chr. geniculata (vergl. Fig. I 36 und Fig. 1 30). Hauptäste, namentlich ihr proximaler Abschnitt, meist an ihrer grösseren Stärke gegenüber ihren Seitenzweigen erkennbar; sie zählen bis 7 Internodien (Fig. I 38 ).

Ast-Internodien 3 bis $4 \% \mathrm{~mm}$. lang, die End-Internodien sind die Internodien 4 bis $8 \mathrm{~mm}$. lang, im Mittel deutlich länger als bei Chr. rigida, die Stammäste demgemäss länger und die Kolonien breiter.

Schuppen der Rinde etwas kleiner als bei Chr. geniculata; Scleriten von $0,16 \mathrm{~mm}$. Länge gehören schon zu den grösseren. Im übrigen sind sie bei beiden Arten identisch. Fig. I 39 stellt

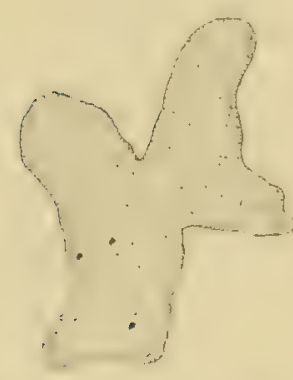

Fig. If0. Chr, rigila. Schuppe aus dem Polypen-Rumpf $\times \mathbf{1 4 5}$. einige derselben, in der Rinde liegend, dar.

Stamm ganz ohne Polypen, auch bei der jungen Kolonie.

Die Polypen gleichen denen von $C / 2 x$. Basis in gcniculata, auch ihre Scleriten. In Fig. I 40 habe

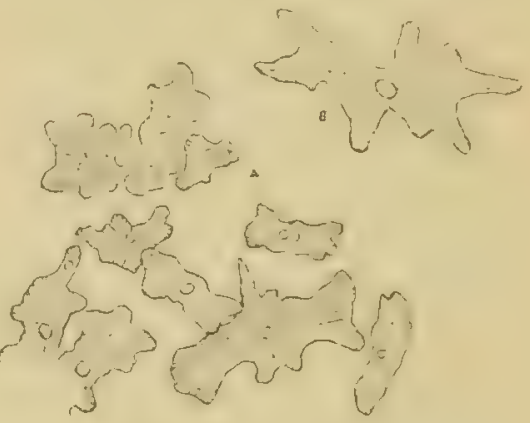

Fig. 139. Chr. rigidu

A Schuppen von der Kinde der StammZweigrinde. $\times 145$. ich einen Rumpf-Scleriten, in Fig. I 4 I einige Scleriten der Tentakel-Rücken und in Fig. 142 zwei Pinnulae-Scleriten bei so starker Vergrösserung dargestellt, dass auch die Oberflächensculptur noch angegeben werden konnte. Die Wärzchen sind auf den Scleriten des Tentakel-Rücken grösser als bei den Rumpf-Scleriten. In Fig. I42, $A$ und $B$, ist die Halbkanalform der Kalkkörper der Pinnulae sehr deutlich.

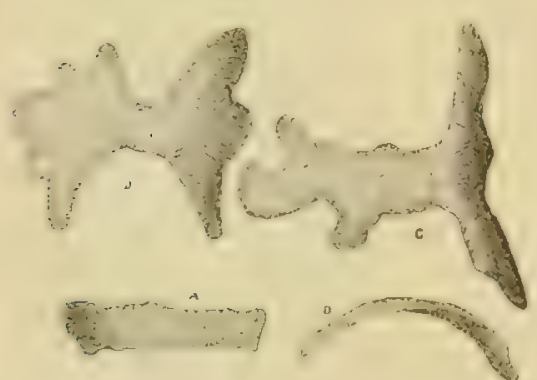

Fig. 141. "Chr, rizilu. Scleriten des Sic Tentakel-Kückens; 1 und 13 ein kialkkörper von ter concaren Seite und ron der liante geschen; D und $C$ zwei Kallkörper you Boden festgewachsen war.

Die kleine Krolonie, die in Figr. 137 abgebildet ist, bringe ich zu dieser Art, weil sie, von derselben Localität stammend, die gleichen Polypen und den gleichen Aststand hat und ihr auch Polypen auf den Stamm abgehen. Der Stamm dieser Kolonie verbreitert

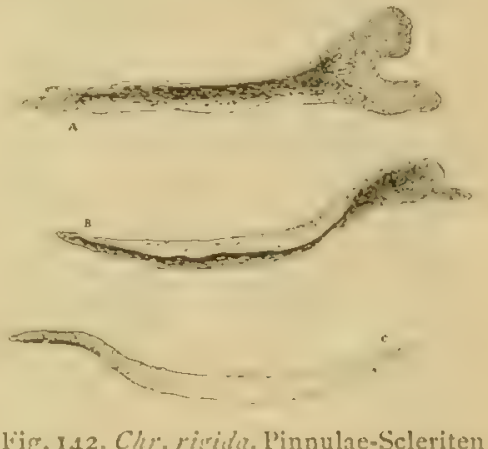

lig. X42. Chr. risida. l'innulae-Scleriten: A von der breiten Scitc, B derselhe kialkkörper halb von der schmalen Seite, $\mathrm{C}$ ein anderer ganz von del schmalen Seite geschen. $X \mathbf{1 4 5}$.

Der abweichende Habitus und das Fehlen von Polypen auf dem Stamm sind die Merkmale auf denen die Trennung dieser Art von Chr. grniculata beruht. 
Der Werth dieser Unterschiede lässt sich aber eigentlich nur an einem weit grösserem Materiale beurtheilen. Ich habe ja oben unter den Namen Chr. pentasticha 2 Kolonien, die eine mit, die andere ohne Stamm-Polypen vereinigt, da sie im übrigen identisch sind. Dem gleichen Unterschied bei Chr. gcniculata und rigida kann ich desshalb auch kcinen entscheidenden I'erth beimessen. Bei letzteren Arten ist aber auch der Habitus der Kolonien sehr verschieden, was bei den beiden Kolonien von Chr. pontasticha nicht der Fall ist. Ich glaube aber, dass es in einem zweifelhaften Falle besser ist, die Kolonien nicht zu einer Art zu vereinigen; denn das füht zur Aufstellung von Sammelarten, welche später zu vielen Schwierigkeiten Anlass geben können.

\section{Unter-Gruppe C 4 .}

Schuppen des Tentakel-Rückens querliegend; Aststand ${ }^{1} / 4$, linksgewunden.

\section{Chry'sogorgia ramosa nov. spec.}

Stat. $95.5^{\circ} 43^{\prime} .5$ N., $119^{\circ} 40^{\prime}$ O. Sulu-Inseln. 522 M. Steiniger Boden. 5 Fragmente.

Ein Fragment zeigt einen $31 \mathrm{~mm}$. langen Stammabschnitt (Fig. $143 \mathrm{~A}$ ), der $2 \mathrm{~mm}$. dick ist und grülichen Goldglanz hat. Aststand ${ }^{1} / 4$, linksgewunden. Die Stammäste entspringen in sehr kleinen Entfernungen von einander; die Stamm-Internodien sind denn auch unten nur $x$, oben $3 \mathrm{~mm}$. lang. Ganz oben ist der Aststand unregelmässig und verjügt der Stamm sich schnell, während die Stammäste oben viel stärker sind, bis $\mathrm{r}^{1} / \mathrm{m}$ m. dick an ihrer Basis. Das grösste Fragment, ein abgebrochener Ast, erreicht nahezu I $10 \mathrm{~mm}$. Länge (Fig. $143 \mathrm{~B}$ ) und hat bis 16 successive Inter-

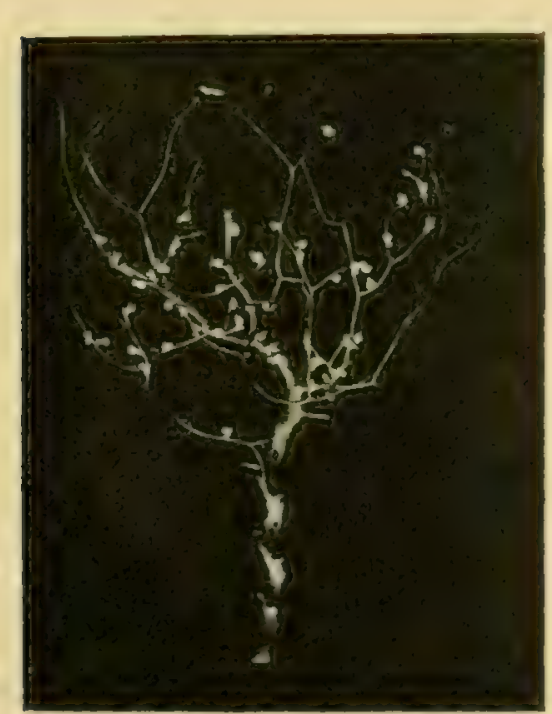

Fig. 143 A. Chr. ramosa Fragment $m$ it Stammabschnit, elwas weniger als nal. Grösse. nodien. Der nächstgrössere Ast ist $75 \mathrm{~mm}$. lang. Den Verlauf der Achsencylinder habe ich, um das spärliche Material zu schonen, nicht verfolgt; die Verzweigung ist aber äusserlich nicht von der anderer Chysogorgia-Arten verschieden.

Die Stammäste breiten sich vorherrschend in einer Ebene senkrecht zum Stamme aus; die dünneren Endzweige sind meist etwas aufgerichtet, also von der Basis der Kolonie,

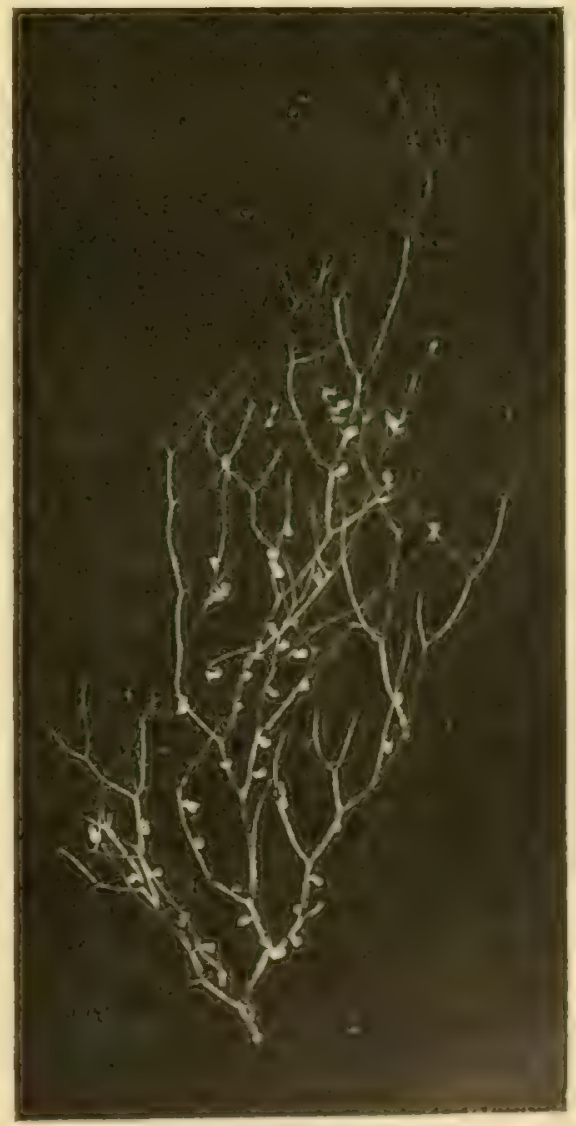

Fig. $14313, \cdots \cdot \quad$. Fragment, etwas weaiger als nat. Git.

vom Boden abgewendet. Die Achsen der Zweige haben einen starken, dunkeln Goldglanz, nur die dünnsten sind heller. Die Länge der Internodien wechselt von + bis Io-I $2 \mathrm{~mm}$.. 
Die Rinde des Stammes enthält ziemlich viele Scleriten, welche einander of theilweise bedecken. Ihre Form und Lage ist aus Fig. I44 ersichtlich; sie sind dünn, ihre Oberfläche

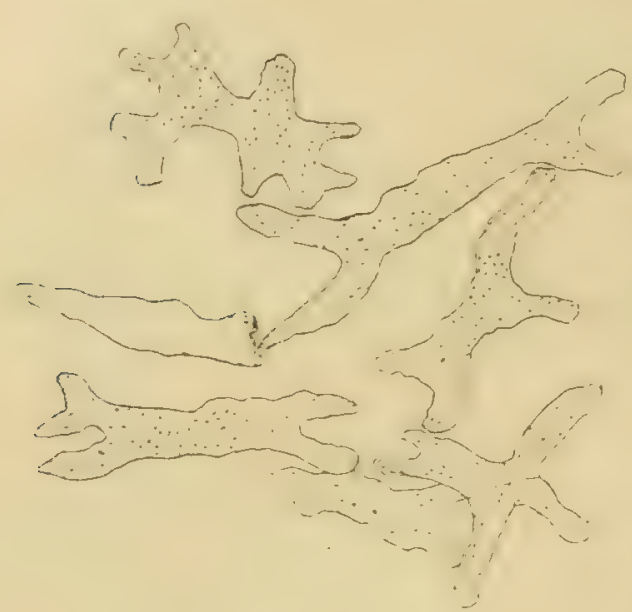

rig. I 44. Chr. romosa.

Scleriten der Stammrinde in nat. Lage. $\times 193$. trägt feine Wärzchen und ihr Durchmesser beträgt bis 0,2 und sogar $0,24 \mathrm{~mm}$..

In der Rinde der Zweige sind die Kalkkörper weniger zahlreich, fehlen oft in grösseren Längsstreifen derselben; auch sind sie dort kleiner, nur bis o, I $4 \mathrm{~mm}$. lang, mit nahezu glatter Oberfläche und abgerundeten, oft verbreiterten, aber ungetheilten Enden (Fig. 145).

Nematozooiden fehlen.

Ein oder zwei Polypen auf den Ast-Internodien, auch auf den proximalsten. Auf dem Stamme ist die Rinde grösstentheils abgerieben, auf den kleinen erhaltenen $\mathrm{Ab}$ schnitten derselben stehen aber keine Polypen.

Die Polypen sind mit vorgestreckten Tentakeln bis $2^{1 / 2} \mathrm{~mm}$. lang, werden möglich noch länger; mit zusammengelegten Tentakeln sind sie bis $2 \mathrm{~mm}$. lang, meist kürzer. Die Rumpflänge ist wohl immer weniger als I mm., die Dicke etwa

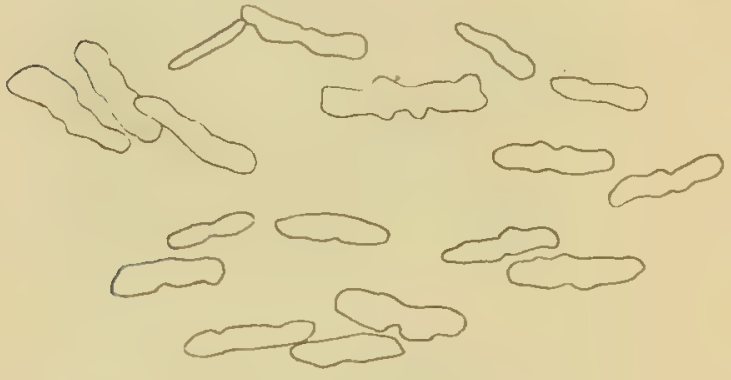

Fig. 145. Cl\%. ramtosa.

Scleriten der Zweigrinde in nat. Lage. $X 120$. $0,8 \mathrm{~mm}$.. Die Form ist wie bei der vorhergehenden Art, d. i. mit kleinem etwas oberhalb der Nitte verengtem Rumpf und mit langen starken Tentakeln.

Schuppenkleid des Polypen-Rumpfes wie bei der vorhergehenden Art, nur sind die Schuppen ganz glatt; die Form von vielen ist wie die in Fig. I fo von Chr. rigida abgebildete Schuppe; ihr grösster Durchmesser bis $0,32 \mathrm{~mm}$.

Schuppen der Tentakel-Rücken gleichfalls wie bei Chr. geniculata und rigida, nur vielleicht noch etwas unregelmässiger von Form. Länge dieser Schuppen, quer zur Tentakellänge, bis $0,18 \mathrm{~mm}$., nach der Tentakel Spitze zu immer kleiner. I ie ()herhiche derselben ist watt.

Scleriten der Pinnulae gleichfalls sehr lang (Fig. 146), sodass sie den Tentakeln ein stachliches Ansehen verleihen; meist sind ihre distalen, in den Pinnulae liegenden Enden (bei welchen in Fig. I 46 die Buchstaben A und $B$ stehen) etwas verbreitert. Länge bis $0,34 \mathrm{~mm}$., Breite in der Nitte der Scleriten (wo dieselben am schmalsten sind) meist etwa $0, \mathrm{O}_{4} \mathrm{~mm}$.. Ründern aufgebogen, sodass eine Hache Rinne gebildet

Fig. 146. Chr. ramosa. I'inumlae-Scleriten, A v. d. concaven, B. v. d. schmalen Seite. $\times 1.45$. wird. Die Scleriten sind gebogen, mit der Concavität nach der Spitze und Riickenseite der Tentakel gerichtet. Die Tentakel zeigen jederseits etwa ro solcher Scleriten.

Geographische Verbreitung: nur in der Sulu-See bei den Sulu-Inseln wie oben angegeben (Siboga-Expedition). 
Folgende drei Arten gehören wahrscheinlich auch zu den Squamosae typicac; aber es fehlen specielle Angaben über die Scleriten ihrer 'Tentakel.

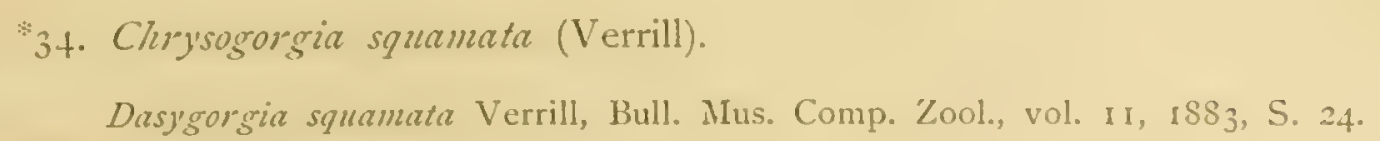

Die Beschreibung, welche VerRILL von dieser Art gegeben hat, ist sehr kurz, ohne Abbildungen und ist gegenwärtig, seitdem mehrere Arten mit Schuppenkleid im Rumpfe der Polypen bekannt geworden sind, wohl nicht genügend.

Geographische Verbreitung: In West-Indien bei St. Vincent und bei Barbados in I03 I resp. 427 M. Tiefe von der Blake-Expedition erbeutet.

\section{Chrysogorgia desbonni. Duch. \& Nich.}

Chrysogorgia desbonni Duchassaing et Michelotti, Memorie d. R. Accad. di Torino, Ser. 2, vol. 23,1866, S. 107 und II5.

Chrysogrorgia desbonni Duchassaing de Fontbressin, Revue des Zoöphytes et des Spongiaires des Antilles, Paris 1870 , S. 17 .

Nach Wright und STUder ${ }^{1}$ ) soll die unter diesem Namen von Duchassaing und Michelotti auf S. I 15 (1. c., im Separatdruck S. 2 I) beschriebene Art eine andere sein als die der S. 107 (Separatdruck S. I5). Wäre dies richtig, so müsste die zuletzt, also auf S. I I 5 beschriebene Art neu benannt werden und dürfte man den Namen Chrysogorgia desbonni nur für die zuerst, S. IO7, beschriebene, nach WRIGHT und Studer (1. c. S. 23) zu den Primnoidac oder Isidac gehörige Art beibehalten. Es scheint mir aber nicht zweifelhaft, dass beide Beschreibungen sich auf dieselbe Art beziehen. Zunächst finde ich weder in den Figuren noch in den Beschreibungen Unterschiede zwischen beiden, weiter hat auch Ducmissaing später (1. c. I\$;o) hervorgehoben, dass beide Beschreibungen sich auf die nämliche Art beziehen.

Die von Duchassativg und Michelotti gegebenen Beschreibungen sind sehr kurz, doch scheint mir die Art daraus und aus den Figuren erkennbar, falls nicht zufällig einige einander ähnliche Arten in dieser Gegend, Guadeloupe, vorkommen.

Aus der Beschreibung und den Abbildungen geht Folgendes hervor: Die kleine Kolonie erreicht eine Höhe von So $\mathrm{mm}$. und hat einen deutlichen Stamm, der unten I mm. Dicke hat und von seiner Basis an nach allen Seiten Stammäste abgiebt. Ob letztere in einer regelmässigen Spirale stehen, ist aus der Figur (Taf. 4, Fig. 5) nicht ersichtlich, aber wohl möglich; sie entspringen 2-3 mm. über einander. Die Stammäste sind sehr lang, alle stark aufgerichtet. bilden einen Winkel von etwa $45^{\circ}$ mit dem Stamme und erheben sich weit uiber die Spitze des Stammes. Sie sind stark verzweigt und aus der citirten Figur ist ersichtlich, dass die Aeste oft über grössere Strecken nur nach einer Seite Seitenzweige abgeben. Letzteres deutet darauf hin, dass die Regel der einseitigen Verzweigung auch fuir diese Art zutriff, dass also Aeste die nach zwei Seiten Zweige abgeben, sympodial gebaut sind. Die Stammiste haben bis zu $11-1,3$

1) Challenger keport, vol. 3I, S. I und S. 23. 
successive Internodien; die Länge der letzteren ist 4 bis $7 \mathrm{~mm}$. Die Achsen sind bernsteinfarbig. Die milchweisse Rinde ist dün, besteht aus, mit der Loupe sichtbaren Schuppen (Duci. et Micri. 1. c. S. I07: „cortice tenui, sub lente squamulis perparvis composito").

Auf dem Stamme und den proximalen Ast-Internodien fehlen, der Figur nach, die Polypen. Weiter stehen I bis 3, meist nur ein Polyp auf jedem Ast-Internodium. Sie sind etwa I mm. lang, mit verschmälerter Basis den Aesten aufsitzend; mit Schuppen in der Wand (1. c.: „squamosis"). Der Mund ist nahezu 8-lappig (1. c.: "ore terminali sub-8-lobato"), womit wohl die Basen der acht Tentakel gemeint sind, welche also nicht ganz im Rumpf zurückgezogen sind. In der Gegend der Tentakel sind die Polypen, nach den Figuren, am breitesten, nach der Basis zu trichterförmig verjüngt.

Die Art wurde in mehreren Exemplaren bei dem Hafen Moule der Insel Guadeloupe von Herrn Desbonnes gesammelt. Leider sind, nach Wright und Studer (1. c. S. 23), die Typen dieser Art verloren gegangen, jedenfalls nicht im Museum zu Turin, wo die Typen der anderen von Duchassaing und Michelotti aufgestellten Arten sich befinden, vorhanden.

Verrill betrachtet gleichfalls die beiden Beschreibungen von Dichassaing und Michelotit als zu einer Art gehörig; denn er citirt dieselben beide ${ }^{1}$ ). Es scheint mir aber nicht zweifelhaft, dass VerRill unter den gleichen Namen eine ganz andere Art beschrieben hat. Erstens würden Duchassaing und Michelotti einer fächerförmigen Verzweigung, wie sie Verrill's Art zeigt, wohl Erwähnung gethan haben, auch deutet sowoh1 Duchassaing und Michelotti's Figur wie ihre Angabe, dass die Art ,arborescent" ist (1. c. S. I I 5), mehr auf ein allseitiges Abgehen der Stammäste. Zweitens hat Verrill's Art in der Rinde höckerige, unregelmässige Kalkkörper, Chr. desbonni Duch. \& Mich. aber Schuppen (siehe Duch. et Mich., 1. c. Taf. I, Fig. 7, 8). Drittens ist die Form der Polypen verschieden: bei Verrill's Art cylindrisch, bei der anderen mit verschmälerter Basis. Als letzter, wichtiger Unterschied kommt dazu noch, dass Duchassarag und Michelotti's Art im Polypen-Rumpf nur Schuppen hat, Verrill's Art in der Basis der Polypen querliegende, warzige, gebogene Spicula. Man vergleiche hierfür nur VElrRiLl's Figur 6, Taf. 2, mit Duchassaing und Michelottis Figuren 7 und 8, Tatel I.

Ich habe V'ERriLL's Art, die zu der Unter-Gruppe A 3 gehört, denn auch neu benannt und auf S. 56 als Chr. occidentalis aufgeführt.

\section{Chrysogorgia fruticosa (Studer).}

Dasy'gorgia fruticosa Studer, Bull. Mus. Comp. Zool., vol. 25, I894, S. 6I.

Nur nach einer vorläufigen Beschreibung bekannt. Die Art unterscheidet sich von den Squamosae typicae dadurch, dass die Schuppen des Polypen-Rumpfes biscuitförmig sind und mit ihrer längsten Achse der Polypen-Längsachse parallel gelagert sind. Ueber die Scleriten der Tentakel wird nichts angegeben, sodass die Art sich nicht genau einreihen lässt. Der Aststand ist $1 / 3$, die Art der Drehung, ob links- oder rechtsgewunden, ist unbekannt. Fur die Diagnose 
der Art sei auf die originale Beschreibung verwiesen. Im Habitus ist die Art der Chr. cupresse $\mathrm{Wr}$. \& St. ähnlich.

Geographische Verbreitung: Nahe der Westkuiste Central-Amerika's unweit Panama, in $\delta_{2} 4$ II. Tịele. (Albatross-Expedition).

Metallogorgia nov. gen.

Achsen rund, mit glatter Oberflïche und starkem Metallglanz. Kolonien mit deutlichem, monopodial gebautem Stamme, welcher nur wenige Seitenzweige abgiebt, sich am Ende aber einige Male durch Abgabe gleichstarker Seitenäste anscheinend dichotomisch theilt und sich auföst, indem er sich sehr stark verzweigt (Fig. 147 und I48). Die Aeste verzweigen sich nach derselben Regel der einseitigen Verzweigung wie beim Genus Chrysogorgia (S. 25); die nach zwei Seiten Zweige abgebenden stärkeren Aeste sind Sympodien (Fig. I 49). Rinde diinn, mit wenig zahlreichen Scleriten. Die Scleriten zeigen weder in der Rinde noch in den Polypen eine Sonderung in eine oberflächliche und eine tiefere Schicht von verschierlener Form.

Das Genus unterscheidet sich von Chrysogorgia nur durch den monopodialen Stamm, wodurch eine ganz andere Verzweigung der Kolonie bedingt wird: W'enn bei einem ursprünglich monopodialen Stamme der unterste Seitenast immer stärker wird als der distale Abschnitt des monopodialen Stammes, übernimmt der Seitenast ja die Fortsetzung des Stammes der Kolonie und ist derselbe sympodial. In solcher Weise könnte sehr gut die sympodiale ChrysogorgiaKolonie aus eine Art mit monopodialem Stamme hervorgehen.

Nur eine Art:

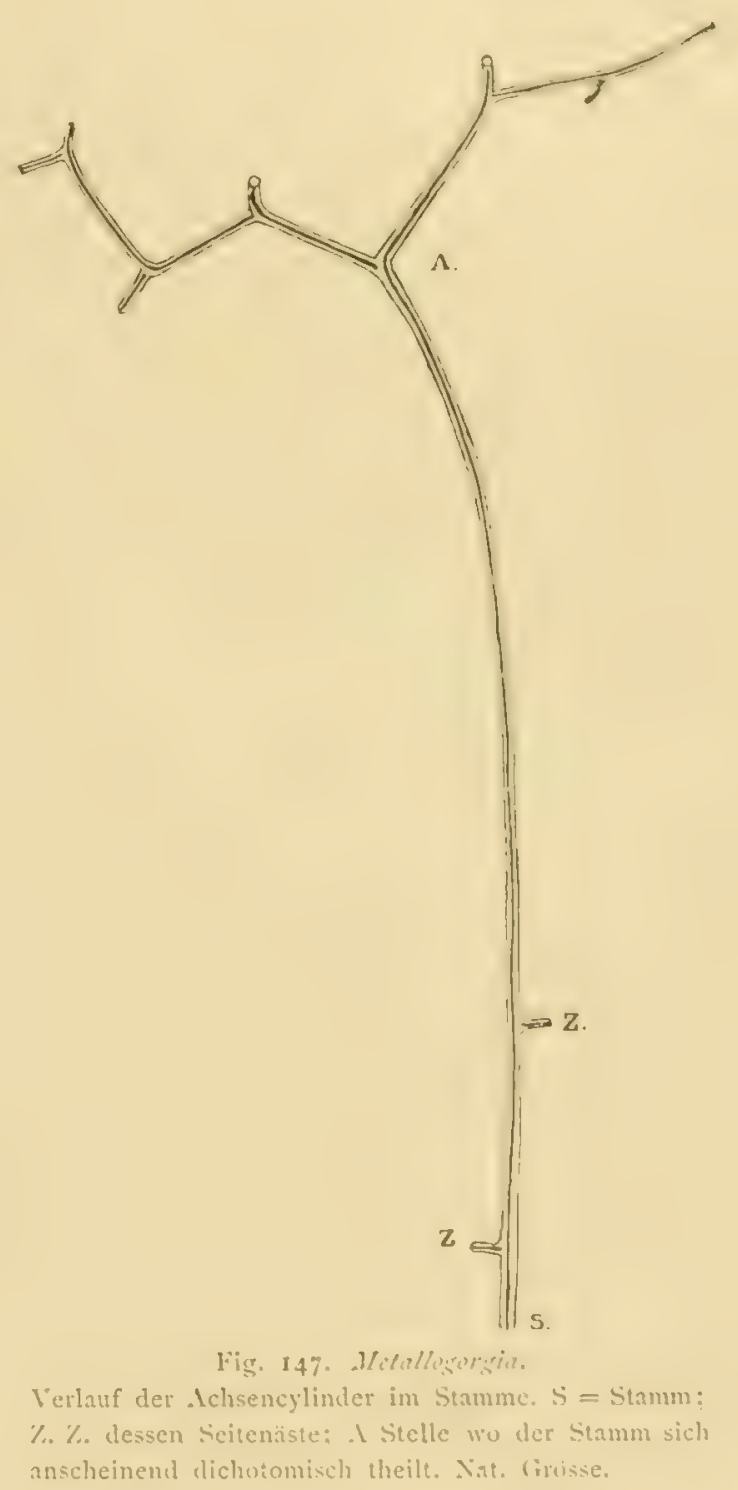

1. Metallogorgia melanotrichos (Wright \& Studer).

Dasygrorgia melanotrichos IVright and Studer, Challenger Report, vol. 31 , IS89, S. 15 und 275.

Stat. $135.1^{\circ} 34^{\prime}$ N., $126^{\circ} 54^{\prime}$ O. Nördlich von Ternate. I994 MI. Sandiger Grund. Ein Stamm mit den oberen Verzweigungen, welche zu dieser Art oder zu ciner sehr nale verwandten gehört. P'olypen und Rinde waren vollständig abgerieben.

Stat. 286. $8^{\circ} 50^{\prime} .2$ S., $127^{\circ} 2^{\prime} .20$. Südlich von Timor. $88_{3}$ 1I. Schlamm (in einer duinnen Lage). I Ex. 
Die im Challenger Report S. I5 beschriebene junge Kolonie habe ich nicht gesehen, wohl die im Appendix S. 275 beschriebenen. Dies ist zu bedauern, da bei ersterer die unteren Seitenäste des Stammes noch erhalten sind, während dieselben bei den anderen und bei der Sibura-Kolonie an ihren Bases abgebrochen sind, sodass ich ihre Terzweigung nicht angeben kann.

Die nachfolgende Beschreibung gründet sich auf die Untersuchung der einen Kolonie der Siboga-Sammlung von Stat. 286 (Fig. I48). Es ist die grösste Kolonie, welche von dieser Art bekannt ist.

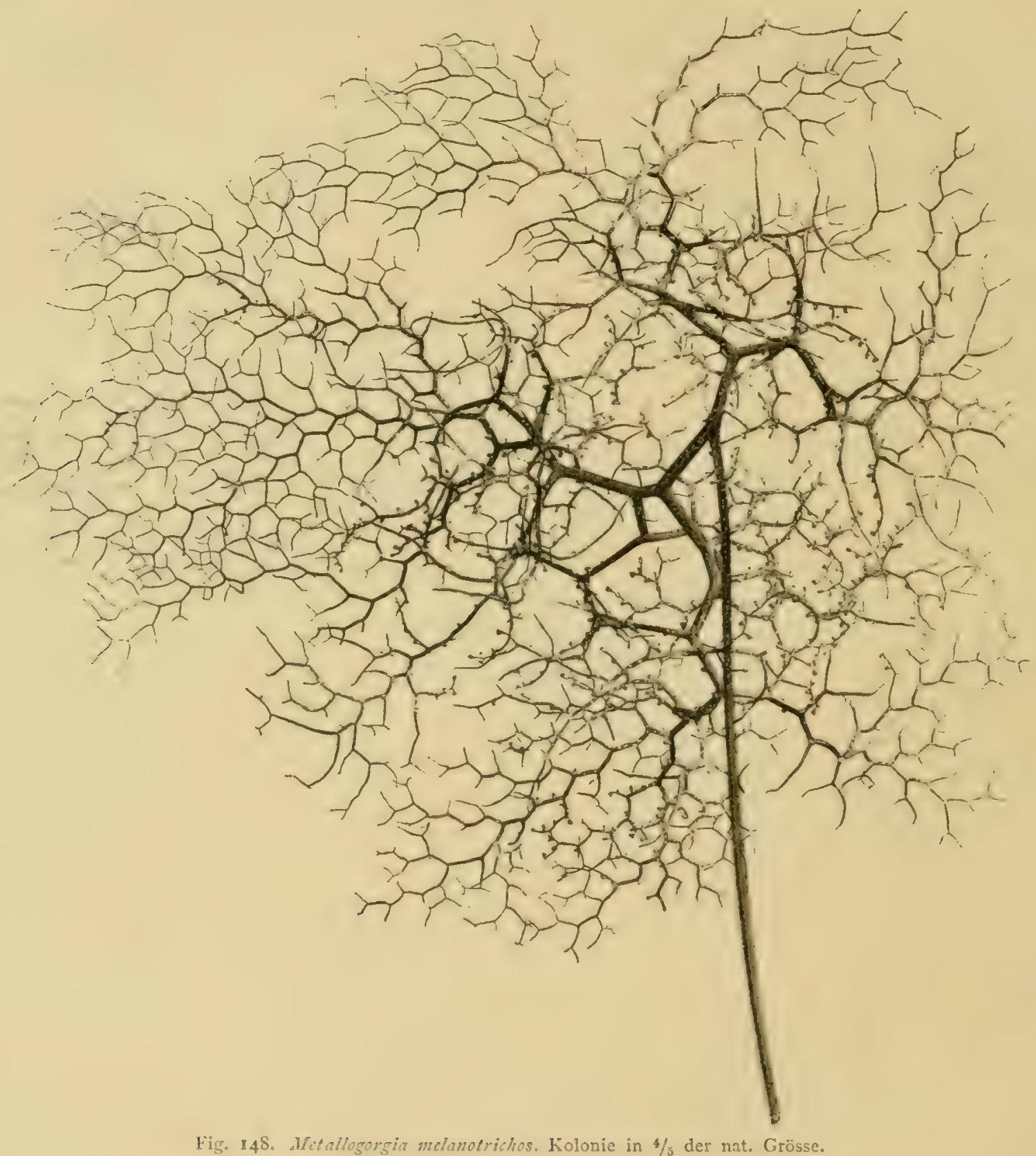

Der Stamm ist $730 \mathrm{~mm}$. lang; seine Achse wird ganz unten schnell stärker, erreicht dort eine Dicke von $5 \frac{1}{2} \mathrm{~mm}$. und ist dann abgebrochen; die starke Zunahme ist wahrscheinlich so zu deuten, dass sie hier in eine kalkige Basalplatte überging. Oben, bei der ersten Gabelung, hat der Stamm $2 \mathrm{~mm}$. Durchmesser. 
Die Achse ist dunkel, mit sehr starkem grünem Metallglanz; sie zeigt schwache Knickungen, an deren Aussenseite sich stets der Ansatz eines abgebrochenen Seitenastes findet. Mehrere Schliffe durch den Stamm der Kolonie der Stat. 135. Siboga-Exp., ergaben, dass jeder Seitenast auch mit einem neuen Achsencylinder anfängt, der Achsencylinder des Stammes aber im Stamme bleibt. Hieraus habe ich auf den monopodialen Bau des Stammes der M. melanotrichos geschlossen.

Die Stammachse trägt ganz unten die Narben von zwei sehr starken Seitenästen; die anderen Seitenäste sind alle sehr viel dünner als der Stamm und stehen nach oben zu immer weiter aus einander, der höchste $S 0 \mathrm{~mm}$. über dem nächstunteren; ein $285 \mathrm{~mm}$. langer oberer Theil des Stammes trägt gar keine Seitenäste. Die Astursprünge am Stamme stehen in einer rechtsgewundenen Spirale, aber unregelmässig.

Oben giebt der Stamm einen dicken Ast ab, ist selbst erheblich seitlich geknickt und verzweigt sich dann weiter stark, ganz wie dieser starke Seitenast (Fig. 148). Der Stamm ist von da ab nicht weiter erkennbar (vergleiche auch Fig. I47). Die Winkel der proximalen Gabelungen sind stumpf, die der anderen Gabelungen meist $90^{\circ}$ oder weniger.

Die Ausbreitung der Aeste findet vorherrschend in einer Schicht; senkrecht zum End-Abschnitt des Stammes statt; die dickeren Aeste sind etwas aufyerichtet. I)er gröisste Durchmesser der Kolonie, senkrecht zum Stamme, beträgt etwa $220 \mathrm{~mm}$, die Dicke, parallel clem Stamme, \pm 90 mm.. Man kann cine dem Stamme zugewendete Unterseite und eine vom Stamme abgekehrte Oberseite der Kolonie unterscheiden. I'on der Lnterseite der stärkeren Aeste gehen einige kurze Zweige, mit nur wenigen, langen Internodien ab (in Fig. 148 nicht gut erkennbar).

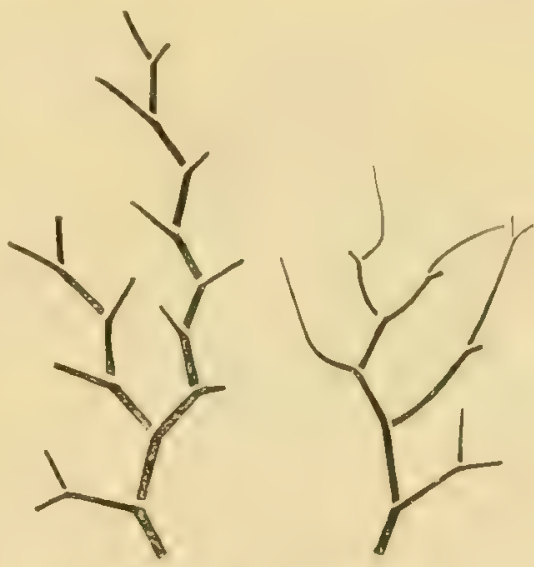

Fig. 149. M. melanobrichos. Verzweigung, schematisch. $\times 4 / 3$.

Verzweigung der Aeste wie bei Chry'sogorgia, was aus Fig. I49 ersichtlich ist; aber nur die distalen, dünneren Zweig-Abschnitte deutlich in einer Ebene ausgebreitet. Die stärkeren, nach zwei Seiten Zweige abgebenden Aeste sind Sympodien.

Die Achsen der stärkeren Aeste sind bronzefarbig, die der dünnsten Zweige braun, durchscheinend.

Der Stamm trägt nur ganz oben noch etwas Coenenchym, worin nur wenige, zerstreute Scleriten liegen; letztere sind glatt, dünn, in einer Richtung deutlich verlängert und in der Mitte, quer dazu, meist verschmälert, mit gerundeten Enden; der Rand ist unregrelmässig fein gezaihnelt; sie sind bis $0,1 \& \mathrm{~mm}$. lang und in der Mitte bis $0,055 \mathrm{~mm}$. breit.

Aehnliche Scleriten, nur oft dicker und nicht in der Mitte verschmälert, liegen in der Rinde der Aeste; auf Fig. I50 sind einige derselben in ihrer relativen Lage im Coenenchym abge-
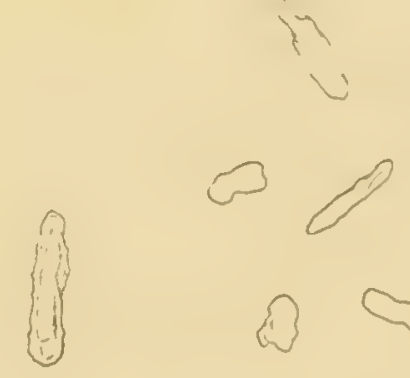

\author{
(5)
}

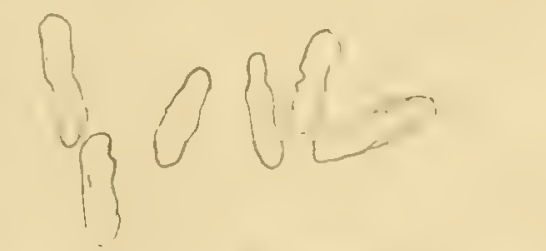

Fig. 150. AY, melanotrichos.

Scleriten der Rinde, in nat. Lage. $X$ So.

bildet; oft liegen die Scleriten noch mehr zerstreut. In der Nähe der Polypen und auf den 
dünneren Zweigen sind sie zahlreicher; bei den Challenger-Exemplaren bilden sie sogar strecken-

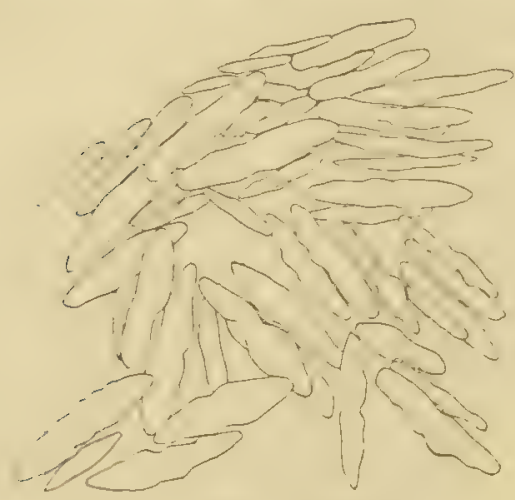

Fig. 151. 1\%. melu:atrichos. Chall.-Ex. Scleriten der Rinde eines dickeren Astes, in nat. Lage. $X$ So. weise eine ziemlich dichte Schicht (Fig. I $5 \mathrm{I}$ ). Länge bis 0,225 mm., meist 0,1 I bis o, $16 \mathrm{~mm}$., Breite bis $0,054 \mathrm{~mm}$.. Die Rinde ist, namentlich auf den dünneren Zweigen, im Verhältniss zur Achse nicht sehr dünn. Auf dem Stamme und den dickeren Aesten zeigt sie feine Längsriefe, meist der Achse parallel oder doch nur wenig schräg.

Nematozooide fehlen.

Der Stamm und die basalen Internodien ihrer Seitenäste ohne Polypen; die stärkeren Aeste mit wenigen, die dünnen mit zahlreichen Polypen, welche dort nur $1 / 2$ bis $3 \mathrm{~mm}$. aus einander stehen. Niemals fand ich zwei Polypen in demselben Querschitt eines Astes; auf den dünneren Zweigen stehen sie alle in einer Reihe, der Oberseite

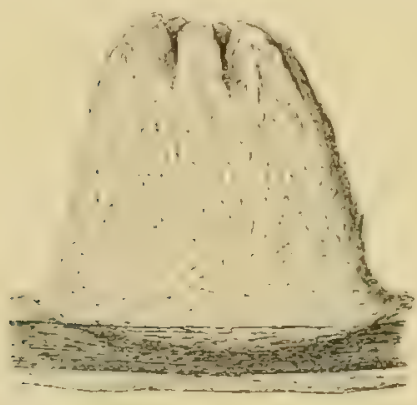

Fig. 152. M. melanotrichos. Siboga-Ex. Polyp, stzrk contrahirt. Die Achse des tragenden Astes schimmert durch. $\times 23$ Basis einen dünneren cylindrischen Rumpf-Abschnitt und sind im Verhältniss zur Dicke merklich

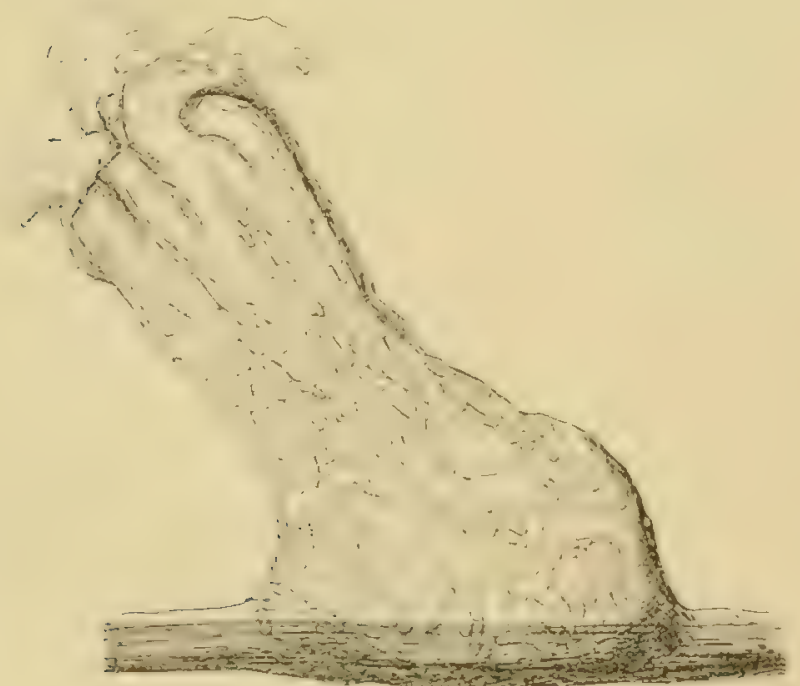

Fig. 153. W. milanolrichos. Challenger-Kx.

Nicht contrahirter Iolyp. Die Achse des tragenden Astes schimmert durch. $\times 23$. länger als der abgebildete Polyp. Wie aus Fig. 152 ersichtlich, sind bei starker Contraction die Tentakel weit nach innen umgelegt. Die Scleriten lassen nur ganz kleine Stellen der Polypenwand frei.

Gänzlich verschieden sehen die wenig oder gar nicht contrahirten Polypen der Challenger-Exemplare aus (Fig. 153); auf der Polypen-Basis bleiben grössere Strecken frei von Scleriten und unter den Tentakeln sind dieselben deutlich in acht tentaculäre Längsstreifen angeordnet, welche sich auf den Tentakel-Rücken fortsetzen. Die theilweise vorgestreckten Tentakel und die im Verhältniss zur Dicke viel grössere Rumpflänge (letztere $2 \mathrm{~mm}$., gegen den Querdurchmesser an der Basis 1,2 , in der Mitte $0,9 \mathrm{~mm}$.) weisen clarauf hin, dass diese Polypen viel weniger stark contrahirt sind, als die des Siboga-Exemplares. Ich fand denn auch 
in den Challenger-Kolonien einige mehr kegelförmige, stïrker contrahirte Polypen, deren Scleriten keine erheblichen Luicken zwischen sich frei lassen ${ }^{2}$ ) und umgekehrt bei der Siboga-Kolonie einige, die in Form und Länge, mit vielen Polypen der Challenger-Typen übereinstimmen. In dem Polypen der Figur 153 enthält die Polypen-Basis Geschlechtsprodukte und ist besonders ausgedehnt, was wohl die Ursache der Unvollständigkeit ihres Scleritenkleides sein mag. Bei gleich starker Contraction wirden die beiden abgebildeten Polypen einander doch wohl sehr ähnlich sein, wenn auch der eine mehr Scleriten enthält als der andere. Von den vier genauer von mir untersuchten Polypen der Kolonien der Challenger. Sammlung enthält aber der abgebildete die wenigsten Scleriten; die Zahl der Scleriten wechselt erheblich.

In der Polypen-Basis liegen die Scleriten oft streckenweise quer. Dies ist angedeutet beim Polypen der Fig. I52; ich fand es auch bei den Challenger-Exemplaren. Es ist aber viel weniger ausgeprägt als bei der zum alten Genus Chry'sogorgia Verrill gehörigen Art (Chry'sogorgia, Unter-Gruppe $\mathrm{A}_{3}$ ).

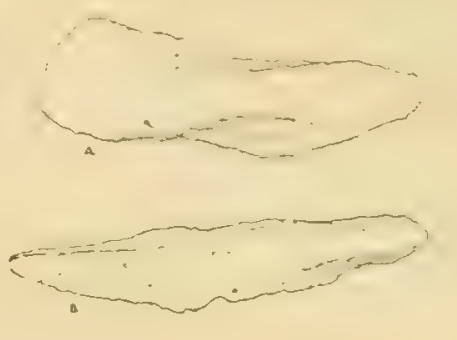

Scleriten des Polypen-Rumpfes ziemlich dünn bis sehr dünn (Fig. 154), alle erheblich länger als breit, mit meist nahezu glatter Oberfläche; die dickeren Scleriten mitunter mit feinen Wärzchen (Fig. I54, B). In der Basis der Polypen sind die Scleriten meist breiter und dünner, wie Fig. I54, A; in der oberen Hälfte des Rumpfes dicker, wie die der Fig. I54, B. Einige Scleriten zeigen auf ihrer flachen Seiten hohe Leistchen (Fig. I 54, C).

In den Tentakel-Rücken nach der Spitze des Tentakels zu, werden die Scleriten stets dicker mit ovalem und schliesslich mit rundem Querschnitt. Dazu treten feine Wärzchen auf der Oberfläche auf, sodass in den Tentakelspitzen Spicula liegen.

Pinnula-Scleriten konnte ich nicht finden.

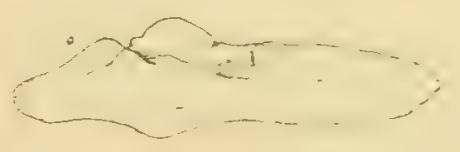

Fig. 154. .M. melanolrichos. Scleriten der Polypen, A aus der Basis, B ル. C aus der Rumpimitte. $\times 145$.

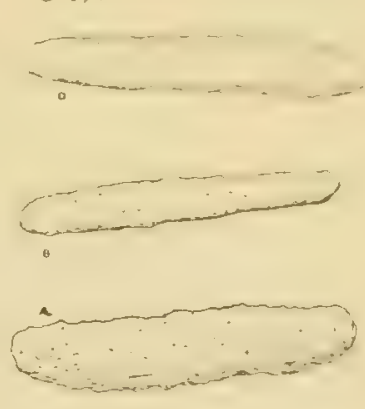

Fig. 155. .T. milanotrichos. Spicula der Tentakel, A.v.d. Breitseite, B v. d. Schmalseite, C schräg gesehen.XI 45 .

Geographische Verbreitung: Von der Challenger-Expedition bei der Insel Ascension, ron der Siboga-Expedition bei Ternate und in der Timor-See erbeutet, in. Tiefen von 765 bis $199+$ M., auf Sand- und Schlammboden.

\section{Iridogorgia Verrill.}

Iridogorgia Verrill, Bull. Mus. Comp. Zool., vol. II, I883, S. 26.

Iridogorgia A. Agassiz, Three Cruises of the l3lake, vol. II, Bull. Mus. Comp. Zool., vol. 15, ISSS, S. 144 .

Iridogorgia IVright and Studer, Challenger Report, vol. 3I, I8S9, S. 6.

Der Stamm bildet eine aufgerichtete Spirale, welche an der Aussenseite eine Reihe langer, dünner, unverzweigter Seitenäste trägt. Rinde dïn, mit wenigen Scleriten. Mit Niematozooiden. Polypen in einer regelmässigen Reihe auf der Oberseite der Aeste, vereinzelt auf dem Stamme; 
sie enthalten im Rumpfe zarte, spindelförmige Scleriten; in den sehr wenig retractilen Tentakeln fehlen die Kalkkörper nahezu vollständig.

Ich habe die einzige bekannte Art nicht untersuchen können. Aus der von A. Agassiz gegebenen Abbildung (1. c. Fig. 456a) lässt sich nicht entscheiden, ob der Stamm monopodial oder sympodial ist. In ersterem Falle ist das Genus ein sehr schönes Beispiel dafür, dass alle Zweige nur in einer Reihe über einander stehen, also von der Lateralität der Rinde. Auf eine solche Lateralität weist auch die Anordnung der Polypen in einer Reihe auf der Oberseite der Zweige hin. Dass der Stamm nicht gerade ist, sondern eine Spirale bildet, hat er mit den sympodialen Stämmen der Chrysogorgia-Arten gemein und dies deutet, meines Erachtens, auch auf einen sympodialen Aufbau desselben bei Iridogorgia hin.

Ich stelle das Genus in die Subfamilie Chrysogorgiinae wegen der dünnen Rinde und wegen der nicht zahlreichen Polypen-Scleriten, die keine Differenzierung in eine oberflächliche und eine tiefe Schicht zeigen, wie bei der dritten Subfamilie Riiscinae. Auch die Nematozooide machen eine nähere Verwandtschaft mit Chrysogorgia wahrscheinlich.

Im übrigen sei auf VERRILL's Beschreibung verwiesen.

Es ist nur eine Art bekannt:

1. Iridogorgia pourtalesii Verrill.

Iridogorgia pourtalesii Verrill, Bull. Mus. Comp. Zool., vol. II, ISS $3, \mathrm{~S} .26$.

Iridogorgia pourtalesii A. Agassiz, Bull. Mus. Comp. Zool., vol. I5, I8S8, S. I44.

Die typischen Exemplare wurden in West-Indien bei Dominica in $976 \mathrm{M}$. und bei Guadeloupe in 132 I M. Tiefe erbeutet. In der Schau-Sammlung des „British Museum" steht eine Kolonie von Iridogorgia, welche in der Nähe der Portugiesischen Küste erbeutet wurde.

$3^{\text {te }}$ Subfamilie Riiseinae.

Kolonien mehrfach verzweigt; in allen Aesten werden nur an einer Seite, auf einem zweigbildenden Streifen, neue Seitenzweige gebildet und diese Seite ist auch für Zweige nachfolgender Generationen die gleiche; ist demnach nicht abwechselnd wie bei Chrysogorgia und Mctallogorgia. Dies ist bei Riisca durch secundäre Verschiebung verwischt.

Rinde dick, mit vielen kleinen Scleriten. Polypen mit dicker Wand, worin viele kleine Scleriten in einer dichten Schicht liegen.

Die Tentakel biegen sich bei Contraction sehr stark nach innen um, wobei die Mundscheibe erheblich nach der Polypen-Basis zu eingestülpt wird. Tentakel gleichfalls mit zahlreichen kleinen Scleriten.

Zu dieser Subfamilie gehören zwei Genera: Riisea und das neue Genus Plarrogorgia. 


\section{Pleurogorgia nov. gen.}

Die vorliegenden Fragmente, welche vielleicht nahezu vollständige Kolonien sind, sind in einer Ebene verzweigt (Fig. I56); jeder Ast giebt nur nach einer Seite Zweige ab; diese Seite ist bei den nachfolgenden Aesten immer die gleiche (Fig. 157). Achsen goldglänzend, glatt. Rinde dick, ganz von kleinen Scleriten erfullt. Polypen einreihig geordnet, meist in der Ebene der Verzweigung stehend; die Tentakel werden bei Contraction regelmässig nach innen über die Mundscheibe zusammengelegt und zeigen dabei eine scharfe Biegung an ihren Bases (Fig. I60). Scleriten klein, in einer dichten Schicht zu $4-5$ übereinander liegend; die Seiten der Tentakel und die Aussenseite der Pinnulae gleichfalls mit einer Schicht von kleinen Kalkkörperchen (Fig. 162).

Die erbeuteten Fragmente gestatten nicht, falls es wirklich nur Fragmente sind, sich von der ganzen Kolonie eine genauere Vorstellung zu machen; die obige Genus-Diagnose ist denn auch nur als eine vorläufige zu betrachten.

Nur eine Art:

\section{Pleurogorgia plana nov. spec.}

Stat. $150.0^{\circ} 6^{\prime}$ N., $129^{\circ} 7^{\prime} .2$ O. Bei der Insel Gebe. ro89 M. Gelbgrauer Schlamm, Sand und Steine. 3 Fragmente.

Von dieser Art wurden die zwei in Fig. I56 abgebildeten Fragmente erbeutet, sowie ein ähnliches Stück ohne Polypen, welches mir zum Theil zur Untersuchung der Verzweigung an Schliffpräparaten diente. $\mathrm{Ob}$ die Fragmente nur kleinere Abschnitte von grossen Kolonien sind, oder ob nur wenig fehlt, lässt sich nicht entscheiden. Eine schematische Darstellung der Verzweigung des einen der in Fig. I 56 abgebil. deten Fragmente giebt die Fig. I57; dieselbe

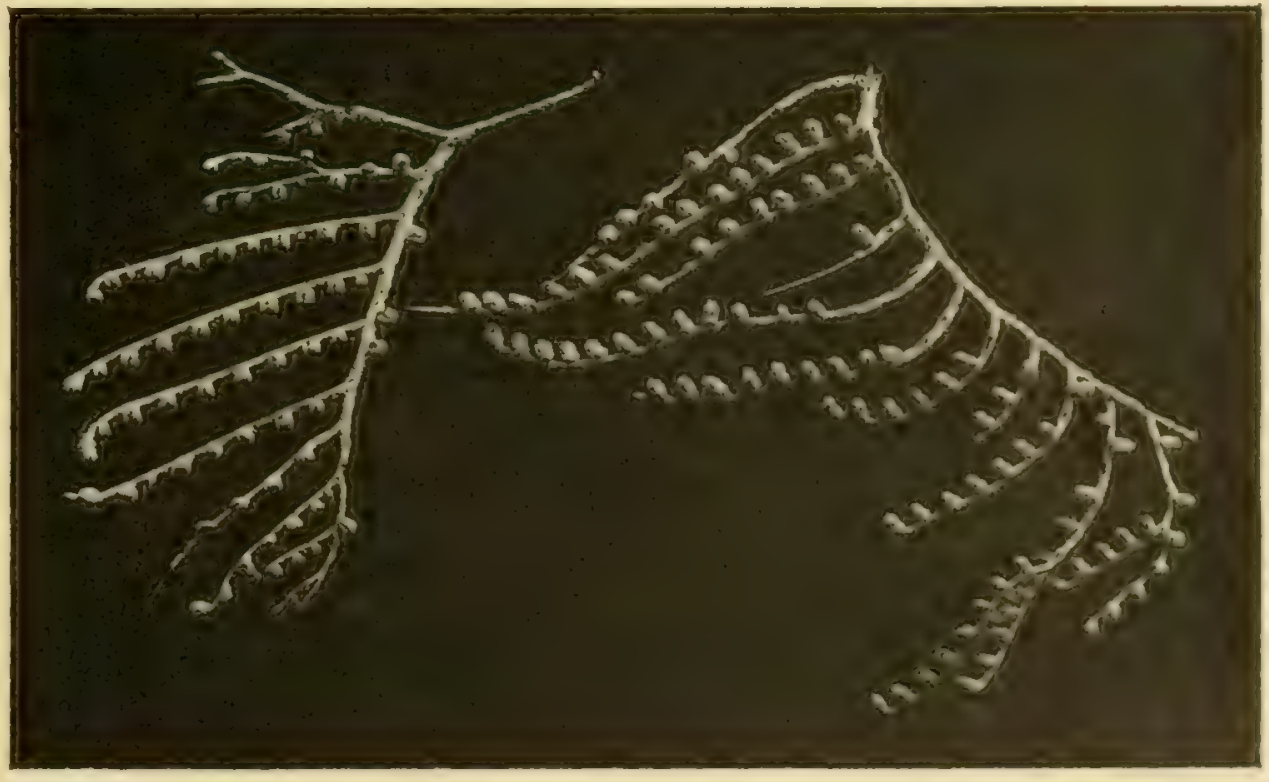

Fig. 156. Ileurogorgia flana. liragnente. $\times 5 / 4$.

beruht, soweit schwarz ausgefüllt, auf der Untersuchung des ganz ähnlichen polypenlosen dritten Fragmentes. Daraus ist ersichtlich, dass alle Zweige nur nach derselben Seite einen Seitenzweig abgeben ${ }^{1}$ ). Diese Regel der einseitigen Verzweigung habe ich dann benutzt um

1) Die Verzwcigung bci A (Fig. 157) liegt ausserhalb der Verzweigungsebene des Fragmentes; die drei dem Seitenzweig rorangchenden Polypen stehen aber, wie aus Iig. 156 ersichtlich, in ciner Spirale, was auf Drehung als Ursache dieser Abwcichung hindeutet. 
den weiss gehaltenen Theil des Schema's darzustellen; derselbe ist also hypothetisch. Und dass

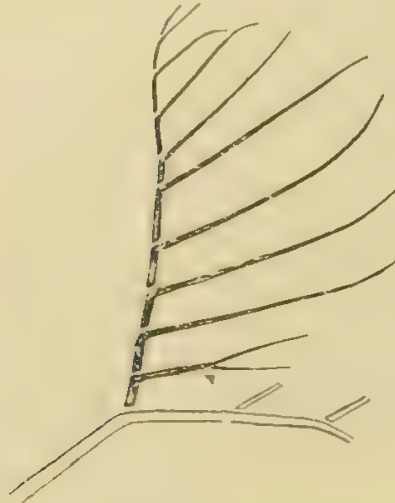

Fig. 157. Pleurogorgia fland. Schema der Terzweigung. nat. Grösse. die hypothetischen Seitenzweige sich auch am Fragmente selbst durch geringere Dicke und schräges Abgehen, wie Seitenzweige verhalten, kann leider nicht als zwingend für die Richtigkeit dieses Schema's gelten, da im schwarzen Theil desselben ja eben die Seitenzweige die stärkere und nahezu gerade Fortsetzung des tragenden Ist-Internodiums bilden.

Gegenüber Chry'sogorgia und Metallogorgia ist wichtig, dass die Zweigbildung immer auf dieselbe Seite der Aeste nachfolgender Generation beschränkt ist (conform schwarzer Theil des Schema's Fig. I 57). Für die Verzweigung kant ich im uibrigen auf die Fig. I 56 verweisen. Das längste End-Internodium erreicht $4 \mathrm{I}^{1} / 2 \mathrm{~mm}$. Länge.

Die glatten, goldglänzenden Achsen werden bedeckt von einer weissen, für Chry'sogorgiidae dicken Rinde; die Dicke der letzteren ist nämlich etwa 1/5 mm., auf den stärkeren Aesten noch etwas mehr. Die Rinde ist nicht
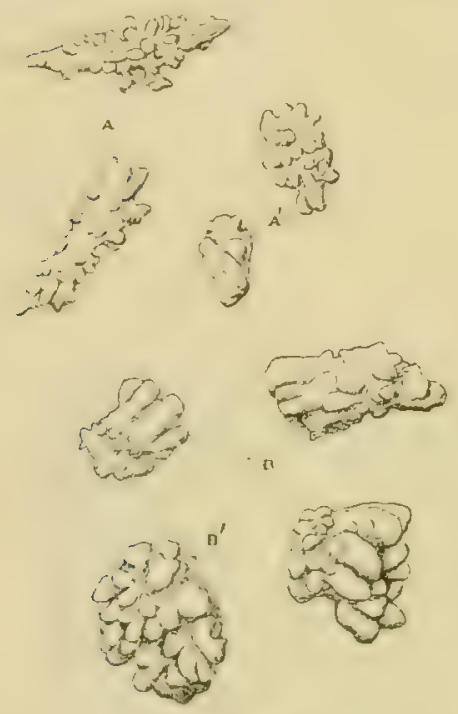

Fig. 15S. plentrogorgia plano. Scleriten. $A A^{\prime}$ der tieferen. $B B^{\prime}$ der oberflichlichsten Schicht, $13^{\prime}$ von der Aussenscite gesehen. $X$ I93.

Seitenzweige entspringen membranös, sondern steif und spröde infolge der grossen Zahl der Scleriten. Letztere sind meist Spicula mit spitzen Enden und grossen, unregelmässigen Höckern; einige sind mehr rund mit stumpfen Enden (Fig. I 58, A, A'). Die Mehrzahl sind weniger als O, I mm. lang, einige aber grösser bis $0,1+\mathrm{mm}$. Die oberflächlichen, unmittelbar unter der Epidermis liegenden Scleriten sind an ihrer freien Seite bedeckt mit besonders hohen und starcken Höckern, wodurch ihr Durchmesser senkrecht zur Epidermis sehr erheblich werden kann, z.B. bis $\mathrm{O}, \mathrm{I} \mathrm{mm}$. (Fig. I5 8 , B von der Seite, B' von der freien Fläche gesehen). Zwischen diesen letzteren Scleriten und den Spicula finden sich alle möglichen vermittlenden Formen.

Ich fand keine Nematozooide; dass sie fehlen ist aber bei den dicken, undurchscheinenden Coenenchym nicht sicher fest zu stellen.

Die Polypen stehen nahezu alle in der Ebene der Verzweigung der Kolonie, in deutlichen Reihen, jedenfalls niemals zwei in demselben Querschnitt; ihre Entfernung beträgt ein bis zwei mm.. Nahezu alle Fragmente der Fig. I56 sind alle Polypen des starken sympodialen Astes abgefallen, ihre Stellen aber sind noch erkennbar. Diese Polypen waren alle nach rechts oben (in dieser Figur) gekehrt; demnach entspringen auch in diesem Fragmente die Aeste, deren unterste Internodien zusammen den sympodialen Ast bilden, alle je auf den Polypentragenden-Streifen des vorhergehenden Astes.

Die Länge der Polypen, welche alle ihre Tentakel melır oder weniger stark zusammengelegt haben, ist bis $2 \mathrm{~mm}$; zwischen den erwachsenen Polypen stehen oft sehr kleine Polypen (Fig. 156). Die Form der Polypen ist, wenn die Tentakel zurückgezogen sind, die eines kurzen Cylinders; viele Polypen sind parallel dem tragenden Zweige verbreitert, haben einen ovalen Querschnitt. Ein Polyp mit theilweise zurickgezogenen Tentakeln ist in Fig. I59 abgebildet. 
In der Fig. I60 ist angegeben, wie weit die Tentakel nach innen umgelegt werden können und

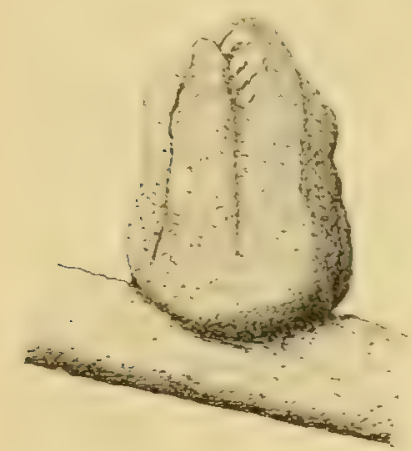

Fig. 159. Plenrogorgia plana. Polyp. $\times 15$. wie dabei die Mundscheibe basalwärts gedrängt wird.

Diẹ Polypen haben dieselbe kreideweise Farbe wie clie Rinde (in Alcohol); die Oberfläche ist bei beiden, bei nicht zu schwacher Vergrösserung deutlich rauh.

Die Scleriten der Polypenwand sind rerschieden, je nachdem sie in der äusseren Schicht liegen oder nicht. Die Scleriten der tieferen Schichten sind ziemlich dicke Schuppen, oft stark in einer Richtung verlängert und dann an den Enden wohl zugespitzt; die Ränder sind tief unregelmässig eingeschnitten, die Oberfläche ist selten glatt, meist mit einigen bis zahlreichen Wärzchen (Fig. I $6 \mathrm{I}, \mathrm{A}, \mathrm{A}^{\prime}$ ).

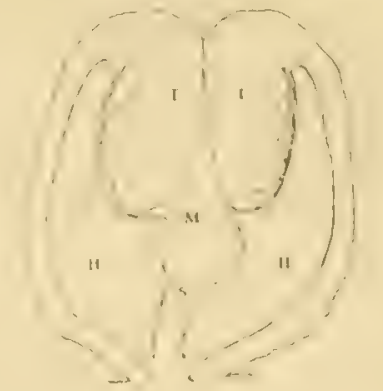

Fig. 160. I'lunogoraia pland. Medianer Längsschnitt eines Polypen mit vollständig zurïckgezogenen Tentakeln. T lentakel; II Mund; S Stomodaeum; II Magenhöhle. $\times 20$. Länge derselben bis 0,23 mm., Breite, bis $0,08 \mathrm{~mm}$; Dicke etwa $0,0 \mathrm{I}_{4} \mathrm{~mm}$., wenn man die Wärzchen mitrechnet etwa $0,02 \mathrm{~mm}$., mitunter noch mehr. Die Scleriten der äusseren Schicht sind dadurch modificirt, dass ihre freie nach der Epidermis gekehrte Seite mit sehr hohen Höckern dicht bedeckt ist ; ihre innere Oberfläche zeigt dichte aber viel niedrigere Wärzchen (Fig. I6 I, B, B'). Bei einigen dieser Scleriten ist der Durchmesser, senkrecht zur Polypenwand sogar der grösste; der Schuppen-Character ist dadurch gänzlich verschwunden. Eine varmittelnde Form ist in Fig. I 6 I bei $\mathrm{C}$ abgebildet. Diese Differenzierung ist ähnlich der bei den Rinden-Scleriten gefundenen; furr letztere ist das Spiculum, für die der Polypen die Schuppe Ausgansform; durch die Umbildung werden die Scleriten einander aber sehr ähnlich, sind oft ganz gleich (vergleiche Fig. I 6 I, B, B' mit Fig. I $\left.58, B, B^{\prime}\right)$.

In der Riickenseite der Tentakel setzen beide Formen

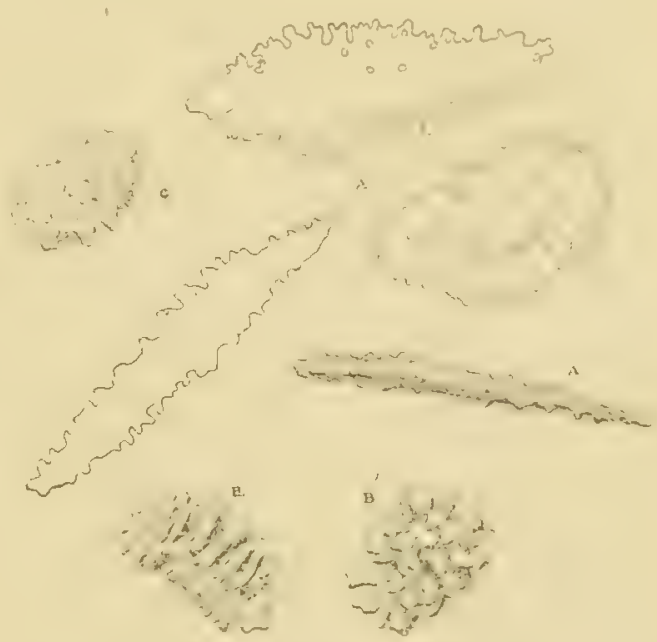

Fig. I6x. P'leurogergiz plana. P'olyp-Scleriten.

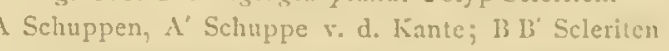
der obertlächlichsten Schicht, B von der kinte, $B^{\prime}$ von der freien Fläche gresehen; $C$ vermittelnde Form zwischen $A$ und B. $\times 193$.

von Polypen-Scleriten sich fort; nach der Tentakel-Spitze zu werden dieselben kleiner, mehr rund, kuglig, unregelmässig höckerig, gleich den in Fig. I58, $A^{\prime}$ und in Fig. I 6 i bei $C$ abgebildeten Scleriten.

In den Seitenflächen der Tentakel liegren hauptsächlich lange Schuppen (Fig. 162, B), mehr nach innen flache, lang-stabförmige Scleriten (Fig. 162, C), ohne oder mit vereinzelten Wärzchen.

In den dorsalwärts und rickwärts gekehrten Flächen der l'innulae liegen kleine,

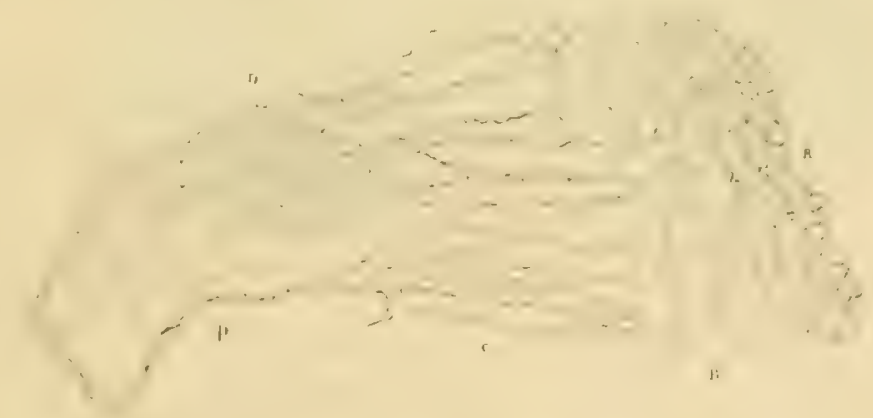

Fig. I62, I'liurogrorsiz plant. Tentakel-Stiick mit Hinnula. $R=$ Tentakel-Licken, $\mathrm{p}=$ I’innula; $13, \mathrm{C}, \mathrm{D}$ siche im Text. $\times 193$. meist annäherend runde Schuppen, nahezu alle mit einigen Höckerchen (Fig. I 62, D). 
Jeder Tentakel hat $\delta$ bis Io Pinnulae in einer Reihe an jeder Seite.

In Mundscheibe und Schlundwand liegen auch noch zahlreiche, sehr kleine Kalkkörper von unregelmässiger Form.

Geographische Verbreitung: nur an einem Orte im Ost-Indischen Archipel wie oben angegeben.

\section{Riisea Duchassaing \& Michelotti.}

Riisea Duchassaing et Michelotti, Memorie d. R. Accad. di Torino, Ser. 2, Tom. 19, I860, S. IS (Separatdruck).

Herophila Steenstrup, Oversigt over det Kong. danske Vidensk. Selskabs Forhandl. og det Medl. Arbeider i Aaret I860, Kjöbenhavn I86I, S. I21. Deutsche Uebersetzung in Zeitschr.

f. d. Ges. Naturwiss., Jhrg. I862, Bnd. I9, S. 74 .

Riisea Kölliker, Icones Histiologicae, 2te Abth., Istes Heft, I865, S. I40.

Riisea Duchassaing de Fontbressin, Revue des Zoophytes et des Spongiaires des Antilles, Paris 1870, S. 17.

Riisea Studer, Arch. f. Naturgeschichte 1887, S. 4I.

Herophila Wright and Studer, Challenger Report, vol. 3I, I889, S. XLI.

Riisen Wright and Studer, Challenger Report, vol. 31, IS89, S. 24.

Da die Beschreibung der einzigen Art dieses Genus unter dem Namen Riisca paniculata im Jahre I860, die als Herophila regia erst im Jahre I 86I im Druck erschienen ist, ist Riisca der ältere Namen und muss beibehalten werden. KöLliker (1.c.) hat die Identität der Herophila regia mit Riisea paniculata durch Vergleichung der Typen festgestellt.

Aus den Beschreibungen der verschiedenen Autoren, namentlich der von KöLLIKER und Steenstrup, und nach Untersuchung eines grösseren Fragmentes der Horophila regia aus Kopenhagen, stelle ich folgende Diagnose der Gattung auf:

Kolonien mit monopodialem Stamm, der mehrere starke Seitenäste abgiebt, welche wieder mehrfach verzweigt sind (Fig. 163). Die Aeste geben nach zwei Seiten abwechselnd gestellte Seitenzweige $\mathrm{ab}$; letztere in gleicher Anordnung noch kleinere Seitenzweige, etc.. Polypen beinahe alle den Zweigspitzen seitlich aufsitzend. Achsen verkalkt, weisslich, ohne Metallglanz; die dickeren Achsen mit stark excentrischem Central-Cylinder; die Oberfläche der Achsen mit unregelmässigen kurzen Längsriefen.

Rinde mässig dick, am getrockneten Exemplare auf den stärkeren Aesten mit zwei deutlichen Längsfurchen, von denen die eine Zickzack von Zweig-Ursprung zu Zweig-Ursprung verläuft, die andere, stärkere, gerade ist; beiden entspricht eine Furche der Achse. Die RindenScleriten sind klein und sehr zahlreich, in mehreren Schichten über einander gelagert.

Polypen mit dicker, von zahlreichen kleinen Scleriten erfüllter Wand. Tentakel bei Contraction stark und regelmässig nach innen gebogen.

Verzweigungs-Modus, Stellung der Polypen, Bau der Achsen, Längsfurchen der Rinde und der stärkeren Achsen unterscheiden dieses Genus genügend vom vorhergehenden.

Es ist nur eine Art bekannt: 
*. Riisea paniculata Duchassaing \& Michelotti.

Riisca paniculata Duchassaing et Michelotti, Mem. d. R. Accad. di Torino, Ser. 2, Tome I9, IS60, S. Is (Separatdruck).

Herophila regia Steenstrup, Oversigt over det Kong. danske Vidensk. Selskabs Forhandl. etc. i Aaret IS60, Kjobenhavn I86I, S. I2I. Deutsche Uebersetzung in: Zeitschr. f. d. ges. Naturw., Jhrg. 1862, Bnd. 19, S. 74.

Riisea paniculata Kölliker, Icones Histiologicae, 2te Abth., Istes Heft, I865, S. I40.

Riisea paniculata Duchassaing de Fontbressin, Revue des Zoophytes et des Spongiaires des Antilles, Paris I870, S. I7.

Riisea paniculata Wright and Studer, Challenger Report, vol. 3I, ISS9, S. 24.

Da eine ausführlichere Beschreibung dieser Art mit genügenden Abbildungen noch nicht gegeben wurde, gebe ich hier eine Schilderung des Exemplares des Kopenhagener Museum, welches StEENSTRUP als Herophila regia beschrieben hat. Das ganze Exemplar habe ich nicht gesehen; der Liebenswürdigkeit von Herrn Dr. G. M. R. Levinsen und Herrn Professor Jungersen verdanke ich aber einige Photographien desselben, von denen eine in Fig. ${ }^{6} 63$ reproducirt ist, und die Möglichkeit ein grösseres Fragment zu untersuchen.

Kolonie sehr gross, eine Höhe von etwa I M. erreichend, mit einem deutlichen Stamme, der viele Aeste, worunter einige sehr starke, abgiebt; die Aeste sind selbst wieder mehrfach verzweigt. Diese Verzweigung ist nicht regellos, sondern jeder Ast und Zweig giebt nur nach zwei Seiten abwechselnde und in gleich grossen Abständen stehende Seitenzweige ab (Fig. I64). SteEnstrup hat dies schon beschrieben und giebt es auch vom Stamme der Kolonie an; letzteres konnte ich aus den Photographien nicht ermitteln, da die abgebrochenen Zweige auf denselben nicht deutlich sind. Steenstrup sagt hieruber, 1. c. S. I II: „Smaagrenene ere igjen stillede afvexlende til de to Sider af „noget storre Grene, og disse atter paa samme

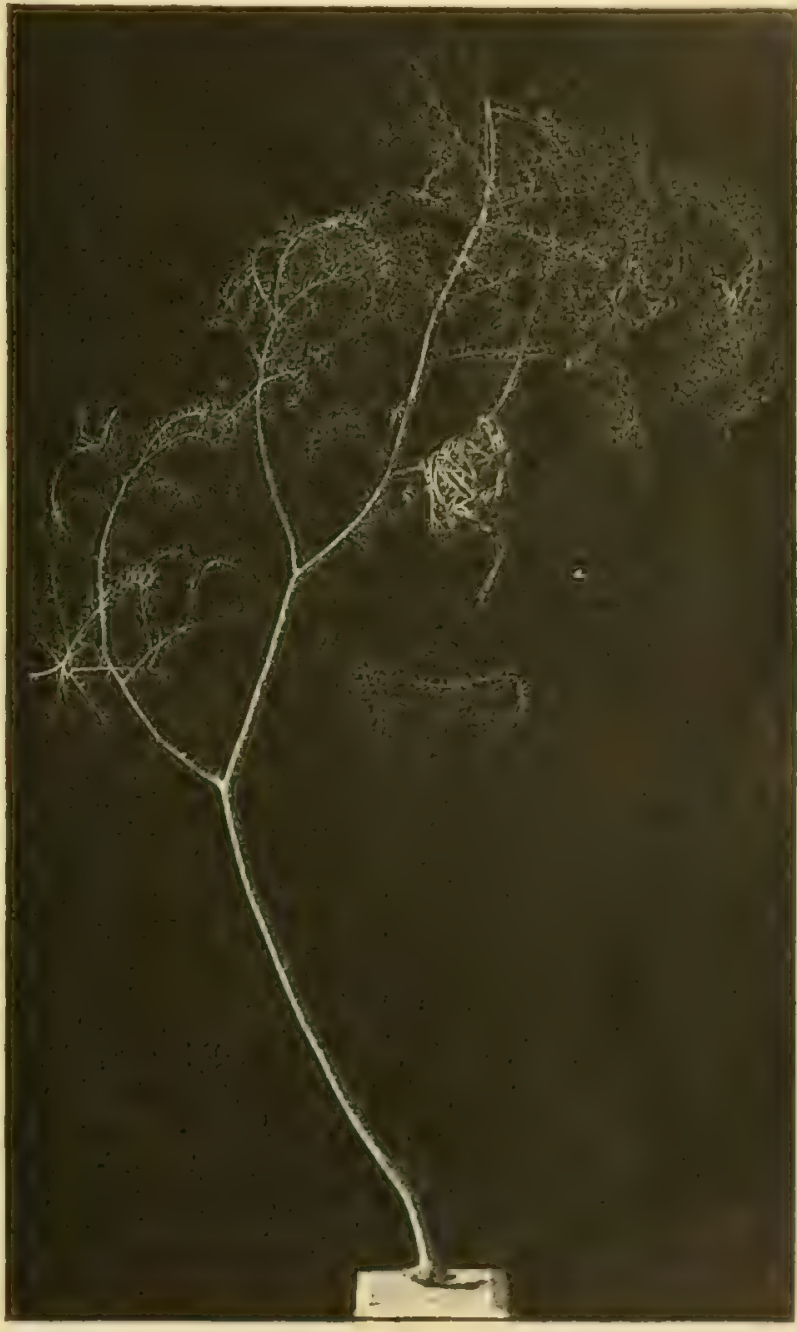

Fig. 163. Kolonic von Riised fariculata, stark verkleinert. „Maade, paa andre Grene, o. s. fr., indtil vi tilsidst see Hovedgrenene i lignende Orden udgaae fra selve Stammen" ").

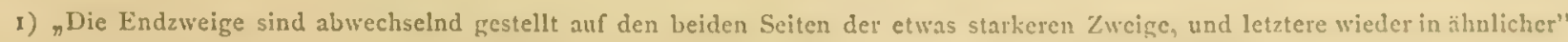

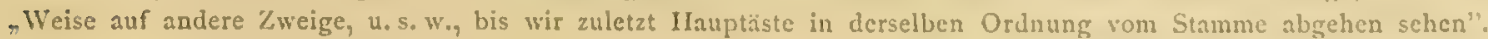

SIBOGA-EXPEDTTIE XIII. 
An den Spitzen der dünneren Zweige, wie eine in Fig. I 64 abgebildet ist, sind die beiden Endzweigreihen meist nicht genau entgegengestellt, sondern schliessen einen Winkel von

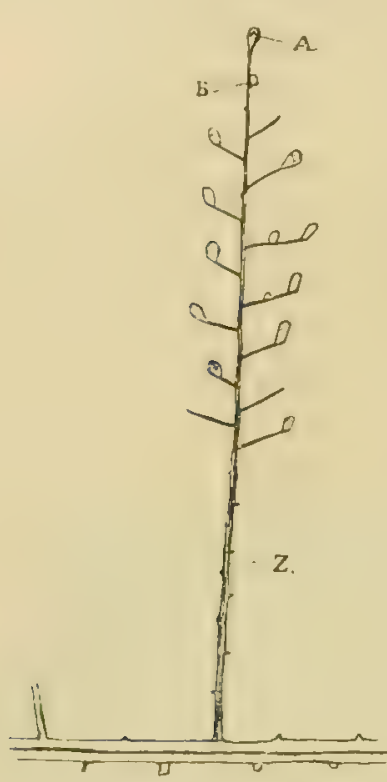

Fig. 164. 'Zweig von Riisea paniculati. $A$ und $B$ Polypea auf dem Zweig Z.; nat. Grösse. weniger als $180^{\circ}$ ein, welcher Winkel in den jüngsten Abschnitten am kleinsten, in vereinzelten Fällen sogar sehr scharf ist. Der tragende Zweig (Z. der Figur I64) trägt am Ende einen oder zwei, selten drei Polypen, immer in einer Reihe und in Entfernungen welche denen der Endzweige nahezu gleich sind; die Polypen stehen immer auf der Seite des Zweiges, wo der spitze Winkel zwischen den Ebenen der beiden Endzweigreihen liegt. Alle Polypen des ganzen Zweiges, mit allen seinen Endzweigen, sind dieser Seite zugewendet. Die Endzweige tragen einen erwachsenen Polypen an der Spitze und oft noch einen kleinen, jungen Polypen in einiger Entfernung von ersterem. Auf den Zustand, der in Fig. I 64 abgebildet ist, wird bei andauerndem Wachsthum ein Zustand folgen, in welchem die jetztigen Endzweige theilweise Seitenzweige tragen, ebenso wie der Zweig $Z$ dieser Figur erst auch nur ein kurzer Endzweig mit einem einzigen, der Spitze schräg aufgesetztem Polypen war.

Alle Zweige, auch die jünsten, haben immer einen erwachsenen schädigten Zweigspitzen niemals. Junge Polypen dagegen finclen sich nicht an den Zweigspitzen, sondern nur proximalwärts vom erwachsenen Endpolypen und immer an derselben Seite des Zweiges wie dieser. Die jungen Polypen entstehen also offenbar nicht an den Enden der Zweige.

Hieraus schliesse ich, dass der Endpolyp A der Fig. I64 auch beim ersten Anfange des Zweiges $Z$ schon dessen Spitze angefügt war. Beim Längenwachsthum dieses Zweiges entstanden proximalwärts vom Polyp A die jungen Polypen und zwar alle an derselben Seite des Zweiges, in einer Entfernung von einander, welche den Entfernungen der nachfolgenden Endzweige gleich kommt.

Auf den Abschnitten von Aesten, welche schon Endzweige abgeben, findet man normaler Weise niemals Polypen; letztere stehen nur distal vom distalsten Endzweig und dabei immer an der Stelle wo, entsprechend der regelmässigen Anordnung der Zweige, später ein Endzweig abgehen wird. Da nun die beträchtliche Grösse aller Endpolypen, auch die ganz kurzer junger Endzweige, nur dadurch erklärt werden kann, dass der Endpolyp eher entsteht als der ihn tragende Endzweig, so muss man annehmen, dass die jungen Polypen des Zweiges Z, Fig. I64, z.B. der Polyp B, jedesmal zum Endpolypen ihres Seitenzweiges werden, indem die Seitenzweige in der Polypen-Basis entstehen und die Polypen auf ihren Spitzen mitführen. Dies erklärt auch das Fehlen von Polypen bei den Bases der Zweige. Einmal fand ich einen Polypen auf einem älteren Ast zwischen zwei Seitenzweigen; derselbe stand aber genau an der Stelle eines fellenden Seitenzweiges, war also an seiner Bildungsstelle verblieben, da die Bildung des Seitenzweiges, welcher sich in seiner Basis entwickeln musste, unterblieb. Das Fehlen dieses Zweiges liess sich bei der regelmässigen alternirenden Anordnung der Zweige leicht constatiren. Dieser Befund stimmt also vorzigglich mit der erörterten Hypothese. Steesstrup hat diese Hypothese schon aufgestellt und ich kann mich ihm nur anschliessen. 
Steexstrur sieht im Endpolypen die Amme der anderen Polypen desselben Zweiges; das ist nicht richtig, da die jungen Polypen immer in einiger Entfernung vom Endpolypen entstehen durch Knospenbildung der Rinde und olne directen Zusammenhang mit dem Endpolypen.

Ich habe bei vier nicht endständigen Polypen, in deren Basis also ein Seitenzweig angelegt werden muss, nach denselben gesucht, konnte aber nichts auffinden. Der sehr zarte Anfang ist aber wohl schwer aufzufinden, namentlich bei altem trockenen Materiale, wie das meinige. Bei mehr Material, vor allem solchem aus Alcohol, werden solche Anfangsstadien sich aber wohl finden lassen $^{1}$ ).

Steenstrup sagt auch noch, dass die jungen Polypen in einer doppelten Reihe grestellt sind; das hat er vielleicht aus der zweireihigen Anordnung der, in ihren Bases entstehenden Seitenzweige geschlossen. Ich fand neben den Endpolyp immer nur einen oder zwei vorhergehende und dabei konnte ich von einer Anordnung in zwei Reihen nichts auffinden. Man kann eine gemeinsame halbirende Ebene durch diese Polypen legen, welche auch den Winkel zwischen den beiden Reihen von Seitenzweigen halbirt. Letzterer Winkel wird, wie schon bemerkt, nach der Spitze des tragenden Zweiges zu immer schärfer; in vereinzelten Fällen liegen die juingsten zwei oder drei Seitenzweige sogar in einer Reihe, in der genannten halbirenden Ebene. In den jüngsten Zweig-Abschnitten nähert sich also die zweireihige Anordnung der Seitenzweige immer mehr der einreihigen und kann sogar in letztere übergehen. Wir sehen also:

I. Dass die Polypen in einer Reihe entstehen.

2. Dass die Seitenzweige in den Bases dieser Polypen und also auch in einer Reihe entstehen.

3. Dass demgemäss die Rinde bei Riisea eine Lateralität zeigt, wie bei Plourogorgia und den anderen Chrysogorgiidae, ersichtlich daran, dass Polypen und Seitenzweige nur auf einem schmalen Längsstreifen der Rinde gebildet werden. Die einreihige Anordnung der Zweige geht aber bei Riisea sehr bald in eine zweireihig gegenüberstehende über.

Die verkalkten Achsen sind schmutzig weiss, bei der Type nach Duchass.ins und Micrelottr wachsgelb. Ihre Oberfläche zeigt deutliche, nicht sehr regelmässige Längsriefe und an stärkeren Abschnitten zwei grössere Längsfurchen; die eine derselben verläuft gerade, die andere, ihr entgegengesetzte von Astursprung zu Astursprung im Zickzack. Dabei liegt der Centralcylinder stark excentrisch (Fig: I65), als Folge von sehr ungleichem einseitigem Dickenwachsthum der Achse (conform Kölliker, 1. c. S. 156 und Taf. 15, Fig. 7). Es werden keine regelmässigen, cylindrischen Verdickungsschichten gebildet, wie bei Chrysogorgia, sondern wellig gebogene, theilweise anscheinend nicht geschlossene Schichten.

Die nach Ducinassarng und Michelottr orange-farbige, bei meinem Exemplare blass orange-gelbe Rinde ist nicht diun, bei einem Zweige von 2,5 mm. Durchmesser etwa $0,24 \mathrm{~mm}$. dick; sie ist ziemlich fest, spröde, glatt. In nicht sehr dünen Zweigen verlaufen auf ihr zwei deutliche tiefe Längs-

1) Ich besitze ein Präparat cines nicht termimalen, erwachsencn lolypen von Chrysogorgia juponica, in dessen 13asis cin ganz keiner Seitenzweig gebildet ist, worauf der Polyp schon zum grösstentheil sitzt; das ist der Zustand, den ich bei f'iisea vergebens suchte. 
furchen, welche den schon erwähnten Furchen des Stammes (Fig. 165, A und B) entsprechen, somit die eine gerade, die andere im Zickzack. Die gerade Längsfurche ist die stärkere; sie verläuft an der Seite der Rinde auf welcher die Polypen entstanden; auf den Zweigspitzen konnte ich die Furche nicht finden, aber wenn man sich dieselbe verlängert denkt, geht sie durch die Polypen. Die entsprechende Seite nenne ich Oberseite der Zweige. Die kleinere, im Zickzack verlaufende Furche gehört dann der Unterseite der Zweige an; sie nähert sich immer den Ansätzen der Seitenzweige, bleibt aber doch deutlich um ein weniges, $\pm 1 / 2 \mathrm{~mm}$., davon entfernt. $\mathrm{Ob}$ die beiden Längsfurchen von collabierten Entodermkanälen herrühren, konnte ich nicht feststellen, die Rinde war dazu zu spröde.

Das stärkere Dickenwachsthum der Achsen findet an deren Oberseite statt, sodass ihr Centralcylinder immer der Mitte der Unterseite am nächsten liegt (Fig. I65).

Die Lateralität der Zweige finde ich also auch ausgesprochen in ungleichem Dickenwachsthum der Achsen und im Bau der Rinde.

Das Auseinander- $\mathrm{I}^{\top}$ eichen der in einer Längsreihe entstehenden Seitenzweige in zwei gegenuberstehende Reihen ist auch wohl Folge des ungleichen Dickenwachsthums der Achsen. Jedenfalls müssen die Zweigreihen sich später durch das stärkere Dickenwachsthum der Oberseite der Achsen immer mehr von einander entfernen, noch später an der Unterseite der Aeste sich einander anscheinend näheren (conform Fig. 165).

Die Zweige wachsen aber an ihrer Oberseite auch stärker in die Länge, denn nur dieses kann die rückwärt gerichtete Biegung, welche die stärkeren Astabschnitte zeigen, hervorrufen.

Die Rinde ist ganz erfült von zahlreichen kleinen Kalkkörpern, aus je zwei höckerigen, durch ein kurzes Zwischenstück verbundenen Kugeln bestehend (Fig. I66; Kölliker, 1. c. S. I40, Taf. 18, Fig. 44). Unter dem Microscope sind diese Scleriten meist gelblich; sie sind bis $0,075 \mathrm{~mm}$. lang, die Mehrzahl etwa 0,065 mm. Kölliker nennt sie ganz zutreffend „Doppelkugeln”.

Fig. 166. Risia faniculata. Doppelkugel der Rinde. $\times 473$.
$\mathrm{Ob}$ die Art Nematozooiden besitzt kann an dem trocknen Exemplare nicht festgestellt werden.

Ueber die Vertheilung der Polypen vergleiche man das oben Gesagte. Die Länge der Polypen ist bis $2,5 \mathrm{~mm}$; d dabei sind sie alle stark contrahirt. Die Tentakel sind regelmässig nach innen gebogen, sodass ihre Bases eine achtstralige Figur bilden, wie bei der vorhergehenden Art. Die Polypen sind kurz birnförmig, am breitesten bei den Tentakeln, auf dem tragenden Zweige meist proximalwärts etwas ausgezogen (Fig. I67). Der Rumpf zeigt acht, mit den Tentakeln abwechselnden Furchen. Die Polypen-Wand ist dick und ganz erfullt von zahlreichen, mehrfach über einander geschichteten Scleriten. Viele derselben sind lange, dünne Schuppen (Fig. I68, A), mit stark unregelmässig gezähntem Rand und mit ziemlich vielen Wärzchen, bis $0,2 \mathrm{~mm}$. und noch etwas mehr lang; sie sind den von Pleurogorgia plana
Fig. 167 . Ritisca faniculata. I'olyp. $A=$ Lweigspitze. $\times 15$

in Fig. I 6 r bei A abgebildeten Scleriten sehr ähnlich, nur mit mehr Wärzchen und etwas kleiner. Ein beträchtlicher. Theil der Kalkkörper ist schmäler und dicker, stabförmig, keine Schuppen sondern abgeplattete Spicula (Fig. I68, B). Daneben fand ich auch nicht wenige 
Doppelkugeln (Fig. I68, C), wie sie in der Rinde liegen; dieselben liegen, soweit ich an den trockenen und schmutzigen Polypen ermitteln konnte, nur in einer oberflächlichen Schicht. Wir finden hier also auch eine Differenzierung der oberflächlichen Polyp-Scleriten zu einer besonderen Schicht wie bei Plourogorgia. Die schuppenförmigen Scleriten bilden die innersten Schichten, die Spicula liegen zwischen beide Schichten in einer dritten Schicht, in welcher auch allerlei vermittelnde Formen zwischen Spicula, Schuppen und Doppelkugeln liegen. Die Scleriten sind meist farblos, ein Theil etwas gelblich.

In den Tentakeln liegen dieselben Scleriten, daneben viele kleinere (Fig. I68, D); die Vertheilung derselben, namentlich ob auch die Pinnulae reich sind an Scleriten (wie bei Pleurogorgia plena), konnte ich an den trockenen, sehr spröden Polypen nicht feststellen.

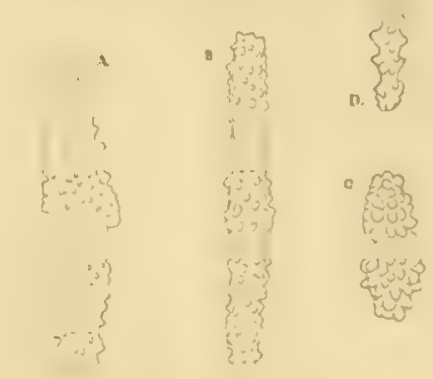

Fig. I6S. Riisia paniculatu. Polyp-Scleriten. $\Lambda=$ Schuppe, I $=$ Spiculum, $\mathrm{C}=$ Doppelkuge a. d. Rumpfwand; $\mathrm{D}=$ Spiculum a. d. Tentakel. $\times 193$.

Diese Art ist mit Plourogorgia plana unzweifelhaft verwandt. Die Polypen sind sehr ähnlich. In Rinde und Polypenwand liegen viele kleine Scleriten in mehreren Schichten über einander. Die Verzweigung ist zwar verschieden, es konnte aber auch für Riisca nachgewiesen werden, dass die Bildung von Seitenzweigen und Polypen nur auf einen schmalen Streifen der Rinde beschränkt ist.

Geographische Verbreitung: Riisea paniculata ist nur aus West-Indien bekannt. Das Exemplar von Ducilassaing und Michelotti stammt von Barbados; Wright und Studer geben an, dass sie Exemplare von Jamaïca gesehen haben. Angaben über Tiefe des Vorkommens liegen nicht vor. 


\section{Bemerkungen über die Stammform der Chrysogorgiidae.}

Für die Verzweigung der Chrosogorgiidae konnte also eine Abgabe von Seitenzweigen ausschliesslich von einem schmalen Längsstreifen der dieselben tragenden Aeste als ursprünglich nachgewiesen werden. (Chrysogorgia S. 25, Pleurogorgia S. 93, Riisea S. 99, Mctallogorgia S. S9 und Iridogorgia S. 92).

Bei den Genera Riisea, Pleurogorgia, Lepidogorgia und Iridogorgia finden wir auch eine ähnliche einreihige Anordnung der Polypen; bei Chrysogorgia und Mrtallogorgia dagegen stehen die Polypen mehr regellos, wenn auch wohl vorherrschend der Spitze der Kolonie zugewendet.

Auch für die Polypen muss aber die eigenthümliche, einreihige Anordnung, welche wir bei vier von den sechs Genera und bei allen drei Subfamilien finden, wohl als der prinitive Zustand angenommen werden; die mehr unregelmässige Stellung derselben bei Clirysogorgia und Mctallogorgia aber als der abgeleitete, secundäre Zustand. Letzterer kann sich leicht durch Drehung und Aufösung des Polypenbildenden Streifens der Rinde aus ersterem entwickelt haben; und damit steht im Einklang, dass auch bei Chrysogorgia und Metallogorgia niemals zwei Polypen in einem Querschnitt eines Astes stehen, was man (namentlich auf den stärkeren Aesten) erwarten müsste, wenn die Rinde in ihrem ganzen Umkreis Polypen bilden könnte.

Bei Riisca und Pleurogorgia fallen zweigbildender Streifen und Polypenreihe zusammen. Wenn bei Iridogorgia der Stamm der Kolonie ein Sympodium ist, so gehen nach Agassiz' Abbildung ${ }^{1}$ ) auch bei diesem Genus die Aeste, deren untere Internodien dann zusammen den sympodialen Stamm bilden, je von der polypentragenden Seite des nächstvorangehenden Astes ab, ganz wie bèi den Fragmenten der Plcurogorgia plana. Es ist denn auch sehr zu bedauern, dass nicht bekannt ist, ob der Stamm bei Iridogorgia ein Sympodium ist (siehe S. 92). Lepidogorgia ist unverzweigt; bei Chrysogorgia und Metallogorgia ist mit dem Verschwinden der einseitigen Polypenstellung auch ein Zusammenhang zwischen der Anordnung der Polypen und der Verzweigung nicht mehr nachweisbar.

Ich glaube das Verhalten der Riiscinae als das ursprünglichste betrachten zu müssen. Und wenn ich auch zugeben muss, dass das Thatsachen-Material noch duirftig ist, so glaube ich doch zur Aufstellung des folgenden Satzes berechtigt zu sein: Die Stammform der Chry'so-

1) A. AgAssiz, Three Cruises of the Blake, vol. II; Bull. Mus. Comp. Zool., vol. 15, 18SS, Fig. 4560 , S. 145. 
gorgiidae hatte wahrscheinlich einen Caulus, der nur auf einem schmalen Längsstreifen sowoh\} die Polypen als auch die Seitenzweige bildete.

Die nicht zu den Chrysogorgizdae gehörigen Gorgoniden sind nahezu alle in ganz anderer Weise verzweigt. Bei Ctenocclla aber geben, wie ich auch an einigen Schliffen controlieren konnte, die Aeste nur nach einer Seite neue Aeste ab, wobei die ganze Kolonie sich in einer Ebene ausbreitet und ähnlich wie die mir vorliegenden Fragmente von Plourogorgia, verzweigt ist ${ }^{1}$ ).

Dass sich der nach Verzweigung und Polypenstand einseitige Caulus der Chrysogorgizidac aus einem radiär-symmetrischen, an allen Seiten Polypen und Zweige tragenden, entwickelt haben sollte, scheint mir zwar möglich, aber nicht wahrscheinlich; auch schon desshalb nicht weil bei allen bekannten Arten, mit Ausnahme von Pleurogorgia, diese Einseitigkeit schon mehr oder weniger verloren gegangen ist. So durch 'Torsion und sympodialen Aufbau des Stammes bei Chry'sogorgia (und Iridogorgia?), durch Auseinander-Weichen der Zweige nach zwei Seiten bei Riisea. Die Tendenz liegt also vor, an Stelle des ursprünglich einseitigen Zustandes einen vielseitigen anzunehmen, was sich schrittweise verfolgen lässt. Die umgekehrte Tendenz würde zu fächerförmiger Ausbreitung führen, diese ist aber nur vorteilhaft bei in constanten, ziemlich starken Meeresströmungen lebenden Arten und diese Bedingungen finden sich jedenfalls wohl nur ganz lokal und ausnahmsweise in der Tiefsee, wo die Chrysogorgizdac leben. Ich glaube denn auch, dass die Lateralität einen tieferen Grund hat. Ich halte es für möglich, dass die Stammform ein kriechender Stolo war mit einseitiger Polypenreihe; unter Erwerbung einer Hornachse richtete er sich auf um einen Stamm, Caulus, zu bilden. Solche verticale Stämme waren entweder schon einseitig verzweigt, wie Pleurogorgia, oder sie waren unverzweigt, wie jetzt die Lepidogorgia-Arten. Für den letzteren Fall müsste man dann noch annehmen, dass der unverzweigte Stamm die Fähigkeit Seitenäste zu bilden, später erwarb, aber nur für den Streifen der Rinde, welcher auch die Polypen hervorbringt. Es liegt aber kein Grund vor, das Unverzweigt-sein von Lepidogorgia als primitiv zu betrachten. Es giebt ziemlich viele unverzweigte Gorgoniden ${ }^{2}$ ), welche gar nicht mit einander verwandt sind und von denen die Mehrzahl sich gewiss aus verzweigten Arten entwickelt hat; und dann muss diese Möglichkeit auch für Lepidogorgia zugegeben werden. Entscheidende Gründe dafur, ob diese Eigenschaft von Lepido. gorgia primitiv oder secundär ist, kann ich aber nicht auffnden und ich muss diesen Punkt unentschieden lassen.

Ich möchte hier noch darauf hinweisen, dass wenn die ersten Gorgoniden (Axifcra von $\mathrm{Kocri}$ ) als Stolonen entstanden, welche sich vom Boden aufgerichtet haben (wie jetzt bei den Pseudaxonia, z.B. Solenocaulon und Semperella), dieselben auch eine polypentragende Oberseite und eine polypenfreie Unterseite gehabt haben können, wie die kriechenden Stolonen der Stolonifera. Und die Möglichkeit, dass die Lateralität der Chry'sogorgiidac davon ein Folge

1) Als Lnterschied ist nur hervorzuheben, dass der Ast, der bei l'merogoryiz die langen, nicht oder wenig verzweigten Endzweige abgiebt, ein Sympodium ist, dessen Analogon bei C/cnocilla, nach zwei Schlilpriparaten und dem IIabitus seines Spirzen. abschnittes zu urtheilen, dagegen ein Monopodium.

Aehnlich wie I'leurogorgia ist z.13. auch noch Stachyoutes trilepis verzweigt, bei welche Art aber der Verlauf der Achsencylinder nicht untersucht wurde.

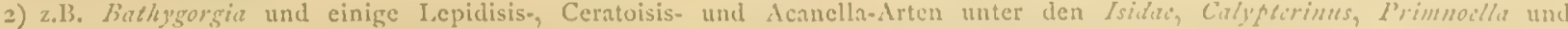

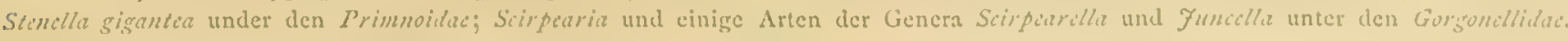


wäre, scheint mir wohl der Beachtung werth. Die radiäre Symmetrie des Caulus der anderen Gorgoniden wäre dann secundär aus dem lateralen Baue hervorgegangen. Ich betrachte es also als möglich, dass die Stammform aller Gorgoniden einen lateralen, einseitig verzweigten Caulus hatte, welche Lateralität bei den Chroysogorgiidae in verschiedenem Grade erhalten blieb, bei den anderen Gorgoniden durch radiären Bau ersetzt wurde.

Dass die Polypen keine Differenzierung in einen tentaculären retractielen und einen basalen. Kelch-Abschnitt zeigen, ist wohl als primitiv zu betrachten. Dass bei einigen Arten, so bei Lepidogorgia und Iridogorgia pourtalesii die Tentakel anscheinend beständig ausgestreckt bleiben, mag aber secundär sein. Auch die geringe Zahl der Scleriten und die Zartheit der Rinde sind wahrscheinlich secundäre Eigenthümlichkeiten der Lcpidogorgiinae und Chrysogorgiinae, welche dieselben in der Tiefsee erwarben, vielleicht bedingt durch die geringe Menge im Meereswasser gelösten kohlensauren Kalkes, während die zahlreichen Nematozooide bei vielen Arten einen besseren Schutz gegen Feinde gaben als die Kalkkörper gewährten. Auch verringerte sich wohl die Zahl der Feinde mit der Einwanderung in die Tiefsee, sodass bei vielen auch die Nematozooide als überflüssig der Rückbildung anheim fielen.

Die relativ dünnen und nicht von einer steifen, kalkreichen Rinde gestützten Achsen blieben verkalkt, möglicherweise weil sie nur dadurch die nothwendige Steifheit erhielten.

Ich habe oben S. 32 schon betont, dass wir annehmen müssen, dass die Nematozooide der Stammform des Genus Chry'sogorgia zukämen; da wir dieselben aber auch bei Iridogorgia finden, müssen wir sie auch für die gemeinsame Stammform dieser beiden Genera, also wohl für die der Subfamilie Chrysogorginnae überhaupt annehmen. Will man in den Nemátozooiden umgebildete Polypen sehen, so scheint mir sogar, dass wir für die ganze Familie der Chr'ysogorgiidae den ehemaligen Besitz solcher umgebildeter Polypen annehmen müssen, die dann aber, wie oben angenommen, bei einer Anzahl der Rückbildung anheim fielen. Sieht man in ihnen dagegen nur Nesseltuberkeln der Epidermis, was doch nicht unmöglich ist, so ist ein Entstehen derselben nur bei der Stammform der Subfamilie Chry'sogorgiinae sehr gut denkbar.

$\mathrm{W}_{\text {RIGHT }}$ und $\mathrm{STUDER}^{1}$ ) meinen, die Chry'sogorgiidac (ihre Dasygorgidae) seien die primitivsten Arten, von denen man die anderen Axifera ableiten könne. Meine Untersuchungen über Verzweigung und Polypenstellung bei den Chry'sogorgiidae haben nun den Unterschied zwischen diesen und den übrigen Axifora erheblich vertieft. Wenn man nun annimmt, dass die gemeinsame Stammform beider dieselbe einseitige Verzweigung und Polypenstellung hatte, wie ich sie als für die Chrysogorgizidae ursprünglich wahrscheinlich machte, dann müsste diese Stammform auch den Chrosogorgiidae, wie ich diese Familie umschrieben habe, zugezählt werden. Und das ist doch eben die Anschauung von Wright und Studer. Nimmt man aber an, dass die Stammform der Gorgoniden (Axifera) einen radiär gebauten Caulus hatte, so war dieselbe keine Chrysogorgiide. Dann kann man aber auch nicht behaupten, dass die Chr'sogorgizidae die Stammform der anderen Gorgoniden lieferten. Mit unser jetztigen Kenntniss kann man, meines Erachtens, diese Frage nicht beantworten.

Die Chrysogorgiidac haben sich weiter specialisirt: so erwarben sie die dünne Rinde, 
die meist wenig zahlreichen, grossen Scleriten, die Eigenthümlichkeiten der Verzweigung, wie z.B. die sympodialen Stämme von Chrysogorgia u. s. w.; sie haben sich aber beziiglich der Polypen wohl nur wenig abgeändert.

Bei unserer jetzigen Kenntniss dieser Thiere können wir auf viele wichtige, namentlich die Phylogenie betreffenden Fragen, noch keine Antwort geben. Das ist aber wohl sicher, dass die von Wright und Studer zu der Familie Dasygorgidae, Verrill's Chry'sogorgiidac, vereinigten Arten thatsächlich einander beträchtlich näher stehen als den anderen Gorgoniden, also eine natürliche Familie bilden, welche sich schon seit langer Zeit von den anderen, jetzt bekannten Gorgoniden abgetrennt hat. 


\section{Ueber den Aststand bei Chrysogorgia.}

Wie oben (S. 22) schon dargelegt, muss auch für die oft ziemlich regellos verzweigten Stammäste der Chrysogorgia-Arten eine Ausbreitung streng in einer Ebene als der ursprüngliche Zustand betrachtet werden. Somit liegt kein Grund vor, wesshalb dies nicht auch zutreffen sollte für den ersten, proximalsten Seitenast, dessen basales Internodium nichts anderes ist als

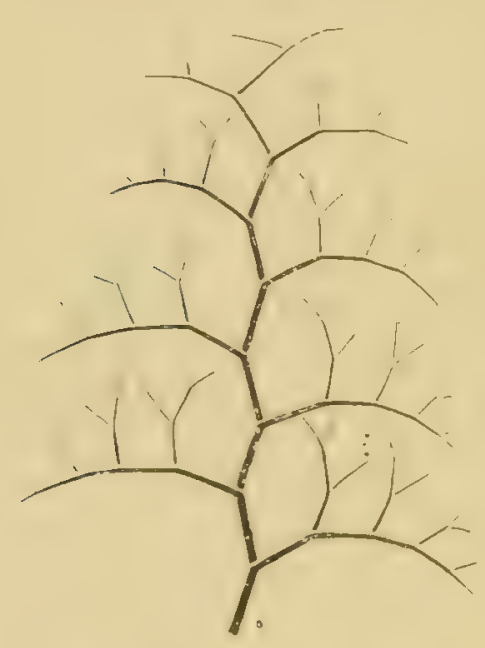

Hig. I69. Iststand $1 / 2$, Schema. $\dot{s}=$ Stamm. das nächsthöhere Stamm-Internodium (des sympodialen Stammes), das sich in den nächsthöheren Stammast fortsetzt. Da die zweigbildenden Seiten der Zweige nachfolgender Generationen abwechseln, d. h. einander zugekehrt sind, so bekommen wir bei strenger Anwendung der Verzweigungsregel von Chrysogorgia (siehe S. 25) eine hypothetische, in einer Ebene ausgebreitete Grundform, wie Fig. I 69 sie wiedergiebt. Der Aststand derselben ist $1 / 2$, d. h. jeder dritte Stammast steht uber dem ersten. Diesen Aststand habe ich nicht gefunden ${ }^{2}$ ).

Wenn die anscheinend nahe mit Chrysogorgia verwandte Iridogorgia pourtalesii aber einen sympodialen Stamm hat (das ist nicht untersucht, scheint aber sehr gut möglich, siehe S. 92), so lässt ihre Verzweigung sich kaum von einer zweireihigen Anordnung der Stammäste ableiten. Man müsste dafür eine Drehung aller Zweige um nahezu i $S 0^{\circ}$ annehmen: ein eigenthümliches Verhalten, welches wir nicht voraussetzen dürfen. Bei Chrysogorgia selbst lässt die Spirale, in der die Stammäste stehen, sich leicht aus einem einreihigen Aststand durch stärkere Drehung ableiten; von einer Anordnung in einer doppelten Reihe am Stamme fand ich keine Andeutung, auch nicht in den wachsenden Spitzen der Kolonien.

Bei den Riiscinac finden wir eine Verzweigungsregel, welche bei einer Kolonie mit sympodialem Stamme eine einreihige Anordnung der Zweige bedingen würde, also den Aststand ${ }^{1} / 1$ (Fig. I 70). Daraus lässt sich der Aststand der Iridogorgia (vorausgesetzt der Stamm sei ein Sympodium) durch eine geringe Drehung ableiten, die von Chrysogorgia durch etwas stärkere Drehung.

1) WRign und STLDER, Challenger Keport, rol. 3f, S. 7, sagen über den Aststand: „In the simplest case the branches arise" ,from the stem in alternating series from the wo opposite sides". Sie führen aber keine . Irt mit diesem . Iststande auf und ich fand in der Challenger-Sammluug auch kein lieispiel dafur. 
Bei der gemeinsamen Stammform von Chrosogorgia und den Riiscinac hatte wohl die Verzweigungsregel entweder der einen oder der anderen dieser beiden Geltung. Die Möglichkeit, dass Chroysogorgia also ehemals der Verzweigungsregel, welche wir jetzt bei den Fragmenten von Plezurogorgia fanden und auch als primitiv für Riisca nachzuweisen versuchten, folgte, muss unbedingt zugegeben werden. Es ist möglich, dass dieser Zustand, nur durch eine geringe Drehung der Verzweigungsebene modificirt, bei Iridogorgia erhalten blieb, während bei Chry'sogorgia die Drehung viel erheblicher wurde und dabei auch die Verzweigungsregel der Stammäste zu dem jetzt gefundenen Modus umgeändert wurde.

Ich kann aber bei unserer ungenügenden Kenniniss die Möglichkeit, dass der in Fig. I 69 abgebildete Zustand doch der primitive fuir Chrysogorgia sei, nicht verwerfen und betrachte sowohl den Aststand $1 / 2$ als auch den Aststand $1 / 1$ als den möglicherweise primitiven. Eine fächerförmige Ausbreitung in einer Ebene

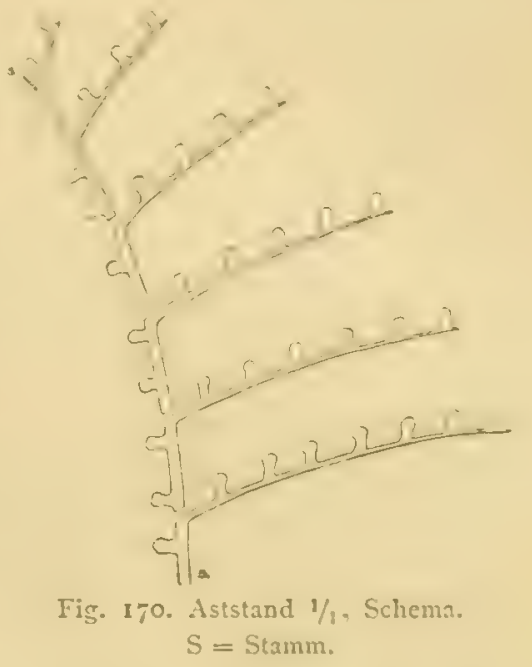
glaube ich aber jedenfalls als ursprunglich betrachten zu müssen. Daraus leite ich die jetzigen Aststände, $1 / 4,1 / 3, \%$ und die mehr unregelmässigen durch verschiedene Stärke und verschiedene Art der Drehung ab.

Die Ausbreitung in einer nahezu verticalen Ebene hat nur Zweck wenn die Arten in einem Gebiete leben mit ziemlich starken Meeres-Strömungen von vorherrschend gleicher Rich. tung, senkrecht zu welcher die Kolonien sich ausbreiten, und das ist in der Tiefsee nicht, oder doch nur unter ganz besonderen Umständen, der Fall. Die Nahrung für die Polypen wird in der. Tiefsee entweder regellos von allen Seiten heranschwimmen oder sie sinkt von oben herab. Hierfür ist aber eine Ausbreitung der Kolonien in einer verticalen Ebene die ungünstigste. Jede Drehung war bei den Arten, welche in die Tiefsee einwanderten vortheilhaft und hatte dadurch Aussicht auf Erhaltung und Summirung. An Stelle der einseitigen Stammastabgabe trat der Stand der Aeste in einer Spirale auf dem Stamme auf. Bei Iridogorgia ist die Drehung noch gering. Bei Chry'sogorgia aber ist der Winkel der Drehung, die Divergenz der nachfolgenden Stammäste, grösser und das giebt eine mehr gleichmässige Vertheilung der Aeste und dadurch der Polypen in Raume um den Stamm. Die mehr horizontale Ausbreitung der Stammäste selbst, welche viele Arten zeigen, ist vortheilhafter für den Fang der von oben herabsinkenden Organismen, welche wohl auch, wenigstens theilweise, als Nahrung dienen. Die Arten, bei denen diese horizontale Ausbreitung der Stammäste statt hat, wie Chr. gcniculata, sibagac, lata, zeigen auch eine viel gleichmässigere Vertheilung der Polypen im Raume als die Arten mit noch nahezu in der verticalen Ebene (parallel dem Stamme) verzweigten Stammästen, wie Clur. capansa. Auch die Drehung der Zweigbildenden Seite der Aeste, welche bei vielen Chrysogorgia-Arten constatirt wurde, führt zu einer mehr gleichmissigen Vertheilung der Polypen und ihre Erhaltung ist deshalb als vortheilhafte Umänderung begreiflich.

Bei einigen Arten finden wir eine unregelmässige, ziemlich stark wechselnde Divergenz der nachfolgenden Stammïste (Chr. oricntalis und squarosa), also einen unregelmissigen Aststand, welchen man sich leicht als aus dem Aststand $1 / 1$ oder $1 / 2$ hervorgegangen denken kann. 
Bei der Mehrzahl der Chrysogorgia-Arten ist aber die Divergenz nicht sehr variabel, bisweilen sogar ziemlich constant. Das scheint mir nicht befremdend, weil die directe Ursache der Drehung doch eine kleine Abweichung in der Lage der Rinde sein muss und diese Abweichung sehr wohl bei allen Stammästen einer Kolonie nahezu dieselbe Grösse haben kann und dadurch auch eine nahezu gleich grosse Divergenz der Stammäste bei einer Art hervorrufen kann.

Von den möglichen Divergenzen, d. h. von allen Abweichungs- IVinkeln von $0^{\circ}$ bis $180^{\circ}$, treten ganz vorherrschend die von nahezu $144^{\circ}$ (Aststand $\% / 5$ ), $120^{\circ}$ (Aststand $1 / 3$ ) und $90^{\circ}$ (Aststand $3 / 4$ ) auf. Erheblich von diesen abweichende Werthe fand ich nur selten (bei Chr. squarrosa und oricntalis, sowie hin und wieder bei Kolonien anderer Arten, wo die meisten Divergenz-Winkel einem der drei genannten Werthe nahe kamen). Man wird sich also abfragen, ob die drei Divergenzen $144^{\circ}$, $120^{\circ}$ und $90^{\circ}$ einen Vortheil vor allen anderen haben; und es ist in der That möglich einen solchen anzugeben ${ }^{1}$ ). Bei den drei genannten Astständen liegt jeder jüngste Stammast ziemlich genau in der Mitte des grössten Zwischenraumes, welchen die benachbarten älteren Aeste frei gelassen haben. Je mehr die Divergenz von den Werthen $144^{\circ}$, I $20^{\circ}$ oder $90^{\circ}$ abweicht, desto weniger genau kommt der neue Stammast über den grössten freien Raum zu liegen, desto mehr Zweigmaterial würde nöthig sein um die Polypen gleichmässig über den ganzen Raum zu vertheilen. Setzt man die Divergenzen auf einen Cirkel ab, so kann man sich hiervon überzeugen. Die Aststände $2 / 5,1 / 3$ und $1 / 4$ geben eine schnelle und gleichmässige Vertheilung der Zweige und Polypen rings um den Stamm herum und es ist deutlich, dass dies für das Empfangen von Nahrung vortheilhaft ist.

Der Nachtheil einer weniger regelmässigen Anordnung scheint demgegenüber nur gering und in Einklang damit steht, dass die Unregelmässigkeit in den Astständen fast immer ziemlich gross ist. So hat Chr. rigida zwar eine sehr regelmässige Divergenz, dieselbe ist aber etwas grösser als $90^{\circ}$, sodass die vier Längsreihen der Stammäste am Stamme sehr steile Spiralen bilden, keine genauen Orthostichen sind.

Die Möglichkeit die regelmässigen Aststände durch die Annahme erklären zu wollen, dass der Stamm durch den Bau seiner Rinde die Fähigkeit habe nach drei, vier resp. fuinf Seiten Stammäste abzugeben, also durch die Annahme der Stamm sei radiär symmetrisch, muss ich abweisen. Der Stamm besteht ja aus den einander folgenden ersten Internodien der Hauptäste, welche Hauptäste nur nach einer Seite Seitenzweige abgeben können.

Auch können die Aststände nicht direct, mechanisch, durch Raummangel hervorgerufen sein, denn die neuen Stammäste haben stets bei ihrer Entstehung allen möglichen Raum.

Meine Ansicht ist also, dass die jetzigen spiraligen Aststände der Chrysogorgia-Arten aus der Ausbreitung der Kolonien in einer verticalen Ebene hervorgegangen sind (Aststand ${ }^{3} / 1$ oder ${ }^{1} / 2$ ) und zwar weil jede Drehung vortheilhaft sein musste und dadurch Aussicht auf Erhaltung hatte. Die Drehung wurde stets grösser bis eine regelmässige und rasch folgende Vertheilung der Stammïste um den Stamme herum erreicht war. Dass die Aststände $1 / 1,1 / 3$, und $\%$ vorherrschen, findet seinen Grund darin, dass diese Stellungen am ausgiebigsten eine vollkommene und gleichmässige Vertheilung der Zweige und dadurch der Polypen um den Stamm zu Stande bringen. 


\section{Ueber das Längenwachsthum der Rinde.}

Die regelmässige, einreihige Anordnung der Polypen bei Lcpidogorgia gestattet es aus deren jeweiliger gegenseitiger Entfernung auf jungen und alten Stammtheilen Schliisse iiber das Längenwachsthum der Rinde zu ziehen. Sehr einfach sind die Verhältnisse aber nicht.

Typisch ist in dieser Hinsicht die Kolonie von Lepidogorgia verrilli der Siboga-Sammlung von Stat. S5 (S. I 2, Fig. I 5). Die Polypen derselben sind von sehr wechselnder Grösse; zwischen den grösseren Polypen stehen kleine und sehr kleine, zweifellos junge Polypen. Von der Spitze der Kolonie ausgehend, findet man meist einen kleinen Polypen zwischen je zwei grösseren. Letztere sind in regelmässiger Reihe an der Spitze der Kolonie entstanden, sind also alle einmal Endpolypen gewesen. Zwischen ihnen entstehen nun später neue Polypen, denn man findet auf der Stammspitze zwischen je zwei dieser erstgebildeten grösseren Polypen, ziemlich genau in der Mitte zwischen ihnen, je einen ganz kleinen jungen Polypen, welcher also niemals Endpolyp war. Diese Polypen zweiter Generation fehlten am vorliegenden Object nur zweimal und zwar ziemlich nahe der Spitze der Kolonie; sie müssen sich dort wahrscheinlich noch bilden. Der eine ist vielleicht doch schon angelegt als sehr kleines Wärzchen der Rinde. Nach der Basis der Kolonie zu werden die Polypen der $2^{\text {ten }}$ Generation immer grösser; sie sind da ja auch älter. Die ältesten, ausgewachsenen sind so gross wie die Polypen der I $^{\text {sten }}$ Generation und unterscheiden sich von ihnen nicht mehr; man kann sie aber noch an ihrer Stellung erkennen. Dass sie niemals fehlen, ist daraus ersichtlich, dass nirgends eine Entfernung der Polypen angetroffen wird, die etwa das Doppelte der Entfernung zweier benachbarter erwachsener Polypen betrige.

Etwas unterhalb der halben Länge der Kolonie treten plötzlich wieder sehr kleine Polypen

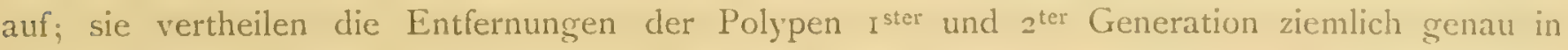
gleiche Hälften. Diese neuen Polypen gehören einer dritten Generation an. An der unteren Hälfte der Kolonie fehlen diese Polypen der $3^{\text {ten }}$ Generation nur in zwei Zwischenräumen zwischen Polypen $1^{\text {ster }}$ und $2^{\text {ter }}$ Generation. Im unteren Abschnitt der Kolonie stehen also zwischen je zwei Polypen der $1^{\text {sten }}$ Generation drei neue Polypen, einer der $2^{\text {ten }}$ und zwei einer $3^{\text {ten }}$ Generation.

Will man nun aus den Entfernungen der Polypen ausmachen, ob die Rinde auch auf älteren Stamm-Abschnitten noch in die Länge wächst, so muss man dafür die Entfernungen der Polypen I $^{\text {ster }}$ Generation vergleichen. Diese sind für die Kolonie, womit wir uns beschiffigen, von der Spitze nach der Basis $z u$ in mm.: $8^{1} / 2-8-7-5^{1} / 2-6-7^{1} / 2-9^{1 / 2}-10-11-$ IO-I2-II - I I $1 / 2-\mathrm{IO}^{1} \%$ - I $2 \frac{1}{2}-\mathrm{I}_{2} 1 / 2-\mathrm{I} 2-\mathrm{I} 4$; sie werden also nach der Basis zu im Mittel nicht unerheblich grösser. Dies deutet auf ein lang andauerndes Lïngenwachsthum der Rinde 
an Stellen, wo die Polypen schon erwachsen sind. Ich muss aber darauf hinweisen, dass ungünstige Umstände, wie allmälige Verringerung der Nahrungszufuhr, eine ähnliche Abnahme der Entfer-

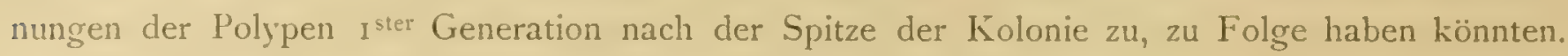

Ich lasse jetzt die Entfernungen aller Polypen der fraglichen Kolonie folgen, wobei die Ziffern I, II, III die Polypen der I $^{\text {sten }}, 2^{\text {ten }}$ und $3^{\text {ten }}$ Generation angeben, die arabischen Ziffern die Entfernungen in mm.: abgeriebene Achse der Spitze - II $3^{1 / 3} \underbrace{\mathrm{I}_{4} \mathrm{II}_{4}{ }^{1 / 2}}_{8^{1 / 2}} \mathrm{I}_{4} \mathrm{II}_{8} \mathrm{I}_{3^{2} / 2} \mathrm{II}_{3} 3^{1}$

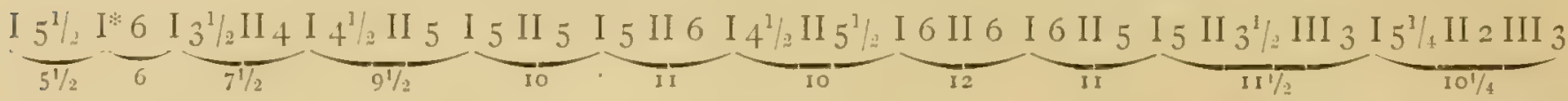

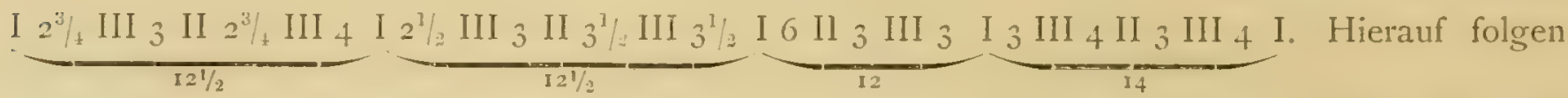

basalwärts noch drei kleine Polypen, dann der polypenlose Stammabschnitt. Bei * war der Polyp $2^{\text {ter }}$ Generation vielleicht schon angelegt als kaum sichtbares Höckerchen der Rinde.

Bei den anderen Lepidogorgia-Kolonien, die ich gesehen, findet die Bildung neuer Polypen viel weniger regelmässig statt und ist es nicht möglich die Polypen I ster Generation von den später zwischengefuigten zu unterscheiden. Nur an der Spitze der Kolonie von Stat. SS der SibogaSammlung (Lepidogorgia pctersi, S. I , Fig. I 4) findet man deutlich kleine Polypen einer $2^{\text {ten }}$ Generation von der Spitze $a b$ in folgender Weise stehend: I II I II I I II I II I II I I (:) I II etc.. Nach unten finden wir dann eine Strecke mit nur erwachsenen Polypen, unterhalb der Mitte des Stammes aber wieder einige ganz kleine Polypen, also wohl eine neue Generation derselben. Die Entfernungen und Grössen der Polypen variiren aber so erheblich, dass es nicht möglich ist, die Polypen erster Generation aus ihrer Stellung zu erkennen. Demgemäss kann auch nicht mit Sicherheit, wohl aber, wegen der doch kaum verneinbaren Einschaltung von Polypen, mit Wahrscheinlichkeit auf eine andauernde Verlängerung der Rinde geschlossen werden. Auch bei der Kolonie der Lcpidogorgia pctersi von Stat. 52, Siboga-Exp., hat eine Einschaltung von neuen Polypen zwischen die älteren erster Generation statt. Dies ist sehr deutlich bei den Kolonien dieser Art in der Challenger-Sammlung, wo zwischen je zwei Polypen immer mehrere neue gebildet werden, sodass ganz unten die Polypen einander sehr nahe stehen. Obwohl, wie gesagt, die Verhältnisse nicht so regelmässig sind, dass die Entfernungen der Polypen $I^{\text {ster }}$ Generation ermittelt werden können und dadurch eventuelles andauerndes Längenwachsthum fur diese Kolonien aus diesen Entfernungen mit Bestimmtheit nicht constatirt werden kann, so deutet doch alles darauf hin, dass immer mehrere neue Polypen zwischen je zweien der ersten Generation gebildet werden, woraus hervorgeht, dass die Entfernungen der letzteren auf älteren Stammabschnitten grösser sind als an den Spitzen, also noch längere Zeit an Länge zunehmen.

Wenn ich oben bei $L$. arrilli von Polypen $2^{\text {ter }}$ und $3^{\text {ter }}$ Generation sprach, so that ich das der Klarheit der Darstellung wegen, nicht weil ich dadurch einen wichtigen Unterschied ausdriicken wollte.

Bei Riisea paniculata sitzt immer ein Polyp der Spitze der Zweige seitlich auf. An der Spitze der Zweige selber (Fig. I6.4, bei A) kann die Rinde also nicht wachsen, denn dann wiirde die Spitze iiber den Polypen hinauswachsen. Das Lïngenwachsthum der Rinde muss, wenigstens an der Seite, wo der Polyp der Rinde aufsitzt, proximalwärts von demselben statt- 
finden und nicht genau an der Zweigspitze. Andererseits entstehen die neuen Seitenzweige schon in der Entfernung von den vorangehenden, welche sie zeitlebens behalten. Die Rinde zwischen den Seitenzweigen verlängert sich also auch nicht mehr. Das Längenwachsthum beschränkt sich bei Riisea mithin auf die kleine Strecke der Rinde zwischen Endpolyp und dem vorangehenden jüngsten Polypen. Der letztere nämlich wird schon annäherend in der gleichen Entfernung vom nächst vorangehenden Seitenzweig gebildet, welche später zwischen diesem und dem Seitenzweig besteht, der an Stelle jenes Polypen abgeht. Es fehlt also bei Riisca das fortgesetzte Längen. wachsthum der Lepidogorgia-Arten wie auch die Verlängerung der Rinde an der Zweigspitze selbst.

Bei Plarrogorgia werden auch noch neue Polypen zwischen den erwachsenen gebildet und sind die Entfernungen zwischen zwei erwachsenen Polypen grösser als die zwischen einem erwachsenen und einem jungen Polypen, nicht aber doppelt so gross. Doch ist das vorliegende Material zu spärlich um Zufall aus zu schliessen, sodass nicht mit Gewissheit auf fortgesetztes Längenwachsthum geschlossen werden kann.

Bei den Genera Chrysogorgia und Motallogorgia stehen meist nur wenige Polypen auf jedem Internodium und die Entfernungen der Polypen variiren dabei meist so erheblich, dass nicht auf eine spätere Verlängerung derselben geschlossen werden kann. Es werden aber viele neue Polypen zwischen den schon erwachsenen gebildet ${ }^{2}$ ), wobei bei einigen Arten (so C/hr. flerilis und Chr. pentasticha) die distalsten Polypen der End-Internodien meist schon ziemlich gross oder ganz erwachsen, selten sehr junge Polypen sind. Ein solcher Zustand ist in Fig. 29 (S. 28), etwas schematisch nach Chr. flexilis abgebildet; die Polypen sind in der Reihenfolge A, B, C, D (vielleicht B, A, C, D) gebildet worden. Es ging also dem abgebildetem Zustand ein Stadium ohne die Polypen B, C und D voran. War nun vom Anfang an die Entfernung der Polypen A und B dieselbe wie jetzt, dann muss vor der Bildung des Polypen B der Endzweig eine polypenlose Endstrecke von der Länge A B besessen haben. Wiewohl nun in diesem Falle so lange Endstrecken gar nicht selten sein dürften, habe ich solche an mehreren, daraufhin untersuchten Kolonien der Chr. flcxilis nicht auffinden können; immer fand sich ein, meist schon ziemlich alter Polyp in viel geringerer Entfernung von der Zweigspitze als der Abstand A B. Dies deutet unbedingt auf eine secundäre Verlängerung der Entfernung der Polypen A und B hin, also auf ein Längenwachsthum der Rinde proximalwärts vom P'olypen B. Gegren die Annahme es seien zwischen A und B ältere Polypen abgefallen spricht, dass die Polypen A und $\mathrm{B}$ der Rinde fest aufsitzen und dass die Rinde keine Beschädigung zeigt. Man kann die Erscheinung, dass die Entfernung der Polypen von der Zweigspitze bei Chrysogorgia meist nur sehr gering ist und wohl nahezu immer deutlich kleiner als die Entfernungen der erwachsenen P'olypen, niemals länger, nur durch die Annahme erklären, dass die Entfernungen der Polypen noch nach der Bilding der Polypen zunehmen. Dadurch werden auch die Polypen ron der Zweigbasis mehr oder weniger weit fortgeschoben, wie die Endpolypen bei Riisea. Nur werden bei Chrysogorgia, wenigstens bei der Mehrzahl der Arten, an den Zweigspitzen von Zeit zu Zeit neue Polypen gebildet und wachsen die Spitzen iiber die ilmen zunächst stehenden Polypen hinaus. Bei Chr.octagonos (Fig. 99, S. 65) sitzt allen Zweigspitzen ein P'olyp auf. Lis ist nicht unmöglich, class 
bei dieser Art die Polypen als Regel während des Wachsthums der Zweigspitzen, denen sie aufsitzen, mit diesen distalwärts verschoben werden, wie die Polypen der Riisea. Zur Entscheidung dieses Punktes ist mein Material aber zu gering und deshalb gehe ich nicht weiter darauf ein.

Ich schliesse aber aus den gefundenen Verhältnissen auch für Chry'sogorgia auf ein Längenwachsthum der Rinde in einiger Entfernung von der Spitze der Zweige. Da die Länge der Internodien bei jungen und alten Stammästen nicht verschieden ist, wachsen anscheinend nur die End-Internodien und kann also auch nur bei letzteren eine Verlängerung der Rinde stattfinden.

Nur für Lepidogorgia muss diese Verlängerung auch noch für relativ schon ziemlich alte Abschnitte der Rinde angenommen werden; für Riisea und Chry'sogorgia ist das ausgeschlossen.

Obwohl selbstverständlich für jedes der angeführten Beispiele Zufall als Erklärung herangezogen werden könnte, so ist solcher für die Gesammtheit der Beispiele doch wohl als ausgeschlossen $z \mathrm{u}$ betrachten. Und dies namentlich deshalb, weil auch bei anderen Grorgoniden anscheinend ein ähnliches andauerndes Wachsthum der Rinde in einiger Entfernung von den Zweigspitzen auftritt. So heisst es bei G. voN Koch ${ }^{1}$ ): "An älteren Colonien entwickeln sich" „nicht selten auch Polypen unterhalb des primären auf der durch Streckung der Rinde ent-" "stehenden Fläche". Mit „primären Polypen" wird der zuerst gebildete Polyp der jungen Kolonie gemeint. Die "Streckung" der Rinde ist aber wohl als Längenwachsthum auf zu fassen, also ein Längenwachsthum der Rinde zwischen Basis der Kolonie und ersten Polypen. Vergleicht man von Koch's Figuren I5 und I6, Tafel 8, mit einander, dann muss (bei Eunicella cavolini) unbedingt auf ein erhebliches Längenwachsthum der schon gebildeten Rinde geschlossen werden.

Bei der Untersuchung des Längenwachsthums der Zweige von Antipathes subpinnata kam G. von $\mathrm{Koch}^{2}$ ) zu folgendem, gut begründeten Resultate:

I. Die Hornachsen der Zweigen wachsen nur an der Spitze.

2. Die Polypen rücken im Laufe der Zeit über das Skelet hinweg den Zweigspitzen zu, indem immer neue Polypen gebildet werden zwischen den älteren und letztere aus einander schieben. An der Zweigspitze selbst fand er nahezu immer (nur eine Ausnahme in 70 Fällen) einen erwachsenen Polypen; dort werden also so gut wie keine neuen gebildet und der Endpolyp rückt zusammen mit der wachsenden Spitze von der Basis des Zweiges hinweg. Die Achse der Antipathiden wird ganz wie die der Gorgoniden, von einem Achsenepithel ausgeschieden. Wo also bei Antipathes eine Verschiebung der Polypen (und damit auch der gering entwickelten Rinde) über die Achse stattfindet, da ist eine ähnliche Verschiebung auch bei den Gorgoniden möglich. Man kann demzufolge aus dem Rindenwachsthum der Chrysogorgiidac nicht auf eine Verlängerung des von ihr bedeckten Achsenabschnittes schliessen. Beweise für das Fehlen einer solchen Verlängerung der Achsen in einiger Entfernung von deren Spitzen konnte ich bei den glatten, nicht wie bei den Antipathiden bedornten Achsen nicht finden. Eine solche Verlängerung ist jedoch bei den Gorgoniden nicht wahrscheinlich, nachdem vos Kocr gezeigt hat, dass solche bei Antipathes nicht vorkommt.

1) Fauna und Flora des Golfes ron Neapel; Gorgoniden, 1857 , S. 24.

2) Festschrift der technischen Hochschule zu Darmstndt, ISS6. 


\section{Uebersicht der Arten der Familie Chrysogorgiidae.}

Iste Subfamilie Lepidogorgiinae.

I. Genus Lepidogorgia Verrill (Strophogorgia Studer).

I. L. petersi (Wr. \& St.).

2. L. verrilli ( $\mathrm{Wr}$. \& St.).

3. L. challengeri (Wr. \& St.).

4. L. gracilis Verrill.

5. L. fragilis ( $\mathrm{Wr}$. \& St.).

2te Subfamilie Chrysogorginat.

2. Genus Chrysogorgia Duch. \& Mich (Chrysogorgia Verrill + Dasygorgia Verrili).

Gruppe A. Spiculosae; mit Spicula im Polypen-Rumpf oder die Rumpf-Scleriten sind, wenn auch ziemlich dünn, doch mehrere Male länger als breit und, wenigstens theilwcise, längsliegend und mit kleinen Wärzchen versehen.

Unter-Gruppe A $I$; Aststand $1 / 4$, links gewunden; nur Spicula in den Polypen, oder höchstens vereinzelte Schuppen in der Polypen-Basis.

1. Chr. lata nov. spec.

2. Chrospec.

3. Chr. tetrasticha nov. spec.

4. Chr. spec.

5. Chr. pusilla nov. spec.

6. Chr. spec.

7. Clir. cupressa (Wr. \& St.).

Unter-Gruppe 12 ; Aststand $3 / 5$, rechts gewunden; mit Schuppen in der Polypen-13asis und in der Tentakel-Spitze.

8. Chir. flexilis (IVr. \& St.).

9. Chr. affinis n. n. (Dasy'gorgia spiculosa Wr. \& St., nec Verrill).

10. Chr. pentasticha nov. spec.

11. Chr. anastomosans nor. spec. 
Unter-Gruppz A 3; Aststand regellos; Scleriten der Polypen-Basis querliegrend, cinen Ring bildend.

12. Chr. oricntalis nov. spec.

13. Chr. fewkesi Verrill.

"14. Chr. oscidentalis n. n. (Chr. desbonni Verrill, nec Duch. \& Mich.).

15. Chr. squerrose (Wr. \& St.).

Anhangr zur Gruppe A: unvollständig belannte Arten.

16. Chr. mixta nov. spec.

17. Clur. agassizii (Verrill).

"18. Chr. spiculosa (Verrill).

"19. Clir. splendens (Verrill).

"20. Chr. clegans (Verrill).

Gruppe B. Squanosue aberrantes; Polypen-Rumpf nur mit Schuppen; Tentakel-Rücken mit dicken Scleriten.

Untir-Gruppe B I; Tentakel-Rücken mit typischen Spicula und ohne Schuppen.

21. Chr. intcrmedia nov. spec.

Unter-Gruppe B 2; Tentakel-Rücken mit dicken, unregelmässigen, längsliegenden Scleriten; Rumpf-Scleriten einen vorspringenden Ring unter den Tentakel-Bases bildend; Aststand 1/4, rechts gewunden.

22. Chr. expansa (Vr. \& St.).

23. Chr. octagonos nov. spec.

Ankang zur Gruppe B: unvollständig bekannte Art:

24. Chr. curvata nov. spec.

Gruppe C. Squamosae typicat; Tentakel-Rücken nur mit Schuppen.

Unter-Gruppe CI; Schuppen der Tentakel-Basis sehr schmal, längsliegend.

25. Chr. japonica (Vr. \& St.).

Unter-Gruppe C 2; Schuppen der Tentakel-Ruicken alle oder doch meist querliegend, nirgends deutlich längsliegend; Aststand $\%$, links gewunden.

"26. Cirr. acanthalla (Wr. \& St.).

27. Chr. pendula nov. spec.

Unter-Gruppe C 3; Schuppen der Tentakel-Rücken querliegend; Aststand $1 / 3$, links gewunden.

28. Chr. silogae nov. spec.

21. Chr. arillaris (Wr. \& St.).

3). Cler. spec.

31. Chr. Serniculata (Wr. \& St.).

32. Chr. rigida nov. spec.

Unter-Gruthe $C$ f; Schuppen der Tentakel-Rticken querliegend; Aststand $1 / 4$, links gewunden.

33. Chr. ramosir nov. spec. 
Anhang zur Gruppe C: unvollständig bekannte Arten.

34. Chr. squamata (Verrill).

35. Chr. deshonni Duch. \& Mich.

36. Chr. fruticosa (Studer).

3. Genus Metallogorgia nov. Sen. (Dasygorgia Verrill pro parte).

I. A1. mclanotrichos (IVr. \& St.).

4. Genus Iridogorgia Verrill.

"I. I. pourtalesii Verrill.

$3^{\text {te }}$ Subfamilie Riiseinac.

5. Genus Pleurogorgia nov. gen.

I. P. plana nov. spec.

6. Genus Riisea Duch. \& Mich. (Herophila Steenstrup).

I. R. paniculata Duch. \& Mich.

Die mit * bezeichneten Arten wurden von der Siboga-Expedition nicht erbentet. 


\section{Nachweis der Litteratur über die Chrysogorgiidae.}

AGissiz, A. Three cruises of the Blake, vol. II; Bulletin of the Museum of comparative Zoology at Harvard College, Cambridge, vol. XV, I 888.

Duchassaing DE Fombressin, P. Revue des Zoophytes et des Spongiaires des Antilles; Masson et fils, Paris Is7o.

et Mrchelotti, G. Mémoire sur les Coralliaires des Antilles; Memorie della Reale Accademia della Scienze di Torino, Seric 2, vol. XIX, Is60.

et Michelotti, G. Supplément au Memoire, sur les Coralliaires des Antilles; Memorie della Reale Accademia della Scienze di Torino, Seric 2, vol. XXIII, I 866.

GRAY, J. E. Catalogue of Lithophytes or stony Corals in the Collection of the British Museum, London I\$70.

Hiles, ISA L. Gorgonacea collected by Dr. WiLley; A. Willey's Zoological Results. Part 2. Cambridge University Press, Jan. I 899 .

Koch, G. von. Die Gorgoniden; Fauna und Flora des Golfes von Neapel, Berlin, i 887.

Kölliker, A. Icones histiologicae oder Atlas der vergleichenden Gewebelehre; 2te Abtheilung, der feinere Bau der höheren Thiere. Istes Heft, die Bindesubstanz der Coelenteraten, Leipzig 1865.

Pourtalés, L. F. DE. Contributions to the Fauna of the Gulf Stream at great depths (2. series); Bulletin of the Museum of Comparative Zoology at Harvard College, Cambridge, vol. I, I869.

Roule, L. Coclentérés; Résultats scientifiques de la Campagne du "Caudan" dans le Golfe de Gascogne; Annales de l'Université de Lyon, vol. XXVI, I896.

Stenstikup, J. J. Beskrivelsen af en ny Koralslaegt af Octactiniernes Orden, og meddelte Jagttagelser over Gangen i Knopskydningen hos denne og flere andre lavere Dyr.; Oversigt over det Kongelige danske Videnskabernes Selskabs Forhandlinger og dets Metlemmers Arbeider i Aaret 1860; Kjöbenhavn (die Jahreszahl des Erscheinens ist nicht angegeben, war aber nicht i860, sondern späiter).

Deutsche Uebersetzung in: Zeitschrift für die Gesammten Naturwissenschaften, Jahrg. I862, Bd. XIX, S. 74 .

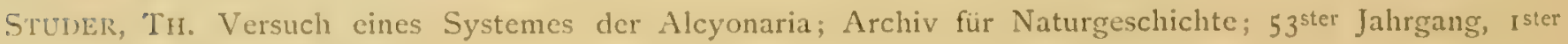
Band, Berlin ISS7.

- Note préliminaire sur les Alcyonaires; Reports on the dredging operations off the IVest Coast of Central America etc. etc., carricd on by the U. S. Fish Commission steamer "Albatross”, during IS9I; Bulletin of the Museum of Comparative Zoölogy at Harvard College, Cambridge. vol. XXV, N" $5,1894$.

VERrili, A. E. Report on the Anthozoa, and o: some additional Species dredged by the "Blake" in I\$ 77 -1879, and by the U. S. Fish Commission Steamer "Fish Hawk" in 1880-82; Bulletin of the Museum of Comparative Zoology at Harvard College, Cambridge. vol. II, No I, I883. 
VERRILL, A. E. Notice of the remarkable MIarine Fauna occupying the outer banks off the Southern Coast of New-England, N" 9; Brief Contributions to Zoology from the ILseum of Yale College, $\mathrm{N}^{0} \mathrm{LV}$; the American Journal of Science (and Arts); 3 Series, vol. XXVIII, IS8 4.

Results of the Explorations made by the steamer "Albatross", off the Northern Coast of the United States, in $188_{3}$; U. S. Commission of Fish and Fisheries; Part XI, Report of the Commission for $\mathrm{ISS}_{3}$; Washington, 1885 .

WRighT, E. P. The Alcyonaria; Report on the scientific Results of the Voyage of H. M. S. Challenger, etc.; Narrative of the cruise, vol. I, second Part, I 885.

and Studer, TII. Report on the Alcyonaria; Report on the scientific Results of the Voyage of H. M. S. Challenger, etc.; Zoology, vol. XXXI, I\$89.

GRAY, (1. c. IS70, S. 47) führt eine liamilie Riiseate Sars auf, citirt aber eine darauf bezigliche Arbeit nicht; ich habe vergebens danach gesucht.

Alle aus der Familie der Chrysogorgiidae bekannten Genera sind aufgefiihrt von DELAGE und HérouARD in ihrem: Traité de Zoologie concrète, Tome II, 2me Partie, les Coelentérés, 190I, S. 424, Fam. Dasygorginae. 
- Inhaltsverzeichniss.

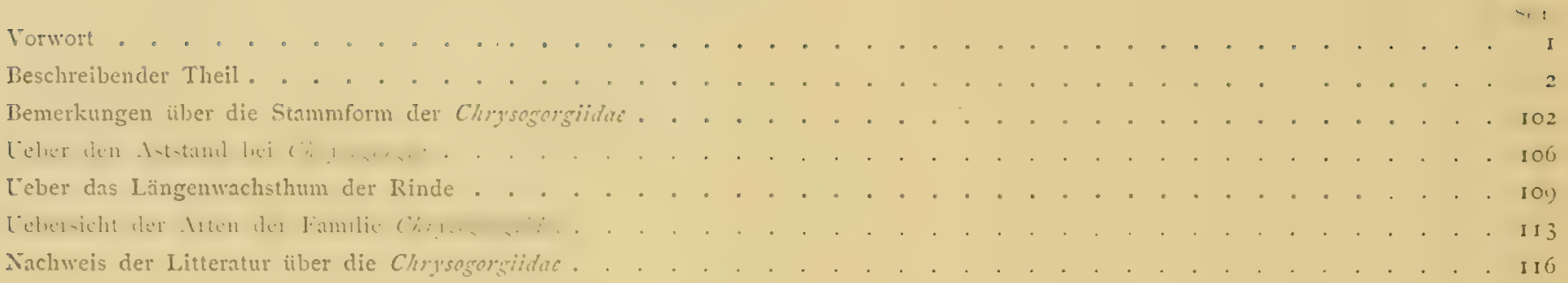




\section{Alphabetisches Register.}

\section{A.}

Abnorme Polypen 46.

Achse von Chrysogorgia 20. Längenwachsthum II 2. Achsencylinder 20.

Alcyonicola 47

Aststände bei Chrysogorgia 22, 106 .

Aststand von Iridogorgia 106.

Axenkanal 20.

C.

Centralstrang der Achse 20.

Chrysogorgia Duch. \& Mich. 3, 7. Diagnose 33. Verrill 53. Nicht identisch mit Chrysogorgia Duch. \& Mich. I8. Synonym mit Dasygorgia Verrill i 8.

- Aststand 22, 106. Bau der Achse 20.

Längenwachsthum der Rinde II I.

- acanthella $7 \mathrm{r}$.

- affinis 47.

- agassizii 60.

- anastomosans 51 .

- axillaris 77 .

- constricta 58.

- cupressa 40.

- curvata 67.

- desbonni Duch. \& Nich. 19. Unterschicde mit Chr. desbonni Verrill 56. Beschreibung 85 .

desbonni Verrill I9, 56. Unterschiedo mit Chr. desbonni Duch. \& Mich. 86.

clegans $6 \mathrm{I}$.

expansa $\sigma_{3}$.

fewkesi 55.

flexilis 43 .

fruticosa 86 .

geniculata 79. Unterschiede mit Chr. rigida 82 .
Chrysogorgia intermedia $6 \mathrm{r}$.

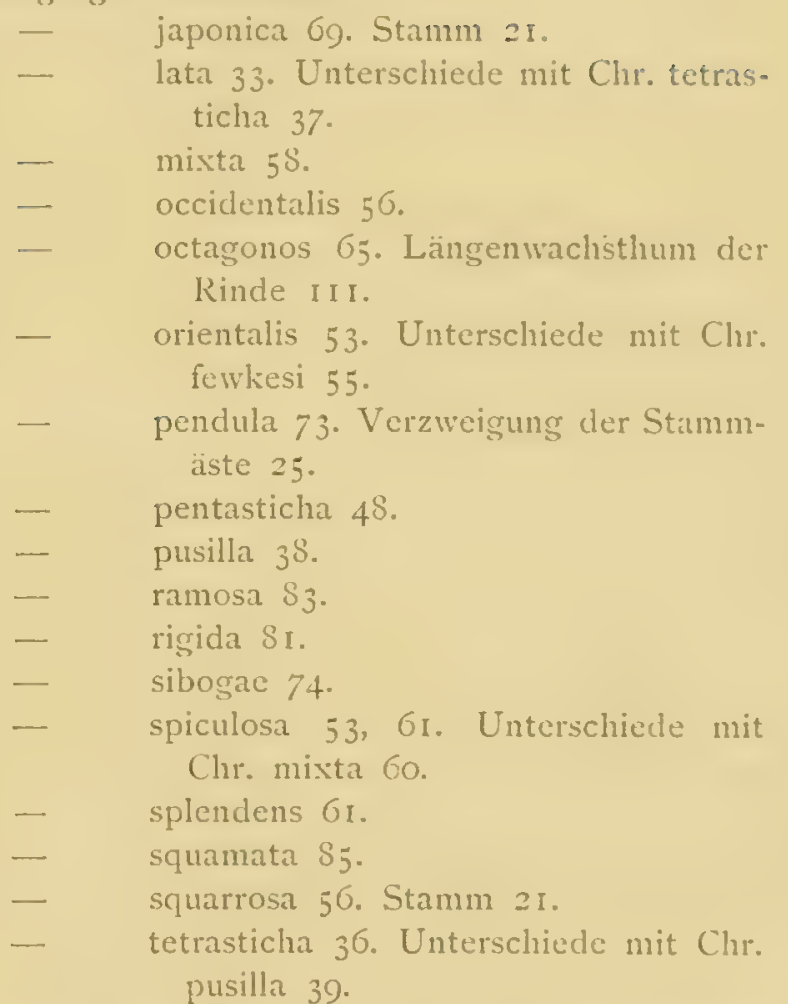

Chrysogorgiidae. Diagnose 3. Nicht Dasygorgiidae zu nennen i9. Ursache der Lateralität $1_{3}$. Vertheilung in Subfamilien 4. Verzweigung 102.

Chrysogrorginae 17 .

Chrysogorginae Wr. \& St. \&.

Cyma helicoidea unipara 26, 27.

D.

Dasygorgia Verrill. Identisch mit Chrysagorgia Duch. \& Nich. Is.

-.- acanthella 7 1.

- agassizii 60.

- axillaris 77 .

- cupressia 40.

- elegins 6r. 
Dasygorgia expansa $\sigma_{3}$.

$$
\begin{aligned}
& \text { - Hexilis } 43 . \\
& \text { fruticosa } 86 . \\
& \text { - geniculata } 79 . \\
& \text { japonica } 69 . \\
& \text { - melanotrichos } 4,87 . \\
& \text { - } \quad \text { spiculosa Verrill } 61 . \\
& \text { - } \quad \text { Wr. \& St. } 47 . \\
& \text { - } \quad \text { splendens } 61 . \\
& \text { squamata } S_{5} . \\
& \text { squarrosa } 56 .
\end{aligned}
$$

Dasygorgiidae $3,19$.

Divergenz-Winkel der Stammäste 21, Io\$.

\section{E.}

Entoderm-Kanäle 6, 27 .

H.

Hauptast 21.

Herophila 96.

$$
\text { - regia } 97 \text {. }
$$

\section{I.}

Iridogorgia 4. Diagnose 91. Aststand 92, I06. pourtalesii 92 .

\section{L.}

Längenwachsthum der Achsen I 2.

Lamippe $4 \pi$.

$$
\text { - der Rinde Iog. }
$$

Lepidogorgia 4. Beschreibung 5. Unverzweigt 103 . Längenwachsthum der Rinde Iog.

\section{- challengeri I4.}

fragilis $5,7,16$.

- gracilis 16.

- petersi 7. Vergleich mit L. verrilli 14.

Lepidogorgia verrilli 12.

Lepidogorginae 4 .

M.

Mesogloea 6.

Metallogorgia 4, I7. Diagnose 87. Längenwachsthum der Rinde III. melanotrichos $S_{7}$.

N.

Nematozooide 31, 104.

\section{P.}

Parasiten 46

Pinnulae der Tentakel 30.

Pleurogorgia 4, 92. Beschreibung 93. Längenwachsthum der Rinde III.

$$
\text { plana } 93 .
$$

Polypen 6, 27, 104. Neubildung bei Chrysogorgia 28.

\section{R.}

Riisea 4, 92. Beschreibung 96. Längenwachsthum der Rinde I 10.

- paniculata 97.

Riiseinae 4, 92, 102.

Rinde. Bau bei Lepidogorgia 5. Bau bei Chrysogorgia 27. Längenwachsthum 109.

Rinden-Scleriten bei Lepidogorgia 6 . bei Chrysogorgia 27. bei Pleurogorgia 94. bei Riisea 100.

\section{S.}

Schuppen 29.

Spiculosae 30, 33.

Spicula 29.

Spirale der Stammäste rechts oder links gedreht 22.

Squamosae aberrantes 61. Provisorische Gruppe 30.

$$
\text { - typicae 30, } 68 .
$$

Stamm bei Chrysogorgia 20; ein Sympodium 21.

Stammast 2I, 22.

Stammform der Axifera (Gorgoniden) IO4; der Chrysogorgiidae 102.

Strophogorgia 4, 5. Synonym mit Lepidogorgia 5.

$$
\begin{aligned}
& \text { - clablengeri } 14 . \\
& \text { - } \quad \text { fragilis } 16 . \\
& \text { - petersi } \% \text {. } \\
& \text { rerrilli } 12 .
\end{aligned}
$$

Strophogorginae 4 .

\section{T.}

Tentakel bei Lepidogorgia 7 .

\section{V.}

Verzweigung 20; der Stammform 102.

Verzweigungstegel bei Chrysogorgia 25 ; nach Wright und Studer 26.

\section{Z.}

Zooide bei Chrysogorgia 30. Fehlen bei Lepidogorgia 6 .

Zweigbildender Strcifen der Rinde 24. 



\section{CONDITIONS GENERALES DE VENTE.}

$1^{\circ}$. L'ouvrage du "Siboga" se composera d'une série de monographies.

$2^{\mathrm{s}}$. Ces monographies paraîtront au fur et à mesure qu'elles seront prêtes.

$3^{\circ}$. Le prix de chaque monographie sera différent, mais nous avons adopté comme base générale du prix de vente: pour une feuille d'impression sans fig. flor. 0.15 ; pour une feuillc avec fig. flor. 0.20 à 0.25 ; pour une planche noire flor. 0.25 ; pour une planche coloriée flor. 0.40 .

$4^{\circ}$. Il y aura deux modes de souscription:

a. La souscription à l'ouvrage complet.

1. La souscription it des monngraphies séparées en nombre restreint.

Dans ce dernier cas, le prix des monographies sera majoré de $25 \%$.

$5^{\circ}$. L'ouvrage sera réuni en volumes avec titres et index. Les souscripteurs à l'ouvrage complet recevront ces. titres et index, au fur et à mesure que chaque volume sera complet.

\section{Déjà paru:}

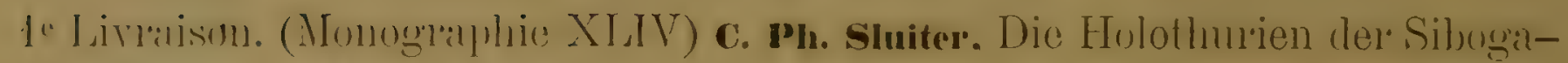
Expredition. Mit 10 Tiat. . . . . . . . . . . . . . / 7.50

Pour les souscripteur's à l'ouvrage complet. , "6.-

$\because$ Liviaison. (Nomnglaphie $\mathrm{LX}$ ) E. S. Barton, The genus Halineda. With 4 plates.

Pour les souscripteurs ì l'ouvrage complet. $\quad, 1.80$

:;" Livarisull. (Monographie, I) rax Weber, Introdnction et description de l'expedition. Avec Liste des Stations et 2 Cartes. . . . . . / 9.-

Pour les sonscripteurs it l'ouvrage complet. „,6.75

1. Livlaison. (Momenglemplic II) G. F. Tydeman. Descriplion of the ship and alphlinness userl for scientific explonation. With 3 plates and illustrations.

$f 2.50$

Pour les souscriptenirs d̀ l'ouvrage complet. $\quad$ "2.-

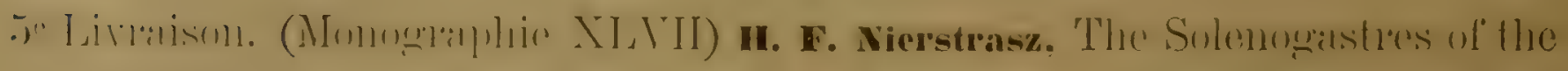
Siboga-Expedition. With six plates . . . . . . . . . 44.90

Pour les senscriptents it lourrige complet. $\quad, 3.90$ 





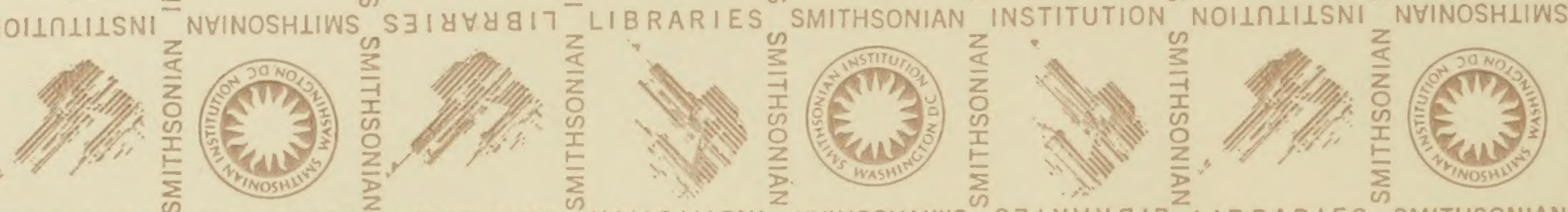

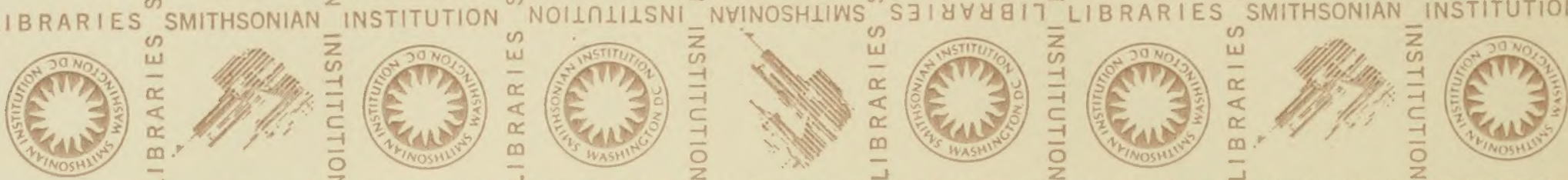

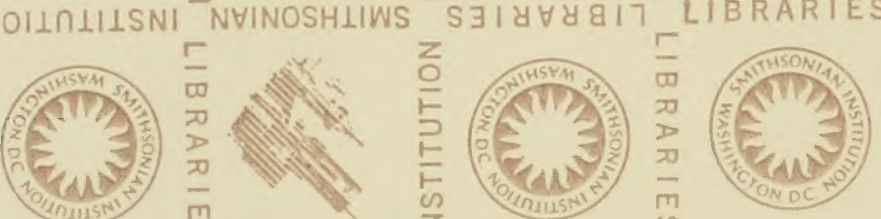

IBRARIES SMITHSONIAN INSTITUTION NOIDIIISNI NVINOSHLIWS

(I)

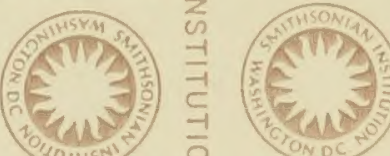

SMITHSONIAN INSTITUTION

NOHNHUSNI

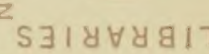

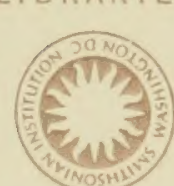

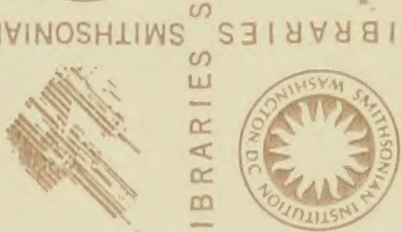

(i)
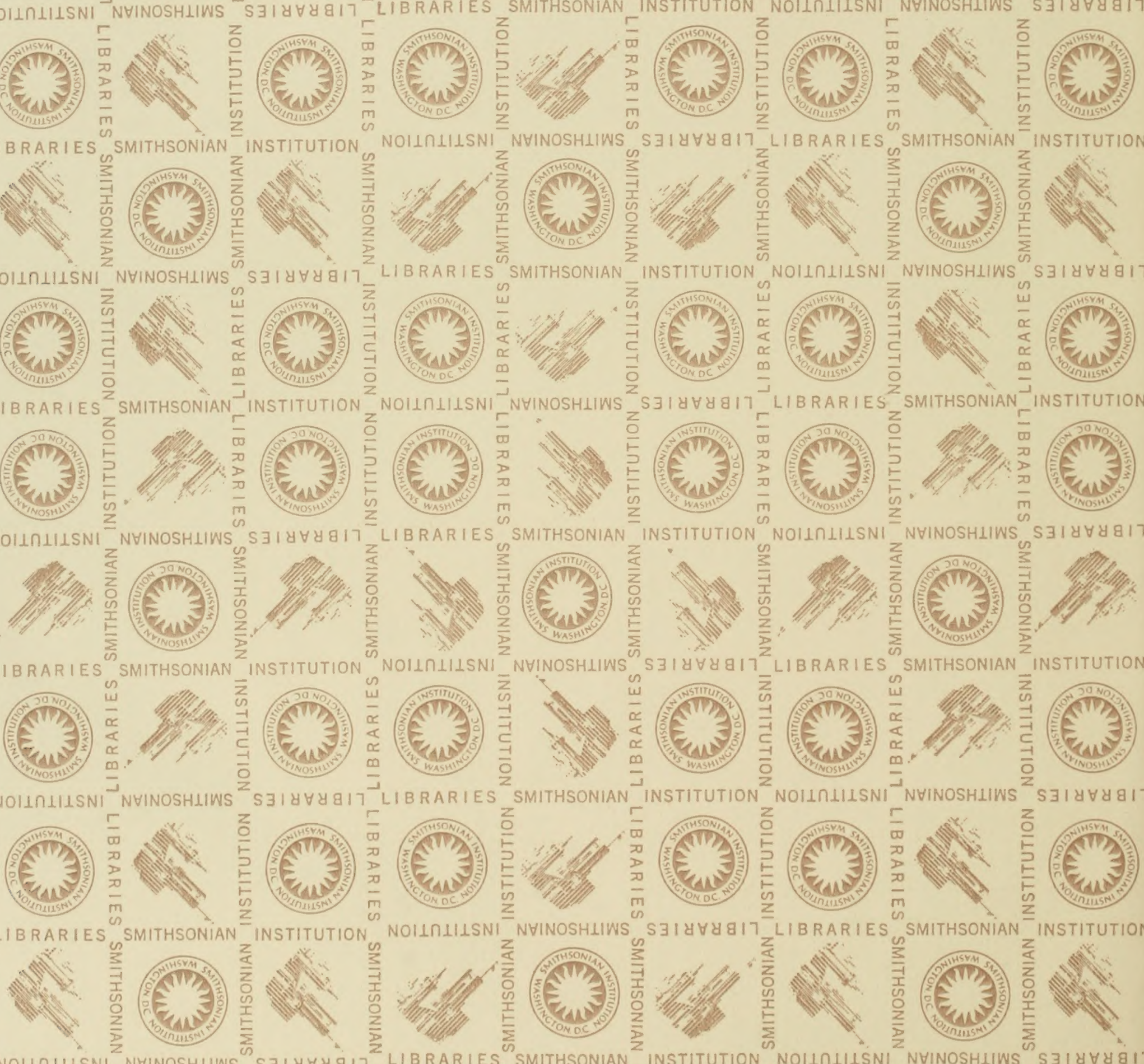

ssilyzart
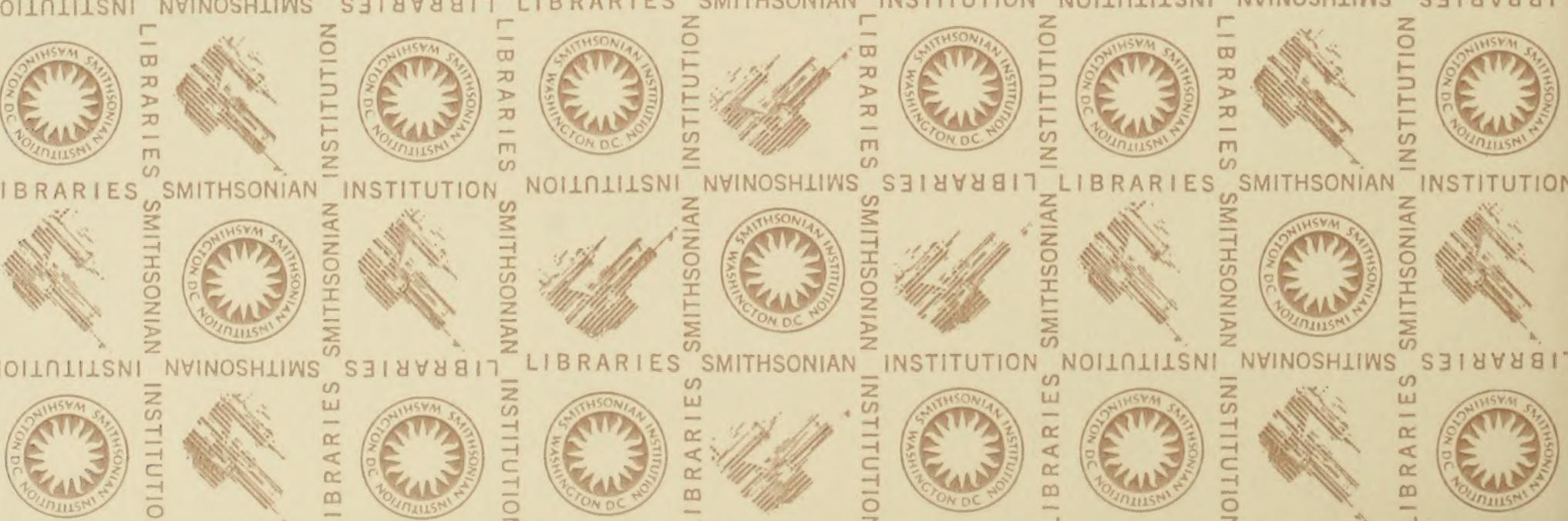


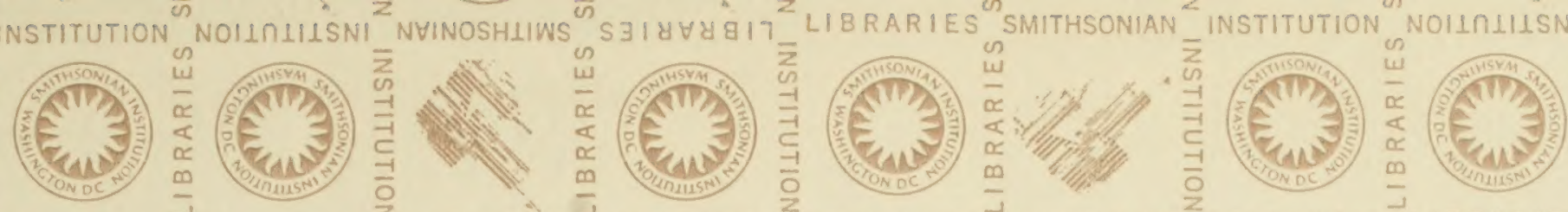

- NYINOSHLIWS
Nin
531 प $\forall$ ४ 817
(iing

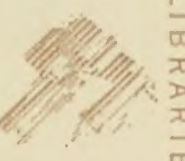
(n)
(1)
(स)

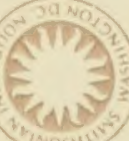

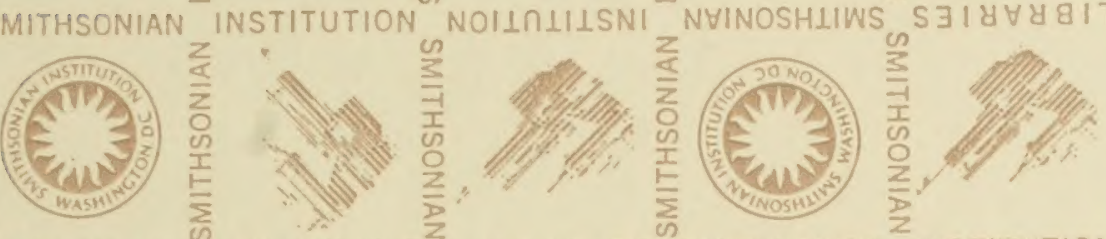

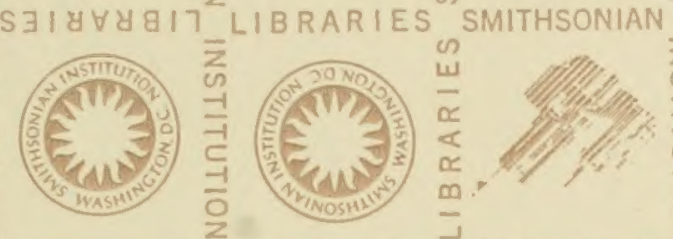

(sim)

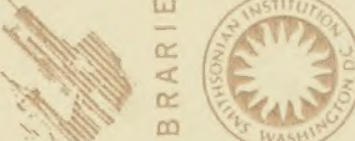

sing:

STITUTION NOIIILIISNI

Fimsty

(a)

Hity

ative

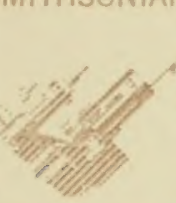

NHINOSHLINS

SIIUYYQ17 LIBRARIES SMITHSONIAN

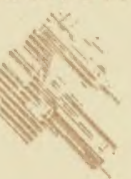

1IIII)

and

NTITUTION NOIINIIISNI NVINOSHIIW

(2)

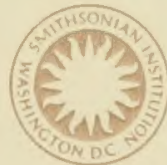

(1)

(IT)

(1)

S IIYYY917 LIBRARIES SMITHSONIAN INSTITUTION NOIINLILSNI

THSONIAN

(and

Fin'

(1)

SMITHSONIAN

Nition

If

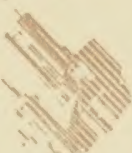

(ans

(1)

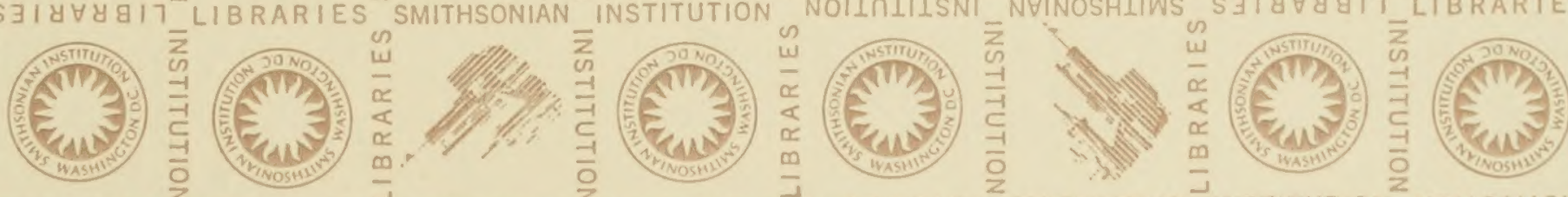

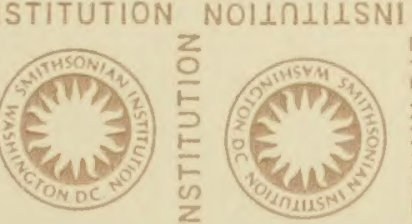

(ivi)

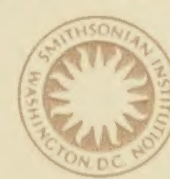

Find

(5)

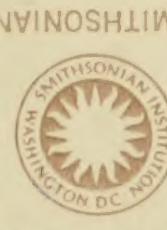

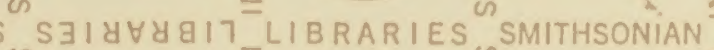

INSTITUTION,
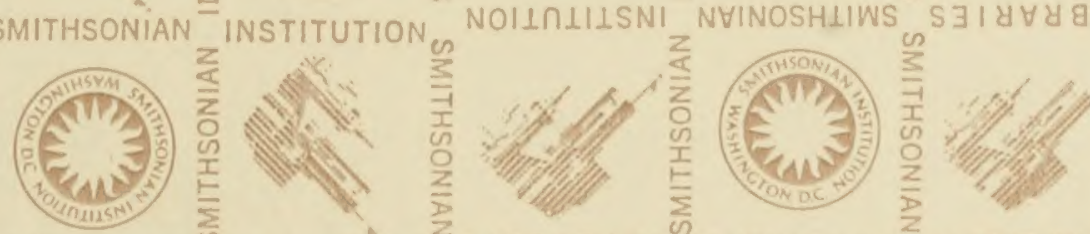

(II)

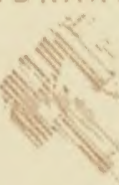

IES SMITHSONIAN
咅

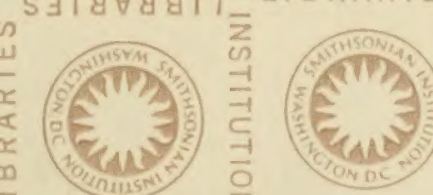




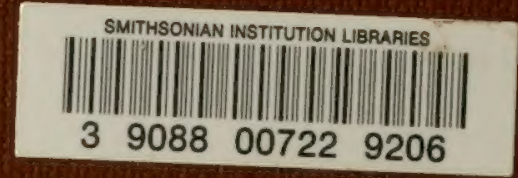

